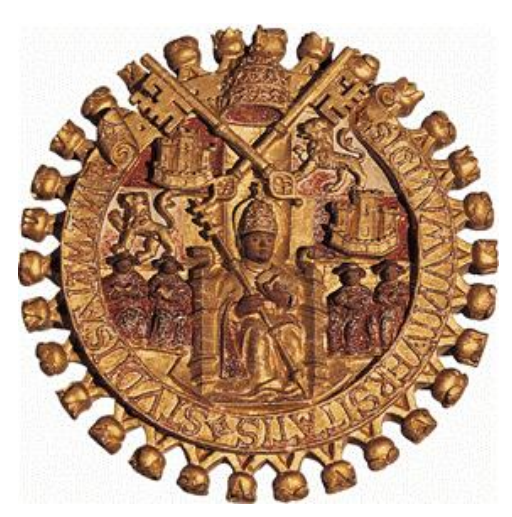

Universidad de Salamanca

Facultad de Derecho

Departamento de Derecho Público General Área de Ciencia Política y de la Administración

\title{
Tesis Doctoral \\ La integración política del adolescente. \\ Las competencias cívicas de los inmigrantes en la escuela secundaria española
}

\author{
Pablo Biderbost Moyano \\ Directora: Dra. Araceli Mateos Díaz
}

Salamanca, 2014 
A mis abuelos maternos, migrantes internos que llegaron a la ciudad en busca de una vejez más digna.

A mis abuelos paternos, hijos de migrantes internacionales que fueron a hacer la América.

A mis padres, quienes me inculcaron el amor por el trabajo diario como valor fundamental. 


\section{ÍNDICE}

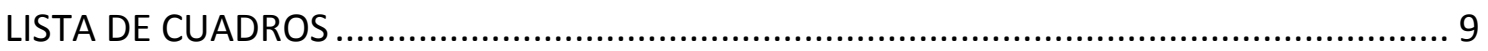

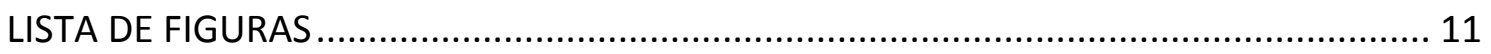

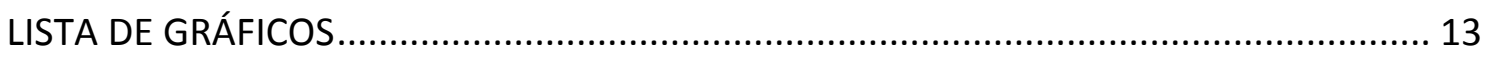

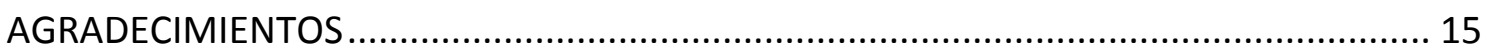

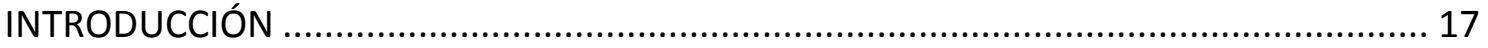

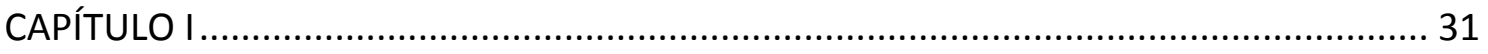

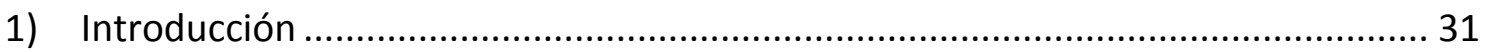

2) Sociedades homogéneas y sociedades multiculturales: aproximaciones desde la

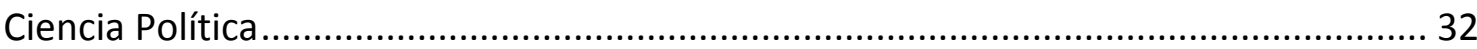

2.1) "No somos todos iguales": La incorporación de la población inmigrante en los estudios sobre cultura política

2.2) La literatura estadounidense y europea sobre cultura política, integración

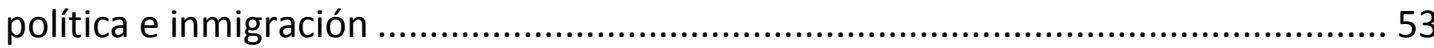

2.2.1) ¿De qué se habla cuando se habla de integración política? .......................... 53

2.2.2) Objetos de estudio de la literatura sobre integración política .......................... 56

2.3) La literatura española sobre cultura política e inmigración. El efecto multiplicador del carácter reciente de la inmigración .............................................. 61

3) La búsqueda de la ciudadanía deseada. La conceptualización y medición de las competencias cívicas

3.1) ¿Qué se sabe de la realidad política? El conocimiento político como competencia cívica

3.2) ¿Cómo se obtiene la información sobre la realidad política? La atención política

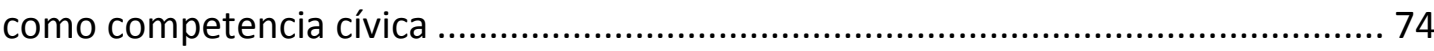

3.3) ¿Qué se afirma respecto a las actuaciones que permiten modificar la realidad política? La participación política como competencia cívica ..................................... 78 3.4) ¿Cuánto se afirma comprender sobre la realidad política y cuán moldeable se la considera? La eficacia política como competencia cívica 91 3.5) ¿Cuán arraigado se encuentra el respeto por las ideas políticas opuestas? La tolerancia política como competencia cívica .

4) La dimensión cívica de la inmigración. El cambio de sociedad y sus implicancias en materia de socialización política

4.1) El estudio de la socialización política en Ciencia Política. Una propuesta de sistematización

4.2) El primer aprendizaje cívico: la familia como agente de socialización política 112

4.3) El aprendizaje cívico influenciado indirectamente por el Estado: la escuela como agente de socialización política

115

4.4) El aprendizaje cívico obtenido con los "iguales": el grupo de pares como agente

de socialización política

4.5) El aprendizaje cívico remoto: los medios de comunicación como agente de socialización política

4.6) El aprendizaje cívico en contextos de responsabilidad laboral: el ámbito de trabajo como agente de socialización política

4.7) La (re)socialización política: el destino inevitable del inmigrante .................... 126

4.8) (Re) socialización política, inmigración y población no adulta .......................... 134

4.9) Inmigración, socialización política e infraciudadanía. Una nota sucinta .......... 136 


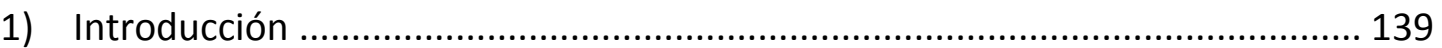

2) Justificación del estudio de la integración política de la población adolescente... 140

3) Objetivos y preguntas de investigación......................................................... 143

4) La integración política como variable dependiente y uso de las competencias cívicas como su principal indicador.

5) Integración política de los adolescentes inmigrantes: explorando factores y

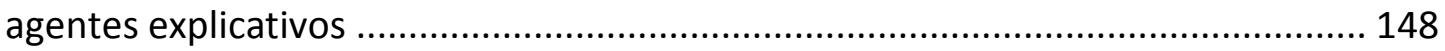

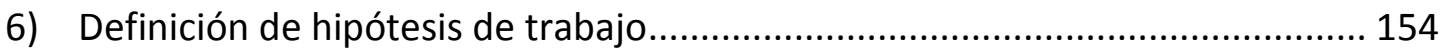

7) Selección de casos y características del proceso de recolección de datos ....... 157

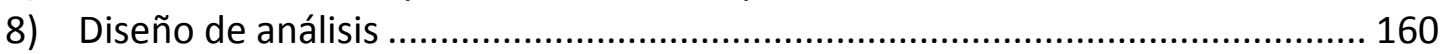

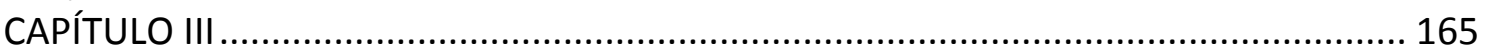

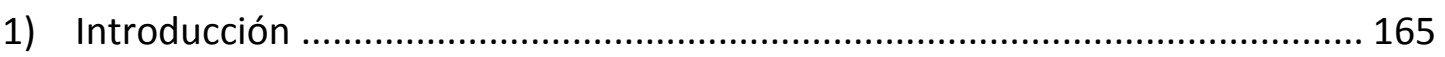

2) La distribución de las competencias cívicas entre adolescentes inmigrantes y

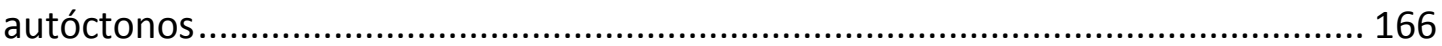

2.1) (Des)conociendo la política. La primera brecha .......................................... 167

2.2) Cuando el origen nacional no importa. Registros en atención política......... 170

2.3) Una nueva brecha: diferencias en participación política............................ 173

2.4) La brecha disminuye. Los registros adolescentes en eficacia política ............ 175

2.5) ¿"Quién tolera qué" entre los adolescentes? ................................................... 178

2.6) Comparando brechas entre adolescentes autóctonos e inmigrantes........... 181

3) Explorando la medida global. Patrones de integración política entre

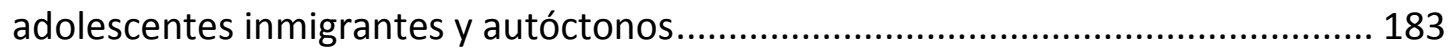

3.1) Comprobación parcial de hipótesis de trabajo .............................................. 185

4) Evaluación de la influencia de factores y agentes de socialización sobre las competencias cívicas. El Análisis de Correlación Canónica como estrategia multivariante

4.1) Complejidad social, análisis multivariante y correlación canónica................. 187

4.2) Aplicando la correlación canónica. ¿En qué difieren nativos de inmigrantes?

4.3) Visualizando los resultados. Construcción de un heliógrafo para el Análisis de

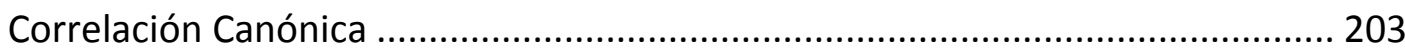

4.4) Comprobación parcial de hipótesis de trabajo ............................................. 207

5) Explicando la integración política. Aplicación de la Regresión Múltiple para la identificación de factores y agentes de socialización relevantes............................. 209

5.1) Características de la Regresión Múltiple y de la Regresión Jerárquica.......... 210

5.2) Identificación de patrones en la muestra global ....................................... 212

5.3) Dividiendo en colectivos. ¿Qué particulariza a la integración política de los

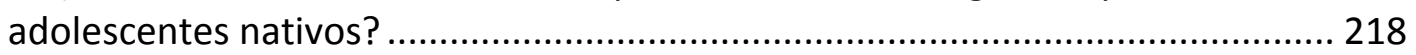

5.4) Dividiendo en colectivos. ¿Qué particulariza a la integración política de los

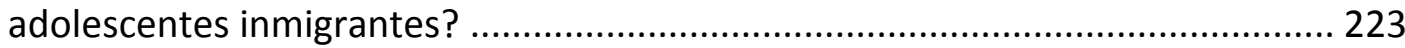

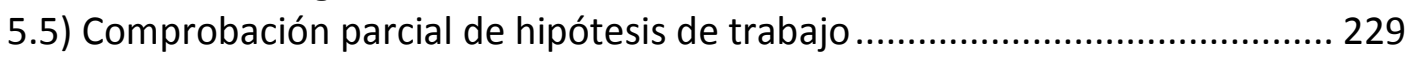

6) Discusión de los hallazgos e identificación de tendencias ............................... 232

6.1) Desde las competencias cívicas hacia la integración política ........................ 232

6.2) Influencia de los factores socio-demográficos .......................................... 239

6.3) Influencia de los factores psico-sociales.................................................... 243

6.4) Agentes y teorías de (re)socialización política............................................ 245 
CONCLUSIONES

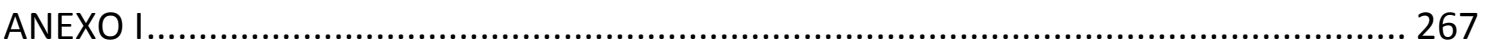

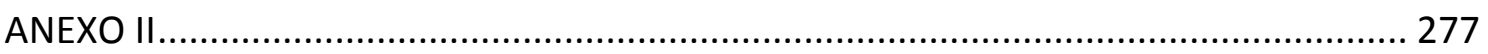

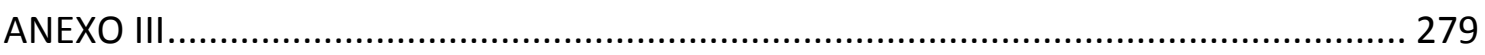

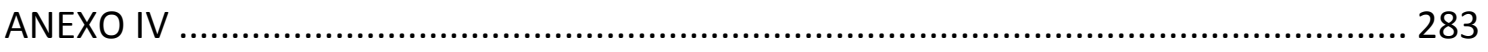

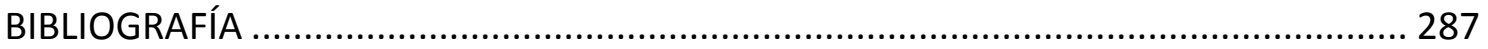




\section{LISTA DE CUADROS}

Cuadro 2.1. Operacionalización de las competencias cívicas como indicadores de la integración

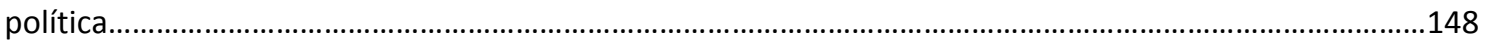

Cuadro 2.2. Selección y operacionalización de las variables independientes de la integración

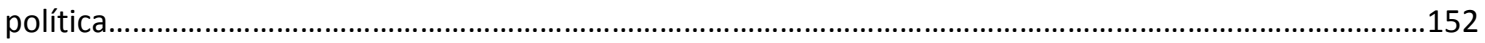

Cuadro 3.1. Medidas de concentración y dispersión para conocimiento político de los adolescentes según

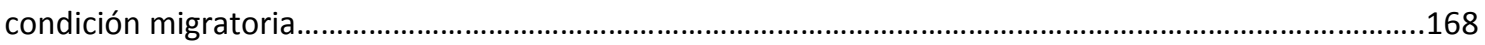

Cuadro 3.2. Medidas de concentración y dispersión para atención política de los adolescentes según

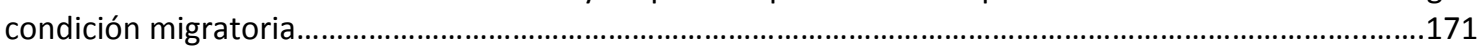

Cuadro 3.3. Medidas de concentración y dispersión para participación política de los adolescentes según condición migratoria.............................................................................................................................174

Cuadro 3.4. Medidas de concentración y dispersión para eficacia política de los adolescentes según

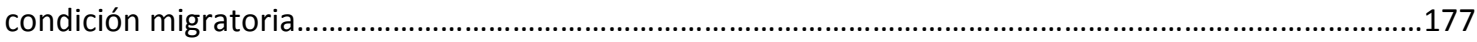

Cuadro 3.5. Medidas de concentración y dispersión para tolerancia política de los adolescentes según

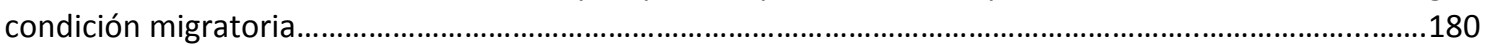

Cuadro 3.6. Comparación de medias en competencias cívicas por colectivo poblacional...........................182

Cuadro 3.7. Medidas de concentración y dispersión para integración política de los adolescentes según

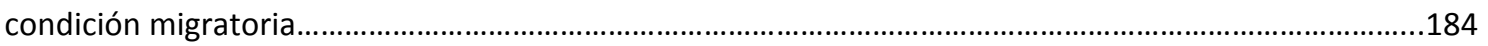

Cuadro 3.8. Comprobación parcial de hipótesis de trabajo.......................................................................186

Cuadro 3.9. Medidas de ajuste global del modelo para el Análisis de Correlación Canónica (Muestra

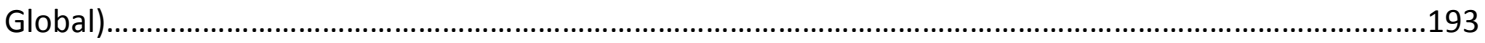

Cuadro 3.10. Medidas de ajuste global del modelo para el Análisis de Correlación Canónica (Muestra

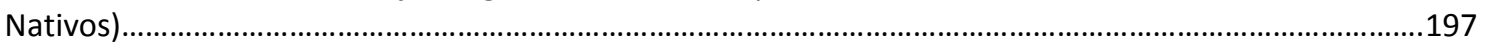

Cuadro 3.11. Medidas de ajuste global del modelo para el Análisis de Correlación Canónica (Muestra

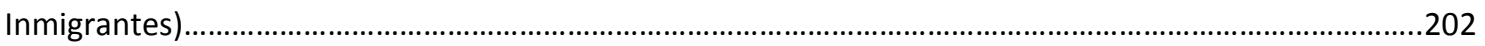

Cuadro 3.12. Comprobación parcial de hipótesis de trabajo................................................................207

Cuadro 3.13. Resumen del Análisis de Regresión Múltiple (Muestra Global en base a Análisis de Correlación Canónica) ...........................................................................................................................213 Cuadro 3.14. Resumen del Análisis de Regresión Múltiple (Muestra Global en base a todas las variables independientes consideradas teóricamente relevantes) ........................................................................215 Cuadro 3.15. Resumen del Análisis de Regresión Múltiple (Muestra Global en base a todas las variables independientes que han presentado significación estadística) ...............................................................217

Cuadro 3.16. Regresión Jerárquica Comparativa (Modelos 1 y 3 para Muestra Global)..............................218 Cuadro 3.17. Resumen del Análisis de Regresión Múltiple (Muestra Nativos en base a Análisis de Correlación Canónica) ............................................................................................................................219 Cuadro 3.18. Resumen del Análisis de Regresión Múltiple (Muestra Nativos en base a todas las variables independientes consideradas teóricamente relevantes) ..........................................................................222 Cuadro 3.19. Regresión Jerárquica Comparativa (Modelos 1 y 2 para Muestra Nativos).............................223 Cuadro 3.20. Resumen del Análisis de Regresión Múltiple (Muestra Inmigrantes en base a Análisis de

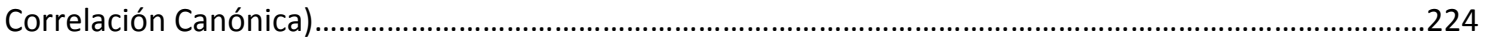
Cuadro 3.21. Resumen del Análisis de Regresión Múltiple (Muestra Inmigrantes en base a todas las variables independientes consideradas teóricamente relevantes) ............................................................226 Cuadro 3.22. Resumen del Análisis de Regresión Múltiple (Muestra Inmigrantes en base a todas las variables independientes que han presentado significación estadística)......................................................228 Cuadro 3.23. Regresión Jerárquica Comparativa (Modelos 1 y 3 para Muestra Inmigrantes).....................229 Cuadro 4.1. Niveles de significación estadística de las Correlaciones de Pearson entre las competencias cívicas y las dimensiones de la variable Status Socioeconómico................................................................279 Cuadro 4.2. Medias, por tipo de itinerario formativo, de los adolescentes inmigrantes en cada

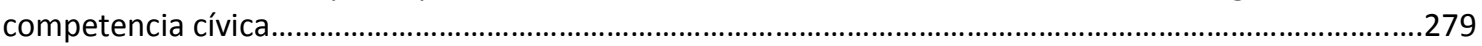
Cuadro 4.3. Niveles de significación estadística de las Correlaciones de Pearson y Comparaciones de Medias. Relación entre competencias cívicas y dimensiones de la variable "Escuela" para el colectivo

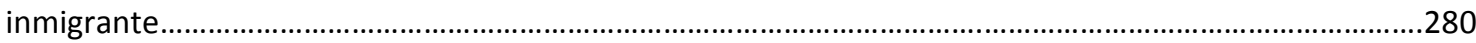
Cuadro 4.4. Niveles de significación estadística de las Correlaciones de Pearson entre integración política y las dimensiones de la variable Status Socioeconómico ...........................................................................280 
Cuadro 4.5. Medias de integración política, por tipo de itinerario formativo, de los adolescentes

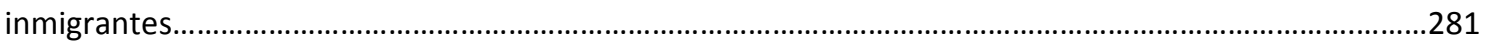
Cuadro 4.6. Niveles de significación estadística de las Correlaciones de Pearson y Comparaciones de Medias. Relación entre integración política y dimensiones de la variable "Escuela" para el colectivo inmigrante. 


\section{LISTA DE FIGURAS}

Figura 1.1. El tratamiento del fenómeno migratorio por parte de la Ciencia Política.....................................40

Figura 1.2. Críticas al paradigma tradicional de cultura política....................................................................49

Figura 1.3. La incorporación de la inmigración en los estudios sobre cultura política.....................................52

Figura 1.4. Tipos de estudios sobre la integración política de los inmigrantes...............................................60

Figura 1.5. Factores antecedentes y competencias cívicas..................................................................101

Figura 1.6. Relaciones causales entre competencias cívicas...................................................................101

Figura 1.7. Agentes y procesos involucrados en la socialización política...................................................105

Figura 1.8. Relación teórica entre socialización política, competencias cívicas e integración política en

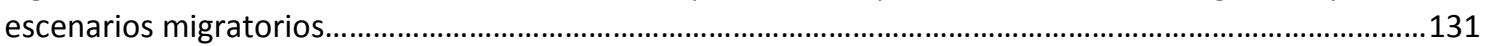

Figura 3.1. Heliógrafo en base a los resultados del Análisis de Correlación Canónica para factores y agentes de socialización $(\mathrm{X})$ y competencias cívicas $(\mathrm{Y})$.

.206 


\section{LISTA DE GRÁFICOS}

Gráfico 3.1. Diagrama de caja de conocimiento político según colectivo (nacional e inmigrante)..............283

Gráfico 3.2. Diagrama de caja de atención política según colectivo (nacional inmigrante)..........................283

Gráfico 3.3. Diagrama de caja de participación política según colectivo (nacional e inmigrante)...............284

Gráfico 3.4. Diagrama de caja de eficacia política según colectivo (nacional e inmigrante).........................284

Gráfico 3.5. Diagrama de caja de tolerancia política según colectivo (nacional e inmigrante).....................285

Gráfico 3.6. Diagrama de caja de integración política para la muestra global................................................285

Gráfico 3.7. Diagrama de caja de integración política según colectivo (nacional e inmigrante)..................286 


\section{AGRADECIMIENTOS}

Esta tesis doctoral es producto de muchos años de trabajo y aprendizaje sobre los diferentes abordajes que ofrece la Ciencia Política para el análisis de los procesos migratorios. Agradezco la dirección de Araceli Mateos Díaz, quien primero como profesora y luego como tutora me acompañó con afecto y dedicación en este desafío de intentar desentrañar la integración política de los adolescentes inmigrantes en España.

Doy las gracias a Manuel Alcántara Sáez quien, desde que arribé a la Universidad de Salamanca, me ha aconsejado, apoyado y estimulado en mi crecimiento profesional. Agradezco también a todo el plantel de profesores e investigadores del Área de Ciencia Política y del Instituto de Estudios de Iberoamérica de la Universidad de Salamanca por facilitar con su trabajo y entrega nuestra formación como doctores.

Este proceso formativo no hubiese concluido sino hubiera contado con el apoyo institucional y económico de diferentes organizaciones. Agradezco a la Universidad de Salamanca y al Banco Santander por haberme becado durante los primeros años de mi formación como doctorando. Doy las gracias así mismo al antiguo Ministerio de Educación y Ciencia de España y al Nuffield College por haberme permitido realizar una estupenda y enriquecedora estancia como Junior Visiting Scholar en la Universidad de Oxford. El apoyo económico e institucional del Colegio de la Frontera Norte fue fundamental para poder sufragar mi visita académica pre-doctoral a esa institución situada en Tijuana. Debo agradecer también a la Swiss National Science Foundation que, con su contribución, me permitió coger el impulso necesario para dar cierre a esta etapa de mi formación.

Quiero recordar y agradecer especialmente a los directores y docentes de los centros educativos en los que recogí datos. Sin su apertura desinteresada y su compromiso por el bienestar de sus alumnos, esta investigación no se hubiese materializado.

No puedo dejar de mencionar en mi lista de agradecimientos a mis seres queridos, sostenes emocionales en este largo camino de la preparación como doctor. Lo mejor de mí se los debo a ellos. Agradezco especialmente a mis padres, quienes siempre me impulsaron para que siguiera mi vocación como cientista social. Doy las gracias a mis 
hermanos, abuelas, tíos y primos, quienes con sus oraciones y aliento, me acompañaron a la distancia "transatlántica" en este proceso. A Guillermo Boscán, por haberme escuchado y orientado, en mis dudas e inquietudes a lo largo de estos años de trabajo. A mis amigos, los de antes y los de ahora, por acompañarme con cariño y respeto sincero en esta larga ( $y$ a veces incomprensible) travesía para la consecución del título de doctor. Sólo mencionaré, so pena de cometer olvidos imperdonables, a algunos de mis hermanos escogidos que he conocido en mis años salmantinos: Iván Alonso, Gisselle de la Cruz, Pablo Ferreiro, Ruth Lobo, Felipe Mancilla, Antonella Marchiselli, José Angel Marcos, Mario Mueses, María Elisa Núñez, Joel Pinho, Nalia Rochin, Mónica Salazar, Vanessa Suazo, Mabel Villalba y Alejandra Tuma.

Agradezco a su vez a quienes me formaron en la visión ignaciana, jesuitas y laicos, por haberme mostrado el camino maravilloso de la "contemplación en acción" o, traducido para los no conocedores de esta mirada, la vía de la reflexión sobre la realidad acompañada del compromiso por mejorarla. Finalmente, doy las gracias a Dios, por su infinito amor y protección a lo largo de mi vida. 


\section{INTRODUCCIÓN}

"Immigration is a permanent feature of European society. If the flow of immigrants...is orderly and well-managed, Member States reap many benefits. These include stronger economies, greater social cohesion, an increased feeling of security, and cultural diversity. Taken together and across all Member States, these benefits advance the European process and strengthen the Union's position in the world".

Justice and Home Affairs Council of the European Union (2004: 15)

La historia de España está signada por los procesos migratorios. Entre la segunda mitad del siglo XIX y los primeros setenta años del siglo XX, millones de personas abandonaron su territorio en busca de nuevos horizontes políticos y económicos ${ }^{1}$. Una débil economía, la profunda desigualdad social, la frecuente irrupción de periodos marcados por un profundo deterioro en la calidad de vida, los antagonismos ideológicos y la imposibilidad de la consolidación de regímenes políticos estables fueron, entre otros factores, los catalizadores de la expulsión de la población.

América Latina y Europa fueron destinos privilegiados de estos flujos. Otras regiones del planeta (América anglosajona, norte de África y Australia), en menor medida, también oficiaron de receptoras de emigrantes procedentes de tierras ibéricas. Distintos efectos son atribuibles a este comportamiento demográfico. La consecuencia más relevante de este perfil emigratorio, expandida recientemente por diferentes cambios normativos, es el elevado número de individuos con nacionalidad española que habitan fuera de las fronteras del Estado español².

\footnotetext{
${ }^{1}$ Bover y Velilla (2005) recuerdan que, por cuestiones vinculadas a la medición de la condición de "emigrantes", resulta difícil estimar el número total de salidas desde España (sobre todo las acontecidas en el siglo XIX). Antiguamente, sólo se registraba como emigrante a quien partía de puertos españoles con billete de tercera clase. Esta estrategia metodológica deflactaba el número real de emigrantes. El uso de estadísticas oficiales de los países de destino es una herramienta útil para paliar esa carencia de datos. A modo de ejemplo, en la Argentina, según datos del Censo Nacional de Población y Vivienda de este país de 1914, residían 841.692 personas con nacionalidad española. Para periodos más cercanos en el tiempo, la estimación de salidas de emigrantes es más verosímil. Carmen González-Enríquez, Investigadora principal de Demografía, Población y Migraciones Internacionales del Real Instituto Elcano, estima que sólo en el periodo transcurrido entre 1959 y 1973 abandonaron el territorio español cerca de 2 millones de personas.

2 Según el Padrón de Españoles Residentes en el Extranjero (PERE) recogido por el Instituto Nacional de Estadística, un total de 2.058.048 españoles residía fuera del territorio nacional en enero de 2014. En tanto, el Censo de los Electores Residentes-Ausentes que viven en el extranjero (CERA), cuantificado por la misma institución, tiene registrados a 1.719.036 individuos (marzo de 2014). Mientras la primera cifra
} 
A comienzos del decenio de 1970, la expulsión de población se detiene por motivos diversos. Ello se vio acompañado por un retorno por goteo de antiguos emigrantes radicados sobre todo en países del entorno europeo. La consolidación del sector industrial español y la crisis del petróleo con la consecuente contracción en los países del Norte de Europa fueron catalizadores económicos de estos procesos. Desde el punto de vista político, el ingreso del franquismo en su fase estertórea contribuyó a los cambios migratorios señalados. En tal sentido, el inicio de la senda de transición hacia la democracia constituyó un aliciente para el regreso a territorio español de individuos otrora enfrentados ideológica y programáticamente a la cosmovisión del régimen autoritario.

Es también en la década de 1970 que, como consecuencia de la persecución política llevada a cabo por las dictaduras del Cono Sur americano, se comienza a observar una llegada incremental de exiliados políticos. Este grupo es, en sentido estricto, el primer eslabón de una cadena que haría de España dos décadas después un destino privilegiado de las migraciones internacionales. La relevancia, tanto política como cultural, de este significativo colectivo de inmigrantes lo hizo destinatario de especial atención por parte de las ciencias sociales hispanas ${ }^{3}$.

Si bien la llegada de inmigrantes a España nunca se paralizó entre los años 1975 y 1995, la elección de España como destino prioritario de flujos migratorios internacionales se acentúo en el último lustro del siglo XX. Diferentes factores de atracción (pull factors) propiciaron este escenario. En el plano político, la consolidación del sistema democrático, la incorporación de España al espacio de integración hoy conocido como Unión Europea y la expansión del Estado de Bienestar fueron variables fundamentales. En el plano económico, el crecimiento sostenido asociado al boom de la

recoge al total de personas que han realizado la inscripción en el consulado de destino, el segundo sólo incorpora a quienes cumpliendo la anterior condición han solicitado poseer "activado" su derecho al voto durante su permanencia en el exterior. Naturalmente, ambas cifras dejan por fuera a todos los sujetos que no proceden a realizar su alta consular. La aprobación de la Ley de la Memoria Histórica (52/2007), por su previsión de concesión de la nacionalidad española a hijos y nietos de antiguos emigrantes, contribuyó a expandir la cuantía de ciudadanos españoles residiendo en el exterior.

3 Cientistas sociales, procedentes de diferentes disciplinas (Historia, Antropología, Ciencia Política, Psicología), han contribuido a la creación y consolidación de una línea de investigación que se ha materializado en la publicación de libros, volúmenes colectivos y números monográficos de revistas científicas y en la presentación de ponencias en congresos o mesas de trabajo con el exilio como foco de estudio. Los aportes de Waiss (1983), Lutz y Walker (1985), Goméz (1993), Del Olmo (2003), Mira (2003), Jensen y Yankelevich (2007) y Coraza (2010) han sido significativos en este terreno. 
construcción, la apreciación de la moneda, la mejora sustantiva en las condiciones de vida y la existencia de un mercado laboral secundario con puestos de trabajo no suficientemente cubiertos por la población nacional propulsaron la llegada de inmigrantes de todo el mundo.

A partir de lo reportado por el Instituto Nacional de Estadística (INE), se estima que entre los años 1998 y 2011 poco más de 5 millones de personas (5.114.402) arribaron a España ${ }^{4}$. El cambio demográfico durante estos años fue de tal envergadura que este país, en base a estadísticas elaboradas por Eurostat, era en 2011 el segundo dentro de la UE-15 con mayor presencia relativa de inmigrantes sobre la población total $(12,3 \%)^{5}$ (Vasileva, 2012). Según recuerda la misma fuente, este porcentaje se incrementó casi 10 puntos en sólo una década (en 2001, se registraba tan sólo un 2.9\% de inmigrantes sobre el total poblacional). De esta manera, España superó en presencia relativa de inmigrantes a los países de la UE-15 con una trayectoria de recepción de extranjeros más consolidada en el tiempo (Alemania, Bélgica, Holanda, Francia y Reino Unido).

Si bien la actual y profunda crisis económica está provocando salidas cuantitativamente relevantes del territorio español tanto de nacionales como de extranjeros en busca de oportunidades laborales en destinos diversos, la población de origen inmigrante no ha huido en estampida como se previó desde ciertos sectores ${ }^{6}$.

\footnotetext{
${ }^{4}$ Estos datos son extraídos del Padrón Municipal elaborado por el INE que incluye tanto a extranjeros residiendo regularmente como aquellos residiendo irregularmente. En ambos casos, para figurar empadronados, deben haber procedido a darse de alta como habitantes del municipio en el que se encuentran radicados.

${ }^{5}$ Sólo Luxemburgo, con un 43,1\% población inmigrante, supera a España en este ratio dentro de la UE-15. En este país centroeuropeo, la inmigración está marcada por una fuerte presencia de individuos originarios de otros países de la UE (37,2\% sobre la población total para el año 2011). Considerando las recientes ampliaciones de la Unión Europa, a la lista de países con una presencia relativa superior de inmigrantes a la observada en España, se debe añadir a Chipre (20\%), Letonia (17\%) y Estonia $(15,7 \%)$.

${ }^{6}$ Los estudiosos sobre la materia acusan a las cifras oficiales de no representar correctamente el número de salidas de territorio español. Al mismo tiempo, difieren en relación a la estrategia a seguir para una cuantificación correcta de este proceso. Según los datos provistos por el INE, entre los años 2008 y 2013 , han salido de España 2.186.796 personas. El 88\% (1.924.714 personas) de ese total corresponde a extranjeros que residían en España mientras que el 12\% (262.082) restante hace referencia al número de españoles que han abandonado el territorio nacional. Esta información es la que transmite a nivel internacional esta institución como datos migratorios oficiales de España en conformidad al Reglamento 862/2007 del Parlamento Europeo y del Consejo sobre Estadísticas de Migraciones y Protección Internacional. El porcentaje que genera más controversias es el vinculado a la salida de nativos. Existe una postura, encarnada en los estudios de Amparo González Ferrer (2013), que estima que el INE infrarrepresenta las salidas de nativos causadas por la crisis. En sus cálculos, 700.000 españoles han dejado el territorio nacional en los últimos años. La postura opuesta, expuesta por Carmen González-
} 
Según las últimas cifras proporcionadas por el INE para el año 2013, 5.546.3287 individuos de origen extranjero se encuentran empadronados en los municipios españoles. Este dato incorpora tanto a inmigrantes regulares como irregulares dados de alta ante su respectivo municipio. En tanto, de acuerdo al Observatorio Permanente de la Inmigración del Ministerio de Empleo y Seguridad Social, el número de extranjeros con certificado de registro o tarjeta de residencia en vigor asciende a 5.503.977. Este dato incluye a residentes extranjeros en condición de regularidad. Ambas cifras ${ }^{8}$ confirman que, a pesar de haber transcurrido un sexenio de crisis económica (20082013), los colectivos inmigrantes conservan centralidad estadística y sociológica $(10,7 \%$ de la población total en España9 ${ }^{9}$.

La conversión de España en una sociedad inmigratoria provocó la multiplicación de investigaciones sobre la cuestión. Como sugiere David Corrochano (2010) en su estudio sobre la producción bibliográfica en ciencias sociales sobre procesos migratorios en España, en un primer momento, fueron las administraciones públicas las que solicitaban a los investigadores reflexiones teóricas y evidencia empírica sobre la temática. A posteriori, la comunidad de estudiosos sobre las migraciones adquiere autonomía, se institucionaliza (mediante la creación de centros de estudios, publicaciones especializadas y posgrados enfocados en estos temas) y se produce su incorporación en redes tanto europeas como globales dedicadas a desentrañar las particularidades de las realidades migratorias.

Los estudios sobre migraciones en España, siguiendo la estela de lo acontecido en el mundo anglosajón, se concentraron grosso modo, en dos abordajes diferenciados (Portes, 1996; Portes, Guarnizo y Landolt, 1999; Vertovec, 1999). En un primer lugar, se desarrollaron líneas de investigación tendentes a descifrar como acontecía la integración de los inmigrantes en la sociedad de acogida en diferentes dimensiones de

\footnotetext{
Enríquez (2013), critica al INE por sobrerrepresentar dichas salidas. Esta estudiosa estima que las mismas se encuentran en torno a las 40.000 .

${ }^{7}$ Según una actualización provisional del INE, aún no elevada al Gobierno de la Nación para su aprobación y publicación en el Boletín Oficial del Estado, la cifra de extranjeros residiendo en España podría haber descendido a 5.000.258 a 10 de enero de 2014. Este dato se obtiene a partir de la población inscrita en el Padrón Continuo (fichero que coordina a los padrones municipales gestionados por el INE).

${ }^{8}$ Estos datos son los regularmente utilizados a la hora de cuantificar a la población inmigrante residiendo en España.

${ }^{9}$ Este porcentaje es proporcionado en la Nota de Prensa del Instituto Nacional de Estadística con fecha de 22 de abril de 2014 en base a la población inscrita en el Padrón Continuo.
} 
la vida social (laboral, educativa, jurídica, cultural, etc.). A este conjunto de estudios, pertenece la presente investigación. En un segundo lugar, se impulsaron líneas de investigación centradas en el transnacionalismo, es decir, aquéllas que procuran observar cómo los inmigrantes, nuevamente en diversas dimensiones sociales, actúan y se relacionan en espacios que trascienden tanto a sus sociedades de origen como a las sociedades en las que se han residenciado.

Como Hollifield (2008) describe para lo sucedido en el resto del mundo, la Ciencia Política en España ha llegado también tardíamente, en comparación a otras ciencias sociales, al estudio de los procesos migratorios. Ello ha implicado lo que es una ventaja y una desventaja a la vez: los politólogos han heredado un marco teórico y herramientas metodológicas desarrolladas ad hoc para el estudio de las migraciones por otras disciplinas ${ }^{10}$.

El campo de los estudios sobre cultura política ha sido, dentro de la Ciencia Política a nivel internacional y también en el contexto español, especialmente pródigo en relación a la consideración de los procesos migratorios. Esto se ha visto materializado, entre otras líneas de trabajo, en estudios sobre la opinión y/o percepción de la inmigración entre los miembros de host societies, en investigaciones sobre las divergencias político-culturales entre autóctonos y recién llegados y en la identificación de las pautas de relación entre los extranjeros y el sistema político de las sociedades de acogida. En esta última aproximación, se incorporan los estudios sobre la integración política de los inmigrantes.

Hay rastros del uso de la integración política de los inmigrantes como objeto de consideración politológica desde los tiempos genésicos de la disciplina. Tan tempranamente como en las décadas de 1950 y 1960, Nathan Glazer (1956) y Robert Dahl (1961) propusieron definiciones conceptuales y operativas de la expresión. Dos decenios después, John Garcia (1981) retoma su aplicación y genera evidencia empírica sistemática en su estudio sobre la situación política de los inmigrantes de origen

\footnotetext{
${ }^{10}$ Una clara ventaja de esta situación radica en que los esfuerzos iniciales necesarios para proceder al estudio de las migraciones se vieron reducidos por la existencia de este "legado" procedente de otras disciplinas. En tanto, una desventaja no menor reside en que esta herencia actúa en cierto modo como limitante de los márgenes de reflexión teórica y construcción metodológica para el estudio politológico de las migraciones. Ambas situaciones han conducido a que el nicho de los estudios sobre migraciones sea, probablemente, el espacio dentro de la disciplina en el que los cientistas políticos más dialoguen con representantes de otras ciencias sociales.
} 
mexicano en Estados Unidos. Veinte años después de los aportes de Garcia, en la primera década del siglo XXI, aconteció un crecimiento exponencial del número de estudios que, dentro de la Ciencia Política, hacen uso teórico y empírico de este concepto.

Concretamente, lo que la tradición de estudios sobre integración política persigue es, primeramente, generar información sobre la pauta relacional de los individuos o colectivos inmigrantes ${ }^{11}$ con el sistema político anfitrión (Bloemraad, 2006; O’Neill, Gidengil y Young, 2012). Para ello, se procede a la medición de determinados rasgos cívicos y/o políticos que ofician de indicadores de la integración política. En estos estudios, se pretende también explicar cuáles son los factores (individuales o ambientales-contextuales) que propician la posesión de determinados niveles de integración política (Togeby, 2004; Middaugh y Kane, 2006; Jennings, 2007). Con tal propósito, se realizan interesantes comparaciones entre poblaciones inmigrante y autóctona y entre diferentes colectivos inmigrantes. La búsqueda de potenciales situaciones de marginación o exclusión política es parte intrínseca de estos abordajes. Por tanto, los niveles de integración política son usualmente de tipo relativo, es decir, de un individuo/colectivo en relación a otro/s.

En los estudios sobre integración política, según se apreciará más detalladamente en el primer capítulo de esta tesis doctoral, se mantiene siempre latente la idea de que la resocialización política que aparejan las experiencias migratorias configura perfiles cívico-políticos diversos. Por ese motivo, este grupo de investigaciones descansa, implícita o explícitamente, sobre la tradición de estudios acerca de la socialización política de los sujetos. Como es sabido, la investigación sobre la socialización política, aunque luego perdió cierto protagonismo dentro del acervo politológico, fue fundamental durante los años en los que aconteció la revolución conductista. Su conocimiento permitía, entre otras cuestiones, entender cómo se

\footnotetext{
11 Fuera de los estudios que se dedican a estudiar la integración política de individuos concretos y colectivos específicos (colectividad inmigrante puntual), existen también investigaciones en la materia sobre agrupaciones de inmigrantes (asociaciones civiles, organizaciones no gubernamentales, etc.). En el caso de la Ciencia Política española, los principales aportes en este plano son los de Morales, González y Sánchez (2005), González y Morales (2006) y Morales y González (2008). En el primer capítulo de esa tesis doctoral, se profundiza sobre la cuestión.
} 
transmitían intergeneracionalmente los patrones de cultura política ${ }^{12}$ (Easton, 1957; Hyman, 1959; Greenstein, 1965; Hess y Torney, 1967; Easton y Dennis, 1967; Niemi y Sobieszek, 1977).

En los últimos años, el aparato teórico y metodológico asociado al estudio de la socialización política ha reaparecido con fuerza para procurar entender cómo los inmigrantes se relacionan con el sistema político de la sociedad en la que habitan (White, Nevitte, Blais, Gidengil y Fournier, 2008). Como en los tiempos inaugurales de la Ciencia Política, el estudio sobre la socialización política es ahora un terreno abonado por colaboraciones transdisciplinares. En ocasiones, en los estudios sobre integración política, existe una mención expresa del interés de los investigadores por detectar cuál ha sido la naturaleza de la socialización política de los inmigrantes en las sociedades tanto de origen como de acogida. En otros casos, esta intención, aunque no central, es de tipo colateral y ello se percibe cuando se analizan pormenorizadamente los diseños de investigación adoptados.

En el ámbito español, tanto por ser la llegada de los inmigrantes relativamente reciente como por el arribo tardío de la Ciencia Política vernácula al estudio de estas temáticas, la incursión en la investigación sobre integración política es novedosa. Uno de los aportes más significativos, por encontrarse adecuadamente fundado teórica y empíricamente, en la materia es el de Laura Morales (2011). Su trabajo, enfocado en población adulta, agrega valor en dos planos. En primer lugar, la información sobre la integración política de los inmigrantes en España es analizada en perspectiva paneuropea lo que facilita el ejercicio de interesantes comparaciones. En segundo lugar, el marco teórico que utiliza de referencia para el análisis de los datos procede tanto de la perspectiva norteamericana (más centrada en los rasgos individuales) como de la mirada europea (más centrada en factores contextuales) a la hora de estudiar las variables que provocan diferentes niveles de integración política entre los inmigrantes ${ }^{13}$.

A pesar de que se han avanzado posiciones en el estudio de la integración política de los inmigrantes en España, lo realizado hasta ahora se centra exclusivamente en

\footnotetext{
${ }^{12}$ El conocimiento de este tipo de datos se consideraba vital, según describe David Easton en 1957, para entender cómo se generaba la estabilidad en los sistemas políticos.

${ }^{13}$ En el próximo capítulo, es posible encontrar mayores detalles sobre la existencia de "mesas transatlánticas separadas" en este ámbito de investigación.
} 
población adulta. Los adolescentes inmigrantes ${ }^{14}$, aunque presentes como objeto de estudio en investigaciones sociológicas, pedagógicas y demográficas en este país, no han sido abordados con esquemas de análisis politológicos ${ }^{15}$. De esta manera, España se encuentra ausente de la agenda internacional de trabajo que, indagando sobre las competencias cívicas de los adolescentes inmigrantes y nativos en diferentes naciones, genera evidencia empírica sobre la integración política de los individuos en este tramo etario ${ }^{16}$. Judith Torney-Purta $(2006,2007)$, en su trabajo para la International Association for the Evaluation of Educational Achievement (IEA), es quien más ha contribuido para fortalecer esta línea de investigación.

La investigación retratada en estas páginas ha deseado contribuir a paliar esta carencia en el ámbito académico español. En tal sentido, el objetivo general de esta investigación es generar evidencia empírica sobre las diferencias en los niveles de posesión de competencias cívicas, como indicador de integración política, entre adolescentes de distintos colectivos (nativos e inmigrantes ${ }^{17}$ ). Los objetivos específicos, derivados del antes mencionado, persiguen detectar patrones de causalidad de dichos niveles mediante el análisis de la influencia de distintas variables independientes.

El marco teórico de la presente investigación se construyó a partir de los aportes de dos tradiciones complementarias de estudios en Ciencia Política. La primera de ellas, ya descrita sucintamente antes, es la vinculada a la indagación sobre la socialización

\footnotetext{
${ }^{14}$ Desde el punto de vista estadístico, resulta difícil cuantificar el número de adolescentes de origen inmigrante residiendo en España. Generalmente, se usa como un indicador indirecto o proxy el número o porcentaje de personas con background inmigrante por debajo de la mayoría de edad o que aún no tienen edad laboral. Según estadísticas del Observatorio Permanente de la Inmigración del Ministerio de Empleo y Seguridad Social de 2013, el 9,01\% (242.290 sujetos) de quienes habitan en España gracias al Régimen Comunitario y el 18,68\% (523.375 sujetos) de quienes habitan en España gracias al Régimen General se encuentran entre los 0 y los 16 años de edad. Según el Padrón Continuo, con datos provisionales a 22 de abril de 2014, el 15,9\% de los extranjeros (795.041 personas) residiendo en España se encuentran en la franja etaria entre los 0 y los 16 años de edad.

${ }^{15}$ Entre los trabajos sobre población adolescente de origen inmigrante en otras disciplinas, deben destacarse los aportes de Rosa Aparicio, Alejandro Portes, Erick Vickstrom y William Haller (2010, 2011, 2013) desde la Sociología; Jaume Funes (2000), M. Siguán (2003), Eduardo Terrén (2007), María Antonieta Delpino (2008) desde las Ciencias la Educación y Amparo González Ferrer (2014) desde la Demografía Social. Dentro de la Ciencia Política, las únicas excepciones a la tendencia descrita son las presentaciones preliminares de los resultados de investigación de esta tesis doctoral sobre integración política de adolescentes (Biderbost, 2009, 2010 y 2011). En el próximo capítulo, se presentan algunas de las razones que, desde dentro de la Ciencia Política, se han esgrimido para desplazar a la adolescencia como objeto de estudio.

${ }_{16}$ Parciales e interesantes contribuciones para reducir el déficit en esta materia se observan en los trabajos de Navarro et al. (2008) y García et al. (2012).

${ }^{17}$ En esta investigación, se ha considerado inmigrantes a quienes han nacido fuera de España.
} 
política y la influencia que ejercen diferentes agentes de socialización y factores sociodemográficos en la asunción, por parte de las nuevas generaciones, de pautas, valores, actitudes y comportamientos. La segunda de ellas es la relacionada a la identificación de los factores sociodemográficos y psicológicos que provocan la adquisición, entre los adolescentes, de diferentes niveles de competencias cívicas. Ambas perspectivas tienen un sello marcadamente anglosajón y se han desarrollado en diálogo constante con lo producido desde otras ciencias sociales. En el próximo apartado, estas aproximaciones a la "naturaleza política" de los más jóvenes serán ampliadas y discutidas.

En base al marco teórico referido, en esta investigación, se ha recogido información sobre los niveles de competencias cívicas poseídos por los adolescentes inmigrantes y nativos. Las cinco competencias cívicas sobre las que se indagó son conocimiento político, atención política, participación política, eficacia política y tolerancia política. El uso de las mismas, como indicador directo o indirecto de la integración política, se encuentra ampliamente justificado en la literatura (Niemi y Chapman, 1998; Yates y Younnis, 1999; Edwards, 2005; Mclntosh, 2006; Torney-Purta, Barber y Wilkenfeld, 2007). En esta investigación, el valor que cada sujeto asume en integración política fue concebido a partir de la construcción de un índice que contempla la sumatoria de los valores poseídos por los sujetos en cada una de las competencias cívicas evaluadas. También se recolectó información sobre las variables que podrían estar incidiendo sobre tales niveles de competencias cívicas: factores sociodemográficos y psicológicos (actitudes pro-sociales) y agentes de socialización política (familia, escuela y grupo de pares).

La recolección de datos fue realizada por el autor de estas líneas en 18 institutos secundarios de educación pública de 11 ciudades españolas gracias a la consecución de financiación externa ${ }^{18}$. La selección de estos centros educativos fue realizada en función de la cuantía de estudiantes de origen inmigrante en base a información proporcionada

\footnotetext{
18 Mayores detalles tanto sobre las primeras fases de la investigación como sobre las técnicas utilizadas para la recolección y análisis de datos pueden ser encontrados en el Capítulo № II del presente trabajo de investigación. La escogencia de las diferentes técnicas ha estado influida, discutida y reflexionada a partir de los intercambios mantenidos con los colegas del Área de Ciencia Política de la Universidad de Salamanca (España), el Colegio de la Frontera Norte (México) y el Nuffield College de la Universidad de Oxford (Reino Unido). En las últimas dos instituciones, se realizaron sendas instancias de investigación.
} 
por las Direcciones de Estadística de las Consejerías de Educación de las diferentes Comunidades Autónomas. La búsqueda de información sobre las variables que provocan la posesión de distintos niveles de competencias cívicas condujo a la aplicación de cuestionarios a adolescentes (de último año de Bachillerato o de último año de la Educación Secundaria Obligatoria), a sus padres y/o tutores y a los directores de centros educativos. La muestra final de adolescentes se encuentra conformada por 516 adolescentes entre nativos (362) e inmigrantes (154). Estos sujetos poseen 32 nacionalidades diferentes y pertenecen a 6 regiones socio-culturales y geográficas distintas. En el caso de la muestra de adultos a cargo de los menores, se obtuvo información sobre 211 padres y/o tutores. La recogida de información tuvo lugar entre los años 2008 y 2009.

El análisis estadístico se realizó en tres fases. En primer lugar, se utilizaron medidas de estadística descriptiva y comparaciones de medias para observar las diferencias entre ambos colectivos (inmigrantes y nativos) en cada competencia cívica. En segundo lugar, la relación entre las diferentes variables independientes (factores sociodemográficos, factores psicológicos y agentes de socialización) y las diferentes variables dependientes (competencias cívicas) fue analizada mediante una técnica multivariante escasamente utilizada pero muy apropiada para diseños metodológicos como el descrito: Análisis de Correlación Canónica (ACC). En tercer lugar, la relación entre las distintas variables independientes y la integración política (como medida global construida en base al registro de los individuos en cada competencia cívica) fue analizada mediante una técnica de estadística multivariante de uso generalizado: Regresión Múltiple (RM). Se ha aplicado, para la visualización de los datos asociados a los resultados de una de las técnicas multivariantes aplicadas (ACC), una herramienta innovadora: el heliógrafo.

Varias son las razones que justificaron la puesta en marcha de una investigación como la referida en estas páginas. La primera de ellas es que sus resultados pueden ser utilizados como un indicador prospectivo de las actitudes y comportamientos políticos de los futuros ciudadanos. La literatura politológica ha avalado este razonamiento desde sus tiempos primigenios (Hyman, 1959; Greenstein, 1965; Hess y Torney, 1967; Easton y Dennis, 1967). Evidencia empírica reciente también aboga por tal continuidad (Granberg y Holmberg, 1990; Torney-Purta, Barber y Wilkenfeld, 2006; Hooghe y 
Wilkenfeld, 2008). Simultáneamente, la generación de información de este calibre puede permitir en un futuro la comparación de los registros, en materia de integración política, entre adultos y adolescentes de origen inmigrante.

En segundo lugar, este tipo de investigaciones pretende iluminar de manera anticipada sobre la eventual generación de escenarios de infraciudadanía y exclusión cívica en España como sociedad de acogida. En otras palabras, estos estudios pueden contribuir a la detección de perfiles concretos de individuos y colectivos en riesgo potencial de ingresar en situación de marginación política. En tal sentido, un estudio como el aquí descrito responde a lo solicitado desde la administración pública en relación a la contribución en la creación de indicadores de integración de los inmigrantes tanto a nivel de la Unión Europea (mediante los instrumentos Common Basic Principles on Integration y European Agenda for Integration 2011 ${ }^{19}$ ) como a nivel de España (mediante el Plan Estratégico de Ciudadanía e Integración 2011-2014²0).

En tercer lugar, esta investigación ayuda a reconocer cuáles son los factores y agentes de socialización que estimulan o perjudican la integración política de los adolescentes inmigrantes en las sociedades receptoras. A tales fines, se intenta identificar cuáles son los mecanismos que podrían encontrarse detrás del vínculo entre las distintas variables independientes y los niveles de integración política de los adolescentes inmigrantes. En cuarto lugar, los resultados pueden modestamente contribuir en la mejora del diseño y ejecución de acciones concretas para evitar escenarios sociológicos no deseados. Estos cambios podrían acontecer en materia de políticas de gestión migratoria (sobre todo aquéllas dedicadas a impulsar la integración de la población extranjera en la sociedad receptora). Las políticas educativas también podrían verse beneficiadas por los hallazgos (sobre todo aquéllas vinculadas al diseño, ejecución y evaluación de programas formales, informales y no formales de educación cívica).

\footnotetext{
${ }^{19}$ Los Common Basic Principles on Integration fueron elaborados por el Justice and Home Affairs Council. En tanto, la European Agenda for Integration (2011) nació como Comunicación de la Comisión Europea para el Parlamento Europeo.

${ }^{20}$ Este documento fue elaborado por la antigua Dirección General de Integración de los Inmigrantes de la la Secretaria de Estado de Inmigración y Emigración (hoy Subdirección General de Integración de los Inmigrantes de la Secretaría General de Inmigración y Emigración).
} 
En último lugar, existe otro relevante motivo para llevar a cabo este tipo de investigaciones. Es el relacionado al aporte que las mismas realizan en la creación de una agenda de trabajo que, comparando no sólo entre centros educativos sino también entre distritos, ciudades y comunidades autónomas (o provincias), procure identificar aquellos contextos que favorecen en mayor medida la adquisición de competencias cívicas por parte de los adolescentes de origen inmigrante. A partir de la consideración de la influencia de factores asociados a diferentes "niveles contextuales" en la integración política de los adolescentes, se seguiría la estela metodológica marcada en los últimos años por estudios semejantes realizados sobre población inmigrante en edad adulta.

La estructura de esta tesis es la que se detalla a continuación. El primer capítulo tiene por objeto contextualizar, teóricamente, el estudio de las competencias cívicas de los adolescentes inmigrantes como indicador de sus niveles de integración política. Para ello, se concentra en tres cuestiones: sistematizar el tratamiento histórico que la Ciencia Política ha realizado de los procesos migratorios, organizar la literatura sobre el estudio de las competencias cívicas tanto a nivel genérico como específico y presentar ordenadamente la trayectoria desde el periodo fundacional de la Ciencia Política hasta el presente de las investigaciones sobre socialización política.

Un segundo capítulo tiene por objeto presentar la estrategia metodológica seguida para llevar a cabo esta investigación. A tales efectos, se amplía la justificación sobre la necesidad de proceder a este tipo de estudios. Luego, se detallan las preguntas y objetivos de investigación. A renglón seguido, se definen conceptual y operativamente las variables dependientes e independientes. Realizado esto, se enuncian las hipótesis de investigación. Se culmina el apartado con una descripción pormenorizada de las técnicas de recolección y análisis de datos.

Un tercer capítulo tiene por objeto analizar estadísticamente los datos recogidos y discutir los principales hallazgos a partir de la literatura referida en el marco teórico. Las diferentes etapas del análisis estadístico (descriptivo y multivariante) se encuentran acompañadas de una revisión sistematizada de las hipótesis de trabajo para informar sobre si se ha procedido o no a su corroboración empírica. En la discusión, se identifican diferentes tendencias y patrones tanto sobre la distribución de las competencias cívicas y la integración política entre colectivos poblacionales como acerca de las causas que la 
propician. Se recomiendan también estrategias que pueden aplicarse para lograr influir sobre tales factores.

Por último, en las conclusiones, se hace mención de los principales hallazgos y de la utilidad que los mismos proporcionan en los planos teórico, metodológico y de diseño e implementación de políticas públicas. Se recuerdan las limitaciones que presenta este trabajo y se propone la senda que, en el futuro cercano, deberían seguir los estudios como el aquí descrito. 


\section{CAPÍTULO I}

"Historians, sociologists, economists, anthropologists, and demographers have a head start in the study of international migration. These disciplines have a large body of literature and a bigger empirical base from which to work. But given the sheer number of political scientist who are now turning their attention to the study of international migration, we are closing the gap fairly quickly".

James Hollifield (2008: 225)

\section{1) Introducción}

El presente capítulo tiene por objetivo contextualizar, teóricamente, el estudio de las competencias cívicas de los adolescentes (con independencia de su origen nativo o inmigrante) como indicador de sus niveles de integración política. Se ha procedido a estructurarlo en tres apartados. El primero de ellos describe el lugar que, históricamente, ha ocupado el abordaje de la inmigración en la Ciencia Política. En tal sentido, se detalla cómo, desde la cultura política, se procedió a su paulatina inclusión como objeto de análisis. También, se hace mención de las formas que ha asumido este tipo de investigación politológica. Al mismo tiempo, se enuncia lo que se entiende por integración política y se argumenta sobre la necesidad de utilizar este concepto para referir a la relación existente entre los individuos y los sistemas políticos en contextos de recepción migratoria.

Los siguientes dos apartados intentan referir y engarzar conceptualmente lo que son las dos familias de investigación que, desde la Ciencia Política y otras disciplinas, han abordado el estudio de las actitudes y el comportamiento político de la población no adulta. Por un lado, se encuentra un apartado que introduce al lector sobre el concepto de competencias, los diferentes tipos existentes y su aplicación en diversas ciencias sociales. A posteriori, se realiza una descripción detallada de cada una de las competencias cívicas sobre las que se ha recogido información en esta investigación. Una vez definidas, se hace mención de la importancia de su posesión en regímenes democráticos. Se enumeran aquellas variables que, según la literatura, las provocan. Acto seguido, se recuerdan lo que son las consecuencias derivadas de su existencia. La 
relación existente entre las diferentes competencias cívicas también es descrita. A continuación, se hace una escueta referencia sobre cómo la competencia cívica en cuestión es regularmente medida.

Finalmente, se encuentra un apartado en el que se desarrolla lo vinculado al estudio de la socialización política. Luego de descrito este concepto, se hace mención de cómo ha sido abordado en diferentes momentos del tiempo. Se realiza un especial énfasis en los motivos que han llevado a su reconsideración en los últimos decenios. Inmediatamente después, se introduce a los que son los principales agentes de socialización política y el modo en el que éstos operan para la transmisión de cosmovisiones. Posteriormente, se describen las particularidades que, en materia de (re) socialización política, presenta la población inmigrante. A modo de cierre, en este subcapítulo, se recuerda tanto el riesgo de creación de situaciones de infraciudadanía que existe en sociedades receptoras de inmigración como el papel estratégico que pueden jugar los poderes públicos para evitar la generación de escenarios sociales de esta naturaleza.

\section{2) Sociedades homogéneas y sociedades multiculturales: aproximaciones desde la Ciencia Política}

La Ciencia Política no ha encontrado sino tardíamente un especial interés en el fenómeno de la migración. Otras disciplinas, como la economía, la sociología, la historia y la antropología, contribuyeron previamente a desentrañar las particularidades de los procesos migratorios y, por tal motivo, los diferentes esfuerzos de comprensión de las migraciones internacionales se han visto influenciados por sus enfoques teóricos y sus métodos de estudio (Brettel y Hollifield, 2008). Si se considera a la filosofía política como antecedente del estudio científico de la política, tampoco en sus textos clásicos se encuentran mayores referencias a la inmigración ${ }^{21}$ (Miller, 2008).

Esta falta de interés de la Ciencia Política por la inmigración ha sido consecuencia de dos circunstancias. La primera de ellas se vincula al hecho de que el diseño y la

\footnotetext{
${ }^{21}$ Según David Miller (2008), en los textos de la filosofía clásica sólo se encuentran alusiones a la tarea que todo Estado posee en relación a quienes llegan a su territorio con la condición, según la terminología actual, de refugiados. El pensamiento político tenía para con la inmigración la actitud que este autor adjudica también a la política de aquél entonces: "indiferencia".
} 
implementación de políticas migratorias stricto sensu no tuvieron lugar sino hasta luego de iniciado el siglo pasado. Anteriormente, las decisiones estatales de tal naturaleza habían asumido un carácter excepcional y eran elaboradas en aras de dar respuesta a circunstancias únicas (Hollifield, 2008). En segundo lugar, este desinterés también es producto de las características epistemológicas de la Ciencia Política como disciplina: su prioridad teórica y metodológica ha sido históricamente las instituciones políticas y no los individuos ${ }^{22}$. Sobre esa base, el estudio del individuo no ciudadano (extranjero ${ }^{23}$ ) resultaba menos atractivo aún.

Incluso en el caso estadounidense, y a pesar de su carácter histórico como sociedad receptora de inmigrantes, los cientistas políticos han llegado con retraso a la incorporación de las migraciones entre sus objetos de investigación. La política norteamericana no priorizó en su agenda la cuestión migratoria durante gran parte de la pasada centuria y, en consecuencia, los politólogos la abordaban marginalmente ${ }^{24}$. Puede afirmarse que, recién en el último decenio del siglo XX y coincidiendo con una mayor acentuación de los flujos migratorios, la inmigración se convierte en un tópico sistemáticamente abordado por la Ciencia Política norteamericana. La excepción más relevante, durante ese largo periodo de silencio teórico y empírico, la han constituido ciertos estudios tradicionales sobre cultura política en los que la presencia inmigrante se filtraba en los análisis que se realizaban sobre los rasgos político-culturales de los diferentes grupos étnico-raciales al interior de la sociedad estadounidense ${ }^{25}$ (Sears 1975; Morales y Giugni, 2011).

\footnotetext{
22 Obviamente, los estudios sobre cultura política y comportamiento político constituyen la excepción a la regla mencionada.

${ }^{23}$ La condición de extranjería se encuentra asociada a la no posesión de la nacionalidad (o ciudadanía en determinados círculos) de la sociedad en la que se habita. La conceptualización de la condición de inmigrante es algo más compleja. Si bien puede haber cierta controversia en relación a la definición de lo que es un inmigrante, se considera generalmente como tal a la persona nacida fuera del territorio nacional. Este nacimiento se encuentra asociado a una circunstancia de arraigo familiar/individual en una sociedad distinta a la actual (es decir, a la de acogida).

24 James Hollifield (2008) sostiene que factores históricos y teóricos han influido en este rezago. En relación a los primeros, sostiene que la caída en los niveles de inmigración en los Estados Unidos entre la década de 1920 (fin de la tercera oleada inmigratoria) y el decenio de 1970 (comienzo de la cuarta oleada inmigratoria) condujo a un relativo desinterés por este fenómeno entre los investigadores. Consecuentemente, la inmigración no figuraba en la agenda oficial del gobierno federal. Como razones teóricas, apunta que, al coincidir el periodo referido con la Guerra Fría y la inmigración no afectar decisivamente el balance de poder entre las dos potencias mundiales, los intereses politológicos se encontraban dirigidos hacia otros objetos de estudio.

25 Dos excepciones frente a esta ausencia de estudios sobre migración merecen ser mencionadas. Uno de ellos es el aporte que Lawrence Fuchs (1956) realiza en relación a la influencia que ejerció la inmigración
} 
En el caso europeo, la conversión de las tradicionales sociedades monoculturales (o cuasi-monoculturales) en sociedades inmigratorias, como consecuencia del desarrollo económico posterior a la Segunda Guerra Mundial, condujo al despertar del interés de la Ciencia Política por esos procesos. Hollifield (2008) recuerda que la ingente llegada de "guest workers" y refugiados a diferentes países de Europa Occidental provocó la aparición de inquietudes científicas entre sociólogos políticos comparativistas (Castles y Kosack, 1972; Freeman, 1979) que, ya en la década de 1970, pretendían estudiar los rasgos fundamentales que presentaban estos fenómenos en diferentes sociedades. La atención sobre estas realidades por parte de los académicos europeos se debió también a que la cuestión inmigratoria fue adquiriendo, paulatinamente, mayor envergadura en la agenda pública.

Con el incremento de los volúmenes migratorios internacionales durante los últimos lustros de la pasada centuria, la Ciencia Política profundiza su preocupación por ofrecer su perspectiva en el análisis de tales transformaciones sociales (Ireland, 1994; Jones-Correa, 1998; Glazer, 1998; Zolberg, 1999). Los cientistas políticos creyeron que era oportuno conocer cuál era la relación existente entre el fenómeno de las migraciones y la actuación de los Estados. Se multiplicaron los esfuerzos para, por un lado, averiguar cómo el poder político podía erigirse en disparador de estos cambios sociológicos (tanto a nivel de expulsión como de atracción de población inmigrante) y, por el otro, identificar cuál era su comportamiento una vez que las corrientes migratorias se institucionalizaban.

Con el tiempo, se han establecido cuatro diferentes líneas de investigación a través de las cuales la Ciencia Política ha integrado a las migraciones en su foco de estudio $^{26}$. La primera de ellas tiene por objeto conocer cuál ha sido el comportamiento de las autoridades políticas en materia de control migratorio, es decir, su desempeño en el establecimiento de reglas de ingreso y egreso de población inmigrante (Cornelius, Martin y Hollifield, 1994; Cornelius y Rosemblum, 1995; Brochmann y Hammar, 1999;

en el sistema de partidos de los Estados Unidos. El otro es el trabajo de Nathan Glazer (1956) que, desde la sociología, analiza la integración política de los diferentes colectivos inmigrantes en la sociedad norteamericana.

${ }^{26}$ Esta clasificación es una propuesta de organización teórica por parte del autor de estas líneas en base a la aportación de Hollifield (2008). Ello no obsta para que, según la perspectiva de otros investigadores, los estudios sobre migraciones en Ciencia Política sean clasificados según una lógica diferente a la aquí propuesta. 
Huntington, 2004; Freeman, 2006; Zolberg, 2008; Biderbost, 2012). Al mismo tiempo, se intenta averiguar qué factores externos conducen a la adopción de diferentes tipos de estrategias en la materia y qué variables producen que un Estado tenga mayores o menores capacidades sobre la cuestión.

El segundo tipo de aproximación, a medio camino entre la Ciencia Política y las Relaciones Internacionales, pretende estudiar cómo las migraciones están moldeando el tradicional concepto de soberanía y de qué manera están afectando a la seguridad interna de los Estados ${ }^{27}$ (Sassen, 1999; Joppke, 1998; Guiraudon y Lahav, 2000; Rudolph, 2005; Adamson, 2006). En este tipo de abordajes, los análisis se centran en el modo en el que los procesos migratorios influyen, por la relevancia que se le adjudican a nivel de política interna, en la definición de las metas de política exterior y, consecuentemente, en los vínculos entre los Estados.

En una tercera línea de investigación, los politólogos se encuentran preocupados por indagar en los procesos de incorporación/integración de los inmigrantes en las diferentes dimensiones de la vida social (laboral, económica, cívica, cultural, religiosa) en los países receptores. Esta línea de investigación parte del supuesto de que la inmigración modifica los patrones sociales $y$, al generar estos cambios sociales respuestas políticas, también el sistema político se ve afectado. A tales efectos, se ha procedido a estudiar cuál es la conducta de los Estados (facilitadora u obstaculizadora) frente a la conversión de los inmigrantes en nuevos sujetos de derechos (Glazer, 1998; Brettell y Hollifield, 2008; Morales y Giugni, 2011).

En otros términos, podría decirse que esta línea de investigación tiene por objeto conocer cuáles son las características de las políticas públicas de gestión de la incorporación/integración de la inmigración y qué resultados éstas propician dados ciertos rasgos entre los miembros de los colectivos poblacionales. Los cientistas políticos que se enrolan en esta corriente de trabajo pretenden averiguar cuáles son los factores sociodemográficos, histórico-culturales, económico-laborales y legal-institucionales que influyen en la elección, por parte de los Estados y de diferentes organismos gubernamentales, de un determinado estilo de gestión de la inmigración y,

\footnotetext{
${ }^{27}$ En algunos abordajes, a los riesgos que la inmigración entraña para la seguridad y la soberanía estatales, se les añade el peligro o la amenaza que la misma importa para la cultura predominante en las sociedades de acogida (Huntington, 2004; Rudolph, 2005). A esta última, Rudolph (2005) la entiende como una especie de soberanía societal.
} 
paralelamente, de los márgenes de ciudadanía reservados para los inmigrantes ${ }^{28}$ (Cornelius et al. 1994; Niessen, Huddleston y Citron, 2007). En tal sentido, en estos estudios, se asume que los procesos migratorios activan mecanismos sociales que llevan a modificar las concepciones vigentes de ciudadanía y, por ende, ciertas instituciones políticas y jurídicas de las sociedades receptoras (Morris, 2002; Koopmans, Statham, Giugni y Passy, 2005).

En esta tercera aproximación, se investiga también sobre cuáles son los comportamientos de las diferentes instituciones y actores políticos en contra y a favor de la llegada y/o incorporación/integración de los colectivos inmigrantes. Entre los primeros, se encuentran los estudios sobre la irrupción en el escenario político de outsiders (líderes políticos no pertenecientes a partidos políticos tradicionales y con un discurso de perfil anti-político), movimientos sociales y de partidos políticos de extrema derecha con propuestas programáticas cuyo eje central es el rechazo de la inmigración (Arzheimer y Carter, 2006; Ivarsflaten, 2005; Casals 2009; Castles y Miller, 2009; Biderbost, 2012). Sobre los segundos, se investiga cuál es la naturaleza de las instituciones y actores que suelen coaligarse para la promoción de la recepción y/o de una incorporación normalizada de inmigrantes. Generalmente, estas alianzas suelen asumir rasgos de "strange bedfellow" por hallarse conformadas por miembros que representan, por un lado, intereses de libre mercado (derecha política) y, por el otro,

\footnotetext{
${ }^{28}$ La política pública de gestión de la inmigración es la que define el acceso a la ciudadanía, es decir, los derechos y obligaciones que le serán reconocidos a los recién llegados en la sociedad receptora. La naturaleza del concepto de ciudadanía ha ido evolucionado hacia formas cada vez más incluyentes. En los actuales regímenes democrático-representativos, la condición ciudadana de un Estado puntual se encuentra reservada a todos los miembros de su sociedad varones y mujeres, nativos o naturalizados, que hayan superado el umbral de la mayoría de edad (límite marcado discrecionalmente según la legislación nacional). En efecto, se encuentran privados del conjunto de derechos y obligaciones que la posesión de la misma acarrea los menores de edad, quienes han perdido tal condición a causa de su incursión en figuras delictivas y los inmigrantes que aún no han procedido, por motivos personales y/o legales, a la adquisición de la nacionalidad, mediante el procedimiento de la naturalización, de la sociedad de acogida. Fundamentalmente, respecto a la última de estas situaciones, se han levantado insistentes voces que reclaman, según la jerga weberiana, la desacralización de la relación que existe al interior del binomio "ciudadanía-nacionalidad" para que el primero de sus componentes pueda abarcar y dar respuesta al número incremental de individuos que, como consecuencia de su involucramiento en procesos inmigratorios, no habitan en su territorio de origen y se hallan imposibilitados de ejercer (parcial o totalmente) los derechos políticos en el sitio en el que se encuentran asentados. Sobre ello, se sostiene que las democracias liberales no logran resolver aún el nudo gordiano que el fenómeno inmigratorio representa debido a que, en su imaginario conceptual, la ciudadanía es emparentada con la nacionalidad (no con otros criterios como la residencia extendida en el tiempo o la expresión de la voluntad en esa dirección por parte del sujeto) (Vallespín, 2005; Zapata-Barrero, 2005; Biderbost, 2009).
} 
posiciones defensoras de la expansión de los derechos individuales (izquierda política) ${ }^{29}$ (Gibney, 2004; Hollifield, 2008).

En el marco de la tercera línea de investigación, no sólo hay estudios en los que la unidad de análisis son las instituciones políticas y actores políticos de cierta relevancia. A ella pertenecen también investigaciones que centran su unidad de análisis en los individuos de a pie. A su interior, una sublínea de trabajo in crescendo es aquella dedicada a explicar cuáles son las características demográficas y actitudinales de, por un lado, los adherentes a consignas anti-inmigración expuestas por líderes, movimientos sociales y partidos políticos y, por el otro, quienes votan en comicios en los que el clivage (o línea divisoria) se ubica en torno a la cuestión migratoria (Givens y Luedtke, 2005; Norris, 2004; Pardos, 2012).

Dentro de los abordajes en los que se releva al individuo como unidad de análisis, se encuentra otra sublínea de investigación a la que pertenece, tanto a nivel teórico como empírico, el presente trabajo. En ella, se procura conocer las diferencias en materia de cultura política (actitudes y comportamientos) entre nativos y extranjeros. Estas investigaciones suelen tener por objeto la detección de eventuales brechas en la distribución de competencias cívicas entre los individuos pertenecientes a diferentes colectivos poblacionales. El hallazgo de potenciales escenarios de exclusión política es, en estos casos, su propósito fundamental ${ }^{30}$ (De la Garza y DeSipio 1999; González-Ferrer y Morales, 2006; Morales y Giugni, 2011).

Este tipo de investigaciones indaga, directa o indirectamente, sobre la (re) socialización política y los niveles de integración política de la población inmigrante (y/o sus descendientes) en la sociedad receptora (Biderbost, 2009). Este último concepto es

\footnotetext{
29 La expresión "strange bedfellow" es utilizada para aquellas situaciones en las que dos posiciones ideológicas supuestamente antagónicas encuentran un punto de contacto. A modo de ejemplo puede decirse que, en relación a la inmigración, ciertos empresarios necesitan de su continuidad en el tiempo para el aseguramiento de la sostenibilidad de sus negocios y, simultáneamente, quienes militan en organizaciones no gubernamentales pro - derechos civiles y sindicatos trabajan por multiplicar las libertades que detentan los recién llegados. Frente a situaciones como la descrita, es posible pensar en alianzas entre ambos sectores que, en otros momentos o frente a otros hechos, resultasen anómalas.

${ }^{30}$ Cuando estas investigaciones son desarrolladas en sociedades en las que los inmigrantes tienen derechos políticos limitados (porque no han adquirido la nacionalidad del Estado receptor o por la naturaleza restrictiva de las normas electorales), las mismas son también útiles instrumentos para generar eficaces diagnósticos del comportamiento cívico de los potenciales ciudadanos.
} 
definido de manera diferente en las distintas aproximaciones sobre la cuestión ${ }^{31}$. A esta cualidad, se debe en parte la falta de sistematicidad atribuible a este tipo de estudios. Otro elemento que ha contribuido a este carácter es que las aproximaciones sobre el tema se originan en disciplinas ${ }^{32}$ que, si bien compartiendo preocupaciones teóricas y empíricas comunes, difieren sutilmente en definiciones conceptuales, operativas y en los espacios académicos en los que se difunden los conocimientos producidos a su interior.

Esta sublínea de trabajo enfrenta retos teóricos y empíricos importantes. Por un lado, la Ciencia Política aún no ha tratado suficientemente cuestiones vinculadas a cómo la integración política de los inmigrantes en las sociedades de acogida se encuentra afectada (por) y, a su vez, afecta su integración en las otras dimensiones ya comentadas. Por otro lado, si bien se ha logrado avanzar en la identificación de los niveles de integración política de individuos y colectivos inmigrantes y cuáles son los factores (personales y/o contextuales) que podrían estar influyendo en ellos, esta tarea se ha realizado prioritariamente sobre población adulta (Portes y Mozo, 1985; Garcia, 1987; Uhlaner, Cain y Kiewiet, 1989; Ramakrishnan y Espenshade, 2001; Bueker, 2005; Koopmans et al., 2005; Bloemraad, 2006; Morales y Giugni, 2011) 33.

El presente estudio pretende dar un paso más allá de lo investigado hasta el momento en el marco de esta última sublínea de trabajo. Para ello, se procede al relevamiento de los niveles de integración política, a través de la medición de competencias cívicas, entre los miembros de la población adolescente inmigrante y nativa en la escuela secundaria española. Este tipo de estudios, aunque más frecuentes en la academia norteamericana en el campo de la cultura política, son poco usuales en

\footnotetext{
${ }^{31}$ Al ser la integración política definida de diversas maneras, también hay matices en la identificación y definición de los indicadores que se utilizan para su medición. En los próximos apartados, se profundizará sobre la cuestión.

${ }^{32}$ Estas disciplinas son, fundamentalmente, la Ciencia Política, la Sociología Política y la Psicología Política. No siendo tan estrictos, sería posible incluir también en este grupo a determinados trabajos procedentes del campo de la Pedagogía Política.

${ }^{33}$ En idéntico sentido, se ha investigado sobre las asociaciones que agrupan a inmigrantes, en la mayoría de los casos, también de edad adulta (Berger et al., 2004; Jacobs y Tillie, 2004; Togeby, 2004; Portes, Escobar y Arana, 2008; Morales y Anduiza, 2009; Aparicio, 2011). En este tipo de investigación, suele usarse la información recogida sobre las organizaciones como indicador indirecto o propiciante de los niveles de incorporación política de los sujetos que poseen la condición de inmigrantes que las componen.
} 
el contexto europeo ${ }^{34}$ (Flanagan, 2004; McIntosh, 2006; Torney-Purta et al. 2006, 2007; Wilkenfeld, 2009).

Por último, una cuarta línea de investigación es la vinculada al estudio del transnacionalismo político. En su seno, se encuentran aquellos trabajos que intentan descifrar los patrones actitudinales y comportamentales de los inmigrantes en relación al sistema político de las sociedad de origen (Itzigsohn, 2000; Guarnizo, Portes y Haller, 2003; Martiniello y Lafleur, 2008; Bolzman, 2011). La siguiente figura facilita la compresión del proceso mediante el cual la Ciencia Política ha incorporado a los procesos migratorios entre sus objetos de estudio.

\footnotetext{
${ }^{34}$ Una interesante excepción a la mencionada tendencia es el trabajo de Morrissey (2011). Sin embargo, su aporte no es politológico. El mismo procede de las Ciencias de la Educación.
} 
Figura 1.1

\section{El tratamiento del fenómeno migratorio}

por parte de la Ciencia Política

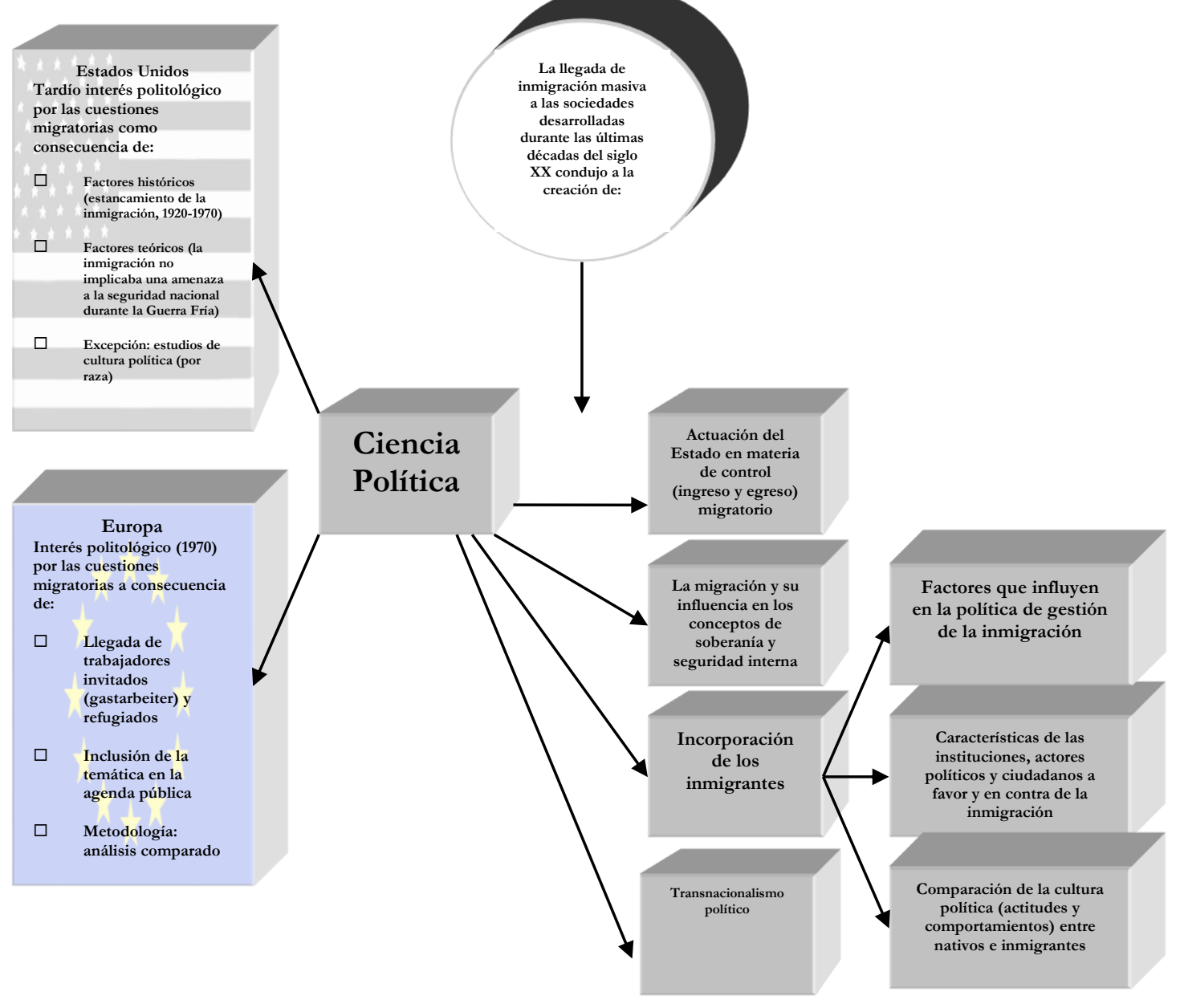

Fuente: Elaboración propia en base a la literatura sobre el tema. 


\section{1) "No somos todos iguales": La incorporación de la población inmigrante en los estudios sobre cultura política}

El presente trabajo se enmarca en la tradición politológica de estudios sobre cultura política. A pesar de los problemas asociados a la definición de este concepto, existe un relativo acuerdo respecto a dos cuestiones. En primer lugar, se acepta que la misma versa sobre los complejos mecanismos que vinculan a la vida política (en su plano institucional y en su vertiente asociada a la esfera pública) con el universo conceptual y representacional que, sobre ella, tienen los individuos que pertenecen a una comunidad política ${ }^{35}$. En segundo término, el análisis de la cultura política se encuentra asociado a una tradición científico-cognitiva embebida de la teoría angloamericana sobre la ciudadanía y de su discurso respecto a la necesidad de contar con ciudadanos políticamente activos para el logro de mayores cotas de democracia (Inglehart, 1988; Verba, Schlozman y Brady 1995; Morán, 1999).

Una definición interesante, de cara al propósito de esta tesis, de cultura política es la ofrecida por Landolt y Goldring (2008). La misma, por un lado, atribuye un carácter determinante al proceso de socialización política y, por el otro, sostiene que la cultura política contiene dispositivos que permiten adaptar la actuación política de los individuos a los diferentes escenarios a los que deben enfrentarse. Estos autores la definen como (p. 4):

"...a skill set or toolkit that is based on networks and shared political socialization and reflected in a group 's mode of doing politics and established basis for organizing. Groups apply this toolkit in a flexible fashion to different situations or encounters...".

\footnotetext{
35 En tal sentido, los aportes conceptuales atribuibles a la aproximación teórica de la cultura política cumplen con la función de "bridging" entre los marcos culturales, psicológicos y sociales de la acción y las realidades peculiares de los diferentes sistemas políticos. La mayor repercusión de su uso se ha dado en áreas referidas a la reflexión sobre la legitimidad de la institucionalidad política, la articulación de la opinión pública en los contextos políticos contemporáneos y los hallazgos de los fundamentos de la estabilidad de los regímenes políticos, en general, y democráticos, en particular (Morán, 1999).
} 
En tiempos de la segunda posguerra, tienen lugar los primeros esfuerzos sistemáticos de la Ciencia Política contemporánea para descifrar las características de la cultura política de diferentes poblaciones. Estos intentos se hallaban enmarcados en la búsqueda funcionalista de, por un lado, la determinación de aquellos factores económicos, sociales y culturales promotores del establecimiento y la estabilidad de los sistemas democráticos y, por el otro, la construcción de modelos de desarrollo político que marquen la pauta por la cual sociedades tradicionales abandonan patrones históricos de comportamiento para adquirir características propias de sociedades modernas. Estos fueron los aportes fundamentales de Almond y Verba (1963) en "The Civic Culture". Desde entonces, el refinamiento conceptual alcanzado en esta área temática ha permitido la definición precisa de las dimensiones que le deben ser reconocidas a la cultura política como fenómeno ${ }^{36}$.

Inicialmente, cuando se hablaba de dimensiones de la cultura política, se hacía referencia a las distintas orientaciones (cognitivas, afectivas y evaluativas) que los individuos manifestaban sobre el sistema político, los inputs al sistema, los outputs del sistema y su desempeño como actores políticos (Almond y Verba, 1963). A posteriori, se han hecho diferentes intentos por pulir esa propuesta multidimensional seminal (Elkins y Simeon, 1979; Almond y Verba, 1980; Inglehart, 1988; Vujcic, 1998). En ellas, generalmente, se ha abandonado la consideración de las clásicas orientaciones como dimensiones y la definición de las últimas ha pasado a estar vinculada a los objetos políticos con los que las personas entran en contacto: el sistema político como contexto amplio en el que los ciudadanos se encuentran insertos, el proceso político (o las cambiantes circunstancias políticas), la dinámica decisoria que acontece al interior de las instituciones políticas y los resultados derivados de esa toma de decisiones.

\footnotetext{
${ }^{36}$ Si bien la obra "The Civic Culture: Political Attitudes and Democracy in Five Nations" de Almond y Verba (1963) es considerada un hito por el especial tratamiento científico que dispensa al concepto de cultura política, la misma es deudora de lo referido sobre la cuestión por parte de un número importante de autores clásicos (Platón, Aristóteles, Maquiavelo, Montesquieu, Rousseau, Tocqueville y Weber), quienes advertían a las sociedades de su época de la existencia de elementos (descriptos con relativa vaguedad) que componían distintos "caracteres de los pueblos". Este abordaje filosófico de la cultura política ha sido eminentemente cualitativo. En tal sentido, una de las innovaciones más importantes del trabajo de Almond y Verba radica en su intento de cuantificación del concepto de cultura política. Otra de ellas se vincula con la aplicación de la perspectiva comparada para la detección de los rasgos predominantes de la cultura política en diferentes países.
} 
En nuestro entorno académico más próximo, Morán y Benedicto (1995) presentaron una propuesta teórico-metodológica sobre las diferentes dimensiones que componen la cultura política. En su esquema, la cultura política puede ser capturada empíricamente según la información de la que se disponga en cuatro áreas: lo vinculado al individuo-ciudadano como actor, la relación entre el ciudadano y lo político, la imagen que aquél tenga del sistema político y la evaluación que haga de los resultados de la acción institucional. Las primeras dos dimensiones hacen referencia a lo que se denominan competencias o activos cívicos de los individuos mientras que las dos segundas forman parte de lo que, académica y profesionalmente, es entendido como "opinión pública".

Con los matices metodológicos del caso, el abordaje tradicional de la cultura política se ha realizado a través de las diferentes dimensiones referidas. Gracias a su aplicación, los primeros hallazgos empíricos concluyeron que, a contrario sensu a lo deseado por la teoría angloamericana de la ciudadanía, los individuos carecían de sofisticación política (Converse, 1962). Aparentemente, entendían de manera limitada su participación en la vida política de sus sociedades y no existía evidencia suficiente respecto a que, detrás de sus decisiones políticas, hubiese una evaluación racional de candidatos, partidos y propuestas ${ }^{37}$.

Lamentablemente, a diferencia del trabajo de Almond y Verba, el desarrollo posterior de los estudios de cultura política estuvo excesivamente centrado en la sociedad norteamericana como modelo o referente conceptual. Los descubrimientos arriba mencionados fueron erróneamente tomados como base y extrapolados a otras realidades políticas. Ello trajo consigo el surgimiento de voces (Huntington, 1968; Butler y Stokes, 1969) que sostenían que para el normal funcionamiento de determinados regímenes democráticos la excesiva movilización de los ciudadanos (como consecuencia de su naturaleza informada) era contraproducente. Tales conclusiones, como es posible

\footnotetext{
${ }^{37}$ Sin embargo, estos hallazgos primigenios fueron ulteriormente refutados por otros que permitían concluir que, en realidad, sí existen entre los individuos niveles aceptables de sofisticación política (Delli Carpini y Keeter, 1993; Kinder y Winter, 2001). Sobre el hallazgo de resultados tan opuestos, Kuklinski y Peyton (2007) han sostenido recientemente que ello es consecuencia de que los investigadores, históricamente, no han partido de las implicaciones derivadas de las conclusiones a las que se ha arribado en las indagaciones previas sobre la cuestión.
} 
observar, se hallaban en las antípodas de lo predicado por la teoría angloamericana de la ciudadanía.

La naturaleza del curso tomado por los estudios de cultura política provocó, entonces, la emergencia de posiciones opuestas al canon imperante (estrechamente vinculado a la teoría empírica de la democracia). Las críticas a la posición teórica y metodológica expuesta en el aporte genésico de Almond y Verba (1963) y, por extensión, al paradigma tradicional ${ }^{38}$ de cultura política han girado en torno a diferentes argumentos. Algunos de los mismos se detallan a continuación.

La primera de estas críticas, expuesta entre otros por Carole Pateman (1980) y Jerzy Wiatr (1980), giraba en torno a que los primeros estudios empíricos sobre cultura política fueron construidos sobre una visión de la democracia ligada excesivamente a la tradición liberal-representativa. En ellos, la dimensión "participativa" de la democracia, heredera del pensamiento de Stuart Mill y Rousseau, brilla por su ausencia. Para Almond y Verba, la democracia, en consonancia con el legado liberal, no es un estilo de vida sino un método político que exige el concurso de los ciudadanos sólo en oportunidad de la celebración de los comicios regulares ${ }^{39}$.

Consecuentemente, el hallazgo, en estos iniciales análisis empíricos, de elevados niveles de apatía y desafección entre ciudadanos de las sociedades democráticas angloamericanas no causa ni sorpresa ni condena ${ }^{40}$. Por ese motivo, la cosmovisión que les daba soporte fue caracterizada, entonces, como ideológica y facilitadora del mantenimiento del statu quo. A esto último, también contribuía el hecho de que, para los padres de la "cultura cívica" la democracia liberal era la única posibilidad real frente

\footnotetext{
${ }^{38}$ Existe otra escuela de tradición sociológica, cuya batería de recursos metodológicos proceden de la tradición hermenéutica y que también se dedicada al estudio de la cuestión. En su caso, lo que se busca es la consecución de un conocimiento más hondo respecto a las maneras en las que se configuran las culturas, los modos de acción social y las distintas dimensiones que conforman el espacio público. No debe olvidarse que otra corriente intelectual que se ha acercado, en las últimas décadas, al estudio de la cultura política ha sido el rational choice (Welch, 1993; Morán, 1999).

${ }^{39}$ Según Wiatr, cualquier otro tipo de participación política que exceda lo estrictamente electoral pareciera, en la cosmovisión de Almond y Verba, resultar disfuncional para los intereses de la democracia. El autor polaco también denuncia que el concepto de democracia utilizado sólo pondere el valor de libertad en detrimento de otras definiciones (como la francesa) que incorporan también el valor de la equidad.

${ }^{40}$ Wiatr recuerda la existencia de una paradoja en relación a la cuestión. Mientras los autores de The Civic Culture dan cuenta de la disconformidad que ciertos sectores de ciudadanos detentaban hacia algunos de regímenes políticos estudiados (México e Italia), nada se decía sobre quienes asumían semejante actitud en las democracias angloamericanas.
} 
a las diferentes opciones totalitarias. Por el contrario, los detractores de esta mirada "liberal" sobre la democracia denuncian la desaparición, en el aporte seminal de Almond y Verba, de otros lenguajes y formas democráticas ${ }^{41}$. De esta primera crítica, se derivan, directa o indirectamente, algunas de las subsiguientes.

El segundo de los argumentos hacía referencia al excesivo psicologicismo de la posición inicial y a la dificultad que ello aparejaba para la construcción de puentes teóricos entre características individuales y atributos reconocidos a un sistema político en concreto (Fagen, 1969; Tucker, 1973). El énfasis "individualista" provocaba que se desconociera el origen de la cultura política. La misma era entendida como dada (Pateman, 1980). Debido a esta visión, en esta fase inicial de estudios de cultura política, se ignoró sistemáticamente la asociación empírica que existía, a nivel personal, entre la posesión de determinadas orientaciones políticas y otros rasgos de tipo sociodemográfico ${ }^{42}$.

Lo anterior conducía a que, según entendían los críticos, se asumiese que la cultura política propiciaba estilos particulares de estructuras políticas y se soslayaba la posibilidad de que, entre ambos elementos, la relación fuese de signo opuesto o circular $^{43}$. Las carencias al respecto, en los estudios genésicos sobre cultura política, serían efecto de la escasa profundidad con la que se han analizado los datos asociados a una (cultura política) y otra variable (estructura política) (Pateman, 1980; Wiatr, $1980)^{44}$. La identificación de la socialización política como correa de transmisión entre ambas variables no era tampoco explorada. Tras esta crítica, se encontraba otra más profunda dirigida a los sistemas democráticos anglo-americanos y a las desigualdades

\footnotetext{
${ }^{41}$ Carole Pateman, incluso, afirma que los autores ni siquiera conocían en profundidad la evolución histórica del concepto de democracia en el marco de la filosofía liberal. En otras palabras, ella sostenía que aquéllos no sólo desconocían otras visiones sobre la democracia sino que la escogida como "verdadera" era conocida de manera insuficiente.

${ }^{42}$ Como la propia Pateman apunta, ignorar la relación entre estas variables iba en contra de lo estudiado hasta ese momento en campos de investigación anejos al de la cultura política (Lazarsfeld, y MacPhee, 1954; Campbell et al., 1960 y Milbrath, 1965).

${ }^{43}$ Wiatr afirma que, en el caso de la obra de Almond y Verba, la existencia de interdependencia entre cultura política y estructura es clara en la introducción teórica pero, luego, tal supuesto no permea el análisis que ellos realizan de la información recogida.

${ }^{44}$ Sin embargo, Gabriel Almond (1980), en su respuesta a estas críticas en el artículo "The Intellectual History of the Civic Culture Concept" publicado en el libro "The Civic Culture Revisited", sostiene que la circularidad (y no la unidireccionalidad) entre cultura política y estructura política era la pauta sugerida en sus reflexiones iniciales.
} 
que los mismos escondían en materia de distribución, entre los ciudadanos, de competencias políticas.

Como tercera observación, se encuentra una que se vincula directamente con la naturaleza de esta tesis doctoral: aquélla que recuerda que existen particularidades, según grupos sociales, en la posesión de rasgos de cultura política. Carole Pateman hizo mención de la incapacidad de los primeros estudios para detectar matices, en tal sentido, entre diferentes colectivos. Primeramente, se habló de las divergencias halladas según género y nivel socioeconómico. Jerzy Wiatr sostuvo que la contribución primera de Almond y Verba falla por qué no procede a la exploración de la distribución de las competencias cívicas entre las diversas subculturas políticas ${ }^{45}$.

En cuarto lugar, se reclama el haber incorporado acríticamente el análisis sistémico parsoniano. Tal falencia se observa en la adjudicación de tareas "políticas" particulares a los distintos estamentos/actores sociales que el texto clásico realiza. Esa estrategia teórica pareciera descansar más en la ya mencionada mirada ideologizada que en una lectura correcta de los hechos. Entre otros efectos, ello ha llevado a, según considera Pateman (1980), sobre-estimar el rol positivo desempeñado por las elites gobernantes en el mantenimiento de la estabilidad de los regímenes democráticos.

La clase dirigente para lograr este cometido, de acuerdo a la formulación inicial, debe gobernar respondiendo a los intereses de la sociedad y en un contexto en el que la participación de los individuos sea limitada para que aquélla cuente con la suficiente dosis de poder para decidir y actuar ${ }^{46}$. En otras palabras, los detractores de esta cosmovisión clásica sostienen que, bajo el argumento de la aparente "bondad" o "superioridad moral" de las elites, se condiciona la participación política de determinados sectores o estratos sociales ${ }^{47}$.

\footnotetext{
45 Esta crítica engarza con la anterior debido a que las diferencias entre subculturas son producto de la influencia que la estructura política ejerce sobre las personas. Esta misma estructura es, de acuerdo a la apreciación de los críticos, la que reserva a los sujetos espacios diferentes dependiendo de sus atributos. ${ }^{46}$ Según Almond y Verba, la participación de los individuos debe concentrarse en instancias electorales. Al mismo tiempo, los individuos, en su perspectiva, no pueden ser calificados de animales políticos. Son, a lo sumo, "homo civicus" que, preocupados, por la dimensión política de su existencia no la confunden con otras esferas que sí constituyen lo prioritario en sus vidas (Pateman, 1980).

${ }^{47}$ Sin embargo, Lijphart (1980), en defensa de la propuesta seminal de Almond y Verba (1963) señala que, tras una fachada de promoción de amplios márgenes de participación de los ciudadanos, pueden también esconderse regímenes políticamente conservadores y socialmente no igualitarios, es decir, atentatorios de los derechos de determinados sectores de la población. En otros términos, el apoyo formal a la promoción de la participación política por parte de un gobierno (o de sus élites dirigentes) no basta, según su parecer, para que ello se traduzca en participación efectiva.
} 
La quinta gran observación se vinculaba a la sobrevaloración que le otorgaron los primeros autores al modelo angloamericano como formato ideal de democracia. Se critica, entonces, su utilización como parámetro para la evaluación de otras manifestaciones de este tipo de régimen (Pateman, 1980; Wiatr, 1980). Según la visión inicial, el "estilo político" británico-estadounidense aseguraba la estabilidad democrática. Tales maneras, a su vez, derivaban de que las sociedades gobernadas bajo las reglas angloamericanas eran aquéllas en la que predominaba la también idealizada "cultura cívica". En esta última, un componente fundamental era el elevado nivel de confianza interpersonal que los individuos declaraban poseer.

Ese engarce entre "cultura cívica angloamericana" y "democracia angloamericana" es, en la visión de Wiatr, la consecuencia de hallar evidencia empírica para situaciones ideológicamente definidas. En otras palabras, si la democracia modélica es la angloamericana, obviamente, la cultura política "propiciatoria" de tales mecanismos es la vigente en las sociedades en la que aquélla se ejerce. Los críticos señalan, así mismo, que no puede generalizarse el que una cultura política, en contraposición a la vigente en el Reino Unido y los Estados Unidos, con escaso nivel de confianza interpersonal y social se encuentre asociada a inestabilidad del régimen democrático. Como ejemplo de ello, Lijphart (1980) menciona la estabilidad lograda por las democracias consociativas europeas (Austria, Bélgica, Holanda), construidas sobre la base de sociedades diversas, en el periodo posterior a la Segunda Guerra Mundial ${ }^{48}$.

Sumado a ello, los críticos afirman que la perspectiva tradicional minimizaba la posibilidad de cambio cultural tanto dentro como fuera de las sociedades angloamericanas. A su vez, delataba la presencia de una elevada dosis de etnocentrismo y un profundo desconocimiento no sólo sobre la realidad política de países no estudiados hasta el momento sino, en consonancia con la tercera crítica mencionada, en relación a la diversidad existente al interior de las sociedades sobre las cuales si se había investigado (Pateman, 1980).

Por último, en el campo de lo estrictamente metodológico, se recela de las primeras aproximaciones sobre la cuestión por diferentes motivos. Arend Lijphart

\footnotetext{
${ }^{48}$ El mismo Lijphart (1980), en su participación en "The Civic Culture Revisited", reconoce que uno de los motivos de la equivocada conclusión sobre la superioridad de las democracias anglo-americanas se debe al número y tipo de países incorporados en la muestra del estudio seminal de Almond y Verba o, en otras palabras, es producto de una mejorable selección de casos.
} 
(1980) recomienda la utilización de índices en los que los mecanismos de ponderación de los diferentes componentes de cultura política sean explicitados. A su vez, Jerzy Wiatr (1980), en relación al modo en el que se procedió a comparar entre países, critica el que se usasen idénticos indicadores en todos los sitios para la medición de los conceptos utilizados. Tal estrategia desconoce, en los hechos, la variabilidad existente entre los casos en materia de atribución de significados a palabras y/o expresiones ${ }^{49}$.

Se critica así mismo el haber enfatizado en exceso los esfuerzos para la medición de la cultura política en detrimento de la realización de idéntico ejercicio en relación a otros conceptos sobre (de) los que aquella ejerce (o recibe) influencia. En el caso concreto de la crítica expuesta por Lijphart (1980), se habla de la incorrecta manera en la que la estabilidad democrática (como referente de la estructura política) ha sido medida. Esta omisión metodológica, según este autor, debilita la asociación empírica que pueda hallarse entre tipos concretos de cultura política y niveles particulares de estabilidad democrática.

Finalmente, se le critica a estos primeros estudios el hecho de haber procedido a la medición del concepto de cultura política sólo a partir del uso de técnicas de tipo cuantitativo. Tal estrategia, en la visión de Pateman, se ha llevado a cabo sin hacer mención de sus eventuales limitaciones ni haberse explorado herramientas complementarias. El siguiente gráfico muestra una propuesta de síntesis de las críticas que le fueron dirigidas a los estudios científicos genésicos sobre la cultura política.

\footnotetext{
${ }^{49}$ Este autor coloca como ejemplo de obra en la que se indaga sobre cuestiones semejantes y que no comete ese error metodológico a Values and the Active Community (1971). Él fue uno de los participantes en el proyecto de investigación que condujo a su publicación.
} 
Figura 1.2

Críticas al paradigma tradicional de cultura política

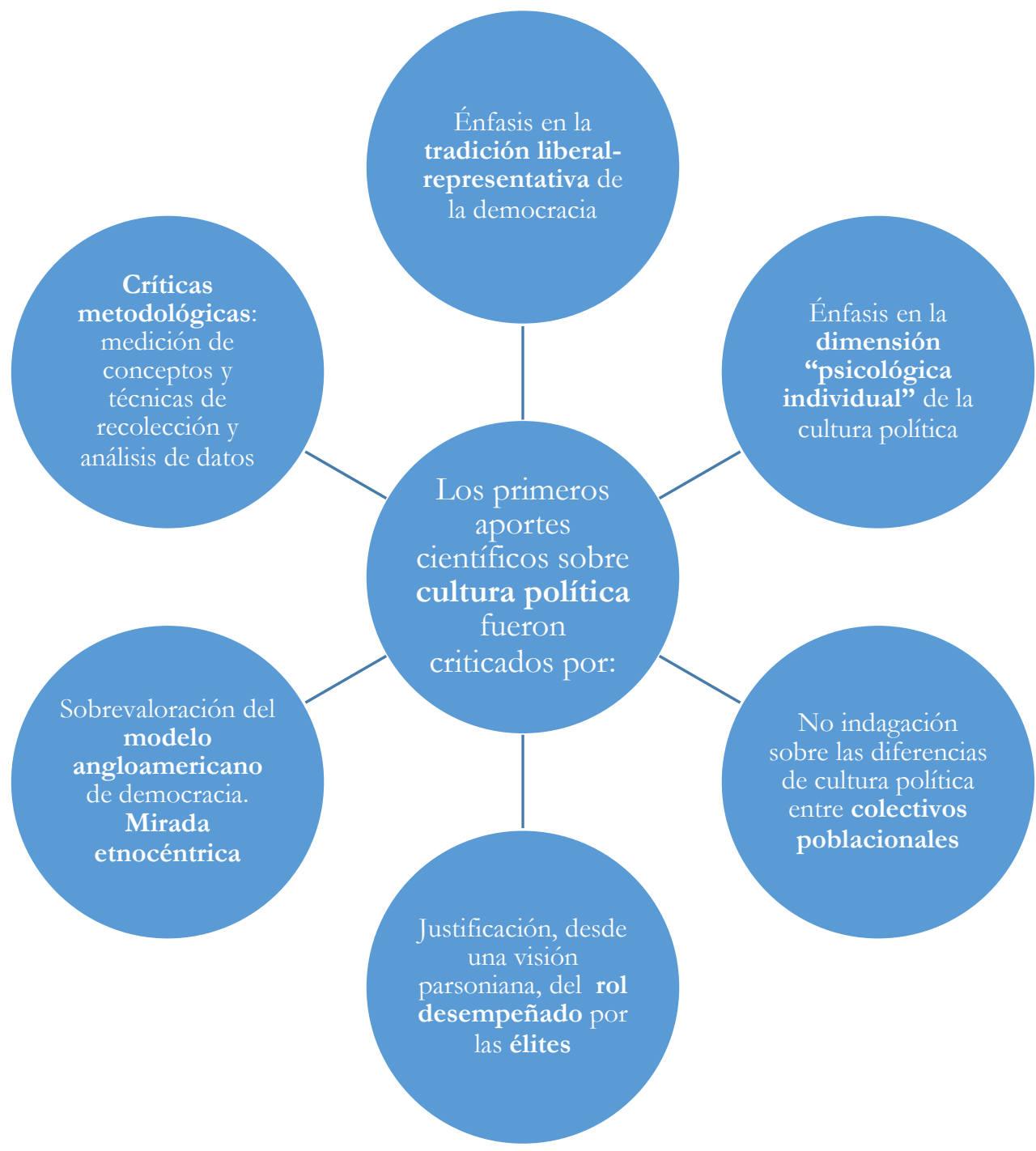

Fuente: Elaboración propia en base a la literatura sobre el tema.

La crítica pronunciada por Carole Pateman en relación a la ausencia de análisis sobre las diferencias existentes entre colectivos poblacionales ha sido ampliamente justificada por los cambios en la realidad social acaecidos en los últimos decenios. La 
supuesta "homogeneidad cultural" de las sociedades descrita inicialmente se ha visto confrontada por la activación de diferentes procesos. Will Kymlicka (1995) es quien los ha sistematizado con mayor precisión. Por un lado, la implosión de la antigua Unión Soviética, la consecuente desaparición de muchos de los regímenes que asumían rasgos propios del comunismo real, la irrupción de la tercera ola de democratización y los avances acaecidos internacionalmente en materia de reconocimiento de los derechos de los pueblos aborígenes facilitaron la (re) aparición de reclamos nacionalistas y étnicos que, prontamente, lograron ser canalizados a través de movimientos sociales y partidos políticos. Por otro lado, la profundización de las corrientes migratorias, tanto desde países en vías de desarrollo hacia los países desarrollados como entre naciones subdesarrolladas, ha provocado el abandono del carácter monocultural de muchas sociedades y ha acentuado el perfil poliétnico de diferentes sociedades con marcada tradición inmigratoria.

La incremental aceptación, por parte de la comunidad científica, de este escenario de "diversidades" ha aparejado la puesta en marcha de investigaciones que tienen por objeto detectar cuáles son las particularidades en términos de cultura política de los diferentes colectivos. No sólo se ha indagado de manera intensiva (al interior de estos nuevos o redescubiertos grupos) sino que también se ha procedido a la realización de ejercicios de comparación extensiva entre colectivos. Al mismo tiempo, estas transformaciones generaron oportunidades para examinar antiguas teorías aplicadas sólo a grupos puntuales, ampliar los alcances del conocimiento obtenido previamente y desarrollar nuevas propuestas teóricas y metodológicas.

El caso concreto del arribo de los inmigrantes a las sociedades receptoras constituye una circunstancia propicia para el estudio de las continuidades y discontinuidades en materia de cultura política entre los individuos inmigrados. Tales contextos posibilitan la obtención de información respecto a la activación de procesos de (re) socialización política y lo que ello implica en términos de configuración de nuevas identidades políticas y de alteración en los esquemas axiológico-políticos de los individuos. Sin embargo, este tipo de investigaciones suele enfrentarse a serios obstáculos de naturaleza metodológica. Por un lado, resulta dificultoso trabajar con muestras lo suficientemente amplias como para lograr abarcar los diferentes matices (demográficos y socio-culturales) que particularizan a los escenarios inmigratorios (Cho, 
1999; Diez Nicolás, 2005; Jennings, 2007). Por otro lado, existen inconvenientes para lograr medir, en el caso de un mismo sujeto, cuáles eran sus rasgos político-culturales previos a la emigración y cómo los mismos han cambiado una vez que ha acontecido el traslado de una sociedad a otra (Inglehart y Norris, 2009).

La incorporación de los colectivos inmigrantes como unidad de análisis en los estudios de cultura política responde no sólo a la inquietud intelectual que procura proceder a la detección de patrones de continuidades y discontinuidades vinculados a la experiencia migratoria. Responde también a la preocupación, existente tanto en círculos académicos como políticos, sobre los niveles de integración política que la población extranjera logra en las sociedades de acogida. En los últimos lustros, en los países de inmigración masiva, se ha generado una discusión en torno al tipo de ciudadanía deseada para los miembros del colectivo inmigrante que, año tras año, deciden radicarse en sus territorios ${ }^{50}$. La afirmación reiterada acerca de la situación de infraciudadanía (por los derechos políticos que le son negados) en la que se encuentran los inmigrantes en algunas sociedades receptoras ha obligado, entre otros motivos, a reconducir las preguntas de investigación sobre cultura política.

Cada vez son más frecuentes los diseños de investigación que, a través de definiciones propias de la cultura política, intentan proporcionar una especie de diagnóstico de los rasgos ciudadanos (potenciales y actuales) que los miembros de los colectivos inmigrantes poseen ${ }^{51}$. En este corpus, se recupera la idea que estuvo presente en el génesis de los estudios sobre cultura política: la implicación cívica por parte de los individuos contribuye al fortalecimiento de los regímenes democráticos ${ }^{52}$ (Ortega y

\footnotetext{
${ }^{50} \mathrm{El}$ indicador más relevante de la existencia de una discusión en tal sentido en las sociedades de acogida es la constante renovación que sufren las normas que regulan el derecho de extranjería y la concesión de nacionalidad a foráneos.

${ }^{51}$ Estos estudios, generalmente, han sido llevados a cabo desde una perspectiva multiculturalista que, al mismo tiempo que alienta a los inmigrantes a hacer uso efectivo de los derechos y obligaciones democráticas reconocidas en las sociedades de destino, sostiene que le deben ser respetadas sus particularidades étnico-culturales (Kymlicka y Bashir, 2008; Inglehart y Norris, 2009).

52 En la literatura politológica más reciente, para hacer referencia a la fortaleza de los regímenes democráticos se hace uso de la expresión de "calidad de la democracia". Este concepto remite a los procesos mediante los cuales la población selecciona y controla a sus gobernantes. Su uso implica centrar el análisis sobre los procedimientos establecidos para escoger y controlar gobiernos considerando el contexto social en el que funcionan (Levine y Molina, 2007; Alcántara, 2008; Alcántara y García Díez, 2009). En el caso de las sociedades de acogida, se entiende que los inmigrantes, como miembros que son de las mismas y como receptores de exumos del sistema político (políticas públicas), deben poseer las herramientas necesarias para participar (directa o indirecta) en los procesos políticos de toma de decisión. En tal sentido, se juzga necesario que ello suceda incluso antes de su naturalización (conversión en
} 
Morales, 2006). La siguiente figura resume los procesos históricos que condujeron a la incorporación de los inmigrantes, entre otros nuevos colectivos, como objeto de estudio en las investigaciones sobre cultura política a nivel internacional.

Figura 1.3

La incorporación de la inmigración

en los estudios sobre cultura política

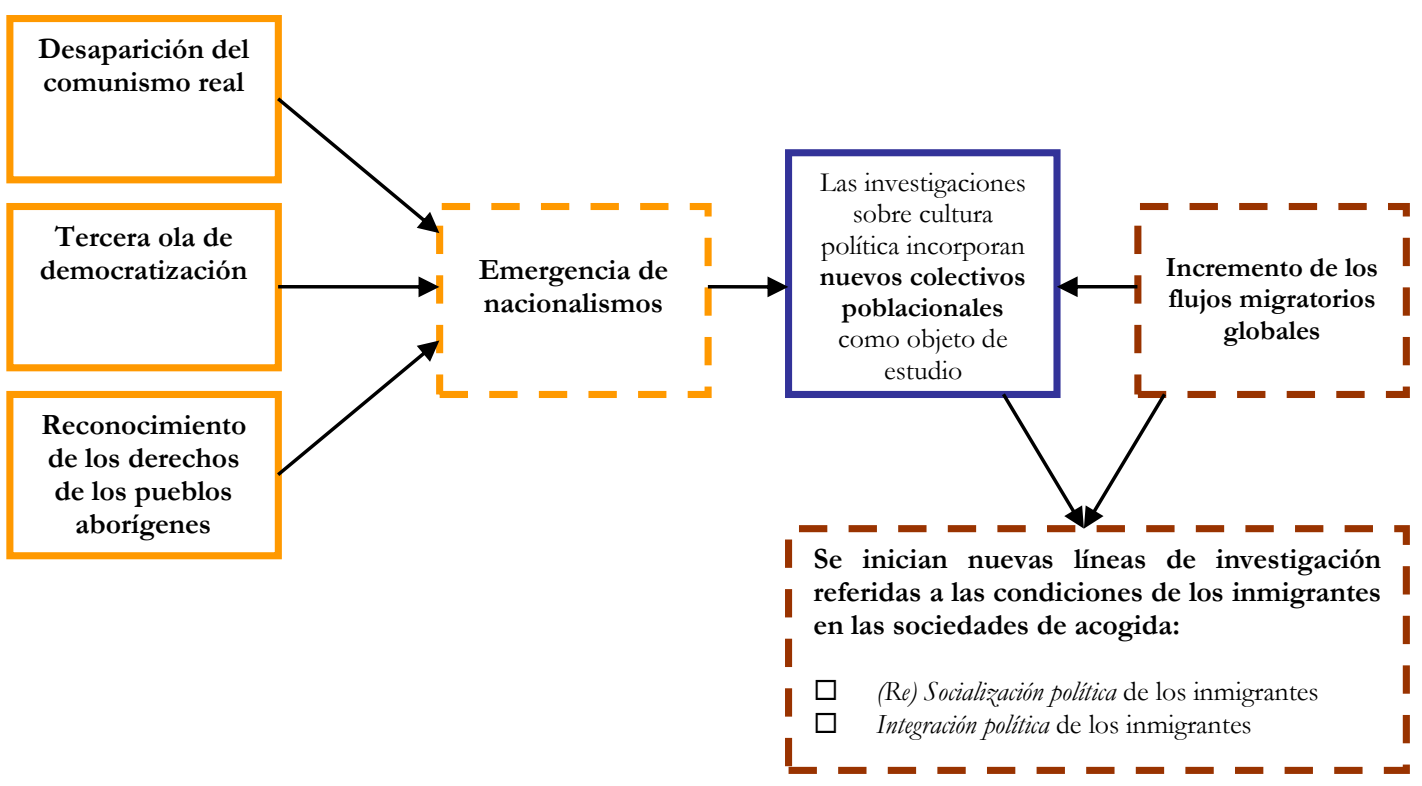

Fuente: Elaboración propia en base a la literatura sobre el tema.

ciudadanos nacionales) y con independencia de la posesión (o no) de los derechos de sufragio activo y/o pasivo. 


\section{2) La literatura estadounidense y europea sobre cultura política, integración política e inmigración}

\subsection{1) ¿De qué se habla cuando se habla de integración política?}

La literatura producida en Estados Unidos ${ }^{53}$ y Europa que, desde la cultura política, coloca a los inmigrantes como objeto de estudio ha crecido notablemente en los últimos años. El propósito último que subyace a estos trabajos es reflexionar sobre cuáles son (o deberían ser) los niveles de integración política ${ }^{54}$ de los newcomers en las sociedades de acogida ${ }^{55}$ (Hammar, 1989; Rex y Singh, 2003; Jacobs y Tillie, 2004; Portes et al. 2008). De manera más o menos explícita, estas investigaciones pretenden detectar escenarios actuales o potenciales de marginación o exclusión cívica (Biderbost, 2009).

A pesar de este impulso observado en los estudios politológicos sobre inmigración en el mundo occidental, la motivación para los mismos difiere entre Estados Unidos y Europa. Laura Morales (2011) recuerda en su libro "Social capital, political participation and migration in Europe. Making multicultural democracy work?" que la perspectiva prevaleciente en la academia anglosajona privilegia la indagación sobre los factores individuales y del ambiente cercano que influyen en la integración política de los sujetos en las sociedades de acogida.

En tanto, en la academia europea, la mirada se ha centrado fundamentalmente en detectar qué modelos de ciudadanía han favorecido la integración política de la población extranjera en las sociedades nacionales receptoras. La tradición europea también ha estudiado, tomando prestado elementos de la teoría de los movimientos sociales, cómo las capacidades organizativas y el capital social de las agrupaciones

\footnotetext{
53 Lo producido en la materia en los Estados Unidos resulta, en cierto sentido, representativo de lo que se ha generado en la academia de otros países anglosajones (Australia y Canadá) con idéntica tradición inmigratoria.

54 La alusión al concepto de integración política no es siempre explícita en estos estudios. En parte importante de las investigaciones, se hacen referencias indirectas al mismo.

${ }^{55}$ En los últimos años, en el marco de la literatura vinculada a transnacionalismo, se han multiplicados los estudios que indagan sobre la situación política de los inmigrantes en relación a sus sociedades de origen. En este apartado, sin embargo, sólo se procederá a describir las investigaciones que vinculan, en el plano político, a los inmigrantes con las sociedades de destino. El trabajo de Zapata-Barrero, Gabrielli, Sánchez y Jaulin (2013) constituye un recurso interesante para todos aquéllos interesados en explorar la relación existente entre las sociedades de origen y el comportamiento político de los emigrantes.
} 
inmigrantes influyen en la integración política de los mismos. Esta situación de "mesas separadas" ha comenzado a superarse gracias a los recientes esfuerzos de investigadores que intentan unir la visión "micro" estadounidense con la mirada "macro" europea.

Otro aspecto en esta área de estudios que tampoco refleja uniformidad entre los investigadores occidentales es el vinculado a la utilización y definición de conceptos que refieran/describan la "situación política" que presentan los inmigrantes en las sociedades de destino. En ello, ha influido el que la producción científica sobre estos temas procede de diferentes disciplinas (Ciencia Política, Sociología Política, Psicología Política, fundamentalmente). Mientras un grupo importante de científicos sociales opta por el uso del concepto de integración política, otros estudiosos prefieren la aplicación de las expresiones asimilación política o incorporación política. Morales (2011) advierte sobre el riesgo que implica el elegir el concepto de asimilación al referirse a la dimensión política de la migración. El mismo, menos problemático cuando se estudia la convergencia económica, laboral o educativa entre foráneos y autóctonos, puede encontrarse sesgado de etnocentrismo cuando se analizan rasgos políticos.

En tanto, el concepto de incorporación política, en la perspectiva de esta autora, describe el proceso por el cual un individuo (o un colectivo de individuos) de origen inmigrante se incluye políticamente en la sociedad en la que habitan ${ }^{56}$. El concepto de integración política, paralelamente, describe cómo se encuentra en un momento dado en el tiempo la inclusión política de un individuo (o un colectivo) inmigrante en la sociedad receptora. Como es posible observar, la incorporación y la integración son, en la visión de esta autora, dos caras de una misma moneda conceptual: la inclusión política. Por la última expresión, debe entenderse la ausencia de exclusión o marginación de los procesos políticos en los que se procede a la toma de decisiones.

El autor de estas líneas también cree que resulta más apropiada la utilización del concepto de integración política por diferentes motivos. En primer lugar, el uso en

\footnotetext{
${ }^{56}$ El concepto de incorporación, para referirse a la situación de los inmigrantes en las sociedades de acogida, fue ampliamente utilizado en el campo económico luego de su uso por parte de Portes y Rumbaut (1990). Estos autores, según recuerda Bolzman (2009), decían que la expresión era la más adecuada para describir cómo diferentes colectivos inmigrantes lograban insertarse en la estructura socioeconómica de la sociedad receptora. Esta inserción, de acuerdo al criterio de estos autores, no debía necesariamente alinearse conforme el tiempo pasaba con la de los autóctonos sino que se encontraba influida por la segmentación social del mercado de trabajo y la estratificación social de las sociedades de destino.
} 
Ciencia Política de la expresión "integración” engarza mejor con su aplicación por parte de otras disciplinas científicas para referir a la situación que presentan los inmigrantes en diferentes dimensiones de la vida social (sistema educativo, mercado de trabajo, sistema sanitario, etc.). En tal sentido, su uso permite ver cuán similares/diferentes son los inmigrantes y autóctonos entre sí de cara a evitar situaciones de marginación política. En segundo lugar, existen registros del uso de la expresión para referirse a los procesos migratorios tan tempranamente como en el decenio de 1950 (Glazer, 1956) ${ }^{57}$. En tercer lugar, la expresión, en comparación a las otras ya referidas, tiene menos carga "valorativa" (o connotación negativa). Finalmente, el concepto refleja mejor lo que se ha intentado medir y analizar en la investigación que se está comentando en esta tesis doctoral (las diferencias entre adolescentes inmigrantes y autóctonos en materia de competencias cívicas en un momento dado del tiempo).

Con independencia de la expresión utilizada, lo que esta tradición de estudios persigue es, primeramente, generar información sobre los vínculos de los individuos o colectivos inmigrantes con el sistema político anfitrión (Bloemraad, 2006; O’Neill, Gidengil y Young, 2012). A tales fines, se procede a la medición de determinados rasgos cívicos o políticos que ofician de indicadores de la integración política. En estos estudios, se pretende, a su vez, explicar cuáles son los factores (individuales o ambientalescontextuales) que propician la posesión de determinados niveles de integración política (Togeby, 2004; Kahne y Middaugh, 2006; Jennings, 2007). Con tal propósito, se realizan interesantes comparaciones entre poblaciones inmigrante y autóctona y entre diferentes colectivos inmigrantes. En consecuencia, los niveles de integración política son usualmente de tipo relativo, es decir, de un colectivo en relación a otro ${ }^{58}$.

\footnotetext{
${ }^{57}$ Nathan Glazer, en su obra "The integration of American Immigrants" (1956), propone un concepto multidimensional de integración en el que, junto a elementos sociales y culturales, la situación política de los inmigrantes en la sociedad de acogida juega un rol preponderante. En su definición conceptual de la integración política, la misma se aproxima a lo que hoy se asemejaría más al concepto de "patriotismo" o "afinidad con el interés nacional". Tiempo después, en 1961, Robert Dahl en su trabajo "Who governs?: democracy and power in an American city" hace uso también de la expresión "integración política" de los inmigrantes al describir cómo las organizaciones étnicas la propician. Como antecedente más remoto de creación de indicadores para la medición de la integración política, se encuentra el trabajo de John Garcia (1981) titulado "Political integration of Mexican immigrants". En 1982, James Lamare creó los primeros indicadores para medir la integración política en inmigrantes no adultos.

${ }^{58}$ Existe otro tipo de estrategia metodológica que considera a la integración política como un valor absoluto. Morales (2011) recuerda que Bengtsson (2010) considera que, si un inmigrante no se encuentra integrado políticamente, la sociedad a la que pertenece tampoco lo está.
} 
Cabe agregar que, en los estudios sobre integración política, se mantiene siempre latente la idea de que la resocialización política que apareja toda experiencia migratoria configura perfiles cívico-políticos diversos. Por ese motivo, este grupo de investigaciones descansa, implícita o explícitamente, sobre la tradición de estudios acerca de la socialización política de los sujetos ${ }^{59}$.

\subsection{2) Objetos de estudio de la literatura sobre integración política}

Este acervo bibliográfico sobre integración política de los inmigrantes puede ser agrupado según la tipología que se enuncia a continuación ${ }^{60}$. Cada línea de trabajo, como podrá apreciarse, usa conceptos e indicadores distintos. En primer lugar, se encuentran los estudios que tienen por objeto observar cuáles son las características cívicas (previas al protagonismo político o actuación política explícita) de los inmigrantes. En segundo término, se hallan las investigaciones que pretenden conocer cuál es el desempeño socio-político de los recién llegados. Entre ellas, se ubica un conjunto de estudios que intenta identificar cómo la naturaleza organizativa, el capital social y las estrategias de movilización de las agrupaciones de inmigrantes influyen en sus niveles de integración política. En tercer lugar, se agrupan las investigaciones que analizan cómo el entramado institucional de la sociedad de acogida y la filosofía sobre la que el mismo descansa propician diferentes niveles de integración política. En cuarto lugar, existe literatura que indaga, una vez que los extranjeros han entrado en contacto con el sistema político de la sociedad de acogida, sobre cuál es su percepción y evaluación del mismo.

En la primera línea de trabajo, se tiene por objeto describir cuáles son los valores cívicos y la identidad política de los recién llegados (Garcia, 1987; De la Garza, Falcon y

\footnotetext{
${ }^{59}$ En ocasiones, existe una mención expresa del interés de los investigadores por detectar cuál ha sido la naturaleza de la socialización política de los inmigrantes en las sociedades tanto de origen como de acogida. En otros casos, esta intención, aunque no central, es de tipo colateral y ello se percibe cuando se analizan pormenorizadamente los diseños de investigación adoptados.

${ }^{60}$ Esta tipología intenta presentar de manera simple y concisa el conjunto de trabajos que, en el campo de la cultura política, se han realizado sobre la integración política de los inmigrantes. En tal sentido, es una propuesta (entre otras) que puede ayudar a arrojar luz en la labor de sistematización de este tipo de abordajes.
} 
Garcia 1996; Durand, 2000; Flanagan, Syvertsen, Gill, Gallay y Cumsille, 2009; Maxwell y Bleich, 2014). Se busca observar, entre otras cuestiones, cómo acontece (o no) el proceso armonización entre los registros cívicos de los foráneos y aquéllos detentados por la población autóctona (Huddy y Khatib, 2007; Inglehart y Norris, 2009; Demireva y Heath, 2014). En ellos, suele interrogarse sobre las diferencias en materia de ideas como equidad de género, visiones sobre libertad sexual, valores religiosos y actitudes democráticas (Norris e Inglehart 2004; Roggeband y Verloo, 2007). El interés por este conocimiento radica, en el caso concreto de los Estados Unidos, en el hecho de que, para ciertos sectores conservadores de la sociedad, la inmigración representa un fuerte reto a la persistencia de su ethos colectivo ${ }^{61}$ (Shaw, de la Garza y Lee, 2000; Huntington, 2004).

A su vez, entre los investigadores que han buscado reconocer los rasgos arquetípicos de la cultura política de los inmigrantes en las sociedades anglosajonas, se encuentran aquellos que han indagado sobre las competencias cívicas ${ }^{62}$ que presentan los individuos (Niemi y Chapman 1998; Yates y Younnis 1999). Estos activos hacen referencia a atributos cuya posesión se considera valiosa para evitar escenarios de desigualdad política, es decir, situaciones en las que el terreno de lo político quede en manos de ciertos sectores sociales en detrimento de otros excluidos cívicamente. En estas investigaciones, se supone que dicha exclusión es factual y puede manifestarse con independencia de las libertades formales que puedan ser reconocidas, a todos los ciudadanos, por un ordenamiento jurídico puntual63 (Metz y Younnis, 2005; McIntosh, 2006; Torney-Purta et al. 2007).

La segunda línea de trabajo se centra en las características que asume la participación social y política de los inmigrantes (DeSipio, 2002; Rivera, Bada y Escala, 2005; Stoll y Wong, 2007). Dentro de esta literatura, es posible identificar tres sublíneas distintas de investigación.

\footnotetext{
${ }^{61}$ Suele definirse al "credo americano" como aquél que sintetiza las principales adhesiones ideológicas que han caracterizado al pueblo estadounidense desde los tiempos genésicos del Mayflower: democracia, capitalismo, liberalismo y protestantismo (Bouton y Page, 2002; Huntington, 2004).

${ }^{62}$ Las competencias cívicas reciben ocasionalmente también la denominación de actitudes políticas.

${ }^{63}$ En el próximo capítulo "La búsqueda de la ciudadanía deseada. La conceptualización y medición de las competencias cívicas", se procederá a desarrollar con amplitud los rasgos propios de este tipo de investigaciones.
} 
Por un lado, se encuentran los trabajos que pretenden iluminar respecto al perfil asociacionista de los sujetos y de las agrupaciones de las que forman parte. Se procura, entre otras cosas, identificar aquellas variables que favorecen u obstaculizan la membresía de individuos de origen inmigrante en asociaciones de naturaleza diversa (socio-cultural, religiosa, deportiva, ambiental, política en sentido estricto, entre otras) (Preston, Kobayashi y Man, 2006; Landolt y Goldring, 2008). Dentro de este subgrupo, se incorporan también los estudios que tienen por objeto averiguar cuáles son los elementos, tanto contextuales como referidos al colectivo inmigrante, que provocan el surgimiento de determinadas asociaciones que reivindican posiciones o intereses propios de los recién llegados (White et al., 2008). También se indaga respecto a cómo los recursos de las asociaciones de inmigrantes posibilitan la generación tanto de redes en las que aquéllas se agrupan como de líneas más o menos fluidas de comunicación con las autoridades políticas de la sociedad de acogida (Fennema y Tillie, 2001). A su vez, en este subconjunto, se estudia cómo las características de las organizaciones a las que pertenecen los inmigrantes potencian o retraen sus niveles individuales de integración política (Togeby, 2004; Berger, Galonska y Koopmans, 2004).

Por otro lado, se encuentran las investigaciones en las que se intenta descifrar cuál es y cómo acontece la participación política de los individuos con background inmigrante en actividades ajenas a la emisión de sufragio (Zabin y Escala, 2002; Barreto y Muñoz, 2003; Wong, 2006). En otras palabras, se indaga sobre su comportamiento político (si éste es entendido como un continuum que se extiende desde situaciones menos exigentes hasta otras que requieren de mayor esfuerzo) tanto en acciones que implican relativo compromiso (inscripción para la habilitación al voto en sitios en los que no es obligatorio, membresía a partidos políticos o asistencia a mítines y manifestaciones políticas) como en otras que requieren de mayores dosis de implicación (colaboración en campañas, recolección de fondos o postulación a cargos públicos).

Dentro de esta segunda línea, hay una tercera sublínea que incluye a otras investigaciones que pretenden reconocer cuáles son las características propias de los miembros de los colectivos de origen inmigrante en su desempeño como electores ${ }^{64}$

\footnotetext{
${ }^{64}$ Estas investigaciones sobre comportamiento electoral pueden centrarse en focos diferentes. En primer lugar, pueden hacerlo en individuos que detentando la nacionalidad (con independencia de si la misma ha sido obtenida por la vía de la naturalización o por nacimiento) de la sociedad analizada poseen un background inmigrante (Cho, 1999; DeSipio, 1996; Escobar, 2004). En segundo lugar, en los sujetos que
} 
(Jackson, 2003; DeFrancesco y Merolla, 2006; Heath, Fisher, Rosenblatt, Sanders y Sobolewska, 2013). Estos estudios sobre el comportamiento electoral, al igual que se comentaba para las pesquisas sobre el asociacionismo inmigrante, intentan reconocer cuáles son los factores individuales y ambientales que propician o no el rol activo de estos sujetos en los comicios como, así también, cuál es el sentido de sus decisiones (sufragio) en contextos electorales. En estas investigaciones, también se indaga sobre las consecuencias del comportamiento electoral de los inmigrantes en materia de (re) configuración del mapa de distribución del poder político entre los diferentes grupos sociales en una sociedad dada (Fraga, Garcia, Hero, Jones, Martínez y Segura, 2006; Ayers, 2007; Bilodeau, 2009).

El tercer conjunto de investigaciones, de tradición europea, es el que procede a la identificación de los elementos que en el sistema político de la sociedad de acogida favorecen u obstaculizan la integración política de los inmigrantes (Bevelander y Spang, 2014). En estas investigaciones, generalmente, se procede a la utilización del método comparado. A tales efectos, se contrasta la realidad evidenciada en distintas regiones y países. Es una perspectiva que hace uso recurrente de las teorías de estructura de la oportunidad. Al mismo tiempo, al analizarse los componentes de los sistemas políticos, no sólo se observa la influencia de dispositivos concretos (sistema electoral, legislación que regula la naturalización, etc.) sobre la integración política (Geddes, Niessen, Balch, Bullen y Peiro, 2005) sino que, también, se toma en consideración el sustrato culturalfilosófico sobre el que descansa cada entramado institucional. En otras palabras, se procura identificar cuán fácil/difícil resulta en escenarios culturales concretos el proceso de admisión política de nuevos individuos y colectivos (Layton-Henry, 1990; Ireland, 1994; Penninx, Martiniello y Vertovec, 2004; Koopmans et al. 2005; Joppke, 2007).

El cuarto y último grupo de investigaciones tiene por objeto generar información sobre la percepción y la evaluación que los inmigrantes poseen sobre las instituciones políticas, los actores políticos y el proceso político protagonizado por unos y otros (DeSipio, Pachon, de la Garza y Lee, 2003). En esta línea de investigación, suelen encontrarse regularmente dos elementos adicionales. Uno de ellos es la intención de

no poseyendo la nacionalidad de la sociedad en la que residen se le reconocen algún tipo de derechos políticos (Varsanyi, 2005). Finalmente, pueden analizar a uno y otro colectivo de los aquí mencionados (Leal, 2002). 
averiguar si los inmigrantes perciben discriminación en el trato que les dispensan las agencias gubernamentales y las autoridades públicas (Garcia, 1987; Rothstein y Stolle, 2002; Schildkraut, 2005). El otro es el interés por averiguar los niveles de confianza que los inmigrantes poseen en las instituciones políticas de la sociedad anfitriona y los factores que los propician (Fennema y Tillie, 2001; Michelson, 2003; Liu y Baird, 2012). Para obtener un resumen gráfico de los diferentes tipos de estudios sobre integración política, por favor ver la siguiente figura.

Figura 1.4

Tipos de estudios sobre

la integración política de los inmigrantes
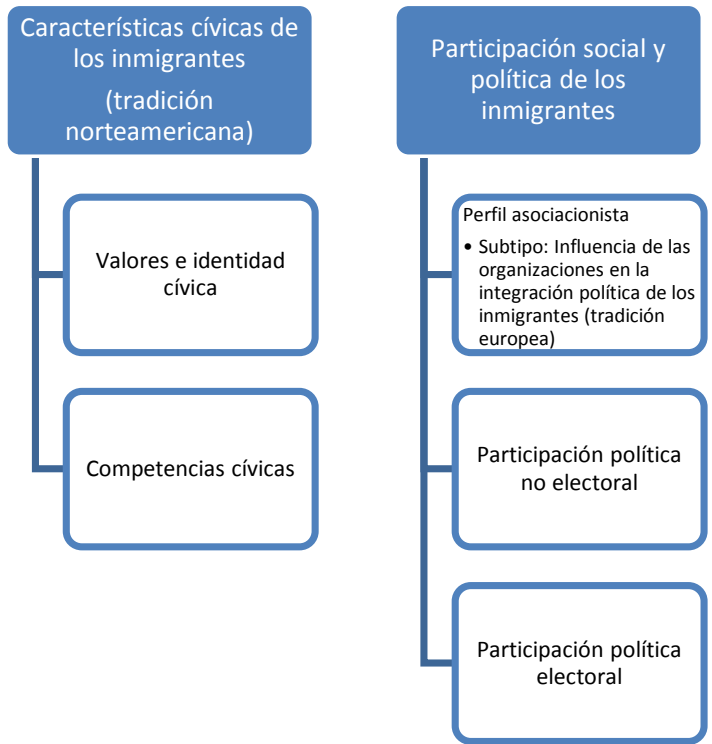

\section{Características del \\ sistema político \\ (tradición europea)}

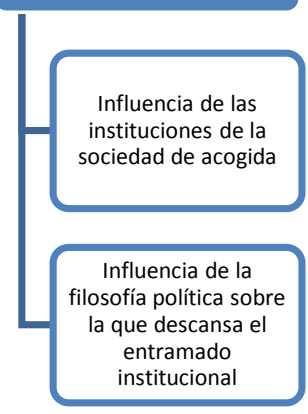

Percepción y evaluación

de las instituciones

políticas por parte de los inmigrantes

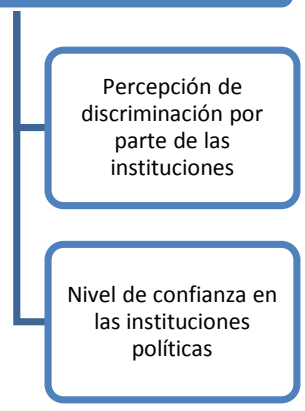

Fuente: Elaboración propia en base a la literatura sobre el tema. 


\section{3) La literatura española sobre cultura política e inmigración. El efecto multiplicador del carácter reciente de la inmigración}

En la academia española, a diferencia de lo que sucede en las sociedades anglosajonas de tradición inmigratoria y en las sociedades europeas que se convirtieron en receptoras de inmigración más tempranamente, la producción científica sobre cultura política de los inmigrantes es reciente y se encuentra mucho más acotada. Ello es consecuencia de que, al igual que la Ciencia Política tardíamente incluyó a los procesos migratorios entre sus objetos de estudio en comparación a otras ciencias sociales, el interés politológico español no prestó, sino hasta bien avanzado el fenómeno, atención al acontecer de estas transformaciones sociológicas con indudables repercusiones en el plano político-institucional (Corrochano, 2010). Conforme el fenómeno inmigratorio ha ido ingresando en la agenda mediática y política, su análisis desde una perspectiva politológica se ha acumulado y diversificado.

Las primeros (y también principales) aportes de esta disciplina en torno a la inmigración en España han versado sobre dos cuestiones específicas. Por un lado, se hallan los estudios sobre la naturaleza de las políticas públicas dirigidas a gestionar la llegada e integración de los inmigrantes (Colectivo IOE, 2001; Agrela, 2002; Pajares, 2002; Arango, 2005a, 2005b; López, 2005; Ayuso y Pinyol, 2010; Delgado, 2010; Moreno y Callejo, 2011; Sánchez, 2011; Izquierdo y Cornelius, 2012). Por otro lado, se ubica la discusión filosófico-política respecto a los aportes positivos y los desafíos que la inmigración implica para las sociedades y Estados receptores (Zapata-Barrero, 2000; Lucas, 2003; Aparicio y Tornos, 2002; Vallespín, 2005; Velasco, 2012).

Dentro de los estudios propios del campo de la cultura política65, se han analizado las reacciones y actitudes de la población autóctona frente al fenómeno en

\footnotetext{
65 En los últimos años, de manera paralela a lo aquí descrito, ha crecido una línea de investigación politológica que tiene por objeto describir y explicar cómo el issue de la inmigración ha sido incorporado por parte de la clase política y de los partidos políticos (Morales y Ros, 2012). Al respecto, se ha estudiado sobre el discurso político acerca de la inmigración (Sánchez Montijano, 2008; Zapata-Barrero, 2008), la emergencia de partidos políticos con claras consignas anti-inmigración (Casals, 2009; Hernández, 2011; Biderbost, 2012) y la respuesta del electorado vernáculo ante estas plataformas partidarias (Biderbost, 2012). A este conjunto teórico, también se vinculan ciertos estudios de raigambre politológica que analizan cómo los procesos migratorios son tratados desde los medios de comunicación locales (Moreno, 2006; Zapata-Barrero y Van Dijk, 2007).
} 
términos globales (Cazorla, 1995; Diez Nicolás, 1999; Colectivo IOE, 2000; Mateos y Moral, 2000; Molero, Navas y Morales, 2001; López-Maestre y Scheu, 2003; Morán, 2003; Ramírez y Rodríguez, 2006; Herreros y Criado, 2009; Echazarra y Morales, 2012; Méndez, Cebolla y Pinyol, 2013). También se han relevado, entre los autóctonos, sus percepciones sobre aristas particulares de los procesos migratorios que convirtieron en el pasado cercano a la sociedad española en receptora neta de población extranjera (Cea D’Ancona y Valles, 2000; Techio y Calderón-Prada, 2005; Pérez y Desrues, 2007; Moya y Puertas, 2008; Rinken, Silva, Velasco y Escobar, 2009).

Han aparecido así mismo, en los últimos años, investigaciones sobre los rasgos cívicos y de cultura política de la población de origen inmigrante. En términos generales, es posible afirmar que existen cinco tipos diferentes de abordajes sobre la cuestión ${ }^{66}$. En primer lugar, como consecuencia de las reformas constitucionales que tuvieron lugar en muchos de los países de los que son originarios los inmigrantes radicados en España, se ha incrementado el interés por descifrar cuáles son las actitudes y los comportamientos políticos de este colectivo al hacer uso del derecho al sufragio como residentes en el exterior ${ }^{67}$ (Parra, 2006; Sánchez, 2008; Moraes, Bermudez, Escrivá y Padilla, 2009; Biderbost y Boscán, 2011). Básicamente, los esfuerzos se han concentrado en definir qué rasgos particularizan, en relación a la participación en la elección de las autoridades políticas de las sociedades de origen, a cada colectivo inmigrante.

Las restantes cuatro miradas remiten (directa o indirectamente) a la integración política de los inmigrantes en España como sociedad de acogida. Un grupo de trabajos tiene por objeto conocer cuáles son las cosmovisiones a las que adhieren los inmigrantes (Veredas, 1998; Basabe, Zlobina y Páez, 2004; Ruiz y Usero, 2005). En algunas investigaciones pertenecientes a este grupo, a tal indagación se adiciona un segundo paso analítico: se observa si el background cultural de los inmigrantes los separa o acerca

\footnotetext{
${ }^{66}$ Esta es una propuesta (entre otras posibles) que pretende contribuir en la labor de sistematización de los abordajes, desde el campo de la cultura política, sobre los inmigrantes radicados en España. Su propósito es la organización de los aportes en la materia y, bajo ningún punto de vista, la cobertura exhaustiva de todo lo trabajado en esta área.

67 Estas modificaciones se han dado, fundamentalmente, en las reformas constitucionales y legislativas que tuvieron lugar en los países latinoamericanos que, según criterios politológicos diversos, merecen el reconocimiento de regímenes democráticos y lo que ello implica en materia de celebración de comicios calendarizados. No acontece semejante transformación en otros países de los cuales también proceden inmigrantes que se han radicado en España y en los que los regímenes políticos son de tipo autoritario. La situación de algunos Estados norafricanos puede resultar ejemplificadora al respecto.
} 
a lo expresado por la población autóctona (Díez Nicolás, 2005; Carabaña, 2006; Moya y Puertas, 2008) ${ }^{68}$.

Otro grupo de investigaciones pretende arrojar luz sobre cuáles son los tipos y niveles de asociacionismo y participación social entre los miembros de los colectivos inmigrantes radicados en España. En tal sentido, se ha escrito, entre otras cosas, sobre el perfil asociacionista que caracteriza a diferentes colectivos inmigrantes (Ancin, 2004; Izquierdo, 2009; Escrivá, Bermúdez y Moraes, 2009; Aparicio, 2011), la relación entre las asociaciones de inmigrantes, los sindicatos y los partidos políticos (Cachón, 1998; Veredas, 2000; Ortega y Morales, 2006), el sometimiento a prácticas clientelares y de cooptación política sufrida por estas asociaciones (Veredas, 2003), los factores condicionantes de la movilización étnica entre inmigrantes extracomunitarios (Jabbaz y Simó, 2004; Veredas, 2004; González-Enriquez, 2005) y la inserción de las agrupaciones a la que pertenecen los inmigrantes en redes interorganizativas (Ortega y Morales, 2006).

Al ser recientes en el escenario hispano tanto la inmigración masiva como el reconocimiento legislativo del derecho al voto para los inmigrantes no comunitarios, estos conjuntos de estudios se han concentrado naturalmente en la investigación del asociacionismo inmigrante en detrimento de la indagación sobre la participación política de los miembros de este colectivo ${ }^{69}$. Sin embargo, en contraste con esta carencia en el marco de la Ciencia Política empírica, su vertiente normativa ha discutido sobre las cuestiones tantos positivas como negativas que acompañan a la posibilidad de participación política entre en los inmigrantes (Cachón, 2000; Mezzadra, 2005; ZapataBarrero, 2005; de Lucas, 2009). En estos últimos trabajos, se suele aludir directa o indirectamente a la cultura política que caracteriza a estos colectivos y se discute lo vinculado a la (re)definición del concepto de ciudadanía que los procesos migratorios propician.

\footnotetext{
68 En el caso de algunos de estos trabajos, el foco de interés radica, en la clave de la tradición teórica y metodológica iniciada por Inglehart (1988), en conocer cuáles son los valores (materiales/postmateriales) que afirman poseer los individuos y las conexiones que puedan existir entre los mismos y su comportamiento social y político.

${ }^{69}$ Dos excepciones merecen ser mencionadas al respecto. La primera es el estudio de Amparo GonzálezFerrer (2011) sobre la participación electoral de los inmigrantes naturalizados. En su muestra, de carácter europeo, incluye dos ciudades españolas: Madrid y Barcelona. La segunda excepción a la regla es el trabajo de Morales y San Martín (2011).
} 
Otro grupo de investigaciones, dentro del cual se inscribe la presente tesis doctoral, intenta describir y/o explicar, stricto sensu, la integración política de los inmigrantes en la sociedad de acogida. Inicialmente, se profundizó sobre la integración de las organizaciones que representan los intereses de los inmigrantes en los cauces políticos-institucionales establecidos en la sociedad española (Morales, González-Ferrer y Sánchez, 2005; González-Ferrer y Morales, 2006; Morales y González-Ferrer, 2008). Se usaba, en estos casos, la integración política de las asociaciones como proxy de la integración política de los individuos representados en tales organizaciones. Posteriormente, se describieron y explicaron los niveles de integración política de los individuos (adolescentes y adultos) (Morales, Anduiza, Rodríguez y San Martín, 2008; Morales y Morariu, 2011, González-Ferrer, 2011; Biderbost, 2008, 2010; Bermúdez, 2011). En estas investigaciones sobre sujetos concretos, se ha trabajado con diferentes conceptos multidimensionales de integración política en los que se miden para su obtención/generación tanto actitudes políticas como diferentes tipos de comportamientos políticos. En ambos tipos de pesquisas (estudios sobre asociaciones de inmigrantes o sobre individuos de este origen), se ha hecho referencia a los gaps (brechas) cívicos que existen entre autóctonos e inmigrantes y a los peligros que su continuidad en el tiempo encierra ${ }^{70}$.

Finalmente, existe un pequeño grupo de investigaciones que intenta conocer cuál es la percepción y la evaluación que los inmigrantes radicados en España realizan de sus instituciones y actores políticos (Biderbost; 2007b; Sarrible, 2007; Herzog, Gómez, Gómez, Valderrama y Alexaindre, 2009; Álvarez-Miranda, 2012). En estos estudios, en ocasiones, también se compara la percepción/evaluación de los inmigrantes sobre la institucionalidad política de la sociedad de acogida con aquella que expresan en relación a idénticos resortes en la sociedad de origen.

\footnotetext{
${ }^{70}$ Parte importante de esta producción forma parte de la ya mencionada tendencia que busca unificar tradiciones intelectuales norteamericanas y europeas. Frecuentemente, esta literatura analiza la situación española en el marco de lo que acontece en el continente europeo.
} 


\section{3) La búsqueda de la ciudadanía deseada. La conceptualización y medición de las competencias cívicas}

En la perspectiva anglosajona sobre ciudadanía, existe un tipo de estudios sobre cultura política que pretende arrojar luz respecto a cuáles son (y en qué niveles/intensidades) las competencias cívicas concretas deseables (y estimulables) entre los individuos (y los colectivos poblacionales a los que éstos pertenecen) al interior de las sociedades. En ellos, se ha pretendido observar cuán arraigados se encuentran, entre los sujetos, los "bienes cívicos" que favorecen su protagonismo político y contribuyen, consecuentemente, a la estabilidad del régimen democrático ${ }^{71}$ (Tocqueville, 1956; Lipset, 1987; Waldstein y Reiher, 2001).

Cuando se habla de competencias (sociales, cívicas, culturales, físicas, emocionales, intelectuales, laborales y motivacionales) en el terreno psicosocial, se hace referencia, según Schaie y Willis (1999), a las capacidades poseídas por los individuos que les permiten ejecutar acciones que, por un lado, facilitan modificar el medio ambiente de inserción y, por el otro, adaptarse a éste. Si un sujeto es "competente", tiene la habilidad para seleccionar aquellos rasgos contextuales que son necesarios para el procesamiento de información, puede iniciar una secuencia de actos que le conducirán a la consecución de sus objetivos y posee las herramientas necesarias para, a partir del aprendizaje basado en sus éxitos y fracasos, planificar vías alternativas de acción (Patti y Cepeda, 2007).

La posesión de competencias implica, a su vez, que las personas cuentan con conocimientos, habilidades y auto-controles que les facultan entender y maximizar sus opciones disponibles, interactuar responsablemente con sus semejantes y obtener niveles aceptables de autoestima para proceder a la conquista de sus deseos y objetivos. En términos coloquiales, suele afirmarse que las competencias son la llave que crean las condiciones para que los seres humanos superen satisfactoriamente los desafíos a los que deben enfrentarse a lo largo de su vida. De lo último, se concluye que la posesión de competencias tiene un sentido funcional: resultan útiles dependiendo del contexto en el que se habite. Las competencias de índole cívica pertenecen a este conjunto de

\footnotetext{
71 Según recuerda Linares (2008), el empoderamiento de los ciudadanos también se ha encontrado teóricamente asociado a la idea de fortaleza del imperio del derecho (o rule of law en su voz inglesa).
} 
atributos que, desde distintas disciplinas, se considera saludable poseer y propiciar (Ruiz-Silva y Chaux, 2005).

El estudio de las competencias cívicas ha ido adquiriendo mayor relevancia porque éstas son consideradas un componente fundamental para realizar un mejor escrutinio de la dimensión política de la vida de los individuos. La información que se obtiene sobre las competencias cívicas remite directamente a las complejas estructuras psico-políticas de las personas e, indirectamente, permite realizar aproximaciones subjetivas a la naturaleza (y performance) de los sistemas políticos en los que dichos atributos son desplegados por los sujetos. En otras palabras, el conocimiento sobre la profundidad y la distribución de las competencias cívicas entre las personas proporciona datos no desdeñables acerca de la vitalidad del sistema democrático y de los principios que, se supone, éste encarna (Wu, 2003).

La literatura sobre competencias cívicas ha ido identificando cuáles son aquéllas cuya presencia es deseable en todo individuo. A pesar de las diferentes denominaciones que se aplican, existen, al menos, cinco atributos que se considera relevante medir como competencias cívicas (Niemi y Chapman, 1998; Edwards, 2005; Mclntosh, 2006): el conocimiento político (incorporación de información vinculada a la realidad política), la atención política (seguimiento de la realidad política), la participación política (actual y/o potencial), la eficacia política (capacidad para la comprensión de la realidad política y autoconfianza respecto a que es posible incidir en ella) y la tolerancia política (respeto por posiciones políticas diferentes a las profesadas por el individuo) ${ }^{72}$.

Todas ellas conforman, según la terminología empleada por diversos autores (Edwards, 2005; Finkel y Ernst, 2005; Mclntosh, 2006), un complejo sistema de pensamiento democrático en base al cual los individuos se vinculan con la realidad política a la que pertenecen ${ }^{73}$. Las competencias cívicas tienden a presentar sus registros en un mismo sentido y existe, entre ellas, una relación de circularidad virtuosa o de retroalimentación que, desde el punto de vista del análisis metodológico, provoca

\footnotetext{
72 En los próximos apartados, el lector podrá acceder a una descripción detallada del concepto y el tratamiento teórico y metodológico que han recibido cada una de las competencias cívicas aquí enumeradas.

${ }^{73}$ Se supone que cada ciudadano tiene la capacidad, gracias a su inmersión en procesos de socialización política, de realizar ejercicios permanentes de diferenciación e integración de los elementos que concurren a la composición de su específico sistema de pensamiento democrático (Finkel y Ernst, 2005).
} 
problemas de endogeneidad. En ocasiones, para una mejor organización teórica y para facilitar el análisis empírico, las competencias cívicas son reclasificadas en dos tipos: las cognitivo-reflexivas y las de naturaleza empírico-práctica. Dentro de las primeras, se encuentra el conocimiento político, la atención política y la faz interna de la eficacia política. Entre las segundas, se ubican la faz externa de la eficacia política, la participación política y la tolerancia política (Sniderman, Brody y Tetlock, 1991; Barber, 2003; Finkel y Ernst, 2005).

Las investigaciones sobre las competencias cívicas de los individuos, tanto en niños y adolescentes como adultos, han tenido por objeto detectar cuáles son las características de los sujetos que presentan menores niveles de activos cívicos, es decir, han pretendido identificar quiénes son las personas que se encuentran en situación de desventaja cívica relativa y cuáles son los factores que pueden estar incidiendo en ello (Yates y Youniss; 1999; Flanagan y Van Horn, 2003). Para evitar la creación o perpetuación de escenarios de exclusión (no integración) cívica en los que se ven involucrados determinados tipos de individuos, estos estudios han estado, históricamente, asociados a proyectos/programas de intervención socio-educativa cuyo propósito es facilitar la adquisición de competencias cívicas a quienes participan en ellos. De esa manera, se intenta contribuir a la generación de una cultura política afín a las instituciones y procedimientos democráticos ${ }^{74}$.

En ocasiones, cuando la unidad de análisis de las investigaciones han sido los niños y/o los adolescentes, tales competencias cívicas han sido agrupadas bajo el paraguas conceptual del "desarrollo cívico" (Torney-Purta et al., 2007). Este último concepto hace referencia al hecho de que el proceso de adquisición de las mismas, al igual que sucede con la incorporación de otros recursos afectivos, psíquicos y físicos, es un fenómeno de tipo evolutivo por el que atraviesan todas las personas y sobre el que es posible incidir a través de mecanismos diversos. Estos estudios pertenecen a la línea

\footnotetext{
${ }^{74}$ Los ejemplos de estos programas abundan en los Estados Unidos de América. Uno de ellos es el proyecto "America 's promise". Esta es una iniciativa de la organización no gubernamental "Alliance for Youth" que tiene por objeto la elevación de las competencias cívicas de jóvenes que pertenecen a los sectores menos privilegiados de la sociedad estadounidense. Otro se vincula a la tarea ejecutada por el "Innovation Center for Community \& Youth Development". Este centro se dedica al ofrecimiento de asesoría y a la creación de material bibliográfico y audiovisual destinado a fortalecer las acciones que, en materia de empoderamiento cívico de los jóvenes, realizan diferentes instituciones norteamericanas (iglesias, escuelas, empresas, entre otras).
} 
de investigación que sostiene que los activos cívicos poseídos por los adolescentes son un correcto predictor de su comportamiento político futuro (Jennings y Niemi, 1981; Verba et al., 1995; Hooghe y Wilkenfeld, 2008; Hooghe y Dassonneville, 2013).

En tal sentido, la posesión de competencias cívicas es considerada, junto a la de otras de naturaleza diversa, fundamental para asegurar un integral desarrollo de los jóvenes. Para este último concepto, se han ensayado diferentes definiciones que hacen referencia, directa o indirecta, a la importancia de la dimensión cívica en la vida de todo sujeto. Una definición útil, por la claridad expositiva, es la elaborada por Karen Pittman $(1991, \text { p. 8 })^{75}$. Para esta autora, el desarrollo de la juventud es:

"...the on-going growth process in which all youth are engaged in attempting to meet their basic personal and social needs to be safe, feel cared for, be valued, be useful, and be spiritually grounded, and to build skills and competencies that allow them to function and contribute in their daily lives"

Lo descrito refleja que la adquisición de competencias, cívicas y de otros tipos, es parte del proceso de socialización política. En tal sentido, la incorporación de estos atributos requiere de la creación de oportunidades en las que los más jóvenes, bajo la tutela y con el acompañamiento de adultos, puedan aprender, practicar y discutir sobre objetos de naturaleza política. Su aparición y conservación, según afirman los expertos en la materia, se encuentra asociada tanto a factores micro (dinámicas familiares y escolares) como a factores macro (institucionalidad política democrática o autoritaria) ${ }^{76}$ (Torney-Purta, 2004; Hooghe, 2004).

Como la posesión de las distintas competencias depende del contexto al que el individuo pertenezca, las de tipo cívico son naturalmente más valoradas en entornos democráticos. Por estos motivos, históricamente, la currícula de muchas instituciones educativas primarias y secundarias ha integrado, en sistemas políticos democráticos, no sólo asignaturas con un propósito pedagógico cívico-político explícito, sino también la

\footnotetext{
75 Esta definición es la utilizada como base por diferentes organizaciones anglosajonas dedicadas a la promoción del desarrollo de los jóvenes (Commonwealth Youth Programme, Innovation Center for Community \& Youth Development, entre otros).

${ }^{76}$ En los próximos acápites, se hará mención de cuáles son, según la investigación empírica, las principales variables causantes de la posesión de las diferentes competencias cívicas.
} 
puesta en marcha de programas de "aprendizaje-servicio"77 y de voluntariado. Los mismos tienen por objeto favorecer el empoderamiento cívico de los niños y adolescentes. Entre las consecuencias positivas que se observan entre quienes han formado parte de propuestas semejantes, se han apuntado las siguientes (Huebner, 2003):

Elevación de los niveles de eficacia personal debido a que se observa que las acciones ejecutadas tienen un impacto palpable en la comunidad y en las vidas de las personas a las que aquéllas van dirigidas (Scales y Leffert, 1999).

$\square$ Contribución a los procesos de creación de identidad personal y reforzamiento de los lazos tejidos al interior de las comunidades de pertenencia (Youniss, McLellan y Yates, 1997).

Optimismo sobre las circunstancias futuras, aumento de la capacidad de resolución de problemas e incremento del auto-estima (Nettles, 1991; Price, Cioci, Penner y Trautlein, 1993).

Mayor probabilidad, durante la adultez, de emisión de sufragio y de incorporación a organizaciones comunitarias (Youniss, McLellan y Yates, 1997).

Menor probabilidad de incursión en actividades delictivas (Bilchik y Howell, 1995).

\footnotetext{
${ }^{77}$ El "aprendizaje-servicio" es el enfoque pedagógico en el que se busca la generación de conocimientos y logros académicos de los educandos a partir de la reflexión que los mismos realizan sobre las actividades que desarrollan para la superación de los problemas sociales de sus comunidades de origen. Estas tareas son ejecutadas bajo la coordinación pedagógica de docentes especializados. Los expertos en la materia sostienen que la participación de los estudiantes en estos procesos les permite apreciar a la educación como un proceso evolutivo, desarrollar su capacidad crítica y conectar sus objetivos individuales con otros comunitarios (Barber y Battistoni, 1993; Rice y Brown, 1998; Waldstein y Reiher, 2001).
} 


\section{1) ¿Qué se sabe de la realidad política? El conocimiento político como competencia cívica}

El conocimiento político es considerado un componente esencial del concepto de ciudadanía. Hace referencia, por un lado, a la cantidad de datos sobre la realidad política y, por el otro, a la capacidad de interrelacionarlos que un sujeto presenta. Para diversos autores, si los ciudadanos cuentan con importantes niveles de conocimiento político, sus decisiones tendrán mayores dosis de responsabilidad, justicia e inclusión. Al mismo tiempo, se sostiene que una sociedad informada realiza una tarea de control más eficiente de las autoridades gubernamentales que aquélla llevada a cabo por sociedades poseedoras, en promedio, de menores niveles de conocimiento político ${ }^{78}$ (Langton y Jennings, 1968; Fraile, Ferrer y Martín, 2007).

En consecuencia, se admite que un sistema democrático será saludable y funcionará correctamente sólo si sus ciudadanos son competentes en materia de conocimiento político (Delli Carpini y Keeter, 1993). Este concepto, por la relevancia que le ha sido atribuida para la creación de ciudadanos comprometidos, ha despertado el interés no sólo de cientistas sociales sino también de líderes políticos, funcionarios, periodistas y miembros de organizaciones no gubernamentales que desarrollan actividades de naturaleza cívica.

Diferentes hipótesis se han ensayado, en la literatura, en relación a los factores propiciadores de los niveles de conocimiento político con los que cuenta con una persona. En primer lugar, un conjunto de autores entiende que los factores sociodemográficos tradicionales (raza, sexo, edad y educación) pueden estar influyendo en la información política de los sujetos ${ }^{79}$ (Mclntosh, Hart y Youniss, 2007). En segundo

\footnotetext{
${ }^{78}$ Fraile et al. (2007) concluyen que la tendencia en España es la de jóvenes con escasos conocimientos políticos. Las autores reclaman, para su superación, la actuación del Estado a través de políticas públicas que tiendan a una "distribución más igualitaria" de recursos socioeconómicos y educativos

${ }^{79}$ Para el caso norteamericano, suele anticiparse que los adultos que reúnen los atributos de ser varones, blancos, ancianos y educados son los que presentan mayores registros en esta competencia. Al hablarse de adolescentes, las investigaciones han concluido que el habitar en vecindarios en los que el ratio de jóvenes/adultos es bajo (generalmente asociado a áreas con cierto desarrollo económico) favorece la posesión de esta competencia cívica. Por ello, se afirma que las desigualdades socio-económicas y educativas se reproducen en el terreno cívico: los menos privilegiados poseerán menores conocimientos políticos con lo que ello implica en materia de desafección política (Dolan y Holbrook, 2001; Hart et al., 2004).
} 
término, se encuentran las explicaciones provenientes del campo de la Psicología Política. En él, hay quienes creen que la estructura psicológica (personalidad autoritaria versus personalidad democrática) de los individuos, su predisposición y los rasgos propios de la socialización de la que hayan sido receptores resultan fundamentales a la hora de entender disparidades en la distribución de los niveles de información política (Peterson, Duncan y Pang, 2002).

Otro concepto utilizado por los psicólogos políticos para explicar la distribución del conocimiento político entre los individuos es el de Personal Political Salience (PPS) o capacidad que tienen los personas para asociar eventos políticos a significados personales ${ }^{80}$. Quienes tienen estos atributos cognitivos prestan mayor atención a lo político y, en consecuencia, se encuentran mejor dotados para incorporar eficazmente información cívica (Peterson et al., 2002; Duncan, 2005).

En el marco de los llamados factores psicológicos, resulta oportuno hacer también mención de las competencias cívicas que favorecen la adquisición de conocimiento político. La evidencia empírica ha detectado que quienes mayores niveles de atención política registran serán también quienes mayores niveles de conocimiento político posean (Mclntosh et al. 2007). Así mismo, mientras más se participe políticamente, más posibilidades existen de tener conocimiento político (Smith, 2002). En tanto, quienes presentan menores dosis de tolerancia política suelen ser quienes menos conocimiento político adquieren (Peterson et al., 2002).

Un tercer grupo de obras enfatizan la importancia de la puesta en marcha de programas de formación cívica (y de la naturaleza pedagógica que a éstos caracteriza ${ }^{81}$ ) como principal activador de procesos en los que acontece adquisición de conocimiento político por parte de los sujetos que en aquéllos participan. En otras palabras, la educación cívicamente direccionada favorece la adquisición de información política (Niemi y Junn, 1998; Finkel y Ernst, 2005).

\footnotetext{
${ }^{80}$ En el caso de estos individuos poseedores de estos esquemas de pensamiento, lo político adquiere una centralidad tal en sus vidas que cualquier evento proveniente de esta esfera (pasado, presente o futuro) provoca en ellos una reacción en el plano emocional. EI PPS no debe ser confundido con el conocimiento político sobre el cual influye (Fiske, Lau y Smith, 1990; Duncan, 2005).

81 La literatura señala que, en el marco de procesos formativos tendentes a la transmisión de competencias cívicas, dos características son especialmente relevantes: las cualidades del personal docente y el carácter abierto/cerrado del ambiente de trabajo (aula o salón de clases) (Harwood, 1992)
} 
Esta competencia cívica constituye, para algunos autores, una condición sine qua non para la posesión de otras de naturaleza predominantemente práctica (Brady, Verba y Schlozman, 1995). Los resultados de diferentes investigaciones acuerdan en que los registros de participación política y eficacia política serán bajos en el caso de los individuos con escasos o nulos conocimientos sobre la realidad política a la que pertenecen ${ }^{82}$. Desde esta perspectiva, pareciera existir una causalidad cívica virtuosa: los más aventajados en términos socio-demográficos (mejores ingresos y mayores niveles educativos) son los que mayor conocimiento político poseerán y, por ende, mejor performance presentarán en otras competencias cívicas (Burns, Schlozman y Verba, 2001).

Asimismo, los individuos que presentan mayores niveles de conocimiento político no son sólo los más activos cívicamente sino que son quienes pueden, en mayor medida, reconocer la existencia de cosmovisiones diferentes, aplicarlas en las decisiones políticas que toman y auto-ubicarse en un continuum ideológico (Converse, 1962). En tal sentido, la capacidad de conectar el background moral personal con la expresión de opiniones sobre asuntos políticos y la emisión de sufragio sólo es poseída por los individuos con ciertas dosis de conocimiento político. En otras palabras, la evidencia empírica reconoce que los individuos que poseen esta competencia política más desarrollada son menos volátiles y más reflexivos frente a influencias externas (Huebner, 2003; Michaud, Carlisle y Smith, 2009)

Entre otros efectos derivados de la posesión de conocimiento político, se sostiene que los individuos que exhiben mejores niveles de información cívica expresan una mayor adhesión a la tolerancia política y a otros valores democráticos básicos ${ }^{83}$ (Dolan y Holbrook, 2001). A su vez, se ha concluido que, si bien tanto el conocimiento político poseído por los sujetos como su particular afectividad (estado emocional) influyen en el modo en el que se elaboran sus percepciones sobre el mundo

\footnotetext{
82 Probablemente, ésta es la razón más importante por la cual se considera valiosa la educación cívica de los individuos. Se observa aquí, entonces, lo que se advirtió previamente: el riesgo metodológico de eventual endogeneidad es elevado debido a que, en situaciones de esta naturaleza, se desconoce la direccionalidad causal.

${ }^{83}$ Stimson (1975) fue pionero en el hallazgo del valor predictivo del conocimiento político como variable independiente de la consistencia de las actitudes. La última se incrementa conforme va aumentando el nivel detentado por los individuos en esta competencia cívica. Numerosas investigaciones han concluido que las actitudes de los individuos poseen mayores registros de estabilidad y fiabilidad en función de sus mayores niveles de conocimiento político (Judd y Milburn, 1980; Zaller, 1992).
} 
político, el impacto real del segundo elemento es atenuado por la actuación de la información cívica en el caso de las personas con elevados niveles en esta competencia política (Marcus, Sullivan, Theiss-Morse y Wood, 1995)

Las investigaciones sobre el conocimiento político han incluido diferentes objetivos. En primer lugar, se ha intentado averiguar qué tipo de información política es retenida y cuál es descartada por los individuos (Bennett, 1995; Delli Carpini y Keeter, 1993). En segundo término, se han explorado las características que diferencian a los ciudadanos que saben de política de aquéllos que no saben de ella (Mondak y Anderson, 2004; McGlone, Aronson y Kobrynowicz, 2006).

Como tercer propósito de investigación, se ha destacado el interés por conocer si los niveles de conocimiento político cambian a lo largo de la vida de los individuos y en los diferentes momentos históricos por los que atraviesa una sociedad (Smith, 1989; Bennett y Bennett, 1993). En cuarto lugar, un grupo de investigaciones pretende arrojar luz respecto a cuáles son los factores y/o procesos facilitadores (u obstructores) de la posesión de esta competencia cívica (Peterson et al. 2002; Prior y Lupia, 2008). Finalmente, destacan los trabajos que tienen por objeto averiguar cómo influye el conocimiento cívico en la posesión de otras competencias cívicas y en el origen de otros procesos psico-políticos (Dolan y Holbrook, 2001; Michaud et al. 2009).

Desde el punto de vista metodológico, los datos sobre esta competencia cívica son recogidos en base a preguntas, incorporadas en encuestas, para averiguar el grado de conocimiento que tiene el interrogado sobre diferentes dimensiones de la realidad política de la sociedad a la que pertenece ${ }^{84}$. Existen dos tipos de preguntas asociadas a esta competencia cívica. Unas tienden a interrogar sobre hechos políticos concretos (personalidades, instituciones, posicionamientos ideológicos y disposiciones legislativas y/o constitucionales de tipo básico). Otras procuran evaluar la capacidad que tiene el interrogado para expresar ideas articuladas sobre datos políticos. Al último tipo de preguntas, se les considera como un correcto indicador de los niveles de sofisticación

\footnotetext{
${ }^{84}$ Tanto en ésta, como en las competencias políticas a describir a posteriori, cuando se habla de cómo las mismas son medidas se hace referencia, solamente, a cómo se procede a ello en investigaciones que hacen uso de métodos cuantitativos como la que se desarrolla en estas páginas.
} 
política del encuestado debido a que, en sus respuestas, puede expresar conexiones complejas entre diferentes datos ${ }^{85}$.

Son recurrentes las menciones que se realizan en la literatura sobre las dificultades que el uso de encuestas apareja en la recolección de datos sobre los niveles de conocimiento político de los individuos A pesar de ser el instrumento más idóneo para la medición del conocimiento político, suele tener mala recepción entre los encuestados por la naturaleza "examinadora" que se le adjudica (Delli Carpini y Keeter, 1993). Los sujetos suelen expresar excusas para no participar en investigaciones en las que se releva información sobre estas cuestiones ya que no desean ser reconocidos como malos ciudadanos. Otra dificultad vinculada a la medición del conocimiento político es aquélla que recuerda el hecho de que, generalmente, la información sobre esta competencia es recabada en períodos pre y post electorales. En consecuencia, las personas suelen expresar niveles de conocimiento político que no son los habituales en temporadas menos "saturadas" de información política (Fraile et al. 2007).

\section{2) ¿Cómo se obtiene la información sobre la realidad política?}

\section{La atención política como competencia cívica}

El concepto de atención política hace referencia tanto al nivel de interés que los individuos presentan en relación a la realidad política de la sociedad a la que pertenecen como a los diversos mecanismos que utilizan para proceder al seguimiento de los hechos políticos. Tradicionales indicadores de esta competencia son la discusión sobre cuestiones políticas (independientemente del ámbito en el que acontezca: familia, trabajo, escuela) y el seguimiento, a través de los mass media, de noticias vinculadas al mundo político (Torney Purta et al., 2007; Giugni y Morales, 2011)

\footnotetext{
${ }^{85} \mathrm{~A}$ posteriori, tanto si se aplica un tipo o ambos de preguntas, suele construirse un índice en base a la cantidad de aciertos y errores del encuestado.

${ }^{86}$ A efectos de la presente investigación, se hará uso indistinto de los conceptos "atención política" e "interés político". Sin embargo, en la literatura, hay quienes otorgan significados diferentes a ambas expresiones (Kinder, 2006; Valenzuela, 2009). Entre ellos, por interés político se entiende a la actitud manifestada por los individuos que reconocen poseer una inclinación o inquietud especial por el mundo político. Para este grupo de investigadores, la atención política suele desdoblarse en dos conceptos. Por un lado, es el seguimiento que se realiza a través de los medios de las noticias políticas. Por el otro, es la participación en discusiones en las que el tema central es de tipo político.
} 
La importancia que se le adjudica a la atención política como competencia cívica radica en que la posesión de la misma facilita (por lo que implica en materia de control de la información) la toma de decisiones (que trascienden lo estrictamente político) en contextos, como los contemporáneos, en los que la política configura (como variable exógena) diferentes dimensiones de la vida social (Niemi y Chapman, 1998; McIntosh et al. 2007). La atención política es, dentro de las competencias cívicas, aquélla que requiere menor nivel de esfuerzo por parte de quien la posee. Por tal motivo, su distribución entre los individuos, en comparación a la de otras competencias cívicas, es menos irregular (White et al., 2008).

Existe discusión en la literatura respecto al origen de la posesión de esta competencia política. Se ha explorado cuál es la influencia de determinadas características sociodemográficas sobre la posesión de la atención política. Al respecto, se ha descubierto que los individuos que pertenecen a grupos (étnicos o raciales) específicos que se encuentran empoderados políticamente (por razones históricas, entre otras) son aquellos que ven incrementados sus niveles de atención política.

Desde la perspectiva de la Psicología Política, se insiste en que el desinterés por cuestiones de naturaleza política puede deberse a la estructura de personalidad de los individuos. Siguiendo este razonamiento, se supone que quienes posean una tendencia a la asunción de conductas autoritarias se encuentran menos entusiasmados por el hallazgo de información (como resultado de la consulta a diferentes fuentes) que pueda contrariar sus rígidos esquemas mentales (Peterson, Smirles y Wentworth, 1997; Wu, 2003).

La literatura también señala la importancia de la posesión de determinadas actitudes pro-sociales como favorecedoras de elevados niveles en esta competencia cívica. En concreto, se ha investigado sobre la influencia, ejercida sobre la atención política, por parte de la empatía y de la disposición a la ayuda. Las actitudes pro-sociales son, según evalúa la Psicología Política, activos psíquicos que los sujetos poseen y que predisponen la posesión o no de competencias cívicas. El que un sujeto las tenga desarrolladas implica que se relaciona con sus pares, es decir, que se encuentra psicológicamente des-centrado y que es consciente de su pertenencia como persona a diferentes comunidades (Metz y Youniss, 2005). 
Otros estudios realizados también en el marco de la Psicología Política han concluido que altos niveles de Personal Political Salience (PPS) traen consigo un elevado interés por realizar un seguimiento atento de lo que acontece en el mundo político (Peterson et al., 2002; Duncan, 2005). Así mismo, se enfatiza que los sujetos que afirman comprender la complejidad de la política (es decir, aquellas personas que poseen eficacia política interna) son quienes mayor interés expresan por conocer la misma.

Desde el campo de la pedagogía política, se sostiene que la posesión de la cualidad de atención política es consecuencia del contacto, por parte de los sujetos, con instancias de formación cívica. Las formas didácticas que esta última asuma resultan, a su vez, un valor agregado de cara a la probable generación de mayores niveles de atención política ${ }^{87}$ (McLeod y Perse, 1994; Duncan, 2005; Finkel y Ernst 2005).

Como consecuencia de la posesión de elevados niveles en esta competencia cívica, pueden señalarse diferentes situaciones. En primer lugar, la atención política propicia mayores umbrales de tolerancia política. Por ello, quienes se definen más tolerantes suelen ser la personas que han crecido (o se encuentran creciendo) en entornos familiares y/o educativos en los que la discusión sobre temáticas políticas es elemento regular. En segundo lugar, la atención política favorece elevados resultados en materia de eficacia política. En tal sentido, quienes más energías dedican a realizar seguimiento de la realidad política serán quienes mejor se auto-evalúan para comprender y actuar en la esfera política. En tercer lugar, la atención política favorece la incorporación de mayores niveles de conocimiento político (Chaffee, 1977; Rubin, 1978; McIntosh et al. 2007).

Finalmente, los individuos que presentan niveles altos de atención política también participan políticamente más. Ello ocurre porque la participación política se incrementa cuando los sujetos incurren con relativa frecuencia en discusiones sobre cuestiones políticas. Especialmente importante a los efectos de propiciar mejores desempeños cívicos es, en el caso de los niños y adolescentes, el pertenecer a familias

\footnotetext{
${ }^{87}$ Una línea de trabajo se ha dedicado a estudiar cuáles son los factores que influirían en la calidad de la atención política. Al respecto, se ha descubierto que la posesión previa de conocimientos políticos facilita la elevación cualitativa (no cuantitativa) de las actividades de atención política llevadas a cabo por los individuos (Hess, 2004).
} 
en las que la discusión política se encuentra institucionalizada ${ }^{88}$ (Jennings y Niemi, 1974; McIntosh et al., 2007). En tal sentido, actividades políticas como la emisión de sufragio, la presentación de peticiones ante las autoridades, el involucramiento en boicots, la recogida de dinero para fines caritativos y la participación en reuniones comunitarias, entre otras, se encuentran empíricamente vinculadas (y parecerían derivar de) a la posesión de esta competencia cívica (Andolina, Jenkins, Zukin y Keeter, 2003).

Las investigaciones que se han llevado a cabo sobre esta competencia cívica pueden agruparse, genéricamente, en dos grupos. En primer lugar, se encuentran aquellas que tienen por objeto detectar cuáles son los elementos que, en el contexto de la transmisión de un mensaje, provocan reacciones cívico-políticas diferentes y cómo se asocian a ello los diversos niveles de "atención política" evidenciados entre los miembros del auditorio (o receptores) (Semetko, van der Brug y Valkenburg, 2003; van der Brug, Semetko y Valkenburg, 2007; Bolce y DeMaio, 2008; Valenzuela, 2009). En segundo lugar, se hallan las investigaciones que pretenden detectar cuáles son las consecuencias cívicas positivas derivadas de la posesión de niveles elevados de atención política (Beck y Jennings, 1991; Geissel, 2008; Pasek, Feldman, Romer y Hall, 2008).

Desde el punto de vista metodológico, los datos sobre la atención política de un sujeto en particular se recogen mediante encuestas en las que pueden incorporarse preguntas sobre: nivel de aceptación/rechazo de situaciones en las que se reflexione, discuta, se procure información o se haga referencia al mundo político y tipo, frecuencia de acceso y credibilidad atribuida a las fuentes de información sobre hechos políticos (McIntosh, 2006). Con el primer tipo de preguntas, se pretende detectar cuán interesante o distante le resulta al encuestado la realidad política. El segundo tipo de preguntas facilita la recogida de información sobre los rasgos predominantes de la instancia generadora de noticias políticas preferida (impresa, audiovisual, experta o relacional), sobre la cantidad de veces en las que en una determinada unidad de tiempo los sujetos tienen contacto con ellas y acerca de cuán fiables les consideran las personas.

\footnotetext{
${ }^{88} \mathrm{~A}$ su vez, determinadas características de los padres y/o tutores de los potenciales ciudadanos parecen ser más relevantes que otras de cara a generar tal situación. El nivel de conocimiento político de los padres y/o tutores se muestra como especialmente importante al respecto.
} 


\section{3) ¿Qué se afirma respecto a las actuaciones que permiten modificar la realidad política? La participación política como competencia cívica}

El concepto de participación política hace referencia al involucramiento, por parte de las personas, en actividades que refieren, directa o indirectamente, al sistema político. Estas actividades pueden ser realizadas de manera individual o colectiva. Su objetivo puede ser la búsqueda de influencia en la toma de decisiones políticas o, solamente, la intención de expresar apoyo a ideas o plataformas políticas en pugna. Inicialmente, en el marco de la Ciencia Política empírica, el voto en contextos democráticos era el único tipo de participación estudiado (Milbrath y Goel, 1977). A posteriori, el elenco de acciones caratuladas como mecanismos de participación política se fue ampliando. Nuevas tipologías y abordajes metodológicos fueron adicionándose para dar mejor respuesta a esta ampliación del concepto.

Esta competencia cívica es, sin margen a dudas, la más estudiada no sólo por los politólogos sino también por los colegas pertenecientes a otras ciencias sociales. Este hecho es el que justifica el que, a diferencia del resto de los atributos sistematizados en este apartado de la tesis doctoral, su tratamiento sea más extenso y detallado.

En términos generales, las incursiones de los sujetos en terreno político han sido entendidas como poseedoras de gradualidad, es decir, diferentes tareas políticas exigen diferentes intensidades y niveles de implicación (Conge, 1988; Burns et al., 2001). En tal sentido, se supone, al menos teóricamente, que las personas que desarrollan actividades políticas sofisticadas (desempeño de cargos públicos) deberían poder ejecutar acciones políticas que requieren menores niveles de compromiso (emisión de voto en comicios) (Verba et al., 1995; Gastil y Xenos, 2010).

Cuatro cuestiones deben ser aclaradas en torno al concepto de participación política. En primer lugar, debe decirse que la presencia de elevados niveles de participación política es considerada un claro indicador de la fortaleza y calidad de los regímenes democráticos (Pateman, 1970; Barber, 1984). Franklin (2001), al respecto, sostiene que la participación política es el alma de la democracia. Por el contrario, reducidos niveles de participación pueden estar manifestando la existencia de procesos 
de desafección política en una determinada sociedad (Levine y Molina, 2007). La extensión (profundización) de la participación política contribuye decisivamente al conocimiento mutuo de las ideas y propuestas ofrecidas por los oponentes políticos. Los procesos participativos favorecen también la legitimación social y mejora cualitativa de las decisiones tomadas por las diferentes instituciones democráticas (Harbers, 2007).

En segundo término, la participación política suele ser catalogada como convencional (o formal) o no convencional (informal). Mientras que la vertiente convencional hace referencia a las actividades políticas generalmente previstas en la legislación (y cuyo uso suele ser promovido desde el poder político), la no convencional remite a acciones de protesta no (o insuficientemente) contempladas en la ley ${ }^{89}$. En ocasiones, las innovaciones en materia de actuación política nacen como participación no convencional y, conforme acontece su aceptación social, mutan a mecanismos reglados. Consecuentemente, se "convencionalizan" (McAdam, 1982).

En tercer lugar, la participación política se ha encontrado, teórica y empíricamente, asociada a otros modos de participación social (Van Deth, 1997). En otras palabras, los individuos que tienden a asociarse a agrupaciones vecinales o desarrollan labores comunitarias en el marco de comunidades religiosas (dos actividades que no tienen carácter político) son, en promedio, quienes más probablemente incurran en actividades políticas (Djupe y Grant, 2001; Einsenstein, 2006; Echazarra, 2011). Por tal motivo, en algunos abordajes, participación política y participación social son tratadas indistinta o complementariamente.

En cuarto lugar, la participación política es considerada una competencia cívica deseable de desarrollar entre los potenciales ciudadanos. La expresión de mayores niveles de participación política, según muestra la evidencia empírica procedente de diferentes disciplinas científicas, es producto de la posesión de otras de las competencias cívicas expuestas en este texto. Al mismo tiempo, como se enunció en su momento al hablarse de circularidad virtuosa entre activos cívicos, la participación política también propicia el incremento en los niveles de esos otros atributos políticos.

Diferentes factores han sido detectados como facilitadores de la participación política. En términos generales, las variables que afectan la participación política son de

\footnotetext{
${ }^{89}$ El listado de acciones de protesta contiene, entre otras, a las siguientes: el boicot, las demostraciones públicas, la ocupación de edificios y la asistencia a huelgas ilegalizadas (Gurr, 1989).
} 
tipo individual (recursos o predisposiciones de los sujetos), de tipo grupal $u$ organizacional (hacen referencia a los colectivos a los que los sujetos pertenecen y que les movilizan o estimulan a participar) y de tipo contextual (refieren a instituciones y situaciones que enmarcan el proceso de participación política) ${ }^{90}$.

Entre los factores individuales, la literatura ha identificado, a su vez, diferentes subtipos. Existen los de esencia sociodemográfica. Se encuentran también los de naturaleza psicológica. En vinculación a estos dos primeros subtipos, se han identificado también factores asociados tanto a la dimensión temporal de la participación como a los procesos de socialización que viven (o han vivido) las personas. Finalmente, se encuentra un tercer subtipo instrumental o económico, es decir, aquél que hace derivar la participación del balance que realizan los sujetos sobre los costes y beneficios vinculados al hecho de actuar políticamente.

A partir de una perspectiva sociodemográfica, se ha hallado soporte empírico para afirmar que existe una fuerte relación entre la pertenencia de los individuos a los estratos económicamente más acomodados y la propensión a participar políticamente (Berelson, Lazarsfeld y McPhee, 1954; Nie, Powell y Prewitt, 1969; Breakwell, Fife y Devereux, 1989; Verba et al. 1995; Bevelander y Pendakur, 2009). Milbrath y Goel sintetizaron en su hoy clásica obra "Political Participation. How and Why Do People Get Involved in Politics?" (1977) los diferentes factores de tipo sociodemográfico que las ciencias sociales habían detectado como conducentes a diferentes niveles de participación política de los sujetos ${ }^{91}$. Variables tales como el sexo, la edad, la pertenencia a ámbitos rurales o urbanos, el estado civil y la pertenencia a minorías étnicas eran, entre otras, las señaladas por estos autores como las más decisivas a la hora de marcar la pauta en materia de participación política de los individuos.

\footnotetext{
${ }^{90}$ Giugni y Morales (2011) asimilan a estos tres grupos de factores a tres tipos de "capitales" ampliamente tratados por la literatura en ciencias sociales: capital humano (variables individuales), capital social (variables vinculadas a los grupos u organizaciones) y capital político (variables contextuales).

91 Dos décadas antes de la sistematización aportada por Milbrath y Goel (1977), Berelson et al. (1954) concluyeron que los diferentes rasgos sociodemográficos provocan presiones cruzadas (cross pressures) en los sujetos a la hora de participar políticamente. En otras palabras, distintas cualidades tenderían a propiciar distintos resultados. A tales efectos, los autores usaron una figura vinculada a los procesos migratorios. Según sus hallazgos, los católicos ricos de origen inmigrante, por su condición religiosa y de nacionalidad, deberían potencialmente sufragar por el Partido Demócrata. Por el contrario, por su carácter socialmente acomodado, deberían emitir su voto por el Partido Republicano.
} 
Ulteriormente, otras variables de tipo sociodemográfico han sido sindicadas como motivantes de las diferencias en materia de participación política entre los sujetos $^{92}$. Lipset (1987) identificó que, en tal sentido, determinadas profesiones y/u ocupaciones liberan tiempo que puede ser invertido en participar políticamente. Las desigualdad en la distribución de poder y responsabilidades al interior del hogar también provoca diferentes niveles de participación política. Al respecto, Burns, Schlozman y Verba (1997) descubrieron que hogares más democráticos en la materia producen miembros más empoderados políticamente.

A las variables sociodemográficas mencionadas, se le debe añadir la religión. Djupe y Grant (2001) concluyeron que la incursión frecuente en actividades religiosas o cultuales, bajo determinadas circunstancias ${ }^{93}$, favorece la participación política de los sujetos. Jones-Correa y Leal (2001) hallaron evidencia empírica que respalda la idea de que la asistencia periódica a un culto religioso se encuentra positivamente asociada a diferentes maneras de participar políticamente con independencia del grupo étnico al que se pertenezca. En tanto, Kelly y Morgan (2005) han encontrado que el nivel de compromiso religioso, en combinación con la fe profesada, predisponen en determinados sentidos la actuación política de los individuos.

Al investigarse sobre sociedades receptoras de migración, se ha estudiado la posibilidad de que la lengua hablada en el hogar pueda encontrarse asociada a los niveles de participación política de las personas. En estas exploraciones, se parte del supuesto de que aquellos individuos de origen extranjero con más dominio de la lengua hablada en la sociedad de acogida serían quienes más probabilidades presentan de actuar en su esfera política (Leighley y Vedlitz, 1999; Brady et al., 1995; Torney-Purta et al. 2006).

Sin embargo, entre todas las variables sociodemográficas, es el nivel educativo el que en mayor medida explicaría la tendencia a participar en política por parte de los

\footnotetext{
92 Carmen Pérez (2006) realiza una interesante síntesis y sistematización sobre estos factores. Aparte de las variables sociodemográficas señaladas por esta autora y desarrolladas en estas líneas, en los últimos años, con el auge de las nuevas tecnologías, también se ha investigado cómo el uso o la posesión de las mismas conduce o no a mayores niveles de participación política. En el marco de estos estudios, se ha detectado que quienes hacen un uso más intensivo de Internet tienen, a su vez, mayor propensión a incursionar en actividades de tipo político (Kavanaugh, Kim, Perez-Quinones, Schmitz y Isenhour, 2008).

${ }^{93}$ En tal sentido, las iglesias estimulan la participación política a través del reclutamiento de "cuadros políticos". También lo hacen cuando los feligreses ven su pertenencia a un grupo religioso como promotora de acciones concretas en el terreno político.
} 
individuos. La posesión de una formación más elevada conlleva un incremento indirecto en los niveles de participación política debido a que provoca inicialmente tanto mayores dosis de conocimiento político como niveles más altos de atención política. La incorporación de estas dos competencias cívicas deriva en una más alta tasa de incursión en actividades propias del mundo político (Verba et al., 1995; Morales y Giugni, 2011). Los individuos educados encuentran también mayor gratificación que sus pares no formados a la hora de participar. Al mismo tiempo, cuentan con mayores recursos para sortear los obstáculos que la participación política exige (Cho, 1999) ${ }^{94}$.

Existe un número importante de factores psicológicos que son asociados empíricamente con los niveles de participación política expresados por los individuos. En estos casos, la participación política es consecuencia de la existencia previa de creencias, valores, actitudes y sentimientos que pueden o no poseer una naturaleza política (Campbell, Converse, Miller y Stokes, 1960). Un primer factor, reconocido en este terreno, es la posesión de rasgos de sociabilidad. Ésta conduce a mayores niveles de participación política. La sociabilidad es entendida como la facilidad que tiene una persona para la generación de relaciones sociales (Milbrath y Goel, 1977). Un segundo factor, el más estudiado en este campo, es el de la identificación partidaria de los individuos (Abramson y Aldrich, 1982; Franklin, 1984). Sobre el mismo se ha concluido que, a mayor empatía/cercanía con un partido político, más probabilidades existen de emitir sufragio (participación electoral). Milbrath y Goel (1977) recuerdan que semejantes mecanismos de identificación subjetiva se activan también con temas políticos y personalidades políticas.

Otro concepto psicológico, ya mencionado en este texto para otras competencias cívicas, es el de Personal Political Salience. El mismo es un atributo poseído por aquellos individuos que asocian eventos políticos con significados afectivos. Quienes lo poseen son quienes mayores niveles actuales y/o potenciales de participación política registran (Duncan, 2005; Duncan y Stewart, 2007). Se ha comprobado que la posesión de este rasgo cognitivo se encuentra relacionado al involucramiento de los sujetos tanto en actividades políticas ordinarias (recogida de

\footnotetext{
${ }^{94}$ Así mismo, desde los estudios en los que se realizan cruces conceptuales entre cualidades educativas y atributos cívicos, se ha hallado que quienes obtienen mejores calificaciones durante su proceso formativo (escolaridad secundaria y universitaria) serán quienes, probablemente, desarrollen mayor cantidad de actividades políticas (Milbrath, 1965).
} 
firmas para realización de petitorios y donación de dinero) como extraordinarias (asistencia a manifestaciones). También, se ha explorado la influencia que sobre esta competencia cívica pueden ejercer diferentes actitudes pro-sociales (Metz y Youniss, 2005).

Otro factor de tipo psicológico asociado a la participación política es el sentido de obligación cívica. Este último hace referencia a la idea presente en diferentes sujetos sobre el carácter imperativo que reviste el ser un ciudadano activo y comprometido. Quienes lo poseen en mayor medida son quienes ven incrementados sus niveles de participación política. Idéntica pauta se encuentra en relación a los individuos que poseen un elevado sentido de auto-confianza (Milbrath y Goel, 1977). Al mismo tiempo, existe evidencia empírica que avala el que la posesión, por parte de los individuos, de lo que se denomina "identidad nacional" les conduce a participar más en el terreno político (Huddy y Khatib, 2007) ${ }^{95}$.

Otro hallazgo importante es aquél que delata que existe vinculación entre la inclinación ideológica de un individuo y sus niveles de participación política. En tal sentido, quienes afirman auto-ubicarse, en un continuum ideológico, en posiciones más liberales (de izquierda), quienes adscriben a valores post-materialistas y quienes sostienen adherir menos al conjunto de principios asociados a la ética de trabajo protestante son quienes manifiestan incursionar en mayor medida en actividades políticas $^{96}$ (Breakwell et al., 1989; Inglehart, 1997).

En el terreno de los factores psicológicos, se han explorado también cuáles son las competencias cívicas que favorecen la participación política (Mclntosh et al., 2007). Se ha hallado que el seguimiento o atención hacia la realidad política provoca mayores niveles de participación (Berelson et al. 1954). Se descubrió que, a mayores registros de conocimiento político, mayor posibilidad de incursión política entre los sujetos (Delli Carpini y Keeter, 1993; Fraile et al., 2007). Se encontró que la tolerancia política

\footnotetext{
${ }^{95}$ La identidad nacional es un modo concreto en el que se procede a la medición del concepto de patriotismo.

${ }^{96}$ En el caso de quienes adhieren a la llamada "Protestant Work Ethic", parecería coherente encontrar valores bajos de participación política. Para estos sujetos, la idea de recompensa (o reconocimiento) se encuentra asociada a su obtención a través del trabajo sostenido y esforzado y no a su búsqueda en ámbitos ajenos a aquéllos en los que desarrollan sus actividades laborales ordinarias (Breakwell et al. 1989).
} 
predispone a determinados tipos de participación política (Gibson y Anderson, 1985; Togeby, 2004).

La eficacia política también produce participación política (Milbrath y Goel, 1977). La evidencia empírica, en relación a esta competencia política en concreto, resulta particular. Por un lado, a mayor eficacia política interna, existe mayor participación política (el evaluarse como apto para comprender el mundo político lleva a actuar en él) (Gastil y Xenos, 2010). Por otro lado, en relación a la posesión de menor eficacia política externa, existen hallazgos contradictorios. Hay quienes han descubierto que, cuando el sistema político no es receptivo a las demandas ciudadanas, ello lleva a actuar menos en el plano político porque poco puede obtenerse (Abramson y Aldrich, 1982). Están también los que, frente a similar situación, han encontrado que las personas deciden actuar más en el plano político con el propósito de cambiar la realidad que les disgusta (Gastil y Xenos, 2010).

La participación política, como se anticipó, también depende de variables asociadas al tiempo. Estos factores temporales se encuentran más o menos asociados a los recursos sociodemográficos y psicológicos descritos hasta el momento. Milbrath y Goel (1977) señalaron en su texto que el involucramiento de las personas en la política del sitio en el que residen se incrementa conforme aumenta el tiempo de radicación física en ese espacio. Esta evidencia empírica aplica, como ha sugerido también Cho (1999), no sólo para los autóctonos en una sociedad determinada sino, también, para quienes llegan a ella desde otras latitudes en calidad de inmigrantes. En tanto, los efectos período histórico, generacional y ciclo vital, clásicos factores "temporales" utilizados en las ciencias sociales, influyen también en el grado y tipo de participación política elegido por los sujetos (Berelson et al, 1954; Fraile et al., 2007).

Vinculadas tanto a la concurrencia de factores sociodemográficos y psicológicos como a las variables temporales descritas, se encuentran las investigaciones sobre socialización. Almond y Verba (1963) mencionaban ya en su obra seminal "The Civic Culture" que diferentes patrones de socialización política producían diferentes niveles y estilos de participación política. Milbrath y Goel (1997) afirmaban que es posible esperar variaciones interculturales en esta competencia cívica ${ }^{97}$. Colomer (1991) ha descubierto

\footnotetext{
97 Nie et al., 1969 también hacen mención a las diferencias existentes en la materia entre distintas las sociedades.
} 
que el recuerdo de experiencias autoritarias tiende a incrementar los niveles de participación de los individuos en jóvenes democracias. Cho (1999), mediante la realización de interesantes comparaciones entre nativos e inmigrantes, descubrió que la socialización es un factor fundamental a la hora de explicar desempeños distintos en el campo político.

En relación a experiencias concretas de socialización, existe otro grupo de variables que suele ser explorado de cara a explicar las diferencias en la distribución de los niveles de participación política entre los ciudadanos. Es el vinculado al estudio de concretas circunstancias vitales que facilitan la incursión de los sujetos en actividades políticas. Una de ellas es la experiencia laboral. El ambiente de trabajo es considerado un auténtico agente socializador político. En consecuencia, en el caso de los adolescentes y adultos jóvenes, quienes posean experiencia como trabajadores presentarían mayores niveles de actuación política que aquéllos que sólo presenten antecedentes académico-formativos ${ }^{98}$ (Breakwell et al. 1989). Dentro del mismo grupo de factores, diferentes investigaciones han llegado a concluir que los sujetos que han pasado por experiencias de trabajo voluntario $\mathrm{y} / \mathrm{o}$ por instancias formativas de "aprendizaje-servicio" declaran poseer mayores niveles de participación política que aquéllos que no han vivido circunstancias similares (Waldstein y Reiher, 2001) ${ }^{99}$.

El último subgrupo de explicaciones asociadas a factores individuales es el de tipo instrumental-económico. Estas se construyen a partir del argumento que sostiene que la participación de los individuos sólo tiene lugar cuando los beneficios derivados de participar son superiores a los $\operatorname{costes}^{100}$ (Downs, 1957). Tal circunstancia conduciría

\footnotetext{
98 Sin embargo, otras investigaciones han revelado que quienes, siendo adolescentes o adultos jóvenes, deben trabajar y estudiar disponen de menos tiempo que quienes sólo estudian y, a su vez, no alcanzan (por sus obligaciones laborales) el mismo nivel de credenciales académicas. Una y otra circunstancia menguarían sus niveles de actuación política (Breakwell et al., 1989).

${ }^{99}$ Muchos de los hallazgos mencionados en relación a los factores (recursos) individuales hasta aquí descritos han sido corroborados y sintetizados también por los artífices del reconocido "Civic Voluntarism Model" (Verba, Lehman, Brady y Schapiro, 1996). Este modelo es un conjunto parsimonioso de hipótesis sobre los factores que causan la participación política. Según la evidencia empírica hallada por estos autores, los factores que provocan el que los individuos participen son su tiempo disponible, su nivel de ingreso, sus niveles de competencias cívicas y sus niveles de acceso a redes de poder e influencia.

100 Los beneficios de participar, según señala Pérez (2006), no son únicamente económicos. Pueden ser de tipo social (detentar una posición de poder o prestigio) o psicológicos (disfrutar por la contribución que se realiza al fortalecimiento del sistema democrático o a la resolución de problemas comunitarios). Al mismo tiempo, los costes no son solamente los asociados a la participación "física". También se incorporan los vinculados a la búsqueda de la información necesaria y previa a la actuación política. Franklin (1984) señala que los sujetos son lo suficientemente racionales para, al momento de participar,
} 
a que los sujetos estuvieran instrumentalmente motivados para participar. Franklin (2001) sostuvo que dicha motivación instrumental es el predictor más correcto de la participación política. En otras palabras, el deseo de influir en el curso de los acontecimientos políticos es lo que conduce a los individuos a participar.

En base a estos postulados, cuando un sujeto debe decidir entre varias opciones en el marco de una elección democrática, se decantará por aquella alternativa que le provea de mayor beneficio neto (beneficios menos costes) ${ }^{101}$. Este razonamiento intuitivo se ha ido sofisticando conforme ha acontecido el paso del tiempo. Según Key (1968), la consideración de costes y beneficios, si bien realizada individualmente, no se ciñe exclusivamente a intereses particulares. Puede también extenderse al contexto, es decir, existen sujetos que proceden a actuar políticamente (o a elegir a una propuesta política determinada) sólo cuando perciben que ello acarrea claros beneficios a su entorno. Al mismo tiempo, la evaluación de costes y beneficios se realiza también en función de una dimensión temporal. En otras palabras, los individuos, para decantarse por participar, pueden apreciar tanto escenarios pasados como futuros. Más recientemente, Stokes (2001) introdujo interesantes variantes en esta mirada sobre la participación política mediante la creación de nuevas hipótesis de trabajo que explican el comportamiento político ante escenarios político-económicos peculiares ${ }^{102}$.

Como se expresó al inicio de este apartado, existe un segundo grupo de factores propiciadores de la participación política vinculados a los grupos y organizaciones a los que pertenecen los individuos. La literatura sobre participación política reseña, en estos casos, como su causante a factores asociados a la movilización de los individuos (Nie et al., 1969; Conge, 1988). Franklin (2001) define a la movilización como las acciones llevadas a cabo por actores políticos (partidos, sindicatos, mass media, lobbies, iglesias, etc.) que conducen a que los individuos sean, por un lado, más conscientes de su rol y poder político $y$, en base a esto último, participen políticamente en un sentido determinado. Por tanto, en la visión de quienes adhieren a este tipo de explicaciones, a

combinar su tradicional identificación partidaria con el apoyo a opciones políticas que les reportan las ventajas deseadas a nivel de políticas públicas.

${ }^{101}$ Este razonamiento es el que se encuentra detrás de lo que se denomina voto normal.

102 La autora norteamericana, para complementar al voto normal, creó las categorías de voto intertemporal, antidotista y distributivista. Las últimas tres expresiones sirven para explicar el comportamiento político en periodos de reformas estructurales (o neoliberales) (Biderbost, 2007a). 
mayor capacidad movilizadora de estos agentes externos, mayor participación política de los ciudadanos.

Estos agentes externos proceden a crear, entre los miembros de su público objetivo, identificación para con sus causas y/o propuestas. Esta identidad es aprovechada estratégicamente en determinadas circunstancias (por ejemplo, comicios o aprobación de leyes) para proceder a la movilización de los ciudadanos en la dirección deseada. Nie et al. (1969) señalaban que la membresía a organizaciones es fundamental para potenciar la participación de aquellos colectivos e individuos en situación socioeconómica de desventaja ${ }^{103}$.

Existe una explicación complementaria en relación a cómo estos actores provocan la participación política de los individuos. Estas agrupaciones favorecerían también la participación política de los individuos por el capital social que les reportan (Putnam, Leonardi y Nanetti, 1993; Portes, 2000; Giugni y Morales, 2011). Este último se traduce en un nivel mayor de bienes intangibles (competencias cívicas, conciencia grupal, sentimientos de solidaridad, etc.) que, a posteriori, conducen a incrementar los niveles de participación política. Leighley (1995), en tal sentido, sostiene que la pertenencia del individuo a redes diversas, densas y politizadas oficia de catapulta para la participación.

Finalmente, se encuentra un grupo de factores de naturaleza sistémica/contextual que promueven la participación política (fundamentalmente pero no exclusivamente, la de tipo electoral) ${ }^{104}$. En tal sentido, determinadas configuraciones político-institucionales (sistemas, dispositivos y circunstancias electorales, sistemas de partidos, mecanismos de consulta previos y posteriores a la toma de decisiones

\footnotetext{
${ }^{103}$ Estos autores sostenían que la existencia de estas agrupaciones permitía el ejercer un contrapeso al mayor nivel de participación política evidenciado entre los miembros de las clases privilegiadas. Más recientemente, Gray y Caul (2000) afirmaron que la pérdida de poder de movilización observada entre partidos políticos y sindicatos (vinculados a la izquierda ideológica) en las democracias industrializadas es la que ha conducido a un deterioro en la cuantía de individuos que votan en los comicios. Estos autores adjudican esta pérdida en la capacidad de movilización a los cambios a nivel de clases sociales que han acontecido en los países analizados.

${ }^{104}$ La literatura sobre los factores institucionales que promueven la participación es amplísima y de larga data (Franklin, 2004). Entre los partidarios de la importancia de estas variables se encuentra Arend Lijphart. El autor holandés sostuvo que el incremento en los niveles de participación electoral viene dado no tanto por políticas tendientes a mejorar los niveles educativos o el interés por la realidad política de la sociedad sino, por el contrario, a partir de la realización de modificaciones pertinentes en diferentes resortes institucionales. En el presente documento, por no adecuarse a los objetivos de la investigación, sólo se hace un rápido repaso a este tipo de aportes.
} 
gubernamentales) políticas públicas y discursos políticos tienden a elevar la participación de los ciudadanos (Fung y Wright, 2001; Harbers, 2007; Giugni y Morales, 2011). En consecuencia, el control (o poder) político sobre la naturaleza de tales mecanismos permite tanto la previsión como la generación de escenarios ad hoc en relación a los niveles de participación de diferentes colectivos sociales.

Concretamente, instituciones como el voto obligatorio, el sufragio por correo o la inscripción automática en el registro electoral favorecen la participación. Otro tanto acontece con determinados tipos de comicios. Los niveles de participación se incrementan cuando las elecciones son presidenciales y nacionales (Franklin, 2001). Tanto cuando las elecciones acontecen en el marco de una situación de crisis (económica o política) como cuando existe una marcada diferencia entre las propuestas políticas enfrentadas, los niveles de participación también aumentan (Milbrath y Goel, 1977). Otro tanto sucede cuando la frecuencia de celebración de comicios no es tan elevada y, por lo tanto, los ciudadanos no sufren de fatiga electoral (Van Egmond, de Graaf y Van Der Eijk, 1998) ${ }^{105}$.

Una vez revisadas las causas de la participación política, se debe proceder a enunciar cuáles son las consecuencias de la misma. La exploración que se ha hecho en las ciencias sociales sobre sus efectos no es tan amplia como la realizada para la detección de sus motivos (Leighley, 1995; Ikeda, Kobayashi y Hoshimoto, 2008). En las siguientes líneas, sólo se hará referencia a los efectos hallados a nivel individual de la participación política ${ }^{106}$. Existe evidencia empírica de que quienes participan presentarán, en comparación a quienes no lo hacen, valores más elevados en diferentes atributos psico-afectivos. En tal sentido, quienes más participan, generan mayores sentimientos de autonomía y (auto) competencia y sensación de bienestar (WeitzShapiro y Winters, 2008).

Los sujetos que más participan presentan, a su vez, elevados niveles de autovaloración. Otro tanto sucede con la autoestima. También se ha registrado que los

\footnotetext{
105 Lógicamente, estos factores institucionales propician o retraen la participación política de las personas con independencia de su condición nativa o inmigrante.

106 Jan Leighley (1995) señala que estas consecuencias son importantes también en el plano de la producción de políticas públicas. A tales efectos, reseña que mayor participación de los estratos humildes de la población conduce a una mayor obtención de beneficios sociales. También en el plano del sistema político, se exploran las implicancias de la participación política sobre la calidad de los regímenes democráticos (Alcántara, 2008; Levine y Molina, 2011).
} 
sujetos que participan políticamente compensan con ello las desventajas asociadas a status desfavorables y obstaculizan la aparición de desórdenes mentales asociados a tal situación (Sanders, 2001).

Al mismo tiempo, la participación política, por la pericia cívica que trae aparejada, permitiría la generación de confianza en las instituciones políticas. El alza en el apoyo al régimen político también es otro de sus potenciales efectos. Quienes más participan políticamente son aquéllos que declaran así mismo menores niveles de alienación. En otras palabras, los sujetos con mayores niveles de participación política suelen ser, simultáneamente, las personas que se autoevalúan menos desafectos en relación a objetos políticos y quienes más positivamente consideran a los diferentes componentes del sistema político (Finkel, 1987; Jennings, 1987; Freie, 1997; Fraile et al., 2007). Mayores niveles de orgullo cívico y sofisticación política también serían consecuencia de una mayor participación política (Leighley, 1995; Gastil y Xenos, 2010).

En relación a las competencias cívicas en este documento estudiadas, la evidencia empírica ubica en la participación política el punto de partida para la posesión de varios de estos atributos. En primer lugar, una mayor participación política propicia dosis más elevadas de eficacia política. En segundo lugar, la tolerancia política de los individuos también se ve incrementada como efecto de la participación política (Finkel, 1987; Schine, 1997; Waldstein y Reiher, 2001; Weber, 2003). Finalmente, otro tanto ocurre con el conocimiento político: a mayor cantidad de oportunidades en las que un individuo incursiona en política, mayores son las probabilidades de asimilar información sobre el entorno político (Smith, 2002).

Repasadas las causas y las consecuencias que la investigación social reconoce para la participación política, es importante hacer mención de cuáles son concretamente las disciplinas que abordan el estudio de este concepto. Las investigaciones sobre la participación política se han desarrollado y se desarrollan en campos tan disímiles como la Ciencia Política, la Sociología Política, la Psicología Política, la Comunicación Política y la Antropología Política. Ello ha conducido a que, para su tratamiento empírico, se adopten diferentes estrategias metodológicas en función de los conceptos, hipótesis y teorías con las que se la relaciona.

Para la Ciencia Política y la Sociología Política, los propósitos fundamentales de las investigaciones que tienen a la participación política como su objeto de estudio son 
dos. Por un lado, se encuentra la intención de generar conocimiento sobre los factores (micro, mezzo y macro) que provocan la participación política, el modo en el que lo hacen y cómo es posible propiciar la activación de círculos políticos virtuosos. Por otro lado, se halla la vocación de generar información sobre los efectos que acarrea una mayor o menor participación en materia de calidad de la democracia, transformaciones de régimen político y creación de clivajes sociales.

Paralelamente, para la Psicología Política y la Comunicación Política la inquietud reside en el conocimiento de los mecanismos y estímulos psíquicos y comunicacionales que generan la participación política y cómo su repetición (ejercitación) influye también en aquéllos. Finalmente, en la Antropología Política, la pretensión científica se centra en la identificación de las prácticas políticas en clave témporo-espacial y en relación a otros elementos observados (ajenos a la naturaleza política) en una cultura o grupo étnico de referencia.

En la Ciencia Política y la Sociología Política, la medición de la participación política suele utilizar preguntas en cuestionarios que tienen por objeto conocer cuáles son el tipo y la frecuencia de las actividades de naturaleza política en las que incursionan los individuos. En ciertas ocasiones, también se incorporan interrogantes relacionados al desarrollo de acciones sociales y/o comunitarias que podrían tener alguna clase de vinculación con otras de esencia política. En el caso de las investigaciones desarrolladas sobre adultos, las preguntas pueden hacer referencia a su participación política y sociocomunitaria pasada, presente y futura. Por el contrario, en el caso de los adolescentes, las preguntas, por su carácter de futuros ciudadanos, sólo hacen referencia, por un lado, a su potencial participación política y, por otro lado, a su pasada y actual participación socio-comunitaria. 


\section{4) ¿Cuánto se afirma comprender sobre la realidad política y cuán moldeable se la considera? La eficacia política como competencia cívica}

La eficacia política es una competencia cívica que se vincula, por un lado, a la capacidad (auto declarada) de comprensión de la realidad política en la que los sujetos se encuentran inmersos y, por el otro, a la creencia de que las acciones políticas individuales y colectivas pueden tener un impacto en el proceso político (Campbell, Gurin y Miller, 1954; Easton y Dennis, 1967; Craig y Maggiotto, 1982; Pasek et al., 2008). Esta es una competencia que se ha trabajado tradicionalmente en la literatura de manera bidimensional ${ }^{107}$ (eficacia política interna y eficacia política externa) (Wu, 2003).

La dimensión interna de la eficacia es definida como el juicio (positivo o negativo) que los sujetos realizan respecto a sus capacidades para entender el mundo político y para participar en él. Complementariamente, la dimensión externa de la eficacia es conceptualizada como la percepción (positiva o negativa) que tienen los individuos respecto a la capacidad efectiva de respuesta del sistema político en relación a sus demandas concretas (Pollock III, 1983). Esta segunda dimensión de la eficacia política también puede ser definida como la sensación que poseen los sujetos en relación a que el sistema político puede ser modificado por las iniciativas de los ciudadanos (Hackett y Omoto, 2009).

Desde las ciencias sociales se afirma que, si no existe una adecuada combinación de ambos tipos de eficacia, los ciudadanos responderían de manera apática y desafecta a los diferentes estímulos ofrecidos por los sistemas democráticos ${ }^{108}$ (Campbell et al., 1954; Craig, Niemi y Silver, 1990; Mattei y Niemi, 2005). La investigación aplicada a relevar los niveles de eficacia política a nivel individual ha confirmado la existencia de

\footnotetext{
${ }^{107}$ En su artículo Multiple indicators in survey research: The concept "Sense of political efficacy" publicado en la revista Political Methodology en 1974, G. Balch, tras la aplicación del análisis de ítems múltiples, descubre que, al menos, la eficacia política poseía una naturaleza bidimensional (Wu, 2003).

108 El concepto politológico de eficacia política puede equiparse, con cierta cautela, al concepto psicológico de auto eficacia (self-efficacy en su voz inglesa). El segundo, más amplio debido a que no se restringe sólo a situaciones de naturaleza política, hace referencia a las ideas que cada sujeto posee respecto a sus capacidades para organizar y ejecutar cursos de acción que permitan el control de escenarios futuros (Bandura, 1995; Morrell, 2005).
} 
una cercana relación entre sus dos dimensiones. En tal sentido, ambos componentes se han encontrado estadísticamente asociados en reiteradas ocasiones (Hackett y Omoto, 2009).

Varios son los factores reseñados por la literatura como propiciadores de la eficacia política. En primer lugar, son frecuentes los estudios que tienden a destacar los efectos positivos que, sobre la eficacia política, son ejercidos por la posesión de determinadas características socio-demográficas por parte de los sujetos. Los hallazgos han destacado, entre otras, la importancia de las siguientes variables: ingresos, niveles educativos, género, raza o grupo étnico, edad, religión y lugar de residencia (las personas se consideran mejor preparadas para enfrentar situaciones políticas cuando éstas acontecen en su círculo geográfico más próximo) (Caprara y Zimbardo, 2004; Caprara, Vecchione, Capanna y Mebane, 2009).

En segundo lugar, como sucede con otras competencias cívicas, la socialización escolar juega un rol activo en la potenciación de la eficacia política. En tal sentido, la literatura destaca que la participación en clases de educación cívica incrementa los niveles detentados por los individuos en esta competencia (Pasek et al., 2008). En el plano educativo, los elementos que más favorecerían el crecimiento de la eficacia política son la utilización de nuevas tecnologías, la creación de atmósferas deliberativas y la apelación a los problemas comunitarios como argumento en base al cual se procede a la construcción de la estrategia pedagógica.

En tercer término, la literatura sobre psicología política ha explorado también la influencia ejercida, por determinados factores cognitivos subjetivos, en los niveles de eficacia política (Easton y Dennis, 1967; Stenner-Day y Fischle, 1992; Wu, 2003; Metz y Younnis, 2005). Entre los mismos, se han explorado los que se detallan a continuación: actitudes pro-sociales, coeficiente intelectual, confianza política, evaluación de la performance gubernamental, apreciación del entorno en el que se vive, expectativas respecto a la situación económica personal y/o ambiental, afiliación ideológica e identificación partidaria.

En cuarto lugar, se ha explorado de qué manera otras competencias cívicas influyen en la eficacia política. Se ha descubierto que existe una clara correlación entre atención política y eficacia política (Chaffee, 1977; Rubin, 1978). En tal sentido, la eficacia política parece incrementarse cuando los individuos realizan seguimiento de la 
realidad política a través de los medios de comunicación. Esto también acontece cuando los sujetos se encuentran inmersos en instancias de discusión y de intercambio de pareceres sobre temas de naturaleza eminentemente política. A su vez, se ha hallado que quienes más conocimiento político poseen mayores niveles de eficacia política exhiben (Burns et al., 2001).

A su vez, la participación política de los individuos facilitaría el aumento de los niveles detentados de esta competencia política. Por un lado, se encuentran quienes afirman que la participación política de tipo indirecto (voto, participación en referéndums e iniciativas populares, involucramiento en campañas electorales y militancia partidaria) provoca el incremento en los niveles de la dimensión externa de la eficacia política (creencia en la capacidad de respuesta del sistema político a las demandas ciudadanas) (Finkel, 1985). Por otro lado, otra línea de trabajo, que tiene por objeto llevar a cabo investigaciones empíricas para aplicar las ideas sugeridas por la teoría sobre la democracia deliberativa, sostiene que los ciudadanos involucrados en procesos de democracia directa (o semidirecta) son aquéllos que mejores niveles de eficacia política exhiben. En este caso, se habla de actividades políticas en las que la participación no se encuentra mediatizada. La dimensión interna de la eficacia política es la promovida por la incursión de los sujetos en estos procesos de deliberación política (Gastil y Dillard, 1999; Morrell, 2005).

En tanto, entre los efectos atribuibles a la presencia/ausencia de eficacia política, la literatura ha reseñado, entre otros, los que se detallan a continuación. En primer lugar, como una lógica consecuencia del modo en el que el concepto está construido, elevados niveles de eficacia política en los individuos tienden a generar respuestas positivas en materia de atención política y participación política. Al respecto, los investigadores han señalado como variables concretas que se asocian a elevados niveles de eficacia política a las siguientes: apoyo al sistema político democrático, seguimiento de la realidad política, involucramiento en campañas electorales, matriculación o registro que habilita para la emisión de sufragio (en aquellas sociedades donde el voto no es obligatorio) y emisión efectiva de sufragio. Todas estas actividades son ejecutadas en mayor medida por personas que se encuentran dotadas de esta competencia (Campbell et al., 1954; Easton y Dennis, 1967; Timpone, 1998; Rudolph, Gangl y Stevens, 
2000; Morrell 2005) ${ }^{109}$. Existe también evidencia empírica sobre la influencia positiva que la eficacia política ejerce sobre la tolerancia política (Duch y Gibson, 1992).

Las investigaciones que, hasta el momento, se ha desarrollado sobre la eficacia política pueden agruparse en dos conjuntos diferenciados. Se hallan las investigaciones que tienen por objeto detectar cuáles son los mecanismos conducentes a la producción de la eficacia política (con independencia de las dimensiones que le componen) (Becker, Amundson, Anderson, Wenzel, Yakubova, Sajaia y Frannea; 2009; Caprara et al. 2009; Anderson, 2010). Se encuentran también aquellos estudios que tienen por objeto desentrañar los complejos mecanismos que conducen desde la eficacia política hacia la generación de resultados cívicos específicos (positivos, negativos o neutros) (Marsh y Tonoyan, 2009; Schyns y Koop, 2010).

Para proceder a la medición de ambas dimensiones de la eficacia política, suelen incluirse preguntas en encuestas y cuestionarios de opinión pública. Ocasionalmente, estas encuestas son administradas también en el marco de experimentos y cuasiexperimentos en el que los sujetos son sometidos a distintas variables externas que podrían estar incidiendo en los niveles de eficacia política. Cuando se hace uso de métodos experimentales, las encuestas son administradas bi-temporalmente (antes y después del estímulo).

Las preguntas utilizadas para averiguar sobre esta competencia cívica hacen referencia tanto a situaciones políticas específicas como genéricas en las que las personas pueden encontrarse insertas. En ambos casos, se le solicita al sujeto que se auto-evalúe frente a las mismas. De esta manera, se observa si los sujetos presentan semejantes registros en esta competencia cívica en función de los diferentes contextos políticos a los que puedan hacer frente ${ }^{110}$.

\footnotetext{
${ }^{109}$ Como puede observarse en lo referido en la literatura, la participación política y la eficacia política conforman una especie de círculo cívico virtuoso: mayores dosis de una de estas competencias políticas traen aparejado mayores dosis de la otra y así de manera sucesiva. Wu (2003) llama la atención respecto a que, para la activación de esta circularidad cívica, los beneficios de la participación deben estar claros para los individuos y que, en las ocasiones en que las tal claridad no existe, deben crearse recompensas institucionales para que eso acontezca.

${ }^{110}$ Quizás, un ejemplo puede ayudar a aclarar lo que quiere decirse en estas líneas. Una persona puede afirmar de sí que misma que comprende los mecanismos que existen detrás de una iniciativa popular y, en consecuencia, desee participar en la misma. Eso no implica, necesariamente, que esa misma persona diga entender y sostenga querer participar en un proceso, como existe en algunas sociedades, en los que la sociedad civil puede adherir u obstaculizar a la candidatura de una persona para acceder a un cargo vacante en la judicatura. Según afirma la literatura, el registro en la eficacia política no es necesariamente
} 
En relación a la eficacia política interna, se utilizan generalmente preguntas orientadas a la comprensión de escenarios políticos. Para conocer la eficacia política externa, se utilizan frecuentemente preguntas sobre la estimada capacidad de influencia personal o colectiva en tales escenarios. En este último caso, también, se pregunta acerca del tipo de respuesta que se espera del sistema político ante estímulos externos. Para ambas dimensiones, el sujeto debe responder a lo interrogado de acuerdo a una escala que presenta un rango limitado (generalmente impar) de opciones que abarcan desde la no comprensión/influencia hasta la máxima comprensión/influencia en los marcos políticos referidos. En otras ocasiones, las preguntas tienen por objeto la mera consecución de una respuesta afirmativa o negativa sobre la situación planteada en cada dimensión de la eficacia.

\section{5) ¿Cuán arraigado se encuentra el respeto por las ideas políticas opuestas? La tolerancia política como competencia cívica}

El concepto de tolerancia política hace referencia a la tendencia de los individuos a permitir la libre expresión política de aquellos grupos y/o personas que poseen pensamientos y demandas opuestas a las suyas (Gibson, Duch y Tedin 1992; Marcus, Sullivan, Theiss-Morse y Stevens, 2005). La inclusión de la tolerancia como valor político, en diferentes textos constitucionales y/o legislativos, deriva de la aceptación por parte de la sociedad de la existencia de un conjunto de normas consensuadas democráticamente que facilitan la libre manifestación de los pareceres con independencia del grupo social, racial, religioso y político al que pertenezcan los individuos. Una sociedad compuesta por individuos con elevados niveles de esta competencia política permite un eficaz y estable funcionamiento de la democracia (Jackman, 1978; Owen y Dennis, 1987). Según Gibson y Anderson (1985), esto último acontece porque la posesión de tolerancia política moldea el diseño de las políticas públicas en una sociedad dada. Por todo esto, es que se afirma que la tolerancia política

(aunque puede serlo) trasladable de una situación a otra ni de una situación específica a otra genérica (o en sentido inverso). 
es considerada uno de los valores fundamentales de los regímenes democráticoliberales

La literatura ha explorado como probables factores con incidencia en los niveles de tolerancia política los factores socio-demográficos. El hallazgo fundamental ha sido que la posesión, por parte del sujeto, de una privilegiada posición socio-educativa favorece la elevación de sus niveles de tolerancia política (Stouffer, 1955; Sullivan, Marcus, Feldman y Piereson, 1981, Duch y Gibson, 1992). Por otra parte, las mujeres han presentado, desde el inicio de los estudios regulares sobre esta competencia, menos tolerancia política. Sin embargo, la evidencia empírica no se expresa, al respecto, siempre en idéntico sentido (Golebiowska, 1999). A su vez, se ha explorado lo vinculado a las creencias metafísicas de los sujetos. Las relaciones entre, por un lado, la denominación religiosa y, por el otro, el nivel de religiosidad (en sus diferentes dimensiones: pensamiento doctrinal, pertenencia a un culto y compromiso en el comportamiento) y el grado de tolerancia política expresado por los individuos han sido exploradas. A mayor implicación religiosa, se ha descubierto menor nivel de tolerancia política (Niemi y Chapman, 1998; Eisenstein, 2006).

Sumados a los mencionados, se encuentran los factores de naturaleza psicológica (o psico-social). Estos, individualmente o combinados, provocan diferentes niveles de tolerancia política. Entre los mismos, se hallan elementos tales como la percepción subjetiva de amenaza (Duch y Gibson, 1992), la posesión de una personalidad segura (Eisenstein, 2006), la internalización de principios abstractos asociados a la democracia (Marcus et al., 1995) y la ideología política profesada (Sniderman, Tetlock, Glaser, Green y Hout, 1989; Duch y Gibson, 1992).

Dentro de este grupo de factores psicológicos, existe un grupo de autores que se ha dedicado a estudiar la influencia que otras competencias cívicas ejercen sobre la tolerancia política. En tal sentido, se ha hallado evidencia empírica que sostiene que los individuos que mayor conocimiento político poseen son quienes más toleran (Dolan y Holbrook, 2001). A su vez, se encuentran quienes enfatizan la incidencia que el "universo comunicacional" del individuo posee sobre el grado de tolerancia que le caracteriza. Este universo se ha operacionalizado en dos variables: una de ellas vinculada a los patrones de comunicación interpersonal al interior de la familia a la que pertenece la persona. La otra hace referencia al tipo de relación establecida entre ésta y los mass media (Owen y 
Dennis, 1987; Eisenstein, 2006). El llamado aquí "universo comunicacional" podría asimilarse a la competencia cívica entendida en este trabajo como "atención política". Así mismo, se ha descubierto también que los niveles de eficacia política y participación política poseídos por los individuos también influyen, de manera directamente proporcional, sobre este atributo (Duch y Gibson, 1992).

Otra dimensión, estudiada como causa de la tolerancia política y vinculada tanto a elementos sociodemográficos como psicológicos, es la temporal (Jennings y Niemi, 1981). En esta literatura, suele trabajarse con dos instrumentos analíticos clásicos en las ciencias sociales: la influencia del ciclo de vida (las personas, a la par que envejecen, ven disminuir sus umbrales de tolerancia) y la incidencia de la generación de pertenencia (las nuevos jóvenes parecen ser más tolerantes que los jóvenes del pasado) (Sullivan, Piereson y Marcus, 1982; Karpov, 1999).

También hay quienes enfatizan el particular rol que la correcta implementación de programas de formación cívica ejerce sobre los niveles de tolerancia política tanto de jóvenes como de adultos (Torney-Purta, Lehmann, Oswald y Schulz, 2001; Amadeo, Torney-Purta, Lehmann, Husfeldt y Nikolova, 2002). La adecuación de tales programas acontece cuando se da lugar al abandono de la antigua práctica, en el terreno de la educación ciudadana, de la transmisión de conocimientos meramente formales y/o legales y la misma es sustituida por propuestas teórico-prácticas que respondan a las diferentes manifestaciones que suele asumir la dinámica de las relaciones entre las personas, los diferentes colectivos sociales y las instituciones políticas. A su vez, se sostiene que la participación de los sujetos en experiencias de "aprendizaje-servicio" puede resultar un acicate para incrementar sus niveles de tolerancia política (Finkel y Ernst, 2005).

Finalmente, se encuentra un grupo de investigaciones que explora la consecuencia de los factores sistémicos sobre los niveles de tolerancia política. Se ha descubierto que, conforme acontecen cambios en el statu quo asociados al reconocimiento de derechos y libertades previamente negados, los individuos elevan sus niveles de tolerancia política. En tal sentido, una mayor incursión en prácticas y/o ejercicios democráticos favorecen el alza de la tolerancia política (Peffley y 
Rohrschneider, 2003; Guérin, Petry y Crete, 2004) ${ }^{111}$. En tanto, Duch y Gibson (1992) han llegado a una conclusión opuesta a lo recién mencionado. Las sociedades con menos experiencia democrática son las que poseen, en promedio, mayores niveles de tolerancia política. Estos últimos autores añaden que otros dos factores sistémicos que afectan la tolerancia política son el éxito electoral de las opciones políticas extremas y la configuración que presenta el sistema de partidos ${ }^{112}$.

Poco se ha estudiado sobre las consecuencias de la tolerancia política tanto a nivel individual como sistémico. Entre los pocos investigadores que se han dedicado a este tema, se encuentran Gibson y Anderson (1985). Ellos señalan que existe, aunque limitada, evidencia empírica sobre dos posibles efectos de esta competencia cívica. Uno de ellos es el que existe sobre el comportamiento político. En tal sentido, la tolerancia (o la intolerancia) política promueve la acción política. La presencia de esta asociación depende de otros dos factores: el contexto en el que tiene lugar la misma y las percepciones que, sobre ese contexto, tienen los sujetos. Esta relación se activa, con mayor frecuencia, entre quienes son activistas o militantes políticos. El otro de estos efectos es el que la tolerancia política ejerce sobre los exumos del sistema político. Las políticas públicas serían entonces consecuencia de la performance promedio de la sociedad en esta competencia cívica ${ }^{113}$.

La tolerancia política ha sido señalada como la promotora de la posesión de diferentes cualidades asociadas a otras competencias cívicas de las estudiadas en estas páginas. Se ha afirmado que la intolerancia política, propia de quienes detentan un carácter autoritario, puede ser la causante de proceso de inhibición psicológica que impide la incorporación de conocimientos sobre la realidad política (Peterson et al.,

111 Se observa, entonces, que existiría una relación circular entre democracia y tolerancia política. Mayores niveles de tolerancia fortalecen el carácter democrático de las sociedades y, a su vez, el ejercicio democrático incentiva la incorporación de pensamientos y prácticas de tolerancia política. Sobre este último hallazgo, hay quienes han llegado a una conclusión diferente: la tolerancia política no aumentaría como consecuencia de las transformaciones democráticas recién descritas sino que, por el contrario, la desaparición y/o reducción de los riesgos externos (grupos terroristas, guerrillas, partidos ubicados en los extremos del arco ideológico) es la que apareja el alza en la tolerancia política que caracteriza a los ciudadanos durante esos períodos de "entrenamiento democrático" (McClosky y Brill, 1983).

112 Según lo descrito por estos autores, a mayor éxito de opciones extremas, existe mayor tolerancia. En tanto, a mayor homegeneidad de los sistemas de partidos, se presentan menores niveles de tolerancia política.

${ }^{113}$ Estos trabajos recuperan un ya clásico aporte de Stouffer (1955) en base al cual se puede intuir que la legislación anticomunista que caracterizó a los Estados Unidos en tiempos de Macartismo pudo deberse a la presencia de marcados rasgos de intolerancia política entre los habitantes de este país. 
2002). Al mismo tiempo, en consonancia con lo sugerido por Gibson y Anderson, se ha descubierto que el desarrollo de la tolerancia política conduce a una mayor predisposición, por parte de los sujetos a, a la participación política tanto a través de mecanismos convencionales como de vías no convencionales (Togeby, 2004).

La inquietud, en ciencias sociales, sobre los niveles de tolerancia política ha conducido a la formulación de diferentes preguntas de investigación. La primera (y clásica) hace referencia a cómo ciertas variables sociodemográficas predisponen la posesión de determinados niveles de tolerancia política (Stouffer, 1955; Williams, Nunn y St. Peter; 1976). La segunda inquietud tiene por objeto observar cómo las características psico-sociales de los individuos, con autonomía de los rasgos sociodemográficos de los mismos sujetos, influyen en los niveles poseídos de esta competencia política (Hinckley, 2010).

La tercera pregunta se vincula a la detección de la brecha existente entre los niveles de tolerancia política que, teóricamente, dicen poseer los individuos y aquéllos que, efectivamente y ante situaciones prácticas, expresan ${ }^{114}$ (Corbett, 1982). A su vez, se ha desarrollado un interesante corpus de investigaciones en el que se intenta determinar cómo acontece la transmisión intergeneracional de pautas de (in) tolerancia política (Owen y Dennis, 1987). Otros autores se han preguntado cómo los contextos políticos (y los procesos que caracterizan a éstos) tienden a influir decisivamente en los niveles de tolerancia política expresados por los sujetos (Guérin, Petry y Crete, 2004; Marquart y Paxton, 2007).

Desde el punto de vista metodológico, la tolerancia política suele ser medida a través de encuestas en las que se interroga a los individuos sobre una batería de preguntas, respecto a cuál es su nivel de aceptación del pensamiento y/o actuación de grupos y/o personas ubicadas en sus antípodas ideológicas (Gibson, 1992). En un primer momento histórico, sólo se interrogaba a los sujetos sobre su nivel de tolerancia en relación a colectivos que, según el criterio del investigador, eran considerados marginales y/o peligrosos políticamente por la sociedad de entonces (generalmente ubicados a la izquierda ideológica). A posteriori, antes de expresar sus niveles de

\footnotetext{
114 Para el caso americano, las investigaciones han encontrado evidencia de que existe una diferencia substancial entre la tolerancia profesada y la practicada por los ciudadanos (Corbett, 1982; McClosky y Brill, 1983).
} 
tolerancia, los entrevistados debían reconocer cuáles son los colectivos que les desagradan para, luego, recién reconocer si les toleran o no. Ello permitió la "emergencia" de nuevos grupos no tolerados que la usanza previa imposibilitaba reconocer. La última es, en el presente, la práctica más extendida para la medición de la tolerancia política ${ }^{115}$. Otra evolución metodológica se observa en la inclusión de preguntas vinculadas a cuán aceptables los sujetos consideran las posiciones esgrimidas por grupos políticos ubicados en ambos extremos del arco ideológico ${ }^{116}$.

A su vez, la tolerancia política suele ser medida, en ciertas investigaciones, de manera complementaria y combinatoria a la tolerancia social y étnica (Bahry, Boaz y Gordon, 1997; Sniderman, Peri, de Figuieredo y Piazza, 2000; McIntosh, Maclver, Abele y Nolle, 1995). Ello se realiza, generalmente, apelando al recurso de pedirle al encuestado que se imagine en diferentes ( $y$, por otro lado, habituales) situaciones en las que debe autorizar (o no) que individuos pertenecientes a grupos étnicos o poseedores de cosmovisiones opuestas puedan proceder (actuar) según lo marcado por los estilos de vida/ ideas que se denosta (Owen y Dennis, 1987; Marquart y Paxton, 2007).

Con independencia de la inclusión o no de preguntas de corte social y/o étnico, las respuestas a los diferentes interrogantes (políticos, sociales, étnicos) suelen ser agrupadas y se procede a la creación de índices que tienen por objeto resumir el grado de tolerancia política atribuible a un sujeto ${ }^{117}$ (Gibson, 2005; Torney-Purta et al., 2007). La figura 1.5 muestra una síntesis gráfica de la relación existente entre las diferentes competencias cívicas y los distintos tipos de factores que las propician. La figura 1.6 muestra la relación causal existente entre las diferentes competencias cívicas.

\footnotetext{
${ }^{115}$ Según el criterio de Gibson (1992, 2005), el primer tipo de medición de la tolerancia política puede ser de relativa utilidad en estudios cross-sectional (por la comparación que implica, en un momento dado, entre sociedades de grupos tolerados y no tolerados) y el segundo tipo de estudios es más útil en estudios longitudinales (ya que permite descubrir la pauta de aparición y desaparición de grupos tolerados y no tolerados).

${ }^{116}$ En los primeros estudios realizados por la academia norteamericana sobre esta competencia cívica, sólo solían incluirse preguntas que hicieran referencia a agrupaciones políticas ubicadas en la izquierda ideológica extrema (comunismo). Con el tiempo, como consecuencia de la necesidad metodológica de extracción del "contenido o sesgo" a estas preguntas, esta práctica muta y comienza a interrogarse también acerca de lo qué se piensa respecto a las propuestas y conductas presentadas por la derecha ideológica extrema (Ku Klux Klan y adherentes al nazismo) (Sullivan, Piereson y Marcus, 1982).

117 Metodológicamente, la tolerancia política ha sido trabajada tanto de manera "dicotómica" como "continua".
} 


\section{4) La dimensión cívica de la inmigración. El cambio de sociedad y sus implicancias en materia de socialización política}

La teoría política sobre socialización política y la reflexión que se realiza sobre este proceso vital en el marco de la teoría del desarrollo cognitivo coinciden en que los individuos construyen su significado sobre el mundo político a partir de las interacciones que mantienen con diferentes agentes externos (Dennis, 1973). Las obras más clásicas de la filosofía occidental ya procedieron a la identificación, en la vida de todo sujeto, de diferentes experiencias formativas que conducen a la adquisición de diversas orientaciones y competencias cívicas ${ }^{118}$ (McDevitt y Chaffee, 2002). Como es sabido, a partir de edades muy tempranas, los sujetos construyen evolutivamente su propia perspectiva sobre lo político conforme son estimulados exógenamente. Este "aprendizaje inconsciente" es el que dota a los individuos de determinadas competencias cívicas que, latentes o semi-activas durante la adolescencia, adquieren forma definitiva en el momento de su conversión en ciudadanos con plenos derecho ${ }^{119}$.

Existen diferentes definiciones para el concepto de socialización política. Un grupo de ellas la describe como el proceso por el cual el contexto de inserción moldea a los personas en base a un modelo político previo, es decir, procurando la perpetuación del status quo. Expresiones como adoctrinamiento, aculturación, transmisión cultural y adopción de normas culturales han sido usadas, no sin sus paralelas críticas por la falta de una completa adecuación y por el sesgo conservador que asumen, como sinónimos de socialización política (Sears, 1975). En Ciencia Política, una clásica definición de este proceso es la que ofreció en su momento Langton $(1969$, p. 4) y que resulta útil por su simpleza y porque es fácilmente operable desde el punto de vista metodológico:

\footnotetext{
118 En el texto de "La República", Platón hablaba acerca de la factibilidad de la puesta en marcha de procesos de formación política que favoreciesen la conversión de los individuos en ciudadanos (McDevitt y Chaffee, 2002).

${ }^{119}$ La literatura no llega a un acuerdo en torno a si los niños presentan (proto) actitudes políticas. Sin embargo, sí se sostiene que la adolescencia es el tramo etario en el que se adquiere una visión compresiva y racional sobre lo vinculado al mundo de lo político (Youniss, McLellan y Yates, 1997).
} 
"...political socialization, in the broadest sense, refers to the way society

transmits its political culture from generation to generation..."120

Numerosos y diversos son los agentes que intervienen en el proceso de socialización política. Entre los, tradicionalmente, señalados por la literatura se encuentran el núcleo familiar, la escuela, el grupo de pares, el ambiente laboral y los medios de comunicación. Cada agente de socialización política, como se verá más adelante, opera con sus propios códigos y es responsable de transmitir diferentes activos cívicos a los individuos en distintos estadios vitales.

La actuación de tales agentes de socialización es especialmente relevante durante la niñez y la adolescencia. Son cruciales para la conformación de la identidad política. El desarrollo de la identidad política facilita, durante la madurez, la normal interacción con el resto de los actores existentes en la sociedad a la que se pertenece. Diferentes investigaciones han arribado a la conclusión de que la configuración de las raíces cívicas de ulteriores manifestaciones públicas (participación en organizaciones políticas, religiosas y comunitarias) de los individuos en la adultez se encuentra en este tramo etario.

Una batería de instrumentos ha sido creada de cara a proceder a la medición de la continuidad de los efectos cívicos de estas primeras etapas de aprendizaje político ${ }^{121}$ (Sears, 1975). Sus efectos son observados tanto en materia de actitudes políticas como (aunque con menor fuerza) en cuestiones vinculadas al comportamiento político. Su poder predictivo es más importante en relación a la presencia, durante la adultez, de pareceres específicos frente a objetos políticos también específicos que en vinculación a la posesión de marcos cognitivos amplios de interpretación de lo político (Sears y Levy, 2003).

\footnotetext{
${ }^{120}$ Como en el caso de la anterior, la definición ofrecida por Gustafsson (1987, p. 225) es también ilustrativa. Esta autora ha conceptualizado a la socialización política como "...(the) process through which young people become politically mature or socialized..." Otra definición, más reciente, que puede resultar esclarecedora es la ofrecida por Wei y Leung (1998, p. 377): “...a process in which political knowledge, beliefs, values and behaviour are learned socially...".

121 Entre las herramientas metodológicas que han sido aplicadas por las ciencias sociales en investigaciones a tales fines, destacan los estudios longitudinales, el uso de incentivos externos para obligar a los sujetos a la modificación potencial de sus orientaciones políticas, las comparaciones intergeneracionales y los análisis de cohorte (Sears, 1975).
} 
La adolescencia resulta también interesante, en términos de socialización política, porque es durante este período en el que se configura la matriz cívica de la próxima generación activa políticamente. Los sistemas políticos suelen sufrir modificaciones como consecuencia de las demandas cívicas exhibidas por la cohorte adulta. Por ello, la observación detenida del proceso de la socialización política entre adolescentes permite obtener información respecto a cuáles, eventualmente, serán las demandas a las que deberán dar respuesta en el futuro cercano los sistemas políticos. Consecuentemente, su estudio permite perfilar las eventuales reacciones que el sistema podría asumir frente a las inquietudes de los futuros ciudadanos (Hooghe, 2004).

A pesar del carácter central de la adolescencia como foco de estos estudios, el proceso de socialización política no se aparca durante este tramo etario. Superando antiguas posiciones que creían estables las orientaciones políticas de los sujetos a lo largo de sus vidas, se ha descubierto que las decisiones de los individuos y el devenir de su propia vida (factores internos) como modificaciones ambientales (factores externos) pueden propiciar alteraciones cívico-políticas ${ }^{122}$.

Acerca de los factores internos, debe decirse que a lo largo de sus vidas, los individuos no dejan de encontrarse expuestos a situaciones que les estimulan y confrontan cívicamente de manera diversa. La conformación de la propia familia ${ }^{123}$, el cambio de ambiente de trabajo, el ingreso o el retorno al mercado de trabajo, la asistencia a clubes deportivos, la militancia comunitaria y/o política, la mudanza a otra ciudad o el involucramiento en procesos migratorios internacionales, entre otros, pueden convertirse en contextos en los que los sujetos pueden reconstruirse cívicamente. Todos ellos proporcionan a las personas nuevas oportunidades de interacción con sus semejantes que permiten el desarrollo de también nuevas sensibilidades y estrategias cívicas.

\footnotetext{
122 Inicialmente, se creía que los cambios cívicos que acontecían durante la adultez eran mínimos. Con posterioridad, tal supuesto teórico se erradica y comienza a sostenerse que las alteraciones distan de ser menores. Para dar cobertura a este switch teórico, comienza a trabajarse con diseños de investigación que incluyen tres efectos/conceptos tradicionalmente trabajados en la Sociología: ciclo de vida, periodo histórico y generación (Niemi y Sobieszek, 1977).

${ }^{123}$ En tal sentido, se ha descubierto que los niños y adolescentes, como objetos de socialización política, también contribuyen a la modificación de las pautas cívicas de algunos de sus agentes socializadores (padres y/o tutores) (McDevitt y Chaffee, 2002).
} 
En relación a los factores externos que activan procesos de resocialización política, diferentes transformaciones sociales implican modificaciones en el perfil cívico de los individuos. El advenimiento de las sociedades post-industriales (con su consecuente redistribución laboral), las crisis económicas, los cambios de régimen, la superación de antiguos cleavages político-partidarios y la globalización, entre otros, modifican patrones cívicos actitudinales y comportamentales (Gustafsson, 1987). En relación al último de los fenómenos mencionados, la inmersión acelerada de las personas en el uso de las nuevas tecnologías evidentemente también posee efectos cívicos insospechados hace un par de años cuando no se disponía de tales portentos (McDevitt y Chaffee, 2002). En la próxima figura, es posible apreciar cuáles son los agentes y los procesos que contribuyen, a lo largo de la vida de los sujetos, a su socialización política.

Figura 1.7

Agentes y procesos involucrados en la socialización política

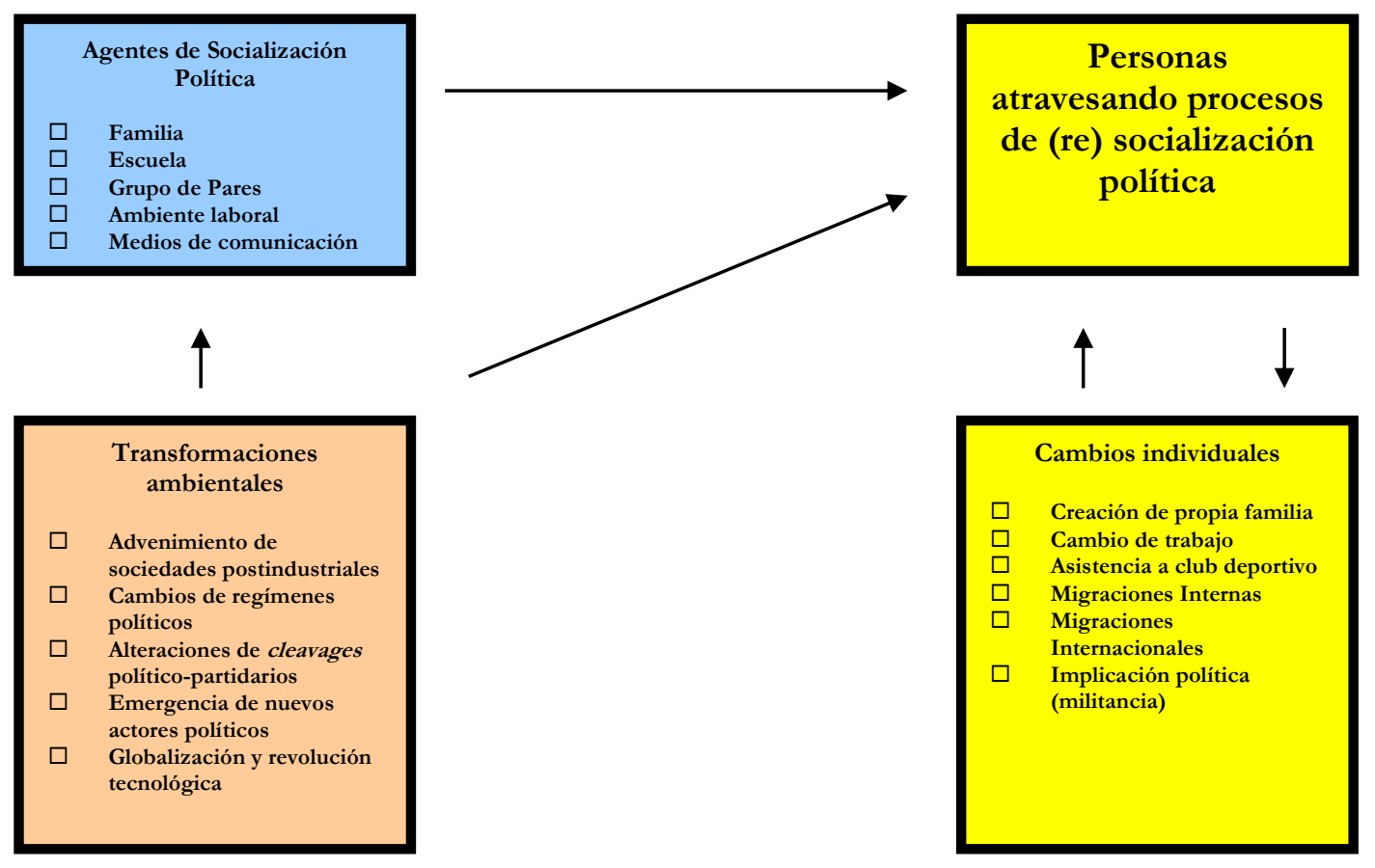

Fuente: Elaboración propia en base a la literatura sobre el tema. 


\section{1) El estudio de la socialización política en Ciencia Política. Una} propuesta de sistematización ${ }^{\mathbf{1 2 4}}$

Los inicios de las investigaciones en materia de socialización política se remontan a los trabajos, desde las ciencias de la educación, sobre los aspectos formales del entrenamiento cívico en el decenio de 1930 (Merriam, 1931). Posteriormente, una vez terminada la Segunda Guerra Mundial, Inkeles y Levinson (1954) intentaron averiguar cuáles eran los elementos que causaban que el carácter cívico difiriese entre las naciones. A su vez, a este grupo, pertenecen los trabajos de Newcomb (1943) sobre la formación de actitudes políticas. Tiempo después, la socialización política se consolida como una subdisciplina con nombre propio gracias a los aportes de Hyman (1959), Greenstein (1965), Hess y Torney (1967) y Easton y Dennis (1967) ${ }^{125}$. La impronta norteamericana de estos estudios resulta innegable (Niemi y Sobieszek, 1977).

En la Ciencia Política, existió un marcado propósito por desentrañar las características del proceso de socialización política hasta fines de la década de 1970. En ese momento, se tenía por objeto descubrir cómo acontecía la transmisión intergeneracional de las actitudes políticas y las pautas cívicas (Sears, 1975). Los esfuerzos de investigación se concentraron, fundamentalmente, en la pretensión de hallazgo de las influencias que, como agentes de socialización, ejercían la familia y la escuela sobre los jóvenes en la interiorización de las pautas cívicas prevalecientes (Jennings y Niemi, 1974).

\footnotetext{
${ }^{124}$ El presente apartado, por motivos de extensión, sólo menciona y sintetiza los principales aportes sobre la socialización política realizados a nivel internacional. Para conocer de manera sistematizada parte de lo trabajado sobre este tema en la academia española, se recomienda consultar el siguiente texto: Morán, M. L. (1999). Los estudios de cultura política en España. Revista Española de Investigaciones Sociológicas (85), 97-129. Contribuciones significativas en la materia han sido en este país, en orden cronológico, la de Manuel Ramírez (1980) sobre la relevancia de una correcta gestión de la socialización política en tiempos de transición a la democracia, la de Manuel Justel (1992) sobre las diferencias entre cohortes en materia de actitudes políticas, la Manuel Salguero (1997) sobre la construcción de lealtad ciudadana mediante la educación hacia las reglas democráticas o la María Jesús Funes (2003) sobre los vínculos entre socialización política y participación. Una cuantía importante de lo producido sobre socialización política en el contexto hispano se ha dado en el marco de la Historia. Fundamentalmente, tal producción se ha centrado en el modo en el que se dio la manifestación de estos procesos tanto en dictadura como en democracia (Gallego, 1982; Cámara, 1984; Ruiz, 1996; Boyd, 1999; Mayordomo, 2000; Fernández, 2003). ${ }^{125}$ El primero de estos autores sistematizó lo trabajado hasta el momento sobre socialización política. Los otros se dedicaron a estudiar el desarrollo, a lo largo de la escuela elemental, de las actitudes políticas en niños.
} 
Por detrás de estas investigaciones, existía la preocupación, derivada de la influencia de la teoría sistémica, por desentrañar los mecanismos a través de los cuales se lograba la estabilidad política. En concreto, estos estudios incluían preguntas tendentes a averiguar cuáles eran las actitudes que los sujetos de una y otra generación expresaban hacia diferentes instituciones políticas $y$, consecuentemente, qué tipo de coincidencias era posible descubrir (Sapiro, 2004). En este contexto, la socialización política era considerada un proceso jerárquico en el que a sus receptores (o socializados) no se les reconocía autonomía en su propio desarrollo cívico. Todas las responsabilidades cívicas recaían en las llamadas instituciones tradicionales (familia y escuela) (Niemi y Hepburn, 1995; McDevitt y Chaffee, 2002).

Paralelamente, en aras de profundizar en la detección de perfiles diferenciados de socialización política, se procedió a estudiar las divergencias y convergencias existentes entre los distintos grupos étnicos (blancos, afroamericanos y chicanos o mexicano-americanos) (Abramson, 1977; Garcia, 1973) y en función de la ubicación geográfica de los individuos (Hirsch, 1971). A su vez, por el mismo motivo, acontece la internacionalización y la aplicación de la perspectiva comparada a estas investigaciones (Torney-Purta, Oppenheim y Farnen, 1975). También, durante este periodo, se comienza a discutir respecto a la idoneidad de los diseños metodológicos para la obtención de información sobre la socialización política (Niemi, 1974; Niemi y Sobieszek, $1977)^{126}$.

Sin embargo, luego de este fructífero período, hubo un relativo desinterés, en los estudios politológicos, por el conocimiento de las transformaciones cívicas que acontecen a lo largo de la adolescencia y la juventud temprana. La socialización política, entonces, fue apartada temporalmente de la agenda oficial de estudios de la Ciencia Política (Gustaffsson, 1987). Diferentes razones se han esgrimido para justificar tal viraje. Se encuentran quienes consideran que ello es debido a que este grupo etario, por un lado, había presentado reducido nivel de incursión en lo político en las sociedades occidentales y, por otro lado, solía ser poseedor de actitudes políticas carentes de plena coherencia (Breakwell et al.; 1989).

\footnotetext{
${ }^{126}$ Niemi y Sobieszek (1977), en su crítica a la metodología de los estudios sobre socialización política, llegaron a afirmar que los mismos hacían uso reiterado de estrategias de medición que fueron innovadoras en el momento que fueron aplicadas por primera vez pero que, a posteriori, carecieron de tal carácter.
} 
Jennings (2007) sostuvo, sobre esta cuestión y teniendo en mente el caso norteamericano, que los mismos niños y adolescentes que parecían cuadrar "políticamente" con sus padres a mediados del siglo XX fueron los que iniciaron tanto las protestas anti-bélicas como las manifestaciones en pro de los derechos civiles que caracterizaron el decenio de 1960. Esta aparente inconsistencia impedía, en el criterio de muchos, la detección adecuada de los vínculos empíricos existentes entre las actitudes y los comportamientos políticos en las nuevas generaciones. Sobre los motivos de esta súbita desaparición, Connell (1987) consideró que se debió a dos debilidades estructurales de los mismos. Una de ellas era de tipo metodológico: los resultados generados eran asumidos imperativamente como válidos y no existía posibilidad alguna de discutirlos. La otra era de naturaleza teórica: estas investigaciones eran acrítica y rígidamente funcionalistas.

Sin embargo, desde otras ciencias sociales, no se partió de idénticos supuestos y se logró desarrollar un aparato teórico y metodológico dedicado a desentrañar las particularidades de la formación, durante la adolescencia, de las competencias cívicas ${ }^{127}$ (Barber, Fennelly y Torney-Purta, 2013). Sumado a ello, la creciente desafección política evidenciada en diferentes democracias occidentales ha conducido a que académicos y hacedores de políticas públicas renueven su interés por identificar cuáles son los factores conducentes a la elevación de los atributos políticos en los jóvenes y, de esa manera, lograr asegurar la existencia de un capital cívico crítico cuando los mismos se conviertan en ciudadanos al acceder a la mayoría de edad ${ }^{128}$ (Putnam, 2000).

Ambas situaciones (el mantenimiento de la adolescencia como objeto de estudio en otras disciplinas con interés en lo político y la aparición de la preocupación por el perfil cívico de los futuros ciudadanos) han provocado que la Ciencia Política vuelva a dedicar esfuerzos para generar información sobre las actitudes políticas de población no adulta y en relación a cómo diferentes agentes de socialización política podrían estar

\footnotetext{
${ }^{127}$ La Psicología Política y la Psicología del Desarrollo son ejemplo de disciplinas que mantuvieron el interés por la cuestión. Sobre esta divergencia de intereses, resulta interesante mencionar que mientras Niemi y Sobieszek recomendaban en 1977 desde la Ciencia Política descartar el estudio de las actitudes políticas de los pre-adolescentes porque estos carecían de la habilidad cognitiva, la Psicología del Desarrollo se pronunciaba en sentido contrario.

128 Jennings (2007) agrega otra razón tras el reverdecer de los estudios sobre socialización política: la irrupción de regímenes democráticos en diferentes países no occidentales. Desde el punto de vista metodológico, este autor opina que la multiplicación de los estudios de panel también ha favorecido la resurrección de estas investigaciones.
} 
influyendo en la cuestión ${ }^{129}$ (Verba et al.; 1995). Estos estudios se han encontrado, frecuentemente, asociados a la evaluación de programas o estilos pedagógicos que tienen por objeto elevar las competencias cívicas de quienes participan en ellos y a la indagación sobre los efectos de las actividades extra-curriculares y de experiencias de aprendizaje-servicio (Jennings, 2007).

Al mismo tiempo, como la definición misma de cultura política fue complejizándose según ha pasado el tiempo, el interés primigenio de la Ciencia Política por la transferencia intergeneracional de los sentimientos y actitudes de los sujetos hacia las instituciones políticas ha dado lugar a la preocupación por generar datos, en clave inter-generacional pero también inter-contextual, sobre otro tipo de conceptos. Entre ellos, cabe hacer mención de los estudios sobre valores materiales y postmateriales y en relación a competencias cívicas (Inglehart, 1988; Mclntosh et al., 2007). La búsqueda de la detección de continuidades y discontinuidades entre individuos pertenecientes a diferentes generaciones y contextos (geográficos 0 culturales) es un elemento recurrente en este tipo de investigaciones.

Este reencuentro entre la Ciencia Política y los estudios de socialización política ha dado lugar al abandono de antiguas creencias y a la generación de nuevas posturas. En tal sentido, la comprobación del deterioro en la perfomance cívica de las nuevas generaciones (en contraste con las previas) de jóvenes y el distanciamiento de sus perfiles cívicos de aquél registrado entre sus progenitores han obligado a matizar el histórico supuesto por el cual la familia era considerada correa transmisora y agente cívico fundamental. Dos posiciones se han erigido de cara a sugerir qué lectura debe hacerse de este aparente progresivo des-emponderamiento cívico ${ }^{130}$. A pesar de diferir en la lectura del diagnóstico de los actuales jóvenes, ambas posiciones asumen que los

\footnotetext{
${ }^{129}$ Los intereses teóricos de la Ciencia Política, de la Psicología Política y de la Psicología del Desarrollo, en relación a la socialización política, suelen diferir. Mientras que a la primera le interesa generar información sobre actitudes políticas de los individuos para luego vincularlas con la estabilidad y salud de los regímenes democráticos, las últimas buscan crear conocimiento sobre el progreso de los individuos a lo largo del proceso de socialización.

${ }^{130}$ El hallazgo de cierto deterioro en la perfomance cívica de los jóvenes en determinados sistemas políticos (como el estadounidense) no debe necesariamente entenderse como extendible a otras realidades. Para llegar a conclusiones como éstas, los estudios cross-sectional no son suficientes sino que se requiere de comparación entre cohortes (generaciones) en el marco de series temporales. La carencia de este tipo de datos reduce el universo de países en los que pueden hacerse estudios con estas características.
} 
sistemas políticos, de persistir estas tendencias cívicas, deberán adaptarse para no contrariar las expectativas ciudadanas y poder lograr sobrevivir (Hooghe, 2004).

Por un lado, se encuentran quienes expresan marcada preocupación debido a que los jóvenes contemporáneos presentan mayores dosis de cinismo político, desconfianza hacia las instituciones políticas y desinterés cívico que los miembros de las cohortes previas. Al interior de esta posición, hay quienes esgrimen que esta situación es consecuencia de que, en ocasiones, los "arreglos institucionales" desestimulan el involucramiento cívico de las nuevas generaciones (Dalton, 2002).

Por otro lado, se encuentran quienes creen que los jóvenes, si bien más escépticos que en el pasado, encauzan ahora sus inquietudes cívicas a través de manifestaciones menos formales (participación en conciertos temáticos, vestimenta de prendas con consignas políticas, boicoteo a productos cuyo background político se desaprueba, entre otros) que las tradicionalmente aceptadas (O'Toole, Lister, Marsh, Jones y McDonagh, 2003). Al mismo tiempo, en su defensa de los rasgos cívicos de las nuevas generaciones, estos autores recuerdan que los jóvenes reconocen ser más activos cívicamente, admiten ser más tolerantes y adhieren en mayor medida a los valores democráticos que las cohortes precedentes (Norris, 1999).

Debe decirse que, a pesar de que la Ciencia Política ha reorientado su interés en este tipo de investigaciones, en ciertos estudios actuales sobre cultura política, no se hace referencia explícita a los procesos de socialización que ofician de marco de los fenómenos abordados (la inmigración, entre otros) (Jennings, 2007). Ello se vincula a que, en determinados círculos académicos politológicos, sigue existiendo una tendencia a la subestimación del estudio de este tipo de procesos. Esta área de estudios suele ser infravalorada porque, para algunos, se encuentra vinculada a la investigación sobre "adolescentes y escuelas". En relación al rechazo en ciertos espacios de la disciplina de los estudios sobre individuos no adultos, Torney-Purta (2004, p. 471) ha expresado que los "...political scientists have to be convinced that anything happening before age 18 makes a difference" ${ }^{131}$

\footnotetext{
${ }^{131}$ Sobre la incomprensible resistencia encontrada en ciertos círculos para con el estudio de la socialización política, ya advertía David Easton en 1957 (p. 398): “...the study of the political experiencies of and the influences operating on the child and the adolescent emerges as an important and neglected área of research...". El hoy clásico autor llamaba politización (politicization) a la socialización política".
} 
A su vez, como la naturaleza de los estudios sobre socialización es profundamente interdisciplinar, el motivo de su rechazo por parte de algunos círculos politológicos reside precisamente en el desconocimiento de los posibles canales de diálogo entre las diferentes ciencias sociales preocupadas por estos procesos. A pesar de ello, muchas de las ideas asociadas al concepto de socialización política sí se encuentran presentes en diferentes estudios camufladas detrás de razonamientos y supuestos que reconocen la existencia de agentes socializadores que propician la adquisición, por parte de los sujetos, de determinadas pautas cívicas o actitudes políticas en detrimento de otras.

Tanto en los estudios contemporáneos en los que se hace mención explícita de su intento de abordaje de la socialización política como en los que no, se asumen tres puntos de partida. El primero de ellos es que la comprensión de la misma contribuye a arrojar luz sobre el futuro curso de la vida institucional de las sociedades (Dalton, Cain y Scarrow, 2003). El segundo entiende que la socialización política, a diferencia de cómo era entendida antaño, es un proceso inter-relacional, es decir, sus destinatarios son a la vez moldeadores cívicos de sus agentes externos (Bodman y Peterson, 1995; McDevitt y Chaffee, 2002).

El último de los rasgos propios de los abordajes actuales es que, distanciándose de los estudios primigenios sobre socialización política, se ha profundizado en la indagación de nuevas variables no sólo a nivel de adolescentes sino también referidas a informantes clave pertenecientes a su entorno (padres, profesores, directivos de escuela, etc.). Estos datos contextuales son, en el criterio de Jennings (2007), fundamentales en las investigaciones contemporáneas. Finalmente, este autor (con una vasta y reconocida trayectoria en la materia), en el cierre a su aportación sobre el tema en el The Oxford Handbook of Political Behavior de 2007, concluye con una afirmación que justifica el emprender una investigación como la descrita en estas páginas. Sostiene que existe un marcado déficit en los estudios sobre los procesos de socialización política: el referido a las investigaciones sobre los cambios que atraviesan los inmigrantes en las sociedades de acogida (tanto población adolescente como adulta) ${ }^{132}$.

\footnotetext{
${ }^{132}$ La investigación relatada en estas páginas tiene por objeto contribuir a la reversión de la carencia descrita mediante el uso de una estrategia de recolección y análisis de datos que, centrándose en los adolescentes, también incorpore información sobre agentes contextuales (familia y escuela).
} 


\section{2) El primer aprendizaje cívico: la familia como agente de socialización política ${ }^{133}$}

En relación al agente de socialización originario, la teoría sostiene que el desarrollo cívico de una persona acontece cuando las generaciones precedentes le transmiten sus conocimientos, valores y comportamientos políticos. En este proceso genésico, los adultos de referencia desempeñan un rol protagónico del cual no son siempre conscientes. La transferencia no automática por parte de éstos, de su cosmovisión cívica, es la base primigenia sobre la que los sujetos construyen su particular comprensión del mundo de lo político (Dudley y Gitelson, 2002). Es, en el contexto familiar, en el que los sujetos adquieren las primeras nociones respecto a sus derechos y obligaciones (conceptos sobre los cuales se construye la ciudadanía) y las primeras ideas sobre cómo los mismos se materializan en sus relaciones con sus seres queridos (McIntosh, 2006).

La familia es el núcleo en el que, por acontecer en su seno los primeros aprendizajes cívicos, se configura el nivel de adhesión que las personas expresarán durante su adultez hacia las instituciones y autoridades políticas. Desde la perspectiva sistémica, las actitudes políticas que en ella se adquieren pueden contribuir decisivamente a la estabilidad de los sistemas políticos democráticos (Easton, 1957; Easton y Dennis, 1967). Por eso, los primeros esfuerzos científicos por desentrañar la naturaleza de los procesos de socialización política se concentraron, casi exclusivamente, en el estudio del rol del núcleo familiar como agente conformador de pautas cívicas.

En concreto, la Ciencia Política, la Sociología Política y la Psicología Política descubrieron, tempranamente, que ciertas actitudes políticas de los hijos son réplica de aquéllas presentadas por sus padres. Esta coincidencia actitudinal se acentúa, según estos primeros estudios, en cuestiones vinculadas al voto, es decir, progenitores y vástagos admiten votar por idénticos partidos y candidatos políticos. La semejanza

\footnotetext{
${ }^{133}$ El presente apartado, por motivos de extensión, sólo menciona y sintetiza los principales aportes sobre la familia como agente de socialización política realizados a nivel internacional. En el caso concreto de la sociedad española, véase Ramos (1990) y Jaime (2000)
} 
también se presentaba en materia de apoyo al gobierno, apego al país y respeto por la autoridad (Jennings y Niemi, 1974).

En estos primeros estadios del estudio de la socialización política, los niños y adolescentes eran considerados meros objetos receptores (al modo de tábulas rasas) de influencias cívicas externas en el marco de procesos "top-down". Tal consideración respondía a la preocupación antaño existente respecto a la necesidad de inculturación política de las nuevas generaciones para que, a posteriori, ello repercutiese de manera positiva tanto en su desempeño cívico individual como en la fortaleza global de los sistemas políticos democráticos.

Sin embargo, los niveles de coincidencia mencionados no se repetían en materia de opinión sobre temas de naturaleza política distintos a los enunciados (por ejemplo, el parecer de cada quien sobre determinada política pública). En tal sentido, los hijos tendían a repetir actitudes de sus responsables a cargo cuando éstas eran estables y cuando las mismas eran similares entre padre y madre (si es que existía presencia de ambos). Inicialmente, se creyó que las figuras paternas (o masculinas) eran más decisivas a la hora de transmitir pautas políticas. Con el tiempo, se descubre que, por el contrario, las madres son quienes más influyen en el perfil cívico de sus hijos (Dowse y Hughes, 1971; Sears, 1975).

En los primeros estudios sobre la familia como agente socializador, se buscaba la presencia de similitudes/disimilitudes en los valores manifestados por padres e hijos. A posteriori, el modo en el que está compuesta la familia y la naturaleza de sus dinámicas internas comienzan a ser considerados de cara a observar cómo actuaban en la trasmisión intergeneracional de pautas cívicas. Se descubrió que las familias en las que la existe sobreprotección provocarían mayor desafección y desconfianza política entre sus hijos. También, se identificó que las familias monoparentales producirían, entre los vástagos, mayor afinidad por los valores autoritarios y menor interés político que las familias nucleares. A su vez, se halló que la naturaleza de la comunicación al interior de la relación parecería ser un factor que influía decisivamente en el nivel de acuerdo, entre generaciones, de las actitudes políticas (Niemi y Sobieszek, 1977).

Conforme los métodos de recolección y análisis de datos fueron refinándose, la influencia de la familia como factor socializador político único comienza a ser discutida. Esta evolución metodológica implicó el abandono paulatino de los diseños de 
investigación en los que los adultos, apelando a su memoria, eran interrogados sobre las actitudes políticas de sus progenitores y tutores (Hess y Torney, 1967; Sears, 1975). Tales diseños de investigación fueron sustituidos por otros en los que las unidades de análisis eran niños o adolescentes y sus responsables a cargo. En estos estudios, se procuraba obtener información también sobre eventuales agentes de socialización política ajenos a la familia ${ }^{134}$. De esa manera, la comparación de los registros entre las diferentes cohortes se daba en base a información real y no supuesta (Jennings y Niemi, 1968; Torney-Purta et al., 2007).

Conforme el estudio de la socialización política fue expandiéndose, no sólo la familia dejó de ser considerada el agente socializador por antonomasia sino que también se descubrió que, a su interior, la causalidad no resultaba ni tan clara ni tan lineal como se suponía (Merelman, 1973; Westholm, 1999). A pesar de que la dirección causal "padres sobre hijos" es la que, en mayor medida, es apuntada por la literatura como la correcta, recientes estudios han señalado que, en ocasiones, la inmersión de los niños y/o adolescentes en procesos cívicos puntuales (programas escolares) puede derivar en la transmisión de habilidades cívicas de éstos a sus padres y/o tutores ${ }^{135}$ (Comber, 2006).

Los adolescentes realizan, en las circunstancias antes descritas, reflexiones conscientes sobre la dimensión cívica de sus vidas (Yates y Youniss, 1998; McDevitt y Chaffee, 2002). Ello origina un proceso "trickle-up" de adaptación familiar consistente en la pretensión, por parte de padres y/o tutores, para conservar su liderazgo en materia cívica. De esa manera, un agente externo a la familia (el sistema educativo), a través de la promoción de la discusión sobre temas políticos y de otros mecanismos, contribuye a que aquélla continúe siendo una transmisora eficaz de ciudadanía y, al mismo tiempo, facilita el mantenimiento de su cohesión y autonomía.

El carácter inter-relacional de la socialización política al interior de la familia implica que, en el caso de los adultos que no hayan adquirido suficientes competencias

\footnotetext{
${ }^{134}$ Desde este momento, la escuela fue considerada el complemento perfecto, en materia de socialización política, de la familia. A su vez, se inician los estudios sobre la eventual influencia de otros agentes de socialización política (medios de comunicación, ámbito de trabajo, etcétera) en las características cívicas de los sujetos.

135 Otros agentes externos, más allá de la escuela, pueden propiciar también la activación de este círculo cívico virtuoso. El caso del grupo de pares puede resultar de particular importancia. Los jóvenes, en el marco de grupos compuestos por personas pertenecientes al mismo tramo etario, construyen cosmovisiones políticas compartidas que tienden a desafiar a las propuestas por las generaciones precedentes.
} 
cívicas en su niñez y adolescencia, tengan una (o varias) segunda(s) oportunidad(es) para ello. Esto, en consecuencia, obliga a que las instituciones educativas prevean el diseño e implementación de programas de docencia y aprendizaje cívico que sean "conscientes" de sus efectos no sólo en los niños y adolescentes directamente implicados sino, también, en sus entornos familiares.

\section{3) El aprendizaje cívico influenciado indirectamente por el}

\section{Estado: la escuela como agente de socialización política ${ }^{136}$}

La escuela es otro de los principales agentes de socialización política. Al interior del sistema educativo (independientemente del estadio formativo en el que se encuentren los individuos), se refuerzan teóricamente los conocimientos sobre los componentes básicos de la ciudadanía y se les permite su aplicación en un contexto diverso (con personas diferentes). En este marco, los lazos afectivos se construyen evolutivamente (y no innatamente como puede, generalmente, darse en el caso de las familias). La función de socialización política que se le atribuye al sistema educativo, si bien asociada generalmente a regímenes democráticos, no es privativa de los mismos. En tal sentido, diferentes tipos de regímenes buscan predisponer cívicamente, según sus particulares intereses, la conducta de sus gobernados ${ }^{137}$ (Capel, Leask y Turner, 2009; Davies, 2010).

La escuela, en una sociedad democrática, tiene por objeto dotar a sus destinatarios del conocimiento, la capacidad de comprensión y las herramientas necesarias para ejercer un rol activo en la vida pública. Tan relevante es considerado el papel de la educación escolarizada en el proceso de socialización política de los

\footnotetext{
${ }^{136}$ El presente apartado, por motivos de extensión, sólo menciona y sintetiza los principales aportes sobre la escuela como agente de socialización política realizados a nivel internacional. En el caso concreto de la sociedad española, aportes interesantes sobre la cuestión son los trabajos de Mata, Lavia y Alkorta (2007) y Guichot-Reina (2011).

${ }^{137}$ En el caso de los regímenes democráticos, se supone que la función socializadora de la escuela debe tender a elevar las competencias cívicas de los ciudadanos de cara a fortalecer la vitalidad de esta forma de gobierno. Por el contrario, en el caso de regímenes dictatoriales, la escuela suele socializar políticamente a través de la exaltación del comandante en jefe o de los rasgos especiales atribuidos a la casta o sector dominante. Se pretende, a través de esto, perpetuar la idea entre los súbditos de la necesaria dependencia del pueblo para con la autoridad.
} 
individuos que, en ocasiones, es equiparado con el concepto mismo de ciudadanía (Gearon, 2010). Al respecto, Crick (2004, p. 2) sostiene:

"...citizenship can refer to an educational process; learning and teaching in schools and colleges show how to improve or achieve the aims inherent in the second and third meanings ${ }^{138}$..."

La impartición de conocimientos cívicos y la difusión de habilidades cívicas en el sistema educativo asumen una naturaleza dual. Por un lado, los mismos son ofrecidos de manera transversal en todo el curriculum académico (formal e informal) y, por el otro, existe una tradición arraigada de creación de asignaturas enfocadas específicamente en la dimensión política de la vida en sociedad. El primero de los abordajes descritos es aquél que acontece a lo largo de la permanencia de los individuos en las diferentes instancias del sistema educativo. Al ser la escuela una versión reducida de la vida en sociedad, las situaciones políticas son recurrentes y el modo en el que se les trata, tanto dentro como fuera de las aulas, va permeando cívicamente en los sujetos. A ello, se le adiciona el hecho de que la presencia de conceptos políticos, al exceder a las materias especialmente designada a tales efectos, obliga a la reflexión y a la toma de posturas en otros espacios curriculares.

Cuando las escuelas socializan políticamente a través de la inclusión de módulos formativos puntuales, los mismos suelen recibir la denominación genérica de "Educación para la Ciudadanía"139. Estas asignaturas suelen pivotear en base a cuatro tipos diferentes de contenidos: información sobre la forma de Estado y el sistema de gobierno (1) ; introducción de y discusión sobre los conceptos cívicos fundamentales

\footnotetext{
${ }^{138}$ Cuando el autor hace referencia aquí al segundo y tercer significado de ciudadanía, recuerda que la misma puede hacer alusión, respectivamente, tanto al pensamiento específico (republicanismo cívico) que sostiene que la participación activa de los individuos favorece la salud de los regímenes democráticos como al ideal de ciudadanía global o conjunto de premisas que tiene por objeto reconocer que todos los seres humanos somos ciudadanos de un único mundo (Crick, 2004).

${ }^{139}$ Las denominaciones que recibe esta asignatura pueden variar de un país a otro o de una región a otra (Formación Ética y Ciudadana, Educación Cívica, Instrucción Cívica, entre otros). Sin embargo, en todos los casos, se hace referencia a su carácter de espacio creador, transmisor y reflexivo de las necesarias competencias cívicas para el normal desarrollo de la vida de los individuos en sociedad. En el caso concreto de España, la creación de la asignatura "Educación para la Ciudadanía" es reciente. Hasta su creación, sus contenidos se encontraban dispersos en diferentes asignaturas (Historia, Geografía, Filosofía, etc.).
} 
(2); datos sobre eventos históricos dotados de relevancia política (3) y exposición sobre los principales "issues" políticos contemporáneos (4). Los primeros dos ejes son trasmitidos para que los individuos conozcan las reglas de juego políticas a las que deben atenerse. En el caso de los conceptos cívicos (democracia, justicia, identidad, diversidad, entre otros), a su vez, se pretende que sean incorporados como los cimientos en base a los cuales las personas deben construir su cosmovisión política. Los anteriores ( 1 y 2 ) asumen una naturaleza procedimental y su conocimiento es necesario para que los segundos ejes ( 3 y 4), de carácter sustantivo, puedan ser efectivamente aprendidos por los sujetos (Davies, 2010).

En relación a los conceptos cívicos (segundo tipo de contenidos impartidos por estas asignaturas) que mayor presencia tienen en el diseño curricular contemporáneo de estos cursos, debe hacerse mención de tres conjuntos diferenciados (Peterson, 2008):

Tradicional Antinomia/Complementariedad de los conceptos de derechos y obligaciones y su imbricación en la definición del concepto de ciudadanía ${ }^{140}$. Al respecto, se trabaja a partir de la idea que la escuela como agente de socialización política debe lograr que los sujetos tengan plena conciencia sobre la posesión de ambos atributos y procedan a su efectiva aplicación. Ello los convierte en competentes cívicamente.

Transformación de las identidades cívicas tradicionales ${ }^{141}$ como consecuencia de la diversificación (cultural, étnica, religiosa, sexual, etc.) de las sociedades. Sobre ello, se considera que el sistema educativo como agente de socialización debe incorporar la faz cívica de diferentes situaciones antes ignoradas en estos espacios curriculares (feminismo, movimientos migratorios, movimientos LGTB, etc.).

\footnotetext{
140 Mientras el primero de estos conceptos procede del universo filosófico del liberalismo, el segundo proviene de la cosmovisión predicada por el republicanismo cívico. Ambas tradiciones teóricas son las que han nutrido tradicionalmente al diseño de propuestas pedagógicas en el campo de la formación ciudadana (Davies, 2010).

${ }^{141}$ En este caso, por tradicionales, se hace referencia a la descripción que estas asignaturas solían hacer del "ciudadano promedio" como poseedor de los rasgos propios de los grupos que constituyen la mayoría social. En la actualidad, en estos espacios, la tendencia es describir a los ciudadanos desde una pauta en la que prime la mención de la diversidad existente en la sociedad.
} 
Superación de la idea del Estado-Nación como único interlocutor cívico válido de los individuos. En los recientes abordajes sobre la materia, la educación formal como agente socializador pretende que los sujetos sean empoderados cívicamente en relación a instancias políticas supranacionales, infranacionales y binacionales (condición ciudadana compartida ante dos Estados como consecuencia del involucramiento en procesos migratorios).

El tercer tipo de contenidos, antes mencionado y trabajado en estas asignaturas, tiene por objeto adquirir entrenamiento para valorar decisiones políticas históricas (tomadas en el pasado) y, de esa manera, iluminar retrospectivamente la actualidad política. La incorporación del último tipo de contenidos tiene por objeto cultivar cívicamente a los educandos para que éstos tengan las capacidades de comprender cuáles son los principales debates políticos actuales, interpretar qué esgrimen en los mismos los principales contendientes (o bandos), estimar cómo las discusiones políticas pueden afectarles y, por último, evaluar cuáles podrían sus posibles actuaciones como ciudadanos para influir en tales disputas.

Sumado a la presencia transversal de los contenidos cívicos en la currícula educativa y a la existencia de asignaturas especialmente creadas a tales efectos, existe otra manera en la que el sistema educativo coadyuva en la socialización política de los sujetos. Es la que se materializa en el "aprendizaje-servicio" (Rice y Brown 1998). Esta es complementaria de las dos previas ${ }^{142}$. Este enfoque pedagógico tiene por objeto concienciar a los estudiantes, a través del desarrollo de actividades en las comunidades a las que pertenecen, sobre diferentes problemas sociales y acerca de las acciones que pueden ejecutarse para superarlos.

El "aprendizaje-servicio" puede incorporar o no un componente reflexivo. En algunos casos, luego del desarrollo de los trabajos asignados, los estudiantes reflexionan, bajo la coordinación de un docente, sobre el origen del problema social sobre el que se ha actuado y sobre la naturaleza de la respuesta que se le ha ofrecido. En otros casos, este componente reflexivo no se encuentra tan explícito a pesar de que, se supone, los alumnos lo desarrollan por su cuenta. Un efecto positivo de esta

142 Por su especial naturaleza, el "aprendizaje-servicio" puede complementar la actividad cívicopedagógica llevada a cabo tanto en el marco de propuestas transversales como en el contexto de una asignatura específica. Por tal motivo, no se le considera en este texto como una tercera vía stricto sensu en la cual el sistema educativo desarrolla su función de socialización política. 
estrategia pedagógica es que facilita que los jóvenes asuman, antes de lo determinado por su reloj biológico, sus responsabilidades (derechos y obligaciones) ciudadanas. Esta práctica pedagógica ha sido pensada para empoderar políticamente a quienes participan en ella y para dotarlos de diversas competencias cívicas. La evidencia empírica respalda este supuesto teórico (Waldstein y Reiher, 2001; Huebner, 2003).

Independientemente de los mecanismos a través de los cuales el sistema educativo socializa políticamente a los individuos, los especialistas en la materia acuerdan en que este proceso no es nunca equilibrado ideológicamente. En otras palabras, muchas de las críticas que se le son dirigidas a la escuela como agente socializador se vinculan a su carácter no neutral ${ }^{143}$ (Arthur, Davies y Hahn, 2008). La pedagogía de la liberación ha reflexionado al respecto. Desde la perspectiva de los críticos, en términos de formación de ciudadanos, el sistema educativo puede estimular la presencia de personas sumisas e inmovilizadas frente al poder constituido o, por el contrario, puede liberar el potencial cívico de quienes son el objeto principal de sus acciones (Freire, 1975).

En aras de evaluar la influencia de diferentes modelos pedagógicos en la adquisición de competencias cívicas por parte de los individuos, los cientistas sociales diseñaron investigaciones en las que se buscaba identificar el rol jugado, en tal sentido, por diferentes atributos escolares: tipos de itinerarios formativos, rasgos de los cursos cívicos, carácter público o privado del centro educativo, modos de aplicación de los recursos didácticos, desarrollo de actividades extracurriculares, entrenamiento y calidad del personal docente, etc. (Ziblatt, 1965; Hess y Torney, 1967; Langton y Jennings, 1968; Ehman, 1969). En un principio, los hallazgos eran claramente contrarios a la existencia de influencia de la escuela en las orientaciones políticas de los sujetos ${ }^{144}$.

\footnotetext{
143 En determinadas circunstancias de tensión política, ciertos sectores suelen considerar que existe apropiación ideológica por parte del gobierno de turno de la función de socialización política ejercida por el sistema educativo. Ejemplos recientes de este tipo de procesos pueden encontrarse en Venezuela (luego de la aprobación del Decreto № 1011 en el año 2000) y en España (luego de la inclusión en la currícula de la enseñanza media de la asignatura "Educación para la Ciudadanía" en el año 2007).

144 Langton y Jennings (1968) concluyeron que los cursos cívicos en la escuela secundaria, para el caso de los Estados Unidos, no ejercían un efecto global sobre las orientaciones políticas de los estudiantes. Sin embargo, al analizarse colectivos poblacionales por separado, sí encontraron un efecto positivo en el grupo de afroamericanos. Para estos, la educación cívica les reportaba información con la que no habían entrado en contacto previamente. En tanto, Niemi y Sobieszek (1977) sugirieron que esta ausencia de evidencia empírica se debe atribuir a que los sujetos sometidos a estudio durante este periodo (cursando, fundamentalmente, estudios secundarios) se encontraban aun conviviendo con sus familias de origen. Ello, en su criterio, menguaba cualquier influencia socializadora ajena a la de la familia.
} 
Sin embargo, tiempo después, diferentes investigaciones comenzaron a avalar la naturaleza "políticamente socializadora" de la escuela. Grossman (1974) detectó que la percepción, por parte de los estudiantes, de climas de apertura en la escuela contribuía a que los alumnos declarasen ser más tolerantes. Goldenson (1978) halló evidencia en relación a que los colegios provocaban la adquisición de competencias cívicas por parte de los adolescentes y complementaban, de esa manera, a las adquiridas a través de la vía familiar. Lee Ehman (1980) encontró fundamentos para afirmar que la currícula escolar ejercía un efecto positivo sobre el nivel de conocimiento político declarado por los estudiantes. Al mismo tiempo, este autor halló elementos para sostener que el clima tanto del salón de clase como de la escuela se encuentra relacionado con las actitudes, hacia el mundo de lo político, que expresan los alumnos.

A posteriori, se ha encontrado nueva y variada evidencia que respalda el rol que desempeña la escuela como agente de socialización política. Dudley y Gitelson (2002) recuerdan que Niemi y Junn (1998) confirmaron que la combinación de acceso a cursos cívicos, la amplitud de temas tratados en la currícula escolar y el uso de la estrategia pedagógica de la discusión coadyuva al incremento de diferentes competencias cívicas entre los adolescentes. Así mismo, se ha hallado sustento para afirmar que la inclusión de discusiones políticas y el tratamiento de temáticas diversas en los programas de los cursos cívicos provoca no sólo el empoderamiento de los estudiantes sino también el de sus padres o tutores. Estos efectos positivos resultan aún más poderosos entre familias pertenecientes a los estratos socio-económicos más bajos (McDevitt y Chaffee, 2000).

También se ha encontrado evidencia para certificar que la participación en actividades extracurriculares favorece la adquisición de diferentes competencias cívicas (Glanville, 1999). La prueba empírica, a su vez, ha corroborado en los últimos años que las experiencias de "aprendizaje-servicio" favorecen el incremento del conocimiento político (Galston, 2001) y de la participación cívica (Michelsen, Zaff y Hair, 2002; Claes, Hooghe, y Stolle, 2009). Finalmente, se ha comprobado que la existencia de ambientes abiertos de clase potencia la posesión de diferentes competencias cívicas (Campbell, 2008). 


\section{4) El aprendizaje cívico obtenido con los "iguales": el grupo de pares como agente de socialización política ${ }^{145}$}

Desde los iniciales estudios sobre socialización política, se ha hecho referencia a la influencia ejercida por los grupos de pares. Langton y Karns sostenían ya en 1969 que teóricamente el peso de los "peer groups" sobre las orientaciones políticas de los individuos podía ser tan relevante como el detentado por las familias o las escuelas. Una definición interesante de grupo de pares es la proporcionada por Allison Ryan (2001, p. 1137):

...an individual 's small, relatively intimate group of peers which interact which each other on a regular basis...

Esta definición difiere de otras menos rigurosas y que añaden, al interior del grupo de pares, a todos los individuos que, en relación a un sujeto tomado como referencia, poseen su misma edad o son sus compañeros de curso, clase o estudios ${ }^{146}$. Como puede apreciarse en su conceptualización, el conocimiento del grupo de pares es fundamental para descifrar el origen de diferentes rasgos que asumen las personas en los tramos iniciales de su vida: niñez, adolescencia y primera juventud. Por ese motivo, la Psicología del Desarrollo lo considera un agente vital para comprender el proceso por el cual los futuros adultos adquieren competencias de signo diverso (culturales, cívicas, cognitivas, etc.).

A pesar de la importancia teórica atribuida en los estudios genésicos sobre socialización política a los grupos de pares, su medición no era frecuente. Niemi y Sobieszek (1977) lo atribuyen a las dificultades metodológicas vinculadas a su correcta operacionalización. Resultaba complicado en estas primeras etapas no sólo proceder a la identificación precisa de quienes conformaban el círculo cercano de los individuos

\footnotetext{
145 En el marco de lo producido en España sobre la influencia ejercida por el grupo de pares en los procesos de socialización política, destaca el aporte de Morán (2003).

${ }^{146}$ En algunas investigaciones, motivado en restricciones presupuestarias o temporales, los grupos amplios de referencia de un individuo son tomados como variable proxy de los grupos más cercanos a éste.
} 
estudiados sino, una vez ubicados, disponer de tiempo y de recursos suficientes para recoger también información sobre los mismos.

Intentando contribuir a la superación de estos obstáculos, Bruce Campbell (1980) propuso y verificó empíricamente un modelo que explicaba los mecanismos a través de los cuáles el grupo de pares moldea la identidad política de los individuos en la adolescencia. Según sus hallazgos, existe una alta probabilidad de que el sujeto tome como propias las actitudes políticas decididas en su grupo cuando estas son altamente visibles al interior del mismo. Ello le otorga al grupo lo que se denomina "campo de poder" sobre el sujeto. Idéntica pauta acontece cuando las actitudes políticas son relevantes en el marco de la simbología grupal. A su vez, el comportamiento político de los individuos está directamente vinculado a la influencia que el grupo realiza sobre sus actitudes políticas. Esto último es posible, según la perspectiva de este autor, porque el grupo domina a la persona mediante dos mecanismos simultáneos y complementarios: la valencia (atribución de importancia dada por el individuo al grupo) y el control (facultad que tiene el grupo de decidir la línea de pensamiento y el curso de las acciones de sus miembros).

Hallazgos más recientes han contribuido a sistematizar la influencia ejercida por los grupos de pares sobre los sujetos en el periodo de la adolescencia. Ryan (2001) afirmó que su poder persuasivo se da por igual entre individuos de diferentes sexos y etnias. Al mismo tiempo, encontró que es importante diferenciar entre el influjo del grupo de pares de aquél ejercido por los llamados "mejores amigos". Estos influjos, aunque activándose en momentos distintos, resultan complementarios. Youniss, McLellan y Mazer (2001) han hallado que la incidencia del grupo de pares no sólo determina el nivel actual de implicación cívica de los individuos (participación en actividades voluntarias) sino que también moldea la intención futura de participación en actividades comunitarias y políticas. Finalmente, dando un paso más allá de lo descrito, McFarland y Thomas (2006) han detectado que la pertenencia, en este periodo vital, a un grupo cívicamente empoderado conduce a que los individuos, en su vida adulta, posean mayores niveles de participación política (obtención de credenciales para votar, emisión de sufragio, colaboración en campañas electorales y actividades de servicio comunitario). 


\section{5) El aprendizaje cívico remoto: los medios de comunicación}

\section{como agente de socialización política ${ }^{147}$}

Los medios de comunicación son, sin lugar a dudas, un formador cívico ubicuo en las sociedades contemporáneas ${ }^{148}$. La disponibilidad de sus mensajes es tal que cualquier sujeto se ve, a pesar de no desearlo, influenciado por ellos. Chaffee, Ward y Tipton (1970) fueron los primeros en señalar que la exposición a los medios de comunicación afectaba el desarrollo cívico en los niños y adolescentes. Su influencia parece ser decisiva en la adquisición de determinadas actitudes políticas. Por un lado, los mass media influyen en las orientaciones que los sujetos elaboran en relación a personajes políticos e instituciones políticas. Por el otro, intervienen en la capacidad cognitiva de los sujetos de conocer los asuntos políticos. Finalmente, contribuyen a moldear el comportamiento político generando información respecto a cómo las personas deben actuar en determinadas circunstancias políticas y cuál debe ser su rol como ciudadano (Wei y Leung, 1998).

En consonancia con lo mencionado, la literatura sobre los efectos de los medios de comunicación en la dimensión cívica de las personas ha identificado y estudiado tres diferentes campos de acción. En primer lugar, los medios de comunicación moldean afectivamente a los sujetos (proponiéndoles cómo evaluar a las figuras/situaciones/eventos políticos). En segundo término, los medios de comunicación influyen cognitivamente en los individuos (permitiéndoles conocer información política y estar conscientes de la realidad política). En tercer lugar, los medios de comunicación predisponen conductualmente a los ciudadanos en materia de voto y de discusión sobre asuntos políticos ${ }^{149}$ (Wei y Leung, 1998).

\footnotetext{
147 Dos aportes, producidos en España, interesantes en relación a la socialización política ejercida desde los medios de comunicación son el de Galindo (1997) y el de Obiols y Blanch (2013).

148 Lamentablemente, en la encuesta realizada para esta investigación, no fue posible incluir preguntas directamente vinculadas al rol ejercido por los mass media como agentes de socialización. Motivos relacionados, por un lado, al tiempo que debía invertirse para responder el cuestionario y, por el otro, a la necesidad de explorar otros factores que se evaluaban más relevantes de cara a explicar las competencias cívicas de los encuestados influyeron en su exclusión.

${ }^{149}$ La capacidad de influencia de los medios de comunicación en la faz cívica de los individuos depende de la naturaleza del medio. En otras palabras, mientras que la lectura de periódicos tiende a la elevación de la eficacia política de los sujetos, la exposición a medios audiovisuales parece encontrarse asociada a una mayor confianza en el sistema político y al reforzamiento de identificaciones partidarias.
} 
A lo largo de la vida de los sujetos, los medios de comunicación cuentan con una capacidad de moldeo actitudinal envidiable. En tal sentido, los mass media pueden contribuir no sólo al cambio de actitudes políticas entre los individuos sino también a su mantenimiento y al entorpecimiento de eventuales modificaciones (McLeod, Kosicki y Pan, 1991). A su vez, en el caso concreto de niños y adolescentes, la inducción política en manos de los medios puede conducir a la activación de procesos cívicos virtuosos (valoración positiva de la atención política como competencia cívica, por ejemplo). Sin embargo, el rol socializador de los medios de comunicación puede conducir, tanto en jóvenes como en adultos, a mayores dosis de cinismo y a menores niveles de eficacia política (Atkin y Gantz, 1978; Wei y Leung, 1998).

A pesar de que a los medios de comunicación se les atribuye el carácter de agente socializador político, ha disminuido el número de quienes piensan que su influencia es irrebatible. Diferentes corrientes teóricas acuerdan en que, con independencia del tipo (social-cultural, económico o político) de idea transmitida por los mass media, los sujetos que la reciben establecen una especie de diálogo con la misma. En este proceso comunicacional, los saberes y adhesiones ideológicas previas con los que cuentan las personas son el baremo cognitivo con el que se evalúa la información emitida por los medios. Aquellas cosmovisiones científicas que calificaban a los individuos como meras "esponjas irreflexivas" (o cuasi irreflexivas) de los datos generados por los medios de comunicación han quedado superadas. En tal sentido, conforme los individuos avanzan en el proceso de socialización política, la capacidad de dialogar con la información que es ofrecida por los medios de comunicación se acrecienta (a consecuencia del incremento en el acervo cognitivo subjetivo) ${ }^{150}$ (Liebes y Ribak, 1991).

\footnotetext{
${ }^{150}$ En otras palabras, a medida que los sujetos se sofistican cognitivamente y acontece el establecimiento de sus actitudes políticas, los medios de comunicación pierden capacidad de moldeo y mantienen, tan sólo, aquélla vinculada al transporte de la información política (Wei y Leung, 1998).
} 


\section{6) El aprendizaje cívico en contextos de responsabilidad laboral: el ámbito de trabajo como agente de socialización política}

Otro importante agente de socialización política es el ámbito de trabajo ${ }^{151}$. El mismo actúa como dador de información política respecto a cuál es la distribución de poder entre los actores de la organización y sobre qué papel, consecuentemente, corresponde ejecutar a cada uno de ellos. Compañeros de trabajo y superiores jerárquicos, a partir de la explicitación que realizan de las reglas de juego políticas vigentes al interior de la unidad laboral, son colaboradores fundamentales en este proceso. De esta manera, los saberes adquiridos cuando las personas se encuentran inmersas en una dinámica laboral pueden ser transferidos y aplicados en su condición de sujetos políticos (Breakwell et al, 1989).

A su vez, al interior del universo laboral de los individuos, existen diferentes dimensiones que parecen tener mayor relevancia de cara a generar resultados cívicos (Karasek 2004). Los sujetos que desarrollan actividades que implican responder a continuas demandas y desafíos y que se ejercitan en procesos de toma de decisiones serán aquéllos que, comparativamente, presentarán mayores competencias cívicas. Sin embargo, el nivel de ingresos, las credenciales educativas y el carácter urbano/rural del lugar en el que las personas habiten parecen, en ocasiones, limitar los efectos cívicos positivos de la socialización encarnada en el ambiente de trabajo.

Si bien el ámbito de trabajo suele ser asociado con aprendizajes cívicos que acontecen durante la adultez, sus implicancias en los jóvenes no son menos relevantes. Diferentes investigaciones han concluido que los adolescentes que tienen experiencia laboral manifiestan mayor interés por la política y se insertan más activamente en ella. Como consecuencia de desarrollar una actividad laboral, la eventual pertenencia a

\footnotetext{
${ }^{151}$ Lamentablemente, en la encuesta realizada para esta investigación, no fue posible incluir preguntas vinculadas a la condición laboral de los adolescentes. Motivos relacionados, por un lado, al tiempo que debía invertirse para responder el cuestionario y, por el otro, a la necesidad de explorar otros factores que se evaluaban más relevantes de cara a explicar las competencias cívicas de los encuestados influyeron en su exclusión. Sin embargo, se prevé su incorporación en futuras réplicas de la investigación que se presenta en este documento.
} 
sindicatos potencia aún más el protagonismo cívico de los trabajadores pre-adultos (Willis, 1977; Cochrane y Billig, 1983).

A pesar de conocerse los efectos cívicos positivos del ambiente laboral como agente socializador, no es sistemáticamente utilizado como instrumento a tales fines. Por el contrario, en las sociedades occidentales, el sistema educativo formal es la instancia a la que se le atribuyen las mayores responsabilidades en materia de generación de competencias cívicas en los sujetos. Ingentes recursos humanos y financieros son dedicados a tales fines. Dado este escenario, existen voces que reclaman que se propicie una profunda discusión que tenga por objeto evaluar si una parte de tales recursos pueda ser potencialmente invertida en otros aparatos de formación cívica como es el caso de los ámbitos de trabajo ${ }^{152}$ (Crick, 2004; Davies, 2010).

\section{7) La (re)socialización política: el destino inevitable del inmigrante}

La inmigración implica no sólo un traslado físico de un país a otro o la inmersión en una nueva cultura. Quienes optan por emigrar (o se encuentran obligados a ello) abandonan, a su vez, un sistema político, es decir, un conjunto de instituciones, actores y valores políticos sobre los que se tiene algún tipo de conocimiento tanto teórico como práctico. A la llegada a una nueva sociedad, el inmigrante debe invertir esfuerzos para el aprendizaje de sus reglas de juego político y de los derechos y obligaciones que le corresponden. En otras palabras, los sujetos involucrados en procesos inmigratorios se ven compelidos a re-socializarse políticamente. Este proceso es, en consecuencia, aquél por el cual el inmigrante se integra cívicamente en la sociedad de acogida.

\footnotetext{
152 En el caso de las sociedades receptoras de inmigración, el ámbito de trabajo puede ser el contexto propicio para colaborar en la (re) socialización política de los extranjeros adultos. Mientras sus hijos atraviesan por un proceso semejante en el marco del sistema educativo, su inmersión laboral puede ser aprovechada también desde una perspectiva cívica. Al mismo tiempo, en las sociedades en las que el particular timing del arribo de la inmigración no permitió la adaptación de las estructuras educativas como agentes de socialización política, el ambiente de trabajo puede oficiar de instancia de formación cívica supletoria. A tales fines, la constitución de concertaciones público-privadas puede erigirse en una útil herramienta. Las empresas y las instituciones públicas pueden invertir conjuntamente recursos destinados a favorecer la integración cívica de los recién llegados en la sociedad de acogida (Flores, Biderbost y Carrera, 2013).
} 
Como se afirmó en apartados precedentes, la inmigración es uno de tantos procesos que, junto y retroalimentando a los agentes de socialización tradicionales, configuran escenarios específicos de adquisición y modificación de pautas cívicas. En tal sentido, nunca puede, teóricamente, considerarse idénticas la socialización política experimentada por los nativos de una sociedad con aquella vivenciada por quienes llegan a ésta procedentes de otros rincones geográficos (Bilodeau, 2009). Los autóctonos pueden modificar, a lo largo de su vida, su identidad cívica como consecuencia de alteraciones ambientales y personales. Sin embargo, sus cualidades cívicas se encuentran asociadas a su relación con un único sistema político ${ }^{153}$.

No acontece del mismo modo entre quienes han inmigrado. Sus perfiles cívicos, en mayor o en menor medida, se encontrarán asociados a las realidades políticas de la sociedad de origen. Tal situación puede entorpecer o facilitar su integración cívica en la sociedad de acogida (Portes, Escobar y Radford, 2007). Dependiendo de cuán cercanas (o lejanas) se encuentren (en términos cívicos) las sociedades de origen y de destino, el inmigrante sólo deberá "desaprender" algunos antiguos códigos para "aprender" otros o, por el contrario, atravesará por situaciones de profunda afectación de su identidad cívica (Berry y Kalin, 1995; Berry, 1997). Esto último puede ocurrir, por ejemplo, en los procesos de (re) socialización política de los inmigrantes que han abandonado sociedades no democráticas para radicarse en el territorio de países democráticos.

Existen en la literatura explicaciones discrepantes respecto a cómo acontece la (re) socialización política de los inmigrantes en las sociedades de acogida (White et al., 2008). Estas explicaciones son tipos ideales que intentan reflejar probables conductas cívicas entre los inmigrantes. Las mismas descansan en las que la psicología crosscultural ha propuesto para explicar la adaptación de los inmigrantes a la realidad de las sociedades de acogida ${ }^{154}$. Dos de estas explicaciones aceptan que, entre los inmigrantes, suceden transformaciones cívicas una vez que se han trasladado de un sistema político a otro.

\footnotetext{
${ }^{153}$ No es éste el caso de quienes siendo nativos han tenido una experiencia previa como inmigrantes en una sociedad distinta a la que los vio nacer. En sujetos con esta trayectoria, también su perfil cívico podría ser resultado de la interacción entre las vivencias al interior de uno y otro sistema político.

${ }^{154}$ En esta subdisciplina psicológica, se discute respecto a si los inmigrantes, en la sociedad de acogida, mantienen sus actitudes y comportamientos culturales, los modifican o adoptan una pauta que incluye una y otra posibilidad.
} 
La primera de ellas es la llamada teoría de la exposición (Wong, 2000; Ramakrishnan y Espenshade, 2001). La misma supone que, mientras más tiempo han habitado los inmigrantes en la sociedad de acogida, más incorporarán los rasgos de la cultura política de la misma. Los inmigrantes, en tal sentido, serían una especie de tábula rasa cívica o esponja que asume las tendencias cívicas de la sociedad receptora que le son expuestas e inculcadas por los distintos agentes de socialización. Las minorías sociológicas, entonces, adquieren las cosmovisiones y mecanismos cívicos de mainstream poblacional. El paso de una generación a otra contribuye, asimismo, a la acentuación de los valores políticos de la sociedad de acogida (Alba y Nee, 2003; Inglehart y Welzel, 2005; Torney-Purta et al. 2006) ${ }^{155}$.

La segunda de estas propuestas es la teoría de la transferencia (o transferibilidad) (Black, Niemi y Powell, 1987; Finifter y Finifter, 1989). La misma entiende que los patrones cívicos que los inmigrantes exhibían en origen son transferidos y aplicados flexiblemente en las sociedades anfitrionas. Los conocimientos cívicos primigenios no son impedimento para el aprendizaje de otros nuevos sino que, por el contrario, son aquéllos que contextualizan y, por tanto, facilitan su adquisición. A su vez, entiende que actitudes y comportamientos ć́vicos, con independencia de la nacionalidad de los sujetos (nativos o inmigrantes), se encuentran asociados a sus características sociodemográficas ${ }^{156}$. Ello facilitaría la transferibilidad cívica.

Sin embargo, no toda la literatura es defensora de la idea de la ocurrencia de transformaciones cívicas cuando acontecen procesos inmigratorios. Una tercera mirada, condensada en lo que se denomina teoría de la resistencia, sostiene que difícilmente los inmigrantes adquieren nuevas pautas cívicas en su destino geográfico (Jennings, 2002). A diferencia de los abordajes previos, esta perspectiva considera que la inmigración no implica siempre un estado de apertura a las cosmovisiones existentes en la nueva

\footnotetext{
155 Esta manera de entender cómo acontece la (re) socialización política de los inmigrantes en las sociedades de acogida abreva del trabajo llevado a cabo por la "Chicago School of Sociology" para dar respuesta al creciente rasgos de la sociedad americana como melting pot. Su carácter como principal explicación en torno a estas cuestiones fue puesto, a posteriori, en entredicho por sus asunciones etnocéntricas. En la actualidad, sus aportes siguen teniendo vigencia pero ya desprovistos de su antigua lectura de la cultura angloamericana como superior.

${ }^{156}$ En otras palabras, los rasgos sociodemográficos que potencian (o impiden) la actuación política de los individuos en las sociedades de acogida también lo hacen en la sociedad de destino. En ese sentido, los sujetos en las sociedades anfitrionas, ya sean inmigrantes o nativos, se implicarán más políticamente como consecuencia de la posesión de las idénticas características sociodemográficas (vinculadas al Status Socioeconómico).
} 
sociedad sino que, por el contrario, se acentúa en los sujetos el bagaje cultural originario. A lo sumo, al trasladarse, lo que pueden los inmigrantes hacer es incorporar elementos del nuevo contexto pero sometiéndolos a un proceso de adaptación y subordinación a sus expresiones cívicas originarias.

Según este último modo de comprender la (re) socialización política de los inmigrantes, ni el paso de las generaciones ni la acción de diferentes agentes pueden alterar, entre los inmigrantes y sus descendientes, la existencia de un equipaje cultural que se encuentra manifiestamente determinado por los estilos imperantes en la sociedad de origen. Esta manera de entender la (re) socialización política de los inmigrantes en la sociedad de acogida recibe, en ciertas ocasiones, también el nombre de teoría de la divergencia (Inglehart y Norris, 2009). Como puede observarse, esta propuesta teórica descansa en los supuestos primigenios con los que se trabajó en Ciencia Política sobre la socialización política: las experiencias cívicas posteriores se encuentran fuertemente moldeadas por las experiencias cívicas previas/primeras ${ }^{157}$.

Estas tres teorías reflejan diferentes caminos o perfiles de socialización política en el territorio de acogida. La configuración de estos perfiles diversos viene dada por las disimilitudes que presentan los individuos. Los inmigrantes son afectados por un(os) particular(es) background (o recursos/factores) socio-demográfico (s), psicológico (s), pedagógico (s), sistémico-ambiental (es) e histórico (s) ${ }^{158}$ que les conduce a la vivencia de procesos sui generis de socialización política en las sociedades receptoras. Detrás de estos factores, se encuentran actuando diferentes agentes de socialización. Experiencias diversas de socialización, a la vez, llevan a poseer las competencias cívicas descritas en los apartados previos en grados no coincidentes. La intensidad con la que se poseen

\footnotetext{
${ }^{157}$ Las tres propuestas teóricas difieren, entre otras cosas, en cómo consideran a la experiencia cívica premigratoria. La teoría de la resistencia la evalúa fundamental e inamovible. La teoría de la exposición la ignora y la teoría de la transferencia sostiene que la misma proporciona las claves para una adecuada integración cívica en la sociedad de acogida. Esta investigación, al analizar a inmigrantes en la edad de la adolescencia, no ha recogido datos sobre sus experiencias cívicas en la sociedad de origen.

${ }^{158}$ Entre los factores históricos, pueden encontrarse las características de la socialización política previa a la inmigración, el régimen político de origen y el marco en el que acontece la salida del país de origen (Landolt y Goldring, 2008). Los diferentes tipos de salida de los países de origen (y de llegada a los países de destino) pueden ser categorizados en función de lo que, en el marco de la psicología cross-cultural, son entendidos como factores que propician diferentes resultados culturales. El carácter voluntario (u obligatorio) y permanente (o transitorio) de la inmigración jugarían, entonces, un rol importante a la hora de acontecer los procesos de socialización política en la sociedad de acogida (Berry, 1997).
} 
estas competencias es un relevante indicador de los niveles de integración política que los inmigrantes disfrutan en las sociedades anfitrionas ${ }^{159}$.

Es importante recalcar que, mientras la socialización política es un proceso (elemento dinámico a lo largo del tiempo), las competencias cívicas son un resultado (elemento estático asociado a un momento dado en el tiempo) ${ }^{160}$. A pesar de esta diferenciación teórica, tanto la emergencia de una manifestación específica del proceso de socialización política como la posesión de determinados niveles de competencias cívicas son causadas por los mismos grupos de factores. En tal sentido, la literatura más cercana a los estudios sobre socialización política ve, tras estos factores, la influencia de los diferentes agentes de socialización. La literatura contigua a las llamadas competencias cívicas, en tanto, agrupa a estos factores causales según su especial naturaleza (socio-demográficos, psicológicos, pedagógicos, históricos o sistémicoambientales). Para una mejor comprensión de lo expuesto, en el próximo gráfico, se resume visualmente la relación teórica existente entre socialización política, competencias cívicas e integración política en escenarios migratorios.

\footnotetext{
159 Las competencias cívicas pueden ser utilizadas, entre otros potenciales indicadores, como el benchmark de los niveles de integración política de los inmigrantes en las sociedades de acogida.

160 Una persona puede tener niveles modificables, a lo largo de su vida, en cualquier competencia cívica de las descritas en este volumen. Sin embargo, cuando se procede a su medición en un momento dado del tiempo, se toma una fotografía del atributo. A esa información única reportada por esa fotografía, es a la que se alude con el "carácter estático" de las competencias cívicas.
} 


\section{Figura 1.8}

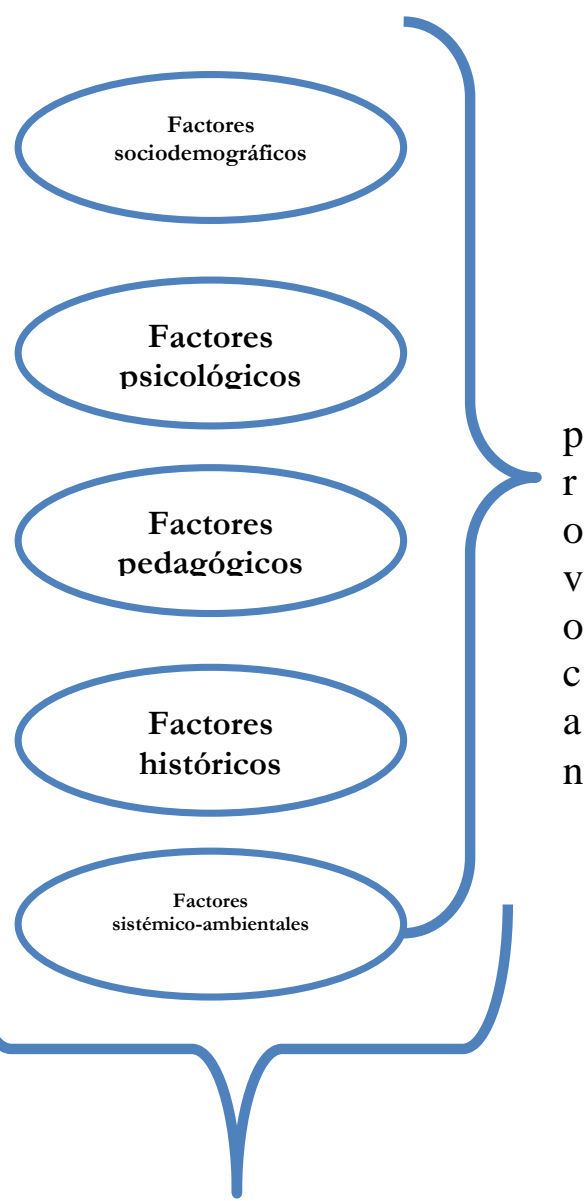

Detrás de éstos, actúan

$$
\text { los agentes de }
$$

$$
\text { socialización }
$$

Relación teórica entre socialización política, competencias cívicas

\section{e integración política en escenarios migratorios}

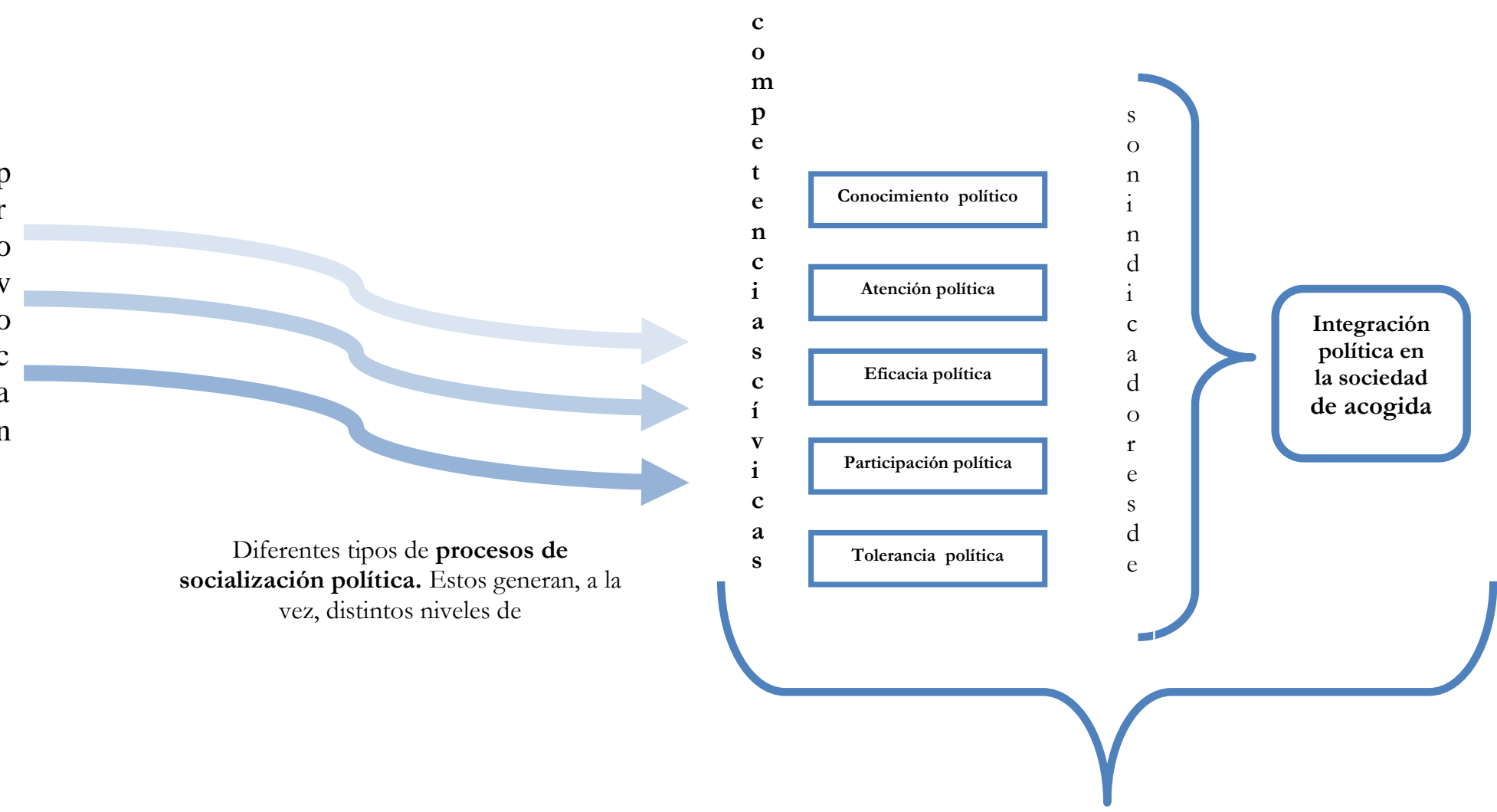

Registro o resultado en un momento dado del tiempo

(carácter estático)

Fuente: Elaboración propia en base a la literatura sobre el tema 
Como se mencionó oportunamente, la integración política de los inmigrantes no se presenta empíricamente de manera uniforme entre todos los colectivos. Sus manifestaciones difieren. Existe un factor (medido a nivel individual y claramente asociado a la recién expuesta teoría de la exposición) que la literatura ha explorado como probable causante de dispares resultados en los procesos de socialización política y, por tanto, de distintos niveles de las distintas competencias cívicas. Es el vinculado al tiempo en el que se ha residido en la sociedad receptora. Mientras algunos individuos y colectivos inmigrantes optan por sumarse a la política formal-electoral de las sociedades de acogida, otros se expresan cívicamente en clave comunitaria y en circunstancias de protesta colectiva (Junn, 1999; Theiss-Morse y Hibbings, 2005; Wong, 2006). Ello podría estar dependiendo del paso del tiempo ${ }^{161}$. En tal sentido, la participación en actividades comunitarias sería más propia de los primeros estadios del asentamiento migratorio. La participación en política electoral/formal se presentaría en estadios más avanzados del asentamiento migratorio en los que se supone que existe un mayor nivel de coincidencia entre la cultura política de los autóctonos y la cultura política de los inmigrantes.

Respecto a la generación de escenarios de integración política de los inmigrantes en los países de acogida, debe recordarse que la misma es un resultado que no sólo es motivado por el background o recursos asociados al inmigrante. Anteriormente, también se ha dicho que este resultado está influenciado por circunstancias o elementos atribuibles a la sociedad receptora. Son los denominados factores sistémicoambientales. El que se logre equiparar, en términos de integración política, a autóctonos e inmigrantes implica no sólo que los extranjeros adhieran a las pautas cívicas de la sociedad de acogida sino que ésta sea lo suficientemente abierta para adaptar sus dispositivos institucionales y no institucionales a tales fines. Por ello, las sociedades que se autodefinen como multiculturales, en comparación a otras en las que prima una

\footnotetext{
${ }^{161}$ Estas diferencias comportamentales entre individuos y colectivos inmigrantes pueden deberse a otra variable también asociada al paso del tiempo: el reconocimiento de los derechos políticos a los extranjeros por parte del entramado jurídico de la sociedad de acogida. Estadios iniciales de asentamiento coinciden con fases en las que no se reconoce a los inmigrantes el derecho al sufragio pasivo y activo. Esta circunstancia se modifica, dependiendo del caso, cuando los foráneos acceden a la residencia permanente o a la nacionalidad del país receptor.
} 
autoimagen monolítica (sin fisuras culturales), facilitarían teóricamente la activación de escenarios con resultados positivos en materia de integración política ${ }^{162}$.

En las sociedades anfitrionas contemporáneas, a diferencia de lo que acontecía en los escenarios inmigratorios en el pasado y como consecuencia de que se ha extendido la creencia en que es posible actuar sobre y contribuir en las transformaciones cívicas de los inmigrantes, existen distintos instrumentos que producen niveles deseados integración política de los newcomers (Biderbost, 2009). Muchos de éstos son informales y espontáneos. La creación, por parte de los autóctonos, de organizaciones no gubernamentales que tienen por objeto facilitar la inclusión de los inmigrantes, la tutela y protección que ofrecen las iglesias de diferentes credos a los extranjeros y la constitución de redes transnacionales entre inmigrantes actuales y potenciales, entre otros, son ejemplo de estas manifestaciones.

Mientras que la práctica política antigua suponía que la masa inmigrada se adaptaría naturalmente a la sociedad receptora, en la actualidad el refinamiento de las políticas de gestión de la inmigración ha permitido la creación de diferentes instrumentos facilitadores de niveles deseados de integración política de los inmigrantes. Estos son los dispositivos formales. Se observa, como se decía en las primeras páginas de este estudio, que la inmigración ha obligado al Estado, en sus diferentes niveles, a influir en los procesos de socialización política ${ }^{163}$. Tanto para adultos como para niños y adolescentes, el Estado, directa o indirectamente, puede contribuir a que los inmigrantes adquieran las competencias políticas necesarias para un adecuado desempeño de su tarea como ciudadanos según las usanzas vernáculas.

En el caso de los adultos, la legislación de muchos países de acogida promueve tanto su inmersión en materia de usos y costumbres cívicas locales. Al mismo tiempo, numerosos estados difunden las bondades de aplicar al proceso de naturalización

\footnotetext{
${ }^{162}$ Sin embargo, en su relevamiento paneuropeo sobre integración política de adultos, Morales y Giugni (2011) no hallaron evidencia ni para respaldar ni para rechazar esta afirmación.

163 Las ventajas de aplicar políticas públicas que coadyuven a la integración de los inmigrantes, según señala Berry (1997), son variopintas. La primera de ellas se vincula al hecho de que la sociedad receptora se convierte en más adaptable en un contexto internacional marcado por la globalización en el que la flexibilidad es un valor deseable. Ello conduce, entonces, a que las sociedades que optan por este tipo de tratamiento frente a la inmigración adquieran ventajas sustantivas en materia de relaciones exteriores y comercio internacional. Al hacer suyas las sensibilidades de otras culturas, es más fácil entender y dialogar con individuos e instituciones que cuentan con diversos backgrounds socio-culturales. Cabe decir también que, así como existen políticas públicas que tienen por objeto facilitar la integración de los inmigrantes, hay otras que, por el contrario, boicotean este objetivo.
} 
(adquisición de nacionalidad) de los inmigrantes ${ }^{164}$. Al interior de ambos procesos, el Estado ofrece seminarios formativos que permiten fortalecer la relación entre el foráneo y el sistema político anfitrión. A tales fines, se habilitan recursos económicos, financieros y humanos que son administrados directamente por los encargados de gestionar la política migratoria (Kymlicka, 1995; Koopmans at al., 2005). No sólo políticas de naturaleza exclusivamente cívica puede aportar a los fines mencionados. Las políticas públicas, en áreas tales como sanidad, justicia, previsión y bienestar social, pueden (si se encuentran correctamente diseñadas) también coadyuvar en este proceso.

\section{8) (Re) socialización política, inmigración y población no adulta}

En el caso concreto de los inmigrantes no adultos (niños y adolescentes), la lógica que se encuentra detrás de los procesos de socialización política es exactamente la misma que se ha descrito en el apartado anterior. Diferentes factores, individuales y ambientales, provocan diversos procesos de socialización política que cristalizan en determinados niveles de competencias cívicas que fungen, a su vez, como indicadores idóneos del grado de integración política en la sociedad de acogida. Es detrás de los factores descritos que actúan los distintos agentes de socialización enumerados a lo largo de estas páginas.

La literatura ha explorado la influencia que, sobre la ocurrencia de tipos específicos de socialización política de un individuo no adulto, presentan diferentes tipos de factores. A tales fines, se han estudiado aquellos elementos que se encuentran vinculados al entorno más próximo a los personas (sean éstas o no inmigrantes). Para ello, se han investigado tanto las características socio-demográficas como la perfomance cívica de los miembros del núcleo familiar al que pertenece el sujeto (Edwards, 2005; McIntosh, 2006; Torney-Purta et al., 2007). La familia, como agente de socialización, es la que se cuela detrás de estos factores o variables.

En estas investigaciones, se ha indagado también sobre determinados factores psicológicos. Para el estudio de la población adolescente, se han observado cuáles son las actitudes pro-sociales poseídas por los individuos que, en el marco de diferentes

\footnotetext{
${ }^{164}$ El caso de los Estados Unidos, cuando promociona las ventajas que poseen los ciudadanos americanos a la hora de aplicar a puestos de trabajo en el gobierno federal, es paradigmático en tal sentido.
} 
procesos de socialización política, conducen a la posesión de niveles diversos de competencias cívicas (Schwarzer, Hahn y Schröeder, 1994). Como se comentaba en apartados previos, los investigadores presumen que la posesión de dos actitudes prosociales en concreto (la empatía y la disposición a la ayuda) pueden estar asociadas a la presencia de elevados niveles de atención política, eficacia política y participación política (Metz y Youniss, 2005).

A su vez, cuando se ha indagado respecto a las competencias cívicas registradas entre menores de edad, se han incluido variables vinculadas al centro educativo al que concurre el individuo y al modelo pedagógico en él imperante (Finkel y Ernst, 2005; Morrell 2005). Los modelos pedagógicos propician, según lo descubierto diferentes cursos de socialización política que, a su vez, generan entre los niños y adolescentes la posesión de diferentes niveles de competencias cívicas.

En tal sentido, puede afirmarse que las escuelas en las sociedades de acogida están obligadas a desempeñar, más allá de su tradicional rol como agentes de socialización política, un papel protagónico en materia de apoyo a la integración política de los inmigrantes menores de edad (Yates y Youniss, 1999). Al respecto, se afirma que escuelas abiertas e inclusivas y lineamientos y prácticas pedagógicas respetuosas de las diferencias socio-culturales son aquéllas que contribuyen a un mayor nivel de integración política de los inmigrantes no adultos (Torney-Purta et al., 2007)

Otra variable, la asociada a la cantidad de años que se ha residido en la sociedad receptora, resulta también relevante para conocer la realidad de la socialización política de los inmigrantes menores de edad. En tales situaciones, los niños y adolescentes han debido abandonar sus países de origen cuando aún no tenían pautas cívicas enraizadas en relación a sus sistemas políticos. La inmigración implica para los no-adultos una alteración en el normal "curso" cívico de los acontecimientos y, consecuentemente, sus identidades cívicas abrevarán de agentes de socialización de uno y otro espacio dependiendo del tiempo transcurrido en uno y otro sitio.

Mientras más temprana haya sido la inmigración, menos probable resultará la identificación, compartida o única, con las pautas cívicas de las sociedades de origen. Los sujetos serán más flexibles y adaptables a los cánones cívicos del espacio receptor 
(Beiser et al., 1988). ${ }^{165}$. Por el contrario, en el caso de los adolescentes que hayan emigrado más tardíamente (es decir, que cuenten con una identidad cívica ya moldeada), la variedad de opciones, en cuanto al resultado de la socialización política, se amplía ${ }^{166}$.

\section{9) Inmigración, socialización política e infraciudadanía. Una nota}

\section{sucinta}

Independientemente de los registros alcanzados en materia de integración política por los inmigrantes en las sociedades de acogida, la socialización política importa un conflicto identitario para los sujetos y colectivos inmigrados. Al mismo tiempo, la presencia de inmigrantes altera los parámetros sociales, económicos y culturales en los Estados de destino. La inmigración modifica, como es harto conocido, patrones en los sistemas laborales y educativos de las sociedades anfitrionas. Lógicamente, también en el terreno cívico y político, renueva lo existente hasta su irrupción. La inmigración provoca la emergencia de nuevas cosmovisiones y mecanismos culturales de comprensión de las realidades políticas.

Si ambas circunstancias no son gestionadas de manera adecuada en el plano cívico (ya sea porque el inmigrante no cuenta con recursos para ello, no le son facilitados y/o los contextos de recepción son hostiles), pueden generarse, como se indicó previamente, situaciones o escenarios de infraciudadanía en las que los individuos con background inmigrante, sin importar si son o no portadores de la nacionalidad del Estado anfitrión, no hacen uso real de los derechos y obligaciones políticos que les son reconocidos legalmente. Las situaciones de infraciudadanía pueden presentarse por

\footnotetext{
${ }^{165}$ Esta ausencia de identificación cívica inicial con lo vinculado a la sociedad de origen no obsta para que, al menos teóricamente, estos inmigrantes puedan desarrollarla una vez que ya se encuentran habitando en la sociedad de destino. Ello puede parangonarse con lo que acontece en materia cultural con los miembros de la segunda y tercera generación de inmigrantes en las sociedades de acogida: a pesar de no haber sido inculcados en determinados tipos de costumbres vinculadas a su origen cultural, terminan adoptándolos por motivos diversos (reacción a la segregación y discriminación, aparición de liderazgos y movimientos que promueven identidades panétnicas y desarrollo de comunidades transnacionales facilitado por los avances tecnológicos, entre otras razones).

${ }^{166}$ Esta ampliación en el elenco de probables resultados se ve acompañada de una mayor dosis de stress por las diferencias cívicas que pudiesen existir entre las sociedades de origen y receptora. Como es imaginable, las tensiones cívicas pueden acrecentarse en el caso de quienes emigran más tardíamente.
} 
falta de flexibilidad tanto en la cultura política originaria (por ejemplo, dificultad para la aceptación de prácticas democráticas para los inmigrantes que proceden de sociedades autoritarias y acceden a otras republicanas) como en la cultura política de la sociedad de destino (por ejemplo, enraizamiento profundo de la idea de ciudadanía asociada a una única nacionalidad o grupo social). De manera aislada o combinada, estas situaciones conducen a la existencia, en materia política, de universos o sociedades en paralelo.

Tomando en cuenta estos riesgos potenciales, debe profundizarse en la idea respecto a que la socialización política, cuando tiene de telón de fondo a realidades migratorias, no es solamente un proceso que afecte a quienes llegan a las sociedades receptoras. En escenarios de esta naturaleza, los procesos de socialización política acontecen acompañados del hecho de que dos diferentes culturas políticas (la de los recién llegados y la de los anfitriones) entran en contacto en múltiples espacios sociales y políticos en los Estados destinatarios de los flujos migratorios. En consecuencia, los nativos, a pesar de no tener que haber re-aprendido cuestiones cívicas formales, si deben adaptarse a los códigos políticos informales de los inmigrantes. Este proceso se da, generalmente, de manera espontánea pudiendo, asimismo, las autoridades políticas influir positivamente en él con el objeto de favorecer resultados elevados de integración política tanto entre vernáculos como entre recién llegados. En estos casos concretos, la planificación política de los procesos de socialización tiene por objeto evitar la creación (o recreación) de escenarios en los que se produzca una afectación negativa de la fortaleza del régimen democrático. 


\section{CAPÍTULO II}

"...we need to assess the degree to which migrants and their children become involved and share the basic values of the settlement polity... we will have to carefully assess whether the patterns of engagement we find reflect exclusion (or excorporation)".

Laura Morales (2011: 41)

\section{1) Introducción}

El presente capítulo tiene por objetivo describir los principales rasgos que, desde el punto de vista metodológico, asume la presente tesis doctoral. A tales efectos, se ha procedido a estructurar el texto en siete apartados. En primer lugar, se amplía con argumentos técnicos la justificación expuesta en el apartado introductorio sobre la necesidad de estudiar la integración política de los adolescentes de origen inmigrante. En segundo lugar, se enuncian las preguntas de investigación y los objetivos perseguidos.

En tercer lugar, se define conceptualmente y se operacionaliza la variable dependiente. Para ello, se describe cómo la medición de las diferentes cívicas competencias cívicas contribuye al conocimiento de la integración política de los adolescentes inmigrantes en las sociedades de acogida.

En cuarto lugar, se mencionan y operacionalizan las variables exploradas para explicar la ocurrencia de diferentes procesos de socialización política que culminan en la posesión de distintos niveles de competencias cívicas. Estas variables remiten a dos grupos de factores diferentes (sociodemográficos y psicológicos) que la literatura ha indicado como probables causantes de la variable dependiente. Entre las variables a explorar, se añade también la actuación de determinados agentes de socialización política sobre los cuales se ha recogido información.

En quinto lugar, se sintetizan los mecanismos que se presume son los causantes de los diferentes niveles de integración política en la población objeto de estudio. Para ello, se presentan las diferentes hipótesis de trabajo derivadas de relacionar a las variables independientes y dependientes. 
En sexto lugar, se explica cómo se ha procedido a seleccionar la población encuestada (adolescentes, padres y/o tutores de los mismos y directivos de escuela secundaria a la que asisten los primeros). También, se mencionan las principales características del proceso de recolección de datos. Finalmente, se justifica la elección del tipo de análisis estadístico al que fueron sometidos los datos recogidos

\section{2) Justificación del estudio de la integración política de la población adolescente}

Según se introdujo en el capítulo anterior, la integración política de los inmigrantes en las sociedades de acogida es un fenómeno que se ha estudiado tanto en Norteamérica como en Europa. En el caso norteamericano, el énfasis se ha puesto en detectar cuáles son las variables individuales que, para una persona en concreto, facilitan sus niveles de integración política. Estas investigaciones, generalmente, han procedido a comparar a autóctonos con inmigrantes y a diferentes colectivos inmigrantes entre sí. Inicialmente, en los Estados Unidos y Canadá, estos abordajes tuvieron como objeto de indagación a la población adulta. A posteriori, se incorporó también a inmigrantes en la edad de la adolescencia. Tal innovación vino acompañada de la recolección de datos referidos a las escuelas a las que éstos asisten para ver cómo las mismas influyen en los resultados cívicos de los estudiantes ${ }^{167}$.

En el caso europeo, en tanto, el estudio de la integración política de los inmigrantes se ha encontrado comúnmente más asociado a la identificación de las variables sistémicas que pueden contribuir a generarla o impedirla. Sólo recientemente, y en el marco de un intento de unir las tradiciones europeas y norteamericanas, se ha procedido a incorporar el estudio de otras variables (individuales y asociadas a los grupos a los que pertenecen los sujetos) que podrían también estar influyendo en los niveles de integración política de los inmigrantes ${ }^{168}$. Estos estudios, al igual que en la academia norteamericana, comparan los guarismos registrados entre nativos e

\footnotetext{
${ }^{167}$ Los aportes de Judith Torney-Purta (Universidad de Maryland) son, como se dijo, los más conocidos en esta materia. Muchos de sus estudios se han desarrollado en el marco del IEA Civic Education Study (CIVED). IEA es la sigla representativa de International Association for the Evaluation of Educational Achievement. IEA es una sociedad científica internacional sin fines de lucro con sede en Bélgica. Tiene por objeto llevar a cabo evaluaciones a nivel global sobre prácticas pedagógicas en terrenos diversos.

168 Laura Morales (Universidad de Manchester) y Marcos Giugni (Universidad de Ginebra) son quienes han realizado el esfuerzo sistemático más importante para unir ambas tradiciones.
} 
inmigrantes. Un elemento que les particulariza es que sus diseños metodológicos buscan hallar potenciales diferencias en integración política en función de las ciudades en las que residen los sujetos sometidos a estudio. Otro elemento que les hace peculiares es que son estudios llevados a cabo con una perspectiva paneuropea, es decir, se ejecutan simultáneamente en distintos países del continente. España es una de las naciones incluidas en la muestra.

Concretamente, para el caso español, el estudio de la integración política de los inmigrantes ha presentado dos etapas. En un primer momento, la inclusión de las asociaciones de inmigrantes en redes decisorias fue el indicador que se utilizó para su registro. Posteriormente, se avanzó hacia la generación de datos sobre actitudes y comportamientos políticos de inmigrantes adultos que fueron utilizados como indicadores de sus niveles de integración política. En ambas instancias, se procedió a identificar cuáles eran los elementos diferenciadores entre colectivos y sujetos inmigrantes de procedencia diversa.

A pesar de las interesantes innovaciones que ha sufrido el estudio de la integración política de los inmigrantes en Europa y España, son casi inexistentes los abordajes que se concentran en población en la edad de la adolescencia ${ }^{169}$. La presente investigación ha sido pensada como un intento para coadyuvar en la superación de este déficit. Los datos recogidos sobre adolescentes, inmigrantes y autóctonos, son útiles por diversas razones. La primera de ellas es que los mismos pueden ser utilizados como una referencia anticipada de las actitudes y comportamientos políticos de los futuros ciudadanos. Al mismo tiempo, la generación de datos de este tipo puede permitir la comparación de los records, en materia de integración política, entre adultos y adolescentes.

En segundo lugar, esta clase de relevamientos pretende iluminar de manera prospectiva sobre la eventual generación de escenarios de infraciudadanía y exclusión cívica en España como sociedad de acogida ${ }^{170}$. En tal sentido, estos estudios facilitan la

\footnotetext{
169 Una excepción en la materia es la investigación de Morrisey (2011). En ella, el autor trata de identificar cómo los métodos de instrucción y el curriculum influyen en la integración política de los adolescentes en determinadas sociedades europeas receptoras de inmigrantes. Su trabajo, como se dijo antes, ha sido desarrollado en el campo de las Ciencias de la Educación.

${ }^{170}$ En cierto sentido, ese conocimiento anticipado permite la obtención de indicios parciales sobre los niveles de calidad de la democracia que podrían caracterizar al sistema político español en un futuro cercano. Naturalmente, de cara a una previsión completa de los "futuros" niveles de calidad de la
} 
detección de perfiles concretos de individuos y colectivos en riesgo potencial de ingresar en situación de marginación política.

En tercer lugar, esta investigación ayuda a identificar qué factores y agentes de socialización favorecen o perjudican la integración política de los adolescentes en las sociedades de acogida. Para ello, se procura desentrañar cuáles son los mecanismos que podrían estar relacionando a las distintas variables independientes con los niveles de integración política de los adolescentes inmigrantes.

Como consecuencia de las razones antes expuestas, en cuarto lugar, los resultados pueden modestamente contribuir en la mejora del diseño y ejecución de acciones puntuales para la evitación de situaciones o escenarios sociológicos no deseados. Dichas transformaciones podrían acaecer en el plano de las políticas de gestión migratoria (con especial énfasis en aquéllas dedicadas a propiciar la integración de la población extranjera en la sociedad receptora). Las políticas educativas, a su vez, podrían verse beneficiadas por los descubrimientos. En tal sentido, los hallazgos pueden ayudar en la (re) definición de proyectos de educación cívica tanto por parte de autoridades públicas como de organizaciones no gubernamentales especializadas en la materia.

Finalmente, existe otro motivo relevante para emprender este tipo de investigaciones. Es el vinculado a la contribución que las mismas realizan en la institucionalización de una agenda de trabajo que, comparando no sólo entre centros educativos sino también entre distritos, ciudades y comunidades autónomas (o provincias), procure reconocer cuáles son los escenarios que mayormente facilitan la adquisición de competencias cívicas por parte de los adolescentes de origen inmigrante.

democracia, los datos referidos deben ser complementados con otro tipo de información no recogida para el presente trabajo. 


\section{3) Objetivos y preguntas de investigación}

El objetivo general de la presente investigación es el siguiente:

- Generar evidencia empírica sobre las diferencias en los niveles de posesión de competencias cívicas, como indicador de integración política, entre adolescentes de distintos colectivos (nativos e inmigrantes).

En función del objetivo general mencionado, los objetivos específicos de la investigación retratada en estas páginas son los que se detallan a continuación:

a) Comparar entre adolescentes de diferentes colectivos poblacionales (nativos e inmigrantes) los registros que presentan en las distintas competencias cívicas

b) Proceder, en base a los registros en competencias cívicas de los adolescentes encuestados, a la creación de un índice de su integración política

c) Reconocer cuáles son los factores (socio-demográficos y psicológicos) que influyen en una distribución no uniforme de las diferentes competencias cívicas y de la integración política como medida global.

d) Identificar cuáles son los agentes de socialización política (familia, escuela, grupo de pares) que influyen en la distribución no uniforme de las diferentes competencias cívicas y de la integración política como medida global.

e) Precisar cuáles son los mecanismos a través de los cuáles los factores y agentes de socialización descritos provocan diferencias en la posesión de competencias cívicas y en el registro de la integración política como medida global.

f) Someter a evaluación empírica dos de las teorías sobre resocialización política de los inmigrantes (exposición y transferencia o transferibilidad) y reconocer cuál es la que mejor responde a la situación de los adolescentes de origen inmigrante incluidos en la muestra estudiada 
g) Discutir sobre las implicancias, en materia de creación de escenarios de infraciudadanía (exclusión cívica), de los hallazgos de la investigación

Sobre la base de los objetivos mencionados, tres son las preguntas de investigación que se ha pretendido responder con el presente trabajo. Son las que aquí se exponen:

a) ¿Cuáles son las diferencias, en materia de competencias cívicas (como indicador de integración política), entre los adolescentes nativos e inmigrantes en la escuela secundaria española?

b) ¿Qué factores y a través de qué mecanismos provocan la existencia de diferencias en integración política entre los distintos colectivos poblacionales?

c) ¿Qué agentes de socialización política y a través de qué mecanismos provocan diferencias en la integración política de la población adolescente?

\section{4) La integración política como variable dependiente y uso de las competencias cívicas como su principal indicador}

La integración política es conceptualmente definida, en esta investigación, como la descripción estática (valores presentados en un momento dado del tiempo) de las actitudes y comportamientos que un individuo (inmigrante o nativo) asume en relación al sistema político de la sociedad en la que habita. En otras palabras, el registro de la integración política es igual a los resultados que, en determinados indicadores, presenta un sujeto en una circunstancia concreta.

La medición de la integración política puede ser considerada como una fotografía que permite conocer las características de un momento dado del proceso dinámico (incorporación política) mediante el cual los inmigrantes convergen, en términos políticos, con la población de la sociedad de acogida. Idealmente, este proceso acaba cuando el factor de la nacionalidad (vernácula o extranjera) no es el que explica la existencia de las diferencias entre los individuos en materia de actitudes y 
comportamientos políticos. En este último escenario, la marginación política no se encuentra asociada a la posesión de un valor en particular de esta variable ${ }^{171}$.

En tanto, la definición operativa de la integración política ha asumido diferentes manifestaciones. Generalmente, los indicadores elegidos para su medición han intentado cubrir tanto información sobre las actitudes políticas de los inmigrantes como datos sobre el comportamiento político de los mismos. Para el caso de los adolescentes, la elección de las competencias cívicas como indicadores de la integración política respeta esta usanza. En el caso concreto de las competencias cívicas incluidas en este estudio, tres de ellas remiten a actitudes (conocimiento político, atención política y eficacia política) y otras dos proporcionan información sobre potenciales comportamientos (participación política y tolerancia política) ${ }^{172}$.

La elección de las competencias cívicas como indicador de la integración política resulta también adecuada porque, en el caso de muestras conformadas por población no adulta (aún no activas cívicamente por impedimento legal), las mismas fungen como el instrumento más adecuado para anticipar actitudes y comportamientos políticos futuros de los encuestados. El objeto de estudio de la presente investigación (adolescentes inmigrantes y nativos en la escuela secundaria española) otorga carta de naturaleza para proceder de esta forma.

Los indicadores elegidos en esta investigación para la medición de las diferentes competencias cívicas respetan lo utilizado generalmente en la literatura sobre la cuestión. Para cada una de las competencias sobre las que se recogió información mediante la aplicación de cuestionarios entre adolescentes y sus padres y/o tutores ${ }^{173}$, la estrategia utilizada ha sido la siguiente:

- Conocimiento político: se procedió a preguntar sobre información no sofisticada acerca del sistema político de la sociedad de acogida. Las preguntas para

\footnotetext{
${ }^{171}$ Cuando la nacionalidad no es un factor que provoca brechas entre nativos e inmigrantes, los últimos pueden considerarse políticamente incluidos. Naturalmente, el que se acceda a este "estadio ideal" no implica que no existan otros factores (distintos a la nacionalidad) que causen entre los individuos "distancias" en materia de integración política.

172 La aplicación de las competencias cívicas también favorece la posesión de indicadores de integración política que pueden llegar a reflejar distintos niveles de esfuerzo o implicación por parte de los sujetos y distintos grados de desafío a sus patrones socio-culturales.

173 La información sobre las competencias cívicas de padres y/o tutores es tratada en la presente investigación como variable independiente de las mismas competencias entre adolescentes. En este caso, lo que se observa es la influencia de la familia como agente de socialización política.
} 
adolescentes y para padres y/o tutores diferían para evitar el trasvase de información que pudiese afectar la medición de la competencia. Las preguntas para uno y otro colectivo eran un total de 5 (cinco). Se creó una escala que otorgaba mayores valores en esta competencia a quienes respondieran correctamente a mayor cantidad de preguntas.

- Atención política: se procedió a preguntar sobre la frecuencia con la que se realizan actividades que tienen por objeto la obtención de información y la discusión sobre la realidad política. El total de preguntas, en este caso, fue de 4 (cuatro): dos de ellas referidas a actividades desarrolladas de manera solitaria y dos de ellas referidas a actividades desarrolladas en el marco familiar. La misma lógica para la redacción de preguntas fue usada en ambos tipos de cuestionarios (adolescentes y padres y/o tutores). Se creó una escala que otorgaba mayores valores en esta competencia a quienes realizarán con mayor frecuencia las actividades sobre las que se preguntaba.

- Participación política: se procedió a preguntar, en relación a situaciones concretas (una claramente vinculada al mundo de la política y otra relacionada con problemáticas socio-comunitarias), si la persona encuestada asumiría determinados comportamientos. El total de preguntas, en este caso, fue de 2 (dos). La misma lógica para la redacción de preguntas fue usada en ambos tipos de cuestionarios (adolescentes y padres y/o tutores). Se creó una escala que otorgaba mayores valores en esta competencia a quienes realizarán las dos actividades que se proponían.

- Eficacia política: se procedió a preguntar sobre ambas dimensiones de esta competencia. En relación a la faz interna, se indagó sobre si el sujeto encuestado comprendía el mundo de la política. En relación a la faz externa, se interrogó sobre la capacidad de influencia que la familia del encuestado tendría en las decisiones que emanan del gobierno. El total de preguntas, en este caso, fue de 2 (dos), una por dimensión. La misma lógica para la redacción de preguntas fue usada en ambos tipos de cuestionarios (adolescentes y padres y/o tutores). Se 
creó una escala que otorgaba mayores valores en esta competencia a quienes respondían positivamente a ambas preguntas.

- Tolerancia política: se procedió a preguntar sobre la aceptación de diferentes situaciones, algunas referidas a avances legales que han registrado los países occidentales en los últimos años (tolerancia política lato sensu) y otras referidas a la respuesta que se daría en contextos en los que las ideas propias podrían ser confrontadas con otras de signo opuesto (tolerancia política stricto sensu). El total de preguntas, en este caso, fue de 4 (cuatro), dos por cada tipo de tolerancia. La misma lógica para la redacción de preguntas fue usada en ambos tipos de cuestionarios (adolescentes y padres y/o tutores). Se creó una escala que otorgaba mayores valores en esta competencia a quienes respondían positivamente a todas las preguntas.

En vistas a crear un índice global de integración política, todas las competencias cívicas han sido consideradas como poseedoras de idéntico valor (el máximo puntaje que un sujeto podía tener en cada una de ellas era de 3 puntos). En base a esta lógica, los valores asumidos por los sujetos en cada competencia cívica fueron sumados. El resultado de ese procedimiento aditivo daba la pauta del nivel de integración política detentado por un individuo con un máximo posible de 15 puntos. El próximo cuadro resume las estrategias que se utilizaron para proceder a la operacionalización de estas competencias cívicas como indicador de la integración política. Al mismo tiempo, a efectos de conseguir mayor detalle sobre la cuestión, es posible consultar el Anexo I que incluye los cuestionarios utilizados durante la investigación. 


\section{Cuadro 2.1}

\section{Operacionalización de las competencias cívicas}

como indicadores de la integración política

\begin{tabular}{|c|c|c|c|c|}
\hline $\begin{array}{l}\text { Competencia } \\
\text { cívica }\end{array}$ & $\begin{array}{l}\text { Tipo de } \\
\text { preguntas }\end{array}$ & $\begin{array}{l}\text { Número de } \\
\text { preguntas }\end{array}$ & $\begin{array}{l}\text { Valor } \\
\text { Mínimo } \\
\end{array}$ & $\begin{array}{l}\text { Valor } \\
\text { Máximo } \\
\end{array}$ \\
\hline $\begin{array}{l}\text { Conocimiento } \\
\text { político }\end{array}$ & $\begin{array}{l}\text { Información acerca del } \\
\text { sistema político de la } \\
\text { sociedad de acogida }\end{array}$ & 5 & 0 & 3 \\
\hline Atención política & $\begin{array}{l}\text { Frecuencia con la que } \\
\text { se realizan actividades } \\
\text { para la obtención de } \\
\text { información y la } \\
\text { discusión sobre la } \\
\text { realidad política }\end{array}$ & $4(2$ y 2$)$ & 0 & 3 \\
\hline $\begin{array}{l}\text { Participación } \\
\text { política }\end{array}$ & $\begin{array}{l}\text { Decisión } \\
\text { afirmativa/negativa de } \\
\text { participación en } \\
\text { determinados } \\
\text { contextos } \\
\end{array}$ & 2 & 0 & 3 \\
\hline Eficacia política & $\begin{array}{l}\text { Dimensión interna: } \\
\text { Comprensión del } \\
\text { mundo político } \\
\text { Dimensión externa: } \\
\text { Capacidad de } \\
\text { influencia en el mundo } \\
\text { político }\end{array}$ & $2(1$ y 1$)$ & 0 & 3 \\
\hline $\begin{array}{l}\text { Tolerancia } \\
\text { política }\end{array}$ & $\begin{array}{l}\text { Lato sensu: } \\
\text { Aceptación de avances } \\
\text { legislativos } \\
\text { Stricto sensu: } \\
\text { Aceptación de } \\
\text { exposición a } \\
\text { posiciones opuestas a } \\
\text { las propias }\end{array}$ & $4(2$ y 2$)$ & 0 & 3 \\
\hline $\begin{array}{c}\text { Integración } \\
\text { política } \\
\text { (índice global) }\end{array}$ & - & - & 0 & 15 \\
\hline
\end{tabular}

Fuente: Elaboración propia.

5) Integración política de los adolescentes inmigrantes: explorando factores y agentes explicativos

En el anterior capítulo, se sintetizó, en base a lo sugerido por la literatura, cómo diferentes factores y agentes provocan determinados tipos de socialización política que propician, a la vez, la posesión de determinados niveles de competencias cívicas en un momento dado del tiempo. Estos niveles son indicativos del nivel de integración política de los individuos. En este apartado, se identifican cuáles son los factores y agentes que 
se han explorado como eventuales causantes de tales atributos cívicos entre los adolescentes autóctonos e inmigrantes en la presente investigación ${ }^{174}$.

Un primer grupo de factores causales explorados es el de tipo sociodemográfico. Entre éstos, el más relevante es aquél vinculado a la condición migratoria (española o extranjera) poseída por los sujetos encuestados (adolescentes y padres o tutores). La existencia de esta variabilidad entre los miembros de la muestra es la que motivó la puesta en marcha de la presente investigación.

Otras variables sociodemográficas sugeridas por la literatura han sido exploradas para ver su incidencia en la producción de determinados niveles de competencias cívicas. A tales efectos, se ha recogido información sobre la cantidad de años de residencia de los adolescentes encuestados en la sociedad de acogida. Debe recordarse que la teoría de la exposición sobre la socialización política es la que enfatiza la importancia de este tipo de variables ${ }^{175}$ (White et al., 2008).

Al mismo tiempo, respondiendo también a lo marcado por la literatura previa, se han explorado variables vinculadas al status socioeconómico de los adolescentes encuestados. Para ello, se recogió información sobre el nivel educativo, el nivel de ingreso y la ocupación de los padres y/o tutores de los adolescentes ${ }^{176}$. Debe tenerse presente que, según la teoría de la transferencia o transferibilidad, este tipo de variables juegan un rol fundamental a la hora de determinar el tipo de socialización política que los inmigrantes presentan en las sociedades de destino ${ }^{177}$ (White et al., 2008).

Así mismo, se ha recolectado información sobre la lengua hablada en el hogar de la muestra sometida a estudio. Esta variable ha sido incorporada en distintos modelos

\footnotetext{
${ }^{174}$ Los cuestionarios (adolescentes, padres y/o tutores y directivos) que sirvieron de instrumento para la recolección de datos fueron diseñados de manera tal que su extensión no generara fastidio/rechazo entre los respondientes. Ello fue especialmente considerado para la preparación del cuestionario para adolescentes (el mismo podía ser respondido en un tiempo no superior a los 10 minutos). De esa manera, se garantizaba un número elevado de preguntas "conscientemente" respondidas. Este motivo concreto fue el que ha producido que el número de variables exploradas sea cuantitativamente limitado.

175 Esta variable también es incluida en los llamados modelos de conectividad social. Estos operan considerando que, a mayor cantidad de años residiendo una persona en una comunidad, mayor incursión en actividades políticas la misma presentará.

176 Para el registro del Status Socioeconómico, se creó un índice aditivo. Los adolescentes presentaban valores más altos en él cuando más alta era la formación de sus progenitores, cuando más nivel de ingreso había en sus hogares y cuando las ocupaciones de sus padres eran de tipo no manual.

177 Es posible observar que la teoría de la resistencia, para explicar la socialización política, no es incluida a efectos de su verificación empírica. Ello es producto de que, como se señaló en el capítulo de marco teórico, su medición exige la recogida de datos sobre la experiencia cívica previa a la inmigración. La misma es inexistente en el caso de los adolescentes cuando son considerados como objeto de estudio.
} 
creados a efectos de explicar las actitudes y comportamientos políticos que asumen los individuos en sociedades receptoras de inmigración (Brady et al, 1995). Al encontrarse la muestra de esta investigación conformada por adolescentes de origen inmigrante, resulta oportuno ver cómo su variabilidad puede estar afectando los valores asumidos en las diferentes competencias cívicas ${ }^{178}$.

A su vez, se ha explorado la potencial influencia del nivel de religiosidad. Este es un típico factor sobre el que se ha indagado, a lo largo de la historia de la Ciencia Política y la Psicología Política, para hallar sus potenciales efectos sobre la cultura política de los sujetos (Djupe y Tobin, 2001; Jones-Correa y Leal, 2001).

Un segundo grupo de factores estudiados en la presente investigación es el de tipo psicológico. Siguiendo lo marcado por la literatura, se ha explorado la influencia que podría estar ejerciendo, entre los adolescentes, la posesión de actitudes pro-sociales sobre los niveles de competencias cívicas (Metz y Youniss, 2005). Estas actitudes, por su especial naturaleza, son previas a la existencia tanto de actitudes políticas como de comportamientos políticos. En concreto, se ha recogido información sobre dos de estas actitudes: la empatía y la disposición o tendencia a ayudar a los otros ${ }^{179}$.

Sumado a estos dos grupos de factores, se ha explorado la influencia que podrían estar ejerciendo diversos agentes (familia, grupo de pares y escuela) a la hora de propiciar determinadas sendas de socialización política entre los adolescentes conducentes a diferentes estadios de integración política. En relación a la familia, se ha recogido información sobre las competencias cívicas de padres y/o tutores para ver si las mismas correlacionan o no con las poseídas por los menores a su cargo. En relación al grupo de pares, se consideró como tal al colectivo de compañeros de clase. Se usó como valores de referencia a los promedios que los mismos presentaban en las diferentes competencias cívicas.

En relación a la escuela, se ha recolectado información sobre el ratio de inmigrantes/nativos en cada centro educativo al que asisten los adolescentes encuestados. También, se ha interrogado sobre el uso de innovaciones pedagógicas en

\footnotetext{
178 Esta variable, como señalan Leighley y Vedlitz (1999), es también utilizada como un indicador de los niveles de integración cultural de los inmigrantes en la sociedad de acogida.

${ }^{179}$ En base a los valores que los individuos presentaban en cada una de las Actitudes Pro-Sociales, se creó una medida resumen. Cada adolescente presentaba valores más altos en esta medida resumen cuando más elevada eran, por separado, su empatía y disposición a ayudar.
} 
la enseñanza de asignaturas vinculadas a la formación cívica. Estas dos "dimensiones escolares" fueron informadas a través del cuestionario que se suministró a los directores de los centros. Al mismo tiempo, sobre las escuelas, se ha recogido datos sobre el itinerario formativo de la institución (Humanidades y Ciencias Sociales versus Ciencias y Tecnología ${ }^{180}$ ). Se preguntó, a su vez, acerca de la frecuencia con la que se discuten temas de política en las aulas. Lo recogido en estas diferentes dimensiones fue incorporado en una única variable "Escuela"181.

El próximo cuadro resume las estrategias que se utilizaron para proceder a la selección y operacionalización de las variables independientes. Al mismo tiempo, a efectos de conseguir mayor detalle sobre la cuestión, es posible consultar el Anexo I que incluye los cuestionarios utilizados durante la investigación.

${ }^{180}$ Esta es la denominación recibida por los itinerarios formativos según la Ley Orgánica de Educación (2/2006) de 03/05/2006 y reglamentada en el Real Decreto de 02/11/2007 (1467/2007).

${ }^{181}$ Esta variable fue condensada en un índice aditivo. Los adolescentes aumentaban sus valores en la variable en las siguientes situaciones: cuando más inmigrantes sobre la población escolar total presentaba un instituto; cuando más innovaciones pedagógicas se aplicaban en las asignaturas de corte cívico; cuando era un centro en el que se impartía formación de Humanidades o Ciencias Sociales y cuando más abierta era percibida la escuela por el alumnado. 


\section{Cuadro 2.2}

\section{Selección y operacionalización de las variables independientes}

\section{de la integración política ${ }^{182}$}

\begin{tabular}{|c|c|c|c|}
\hline $\begin{array}{c}\text { Variables } \\
\text { independientes } \\
\text { exploradas }\end{array}$ & Background teórico & $\begin{array}{l}\text { Tipo de } \\
\text { Preguntas }\end{array}$ & $\begin{array}{l}\text { Unidad de } \\
\text { observación }\end{array}$ \\
\hline \multicolumn{4}{|c|}{ Factores sociodemográficos } \\
\hline $\begin{array}{l}\text { Condición } \\
\text { migratoria }\end{array}$ & $\begin{array}{l}\text { Estudios sobre actitudes y } \\
\text { comportamientos políticos } \\
\text { de los inmigrantes en } \\
\text { disciplinas diversas (Ciencia } \\
\text { Política, Psicología Política, } \\
\text { etc.) (Torney-Purta et al. } \\
\text { 2007; Morales y Giugni, } \\
\text { 2011) }\end{array}$ & $\begin{array}{l}\text { Pregunta abierta sobre } \\
\text { país de nacimiento } \\
\text { (adolescentes) y } \\
\text { nacionalidad de origen } \\
\text { (tutores) }\end{array}$ & $\begin{array}{l}\text { Adolescentes } \\
\text { Padres y/o } \\
\text { tutores }\end{array}$ \\
\hline $\begin{array}{ll}\text { Tiempo } & \text { de } \\
\text { residencia } & \text { en } \\
\text { sociedad } & \text { de } \\
\text { acogida } & \end{array}$ & $\begin{array}{l}\text { Teoría de la exposición de la } \\
\text { resocialización política } \\
\text { (White et al., 2008) }\end{array}$ & $\begin{array}{l}\text { Pregunta abierta sobre } \\
\text { cantidad de años que se ha } \\
\text { residido en sociedad de } \\
\text { acogida }\end{array}$ & $\begin{array}{l}\text { Adolescentes } \\
\text { Padres y/o } \\
\text { tutores }\end{array}$ \\
\hline $\begin{array}{l}\text { Status } \\
\text { socioeconómico }\end{array}$ & $\begin{array}{l}\text { Teoría de la transferencia de } \\
\text { la resocialización política } \\
\text { (White et al., 2008) }\end{array}$ & $\begin{array}{l}\text { Preguntas sobre status } \\
\text { socioecónomico de padres y/o } \\
\text { tutores: } \\
\text { Nivel educativo (cerrada) } \\
\text { Nivel de Ingreso (cerrada) } \\
\text { Ocupación (abierta) }\end{array}$ & $\begin{array}{l}\text { Adolescentes } \\
\text { Padres y/o } \\
\text { tutores }\end{array}$ \\
\hline $\begin{array}{l}\text { Lengua hablada } \\
\text { en el hogar }\end{array}$ & $\begin{array}{l}\text { Brady et al., } 1995 \\
\text { Leighley y Vedlitz, } 1999\end{array}$ & $\begin{array}{l}\text { Pregunta abierta sobre lengua } \\
\text { hablada en el hogar }\end{array}$ & Adolescentes \\
\hline $\begin{array}{ll}\text { Nivel de } & \text { de } \\
\text { Religiosidad } & \end{array}$ & $\begin{array}{l}\text { Djupe y Tobin, } 2001 \\
\text { Jones-Correa y Leal, } 2001\end{array}$ & $\begin{array}{l}\text { Pregunta cerrada sobre } \\
\text { frecuencia en la participación } \\
\text { en actividades vinculadas al } \\
\text { culto }\end{array}$ & $\begin{array}{l}\text { Adolescentes } \\
\text { Padres y/o } \\
\text { tutores }\end{array}$ \\
\hline
\end{tabular}

${ }^{182}$ Como podrá observarse en el Capítulo III, la variable "Género", según la norma en este tipo de estudios, ha sido explorada también para ver sus efectos potenciales sobre las diferentes competencias cívicas y la integración política como medida global. 


\begin{tabular}{|c|c|c|c|}
\hline \multicolumn{4}{|c|}{ Factores psicológicos } \\
\hline $\begin{array}{l}\text { Actitudes pro- } \\
\text { sociales }\end{array}$ & Metz y Youniss, 2005 & $\begin{array}{l}\text { Pregunta cerrada sobre } \\
\text { frecuencia en la que se incurre } \\
\text { en acciones vinculadas a estas } \\
\text { actitudes (empatía y } \\
\text { disposición a la ayuda). }\end{array}$ & $\begin{array}{l}\text { Adolescentes } \\
\text { Padres y/o } \\
\text { tutores }\end{array}$ \\
\hline \multicolumn{4}{|c|}{ Agentes de socialización } \\
\hline Familia & $\begin{array}{l}\text { Estudios clásicos y } \\
\text { contemporáneos de } \\
\text { socialización política en } \\
\text { Ciencia Política y Psicología } \\
\text { (Easton, 1957; Easton y } \\
\text { Dennis, 1967; Jennings y } \\
\text { Niemi, 1974; Mclntosh, 2007; } \\
\text { Torney-Purta et al. 2007) }\end{array}$ & $\begin{array}{l}\text { Preguntas cerradas sobre } \\
\text { competencias cívicas (ver } \\
\text { cuadro 2.1) }\end{array}$ & $\begin{array}{l}\text { Adolescentes } \\
\text { Padres y/o } \\
\text { tutores }\end{array}$ \\
\hline Escuela & $\begin{array}{l}\text { Estudios clásicos y } \\
\text { contemporáneos de } \\
\text { socialización política en } \\
\text { Ciencia Política y Psicología } \\
\text { (Hess y Torney, 1967; } \\
\text { Langton y Jennings, 1968; } \\
\text { Ehman, 1969; Galston, 2001; } \\
\text { Dudley y Gitelson, 2002) }\end{array}$ & $\begin{array}{l}\text { Preguntas sobre: Ratio de } \\
\text { inmigrantes/nativos por centro } \\
\text { educativo (pregunta abierta) } \\
\text { Itinerario formativo de la } \\
\text { institución (pregunta cerrada) } \\
\text { Frecuencia de uso de } \\
\text { innovaciones pedagógicas en } \\
\text { la enseñanza de asignaturas } \\
\text { vinculadas a la formación } \\
\text { cívica (pregunta cerrada) } \\
\text { Frecuencia de discusión sobre } \\
\text { política en los salones de clase } \\
\text { (pregunta cerrada) }\end{array}$ & $\begin{array}{l}\text { Adolescentes } \\
\text { Directivos de } \\
\text { centro } \\
\text { educativo }\end{array}$ \\
\hline Grupo de Pares & $\begin{array}{l}\text { Estudios clásicos y } \\
\text { contemporáneos de } \\
\text { socialización política en } \\
\text { Ciencia Política y Psicología } \\
\text { (Niemi y Sobieszek, 1977; } \\
\text { Campbell, 1980; Ryan, 2001; } \\
\text { McFarland y Thomas, 2006) }\end{array}$ & $\begin{array}{l}\text { Preguntas cerradas sobre } \\
\text { competencias cívicas (ver } \\
\text { cuadro 2.1) }\end{array}$ & Adolescentes \\
\hline
\end{tabular}




\section{6) Definición de hipótesis de trabajo}

Las hipótesis que esta investigación asume como propias, en base a las preguntas y objetivos descritos, son las siguientes:

a) Sobre los niveles de competencias cívicas e integración política

a. Los niveles de posesión de las competencias cívicas serán mayores entre los adolescentes nativos en comparación a sus pares de origen inmigrante.

b. La competencia cívica en la que la brecha será mayor entre nativos e inmigrantes será el conocimiento político debido a que la adquisición de esta competencia requiere, en comparación a otras, mayor tiempo de asentamiento en la sociedad de acogida

c. Como consecuencia de lo mencionado en el punto a), los niveles de integración política serán mayores entre los adolescentes nativos en comparación a sus pares de origen inmigrante.

b) Sobre los factores que influyen en los niveles de competencias cívicas e integración política

a. En relación a la influencia de factores sociodemográficos:

i. Tiempo de residencia: la cantidad de tiempo transcurrido en la sociedad de acogida estará positivamente asociado al nivel de competencias cívicas e integración política poseído por los adolescentes de origen inmigrante 
ii. Nivel socioeconómico de los padres y/o tutores:

1. A mayor nivel educativo de los padres y/o tutores, mayor nivel de competencias cívicas e integración política entre los adolescentes (con independencia de su origen nacional)

2. A mayor nivel de ingreso de los padres y/o tutores, mayor nivel de competencias cívicas e integración política entre los adolescentes (con independencia de su origen nacional)

3. Los padres y/o tutores cuyas ocupaciones sean no manuales tendrán hijos con mayores niveles de competencias cívicas e integración política (con independencia de su origen nacional)

iii. Lengua hablada en el hogar: los adolescentes de origen inmigrante que hablen en el hogar una lengua distinta a la de la sociedad de acogida tendrán menores niveles de competencias cívicas e integración política que aquellos que hablen en las lenguas oficiales

iv. Religiosidad: a mayor nivel de religiosidad del alumno, mayores registros en competencias cívicas e integración política (con independencia de su origen nacional) ${ }^{183}$

b. En relación a la influencia de factores psicológicos:

i. Aquellos adolescentes con mayores actitudes pro-sociales serán los que presenten mayores niveles de competencias cívicas e integración política (con independencia de su origen nacional)

\footnotetext{
183 La única excepción a este supuesto, en base a la literatura previa, se ha esperado para tolerancia política (Niemi y Chapman, 1998; Eisenstein, 2006).
} 
c) Sobre el proceso de socialización política y los agentes en él intervinientes

a. Los niveles de integración política de los padres y/o tutores correlacionarán positivamente con los niveles de competencias cívicas e integración política presentados por sus hijos/tutorados (con independencia de su origen nacional)

b. Las escuelas con un ratio inmigrantes/nativos mayor ${ }^{184}$, como consecuencia de la menor posibilidad de interacción con población autóctona, tendrán individuos de origen inmigrante que presentarán menores niveles de competencias cívicas e integración política que las escuelas que presenten ratios menores.

c. Los alumnos de origen inmigrante que se encuentren cursando los itinerarios formativos de Humanidades y Ciencias Sociales, por el tipo de contenidos impartidos, presentarán valores más elevados en competencias cívicas e integración política que sus pares pertenecientes a otros itinerarios formativos.

d. Las escuelas en las que, según lo declarado por los inmigrantes, son más frecuentes las discusiones políticas tendrán alumnos con mayores niveles de competencias cívicas e integración política.

e. Las escuelas en las que más innovaciones pedagógicas se utilizan para la enseñanza de asignaturas vinculadas a la formación cívica serán las que presentarán individuos de origen inmigrante con mayores niveles de competencias cívicas e integración política.

f. Los niveles de integración política de los compañeros de clase, considerados éstos como grupo de pares, correlacionarán positivamente

\footnotetext{
${ }^{184}$ En esta investigación, este indicador ha sido medido como porcentaje de alumnos inmigrantes sobre el total de la población escolar.
} 
con los registros presentados por cada adolescente en concreto tanto en

sus competencias cívicas como en su integración política. En otras palabras, a mayores valores promedio del curso, mayores valores promedio del individuo.

g. Ambas teorías de resocialización política (exposición y transferencia o transferibilidad) contribuyen a describir los niveles de competencias cívicas e integración política entre los adolescentes de origen inmigrante en la sociedad de acogida.

\section{7) Selección de casos y características del proceso de recolección de datos}

En el marco de esta investigación, se visitaron 11 ciudades españolas ${ }^{185}$. En la muestra de centros, sólo se incluyó a institutos públicos de educación secundaria. Esto es producto de que, según reporta el Instituto Nacional de Estadística (INE), es la escuela pública la que recibe en mayor medida al alumnado de origen inmigrante. Según Alegre y Subirats, para el año 2007 (un año antes de iniciada la recolección de datos), el 81,4\% de los alumnos inmigrantes concurrían a estos centros y sólo el 18,6\% lo hacía a centros privados y concertados ${ }^{186}$.

La selección de los centros educativos fue llevada a cabo en función de información provista por los Departamentos de Estadística de las Consejerías de Educación de las Comunidades Autónomas. Inicialmente, por cada ciudad visitada, se incluía en la muestra a tres centros educativos (aquellos tres en los que hubiese mayor

\footnotetext{
185 Las ciudades que fueron visitadas durante la recogida de datos son Ávila, Barcelona, Burgos, Madrid, Málaga, Salamanca, Segovia, Sevilla, Valencia, Valladolid y Zamora. Las grandes ciudades que conforman la muestra (Madrid, Barcelona, Valencia, Sevilla y Málaga) fueron escogidas por dos motivos: son las urbes más pobladas de España según el INE y las que mayor diversidad de población inmigrante presentan según también la fuente referida. El resto de las ciudades (capitales de diferentes provincias castellanas) fue incluido en la muestra por pertenecer a un distrito político con exigua población inmigrante. Aunque no explorado a los efectos de esta tesis doctoral, la variabilidad observada (cantidad de habitantes y diversidad de orígenes de los inmigrantes) entre las ciudades incluidas en la muestra puede ayudar a futuro a detectar en el marco de análisis multinivel si particularidades distritales importan o no a la hora de propiciar la integración política de los adolescentes de origen inmigrante.

${ }^{186}$ Héctor Cebolla (2009), en su estudio sobre concentración de los inmigrantes en las escuelas españolas, llega una idéntica conclusión en base a datos provistos por la encuesta PISA (Programme for International Student Assesment).
} 
porcentaje de alumnado inmigrante sobre el total de alumnos por urbe $)^{187}$. El proceder de esa manera garantizaba que se tuviera suficiente variabilidad de orígenes nacionales. La mayoría de los centros educativos en los que se procedió a encuestar se ubicaba en distritos urbanos en los que habitan familias pertenecientes a los estratos medio-bajos de la sociedad ${ }^{188}$.

Lo descrito permite percibir que la muestra creada no ha tenido intención de generalización de los resultados de la investigación sino, por ser un estudio de tipo pionero, sólo pretende la comprobación de hipótesis sustantivas. La aplicación de este primer paso permitirá el replicar, a posteriori, la investigación en muestras más amplias e incluyendo la recogida de datos sobre variables que se hayan manifestado como especialmente relevantes para explicar los niveles de integración política de los adolescentes inmigrantes.

Para la preparación de los cuestionarios para la recolección de los datos, se tuvo en cuenta lo que se ha utilizado hasta el momento en investigaciones semejantes. A tales efectos, ha sido especialmente relevante la revisión de la experiencia anglosajona en la materia ${ }^{189}$. Una vez preparados los cuestionarios, fueron probados en una escuela secundaria de la ciudad de Salamanca ${ }^{190}$. Esta prueba permitió asegurar que el lenguaje utilizado en su redacción resultaba asequible para los grupos objeto de estudio. Al mismo tiempo, se pudo comprobar la extensión máxima requerida para su aplicación.

Los datos fueron recogidos durante el bienio 2008-2009191. A tales efectos, se contó con el apoyo económico de la Junta de Castilla y León ${ }^{192}$. También se tuvo el apoyo

\footnotetext{
187 La cuantía de 3 centros por ciudad obedece básicamente a motivos logísticos, es decir, a las "posibilidades reales" de cobertura de institutos por parte del autor de estas páginas.

${ }^{188}$ Este patrón de asentamiento de la población inmigrante en España también es apuntado por Cebolla (2009). A pesar de cierta semejanza en el perfil socioeconómico de los distritos en los que se asientan las escuelas, ello no implica teóricamente que los adolescentes y padres (o tutores) encuestados presenten un status socioeconómico perfectamente coincidente. Por tal motivo, el status socioeconómico ha sido incluido como variable cuya influencia sobre la integración política es evaluada empíricamente.

189 La consideración de los trabajos llevados a cabo por Judith Torney-Purta (Universidad de Maryland) sobre competencias cívicas de los adolescentes han sido especialmente esclarecedora a efectos de preparar el instrumento.

190 La prueba del cuestionario fue realizada en el Instituto de Educación Secundaria Vaguada de la Palma (Plaza de la Palma, s/n) en marzo de 2008.

${ }^{191}$ Concretamente, los datos fueron recogidos entre abril de 2008 y abril de 2009.

192 El presente documento es un subproducto del proyecto de investigación "El desarrollo cívico de los inmigrantes latinoamericanos en España. Adolescentes y Cultura Política". Este proyecto fue financiado por la Junta de Castilla y León (Código de Referencia: SA010B08/ORDEN EDU/1160/2008).
} 
administrativo y logístico de la Agencia de Gestión de la Investigación y del Instituto de Estudios de Iberoamérica de la Universidad de Salamanca.

En cada centro educativo, se aplicaron cuestionarios a tres grupos de personas: adolescentes (nativos e inmigrantes), padres y/o tutores (nativos e inmigrantes) y directivos. Los cuestionarios eran autoadministrados y podían ser respondidos en un tiempo máximo de diez minutos. Los alumnos los respondían en presencia de los investigadores o de los docentes/directivos del centro que colaboraban con los investigadores. Los estudiantes a los que se pasaba la encuesta se encontraban en el último año del bachillerato o, en su defecto, en el último año de la Educación Secundaria Obligatoria (ESO) ${ }^{193}$.

Los cuestionarios de padres y/o tutores eran entregados a los colaboradores por centro. Los últimos se encargaban de hacerlo llegar a los destinarios. Estos cuestionarios eran respondidos en los respectivos hogares y devueltos a los colaboradores. A posteriori, éstos remitían la documentación pre-franqueada vía correo postal al equipo de investigación ${ }^{194}$. Los siguientes datos globales resumen la información sobre la muestra finalmente obtenida:

- 516 adolescentes entre nativos (362) e inmigrantes (154) 195

- 32 nacionalidades diferentes ${ }^{196}$

- 6 regiones diferentes de background/procedencia socio-cultural ${ }^{197}$

- 211 padres y/o tutores

- 18 escuelas secundarias

\footnotetext{
${ }^{193}$ Cuando el instituto mencionado en los listados provistos por los Departamentos de Estadística de las Consejerías de Educación de las diferentes Comunidades Autónomas no poseía bachillerato, se procedió a encuestar a los estudiantes asistentes al cuarto año de la ESO.

${ }^{194}$ El Anexo № II contiene un listado definitivo de los centros educativos incluidos en la muestra por ciudad.

${ }^{195}$ En esta muestra, se ha considerado inmigrantes a quienes han nacido fuera de España.

196 Los países de origen de los individuos incluidos en la muestra son España, Marruecos, Francia, Colombia, Uruguay, Bolivia, Ecuador, Argentina, Brasil, Cuba, Grecia, Venezuela, Filipinas, Alemania, Ucrania, Rusia, Perú, Bélgica, Portugal, Libia, Pakistán, República Dominicana, China, Italia, Rumania, Gran Bretaña, México, Moldavia, Suiza, Costa Rica, Bulgaria y Argelia.

197 Siguiendo la usanza en la materia, se han considerado regiones diferentes a las siguientes: España, América Latina, UE-15 más Suiza, Europa del Este, Mundo Árabe/Islámico y Extremo Oriente.
} 


\section{8) Diseño de análisis}

Para el análisis de los datos recogidos, se decidió que era necesario identificar la pauta de distribución de las distintas competencias cívicas (medidas parciales) entre los adolescentes de origen inmigrante y autóctono. A tales fines, se hizo uso de indicadores típicos de estadística descriptiva. Para ello, se procedió, según se puede observar en el próximo capítulo, a realizar la verificación de las medidas de concentración y dispersión de cada competencia cívica de manera global. Ello fue complementado con una comparación de los registros entre los dos colectivos (nativos e inmigrantes). Esta comparación fue llevada a cabo en vistas a detectar la existencia de diferencias de medias estadísticamente significativas entre ambos grupos. Idéntico procedimiento se ejecutó en relación a la medida global de integración política.

En tanto, para evaluar los diferentes factores y agentes de socialización que se han descrito como probables causantes de las diferencias en materia de competencias cívicas e integración política entre los colectivos vernáculo y extranjero, se hizo uso de dos tests estadísticos de manera secuencial: análisis de correlación canónica y regresión múltiple. El primero fue utilizado para ver cómo se vinculan las diferentes variables señaladas como independientes con cada una de las competencias cívicas. El segundo fue aplicado para ver cómo las diferentes variables independientes contribuyen a la ocurrencia de la integración política como índice o medida global.

El uso del análisis de correlación canónica resulta apropiado a los fines de la presente investigación porque permite detectar cuál es el tipo de relación existente entre dos grupos diferentes de variables desde el punto de vista teórico (uno de ellos independiente y otro de ellos dependiente). Como técnica de dependencia, ayuda a maximizar las correlaciones entre combinaciones lineares de variables. Aunque relativamente desconocida hasta hace un par de años, se afirma que, para estos casos, es el instrumento más potente (Hair, Anderson, Tatham y Black, 2007). La forma general de la correlación canónica se expresa de la siguiente manera:

$$
\mathbf{Y}_{1}+\mathbf{Y}_{2}+\mathbf{Y}_{3}+\cdots+\mathbf{Y}_{n}=\mathbf{X}_{1}+\mathbf{X}_{2}+\mathbf{X}_{3}+\cdots+\mathbf{X}_{\mathbf{n}}
$$

Esta técnica cuenta con numerosas ventajas (Hair et al., 2007). En primer lugar, permite predecir, de manera simultánea, el comportamiento de múltiples variables dependientes a partir de la existencia de múltiples variables independientes. Ello ayuda 
a responder de mejor manera a la complejidad de la realidad social que se refleja metodológicamente en la multidimensionalidad de los conceptos con los que se trabaja. En segundo lugar, a diferencia de otros métodos estocásticos, impone un menor número de restricciones sobre los tipos de datos con los cuales es posible $\operatorname{trabajar}^{198}$. En tal sentido, permite la inclusión, dentro de los grupos de variables independientes y dependientes, tanto de factores métricos como no métricos.

En tercer lugar, el uso de correlación canónica disminuye la probabilidad de cometer errores de Tipo I, es decir, aquél vinculado al hallazgo de relaciones significativas cuando éstas no existen. En cuarto lugar, permiten detectar, al interior de cada grupo o set de variables, cuál es (son) el (los) factor(es) que más contribuye(n) a las relaciones que son halladas. De esa manera, a posteriori, pueden construirse otros modelos (como la regresión múltiple que se usó en un segundo paso) que incluyan sólo a aquéllas variables dotadas de significación estadística.

En el caso concreto de esta investigación, el análisis de correlación canónica pudo ser utilizado porque se cumplen los requisitos exigidos para su implementación (Hair et al., 2007). Por un lado, se tienen, al menos, diez observaciones por variable. De esa manera, se evita lo que se llama "sobreajuste" de los datos. Por otro lado, se respetaban los supuestos que se demandan a los datos para proceder a su aplicación ${ }^{199}$ : linealidad, homocedasticidad y multicolinealidad.

Su uso, en la Ciencia Política, ha sido acotado pero, a la vez, diverso ${ }^{200}$. Sobre objetos de estudio propios o cercanos a la cultura política, ha sido utilizada para el relevamiento de la relación entre características psicológicas (personalidad autoritaria y actitudes pro-sociales) y la manifestación de diferentes tipos de prejuicios políticos y sociales (Whitley, 1999). También se la ha aprovechado para investigar cómo el registro de diferentes competencias cívicas en la niñez y adolescencia se encuentra asociado al

\footnotetext{
${ }^{198}$ Según Hair et al. (2007), el análisis de correlación canónica se asemeja bastante al análisis discriminante por su capacidad para identificar las dimensiones independientes para cada conjunto de variables en vistas a producir el mayor nivel de correlación. Al mismo tiempo, se parece al análisis factorial porque procede a la creación de compuestos de variables.

${ }^{199}$ El supuesto de normalidad no es tan exigente como los otros aquí mencionados. Sin embargo, se recomienda que, en el caso de hallarse variables no normales, las mismas procedan a ser normalizadas (Hair et al., 2007).

${ }^{200}$ Entre otros motivos, su utilización ha sido limitada porque la misma exige la aplicación de lenguaje de programación en archivos de sintaxis. Eso es producto de que los diferentes procesadores estadísticos no incluyen, dentro de sus opciones de análisis, un "botón-función" destinado a la ejecución de este test estadístico.
} 
comportamiento político entre los adultos jóvenes (Krampen, 2002). Ha sido instrumentada para identificar qué factores individuales y ambientales utilizan los editores de noticias en periódicos para considerar la inclusión de información (política y de otra naturaleza) (Chang y Lee, 1992). Finalmente, el análisis de correlación canónica ha sido aplicado para ver cómo se asocian patrones formales e informales de capital social en distintos países en vistas a hallar diferentes regímenes de participación y cohesión (Pichler y Wallace, 2007). No existen, en principio, estudios sobre la integración política de inmigrantes que hayan utilizado esta técnica multivariante para identificar aquéllos factores que la propician ${ }^{201}$.

Los resultados del análisis de correlación canónica son visualizados en base a una técnica innovadora. La misma recibe el nombre de "heliógrafo". Este modo de graficar los resultados de este test multivariante, diseñado por Degani, Shafto y Olson ${ }^{202}$ (2006), tiene por objeto ofrecer al lector un mecanismo de observación de mucha información que supere substancialmente a las tradicionales tablas de presentación en los reportes estadísticos. Su mayor ventaja radica en que facilita la compresión de los patrones descriptivos y explicativos que se encuentran tras las variables utilizadas.

La construcción del heliógrafo, según recuerdan Degani et al. (2006) se encuentra basada en propiedades definidas por Christopher Alexander ${ }^{203}$ (2002) para el diseño de gráficos o diagramas en los que se pretenda crear sensación de totalidad. Estas propiedades son el nivel de escala (para la representación de la fuerza de la significación estadística de distintas relaciones entre variables independientes y dependientes), los patrones y ecos alternativos (para sugerir la existencia de distintas

\footnotetext{
201 El uso del análisis de correlación canónica también se ha dado en el terreno de los estudios sobre políticas públicas. Se la ha utilizado para observar cómo diferentes stakeholders proceden a apoyar o no la implementación de diferentes dimensiones de una política pública (Hensher y Golob, 1999). A su vez, este tipo de análisis estadístico ha sido aplicado para ver cómo las percepciones de los usuarios/ciudadanos pueden afectar los beneficios esperados de la puesta en marcha de concertaciones público-privadas referidas a proyectos de e-government (Gil García, Chengalur y Duchessi, 2007). Finalmente, ha sido instrumentada para el estudio de los factores que contribuyen a la construcción de poder en las organizaciones (Krackhardt, 1990).

202 Degani et al. 2006 han diseñado el heliógrafo para la representación gráfica de resultados de la correlación canónica en el campo de la Ingeniería Aeronaútica. Esta técnica de visualización de datos resulta muy intuitiva para el lector/observador y resulta perfectamente aplicable en las ciencias sociales. ${ }^{203}$ Christopher Alexander es un reconocido arquitecto, matemático e informático austríaco que, entre otros aportes, ha promovido el acercamiento de las técnicas y métodos de su disciplina al público neófito para que éste pueda aprovechar las potencialidades de la misma. Su trabajo le ha hecho merecedor de la incorporación a la American Academy of Arts and Sciences.
} 
pautas descriptivas y explicativas), el vacío (centro interno del dibujo hacia donde convergen los niveles de escala) y el contraste cromático (para apreciar el sentido positivo o negativo de las relaciones entre las variables). Otras propiedades son la superposición (para marcar la probable existencia de variables que asumen diferentes patrones) y la gradación (para reflejar la intensidad de las relaciones entre las variables).

En un segundo momento del análisis estadístico multivariante, se hizo uso de regresión múltiple. Esta es una técnica de dependencia simple que se encuentra basada en el método de los mínimos cuadrados. La regresión suele ser utilizada con dos propósitos fundamentales: predicción y aplicación. Su aplicación, en el caso concreto de esta investigación, tuvo por objeto observar en qué medida las variables independientes, para las que el análisis de correlación canónica ha hallado significación estadística, producen la integración política como índice o medida global.

Como es sabido, el uso de esta técnica se encuentra ampliamente extendido, desde mediados del siglo XX, en las ciencias sociales y económicas en áreas diversas de investigación (demografía, voto, sociología sanitaria, análisis de consumo, efectividad de programas y políticas, etc.) (Guillén, 1992; Hair et al., 2007). La forma general de la regresión mútiple se expresa de la siguiente manera:

$$
\mathbf{Y}_{1}=\mathbf{X}_{1}+\mathbf{X}_{2}+\mathbf{X}_{3}+\cdots+\mathbf{X}_{\mathbf{n}}
$$

La regresión múltiple exige la utilización de variables métricas tanto a nivel de variables dependientes $(\mathrm{Y})$ como independientes. Sin embargo, la aplicación de variables dummies (o ficticias) para representar la influencia sobre la variable dependiente de factores con dimensiones cualitativas es también permitida. Las mismas suelen ser acompañadas, ocasionalmente, por las llamadas variables de interacción o de moderación.

La principal ventaja de aplicar este test estadístico radica en que permite ver cómo contribuyen tanto un conjunto de variables independientes como cada variable en particular a la ocurrencia de una variable dependiente. En tal sentido, su aplicación facilita la obtención de la máxima predicción a partir del conjunto de variables predictores escogidas (Hair et al., 2007). En otras palabras, cómo recuerda Guillén (1992), la regresión faculta el cuantificar la relación entre la variable criterio y las variables independientes y establecer el grado de confianza con el que es posible enunciar que dicha cuantificación responde a la realidad estudiada. 
Concretamente, para esta investigación, la regresión múltiple ha podido ser aplicada porque se cumplen los seis requisitos exigidos para la puesta en marcha de esta prueba estadística. En primer lugar, se cumple con la independencia de los errores (o residuos). En segundo lugar, existe una relación lineal entre los factores predictores y la variable dependiente (tanto a nivel de cada variable independiente como considerando a cada una de ellas de manera aislada). En tercer lugar, existe homocedasticidad. En cuarto lugar, no existe multicolinealidad. En quinto lugar, no se encuentran outliers o puntos de influencia significativos. Finalmente, los errores se encuentran normalmente distribuidos.

La regresión, en sus diferentes variantes, ha sido reiteradamente utilizada para comparar las actitudes y los comportamientos políticos entre colectivos diversos. Ello ha tenido lugar tanto cuando la comparación es realizada entre miembros de diferentes etnias como cuando refiere a las divergencias existentes entre nativos e individuos que revisten la condición de inmigrantes (Leighley y Vedlitz, 1999; Jones-Correa y Leal, 2001; Leal, 2002; Barreto y Muñoz, 2003; Kelly y Morgan, 2005).

El análisis estadístico de los datos fue realizado con el procesador estadístico IBM SPSS Statistics 21. Esta es la última versión disponible de este tradicional programa informático para el análisis cuantitativo de información. En el caso del análisis de correlación canónica, el autor de estas líneas procedió a aprender y a aplicar el lenguaje de sintaxis referido a este test estadístico. Este aprendizaje fue realizado siguiendo las instrucciones del manual operativo del procesador estadístico mencionado $y$, al mismo tiempo, haciendo lectura atenta de las recomendaciones hechas al respecto por expertos estadísticos de diferentes universidades norteamericanas ${ }^{204}$. En tanto, en el caso de la regresión, se hizo uso de la función que este software incorpora a tales efectos.

\footnotetext{
${ }^{204}$ Especialmente esclarecedores han sido los aportes de Amanda Glatfelter de Cleveland State University y Mike Clark, Consultor Estadístico del Departamento de Investigación y Apoyo Estadístico de la Universidad del Norte de Texas.
} 


\section{CAPÍTULO III}

"These analyses indicate the importance of looking at immigrants" preparation for citizenship along multiple dimensions of knowledge, engagement, and attitudes, recognizing the potential strengths of cultural identities in fostering adolescent development, and enhancing the aspects of civic education at school that relate to higher knowledge and engagement".

Judith Torney-Purta, Carolyn H. Barber y Britt Wilkenfeld (2007: 122)

\section{1) Introducción}

El presente capítulo tiene por objeto analizar estadísticamente y discutir los datos recogidos para esta investigación. Para tal propósito, se desarrollan distintas estrategias que permiten someter a verificación empírica las diferentes hipótesis enunciadas en el apartado anterior. El capítulo se encuentra dividido en cinco apartados.

En un primer apartado, se analiza la distribución de las distintas competencias cívicas entre los adolescentes de origen inmigrante y autóctono. Una vez realizada la verificación de las medidas de concentración y dispersión de cada competencia cívica de manera global, se procede a comparar entre colectivos. En este segundo paso, también se verifica si existen diferencias de medias (o de distribuciones de la muestra) estadísticamente significativas entre los grupos. En este primer acápite, también se exploran cuáles podrían ser las causas que se encontrarían detrás de la existencia (o no existencia) de diferencias significativas entre ambas poblaciones.

En un segundo apartado, se analizan las diferencias en materia de integración política entre ambos colectivos. Repitiendo el esquema del punto anterior, se procede a identificar cuáles son los valores que presenta la variable en las medidas de concentración y dispersión más importantes. Luego, se verifica si existen diferencias de medias estadísticamente significativas entre los colectivos. Este apartado termina con una comprobación parcial de las hipótesis de trabajo asumidas por esta investigación. 
A posteriori, se evalúan mediante dos tests multivariantes los diferentes modelos que se han descrito como probables causantes de las divergencias en materia de competencias cívicas (medidas parciales) e integración política (medida global) entre los colectivos vernáculo y extranjero. Por tal motivo, en un tercer apartado, se aplica el Análisis de Correlación Canónica para ver cómo se asocian las diferentes variables independientes (factores socio-demográficos, factores psico-sociales y agentes de socialización) con las diferentes competencias cívicas. Los resultados de este test multivariante serán visualizados mediante el gráfico llamado heliógrafo. Este apartado culmina también con una comprobación parcial de las hipótesis de trabajo evaluadas mediante la correlación canónica.

En un cuarto apartado, se aplica la Regresión Múltiple para ver cómo las diferentes variables independientes influyen en la producción de diferentes niveles de integración política. Este apartado, a su vez, concluye con una comprobación parcial de las hipótesis de trabajo evaluadas mediante esta prueba multivariante. Tanto en el tercer como en el cuarto acápite, se procede a la aplicación de los tests estadísticos mencionados a tres muestras de adolescentes: global, nativos e inmigrantes.

En un quinto y último apartado, se discuten los principales hallazgos de esta investigación. A tales fines, se identifican diferentes tendencias y patrones tanto sobre la distribución de las competencias cívicas y la integración política entre colectivos poblacionales como acerca de las causas que la propician. Se reflexiona también sobre la evidencia empírica en relación a la naturaleza que asumen los procesos de socialización política que atraviesan los adolescentes inmigrantes en la sociedad de acogida. Se sugieren también estrategias que podrían aplicarse de cara a remediar resultados que podrían esconder situaciones de marginación cívica.

\section{2) La distribución de las competencias cívicas entre adolescentes inmigrantes y autóctonos}

En este subcapítulo, la hipótesis principal que se desea verificar es la vinculada a la presunción de que los adolescentes locales presentan valores más elevados que los adolescentes inmigrantes en cada competencia cívica. Al mismo tiempo, se analiza si esas diferencias son mayores en el caso del conocimiento político. 
La presentación se ha estructurado por competencia cívica. Para cada una de ella, se analizarán, en primer lugar, los valores asumidos en las medidas de concentración y dispersión más relevantes (media, mediana y desviación típica) para la muestra global. En segundo lugar, se realizará una comparación de los valores asumidos en la variable entre autóctonos e inmigrantes. Acto seguido, se procederá a verificar el cumplimiento o no de la hipótesis planteada para cada atributo cívico.

El subcapítulo cierra con una comparación de los records, entre colectivos, para cada competencia cívica. A este dato, se le incorpora información sobre la brecha existente en cada atributo a los fines de precisar las pautas de convergencia y divergencia entre los dos grupos incluidos en la muestra.

\section{1) (Des)conociendo la política. La primera brecha}

La performance de la muestra global de los adolescentes en relación al conocimiento político es de tipo bajo ${ }^{205}$. Sobre un total de tres puntos, la media es de 1.06 puntos. Ello implica que, en promedio, sobre un total de cinco preguntas sobre el sistema político español sólo se ha procedido a responder menos de dos de manera correcta $^{206}$. Al analizarse la mediana, se observa que la mitad de la muestra se encuentra al nivel o por debajo de una respuesta correcta (0.6 puntos). Hilando aún más fino y analizando las frecuencias referidas a las cantidades de respuestas correctas, el $51,4 \%$ de los encuestados no ha podido responder correctamente ni siquiera a dos preguntas.

La media, consecuentemente, se encuentra afectada por la existencia de un número reducido de sujetos que presentan registros máximos en la variable (5.6\%). En tanto, el valor relativamente elevado de la desviación típica (0.95 puntos) refleja esa división de la muestra entre muchos individuos con valores exiguos y unos pocos con valores elevados.

Al realizarse una comparación de los valores de esta competencia cívica entre adolescentes inmigrantes y autóctonos, el guarismo favorece a estos últimos. Mientras que la media de conocimiento político es para los locales de 1.23 sobre 3 puntos, los

\footnotetext{
205 Ello coincide con lo que, para la población adulta, se ha hallado en otras investigaciones. A tales fines, pueden consultarse los trabajos de Fraile (2006) y Santiuste (2013).

206 Cada pregunta respondida de manera correcta, sumaba 0.6 puntos. El máximo valor de esta competencia para una persona es de 3 . El mínimo valor, en tanto, es de 0 punto.
} 
adolescentes de origen inmigrante presentan un registro de 0.65 puntos. En otras palabras, los adolescentes nacionales han contestado dos preguntas correctas de media y los adolescentes de origen inmigrante sólo una pregunta.

El análisis de la mediana confirma la desigualdad entre los colectivos detectada para la media. La mitad de la muestra de autóctonos presenta valores iguales o por debajo a 1.2 puntos. En el caso de los inmigrantes, la mitad de la muestra presenta valores iguales o por debajo de 0.6 puntos. Esto último implica que la mitad de los adolescentes extranjeros encuestados han respondido correctamente ninguna o sólo una pregunta.

Entre los adolescentes de origen español, el $22.37 \%$ no ha respondido correctamente a ninguna pregunta. En el caso de los adolescentes inmigrantes, ese mismo registro asciende a $44,73 \%$. Quienes han respondido correctamente, entre los autóctonos, a todas las preguntas son el 7,73\% sobre el total. Ese registro desciende a $0.65 \%$ ( 1 persona) en el caso de los inmigrantes ${ }^{207}$. Los valores de la desviación típica reflejan que la dispersión es mayor entre los nativos que entre los inmigrantes. Mientras los adolescentes locales presentan un valor de 0.97 puntos, los adolescentes inmigrantes tienen un registro de 0.77 puntos $^{208}$.

Cuadro 3.1

Medidas de concentración y dispersión para conocimiento político de los adolescentes según condición migratoria

\begin{tabular}{|c|c|c|c|c|c|}
\hline Condición migratoria & Media & Desv. típ. & Mediana & $\begin{array}{c}\text { Porcentaje } \\
\text { de sujetos } \\
\text { con el valor } \\
\text { máximo } \\
(3)\end{array}$ & $\begin{array}{c}\text { Porcentaje } \\
\text { de sujetos } \\
\text { con el valor } \\
\text { mínimo } \\
(0)\end{array}$ \\
\hline Nacional $(\mathrm{N}=362)$ & 1,23 & 0,97 & 1,20 & $7,73 \%$ & $22,37 \%$ \\
Inmigrante $(\mathrm{N}=154)$ & 0,65 & 0,77 & 0,60 & $0,65 \%$ & $44,73 \%$ \\
Total $(\mathrm{N}=516)$ & 1,06 & 0,96 & 0,60 & $5,62 \%$ & $28,88 \%$ \\
\hline
\end{tabular}

\footnotetext{
207 La menor diferencia de respuestas correctas (sólo un $8 \%$ a favor de los nativos) se dio en el caso de la pregunta en la que se interrogaba sobre quién era el Jefe de Estado en España. Un 46.69\% de los nativos la respondió correctamente. El registro desciende a $38.16 \%$ en el caso de los inmigrantes. En el extremo opuesto, las preguntas que mayor ventaja reportaron a los autóctonos a nivel de respuestas correctas fueron la que interrogaba sobre la cantidad de años que había gobernado el Partido Popular (PP) a nivel nacional en su última gestión (1996-2004) y la que solicitaba a los encuestados nombrar a tres ministros de la legislatura en curso. La diferencia porcentual fue de $35 \%$ en el caso del interrogante sobre el gobierno del PP y de $23 \%$ en el caso del interrogante sobre los ministros nacionales.

${ }^{208}$ Tal diferencia se debe a dos circunstancias: la mayor cuantía de los primeros y el que el grupo de los nativos posee, aunque escasos, representantes con elevados registros en esta competencia cívica. Esto no sucede, como se ha enunciado, para el colectivo conformado por inmigrantes.
} 
El diagrama de caja para esta figura (ver gráfico 3.1 en Anexo № 4) refleja las diferencias entre ambos colectivos. Para los adolescentes inmigrantes, la mayor concentración se da entre los valores más bajos de la variable. En tanto, la distribución de los sujetos es más uniforme entre los nativos y su mayor concentración se da en la franja propia de los valores considerados de tipo medio.

Una vez comparadas las medidas de concentración y dispersión entre ambos colectivos, debe procederse a revisar si la diferencia de medias es estadísticamente significativa. Aplicada la prueba Kolmogorov-Smirnov (K-S) para muestras independientes, se observa que las distribuciones de la variable entre las diferentes muestras son distintas ( $p$ valor igual a 0.000$)^{209}$. Se puede concluir efectivamente que la diferencia entre grupos en conocimiento político no es sólo aparente sino que reviste relevancia desde el punto de vista estadístico.

Estos resultados vienen a confirmar las hipótesis iniciales. Existe un profundo gap en conocimiento político entre adolescentes locales y extranjeros. El mismo puede deberse al tiempo que se ha residido en la sociedad de acogida. El conocimiento de su sistema político no es instantáneo. El adquirir información sobre las particularidades política puede verse facilitado con el paso del tiempo.

Al aplicarse la Correlación de Pearson entre esta competencia cívica y las diferentes variables independientes, efectivamente, emerge "Cantidad de Años de Residencia" en la sociedad de acogida como estadísticamente significativa (.332 con un $p$ valor igual a .000). Este hallazgo encuentra respaldo en la literatura (Cho, 1999). Sin embargo, es ligeramente superada por "Grupo de Pares" (.336 con un p valor igual a .000). El hallazgo de esta pauta responde también a lo sugerido por la literatura (Campbell, 2008). En otras palabras, la combinación de mayor paso del tiempo con la existencia de un grupo de pares cívicamente "estimulante" proporcionaría mayores niveles en esta competencia cívica ${ }^{210}$. En ambas variables independientes, los locales se posicionan mejor (16.98 versus 4.86 para "Cantidad de Años de Residencia" y 8.05

\footnotetext{
${ }^{209}$ Se aplicó este test estadístico porque la distribución de la variable es no normal. La aplicación de la prueba T, para muestras normales, arrojó idéntico sentido en el resultado ( $p$ valor igual a 0.000).

${ }^{210}$ Este resultado se repite tanto para la muestra sólo conformada por nativos (.222 para "Grupo de Pares" y .208 para "Cantidad de Años de Residencia" con un p valor igual a .000) o por inmigrantes (.435 para "Grupo de Pares" y .211 para "Cantidad de Años de Residencia" con un p valor igual a .000).
} 
versus 7.37 para "Grupo de Pares") y la comparación de distribuciones entre grupos delata diferencias estadísticamente significativas (Prueba K-S con un p valor igual a .000) en ambos casos.

Este resultado confirma que la integración política de los adolescentes inmigrantes puede verse negativamente afectada por esta competencia cívica. Un individuo que no conoce los resortes institucionales del sistema político de la sociedad de acogida no sólo se encuentra en menor capacidad de demandarle o reclamarle acciones sino que difícilmente sea incluido en procesos de tomas de decisiones en asuntos que le atañen directamente. A la vez, los individuos menos dotados de este atributo cívico son más influenciables a presiones externas. Al mismo tiempo, desde una mirada holística o sistémica, ciudadanos menos informados políticamente provocan que el control sobre las autoridades sea cualitativamente inferior (Fraile et al. 2007).

\section{2) Cuando el origen nacional no importa. Registros en atención política}

El registro de la muestra global de los adolescentes en relación a la atención política es de tipo medio-alto ${ }^{211}$. Sobre un total de tres puntos, la media es de 1.74 puntos. La mediana presenta valores semejantes (1.80 puntos). El valor asumido que presenta mayor frecuencia (69 personas) es también 1.80. En tanto, la desviación típica es más bien reducida (de sólo 0.45 puntos). Sólo dos sujetos poseen los valores más elevados de la variable (0,4\%). Otro tanto acontece con los valores más bajos. A su vez, el $50.8 \%$ de las personas presenta valores cercanos a la media (entre 1.50 y 1.95 puntos).

Al realizarse una comparación de los valores asumidos por esta competencia cívica entre adolescentes inmigrantes y autóctonos, no se perciben grandes diferencias. Las medias son casi coincidentes (1.75 puntos para los nacionales y 1.73 puntos para los

\footnotetext{
${ }^{211}$ Cuatro preguntas fueron hechas para el registro de esta competencia. Dos en relación al seguimiento de noticias y dos en relación a dinámicas familiares que sugieren cierto interés por el mundo de lo político. Se otorgaba mayor valor a la persona que realizara cada actividad con mayor frecuencia. El rango de valores para cada actividad iba de 0 a 4 . Los valores en cada pregunta eran sumados y el total era dividido por 5.33 a efectos de conseguir un rango de valores que igualara el registro de la variable con las restantes competencias cívicas. El máximo valor de esta competencia para una persona es de 3 . El mínimo valor, en tanto, es de 0 punto.
} 
inmigrantes). Las medianas, a su vez, son iguales (1.80 puntos). La desviaciones típicas son prácticamente semejantes ( 0.45 para los locales y 0.46 para los extranjeros) ${ }^{212}$.

Esta semejanza en los registros se concreta aún más cuando se analizan los porcentajes de sujetos que, dentro de cada grupo, se ubican en posiciones máximas y mínimas. Entre los adolescentes de origen español, quienes realizan con máxima frecuencia todas las actividades de seguimiento a la realidad política son el $0.27 \%$ de la muestra (1 persona). En el caso de los adolescentes inmigrantes, ese mismo registro asciende a $0.65 \%$ de la muestra (también 1 persona). Ambos porcentajes se repiten al momento de analizarse quienes son los sujetos, dentro de cada grupo, que realizan con la menor frecuencia posible las cuatro actividades de seguimiento político incluidas en el cuestionario.

\section{Cuadro 3.2}

Medidas de concentración y dispersión para atención política de los adolescentes según condición migratoria

\begin{tabular}{|c|c|c|c|c|c|}
\hline $\begin{array}{c}\text { Condición } \\
\text { migratoria }\end{array}$ & Media & Desv. típ. & Mediana & $\begin{array}{c}\text { Porcentaje } \\
\text { de sujetos } \\
\text { con el valor } \\
\text { máximo } \\
(3)\end{array}$ & $\begin{array}{c}\text { Porcentaje } \\
\text { de sujetos } \\
\text { con el valor } \\
\text { mínimo } \\
(0)\end{array}$ \\
\hline Nacional $(\mathrm{N}=362)$ & 1,75 & 0,45 & 1,80 & $0,27 \%$ & $0,27 \%$ \\
Inmigrante (N=154) & 1,73 & 0,46 & 1,80 & $0,65 \%$ & $0,65 \%$ \\
Total $(\mathrm{N}=516)$ & 1,74 & 0,45 & 1,80 & $0,38 \%$ & $0,38 \%$ \\
\hline
\end{tabular}

Fuente: Elaboración propia.

El diagrama de caja en el gráfico 3.2 (ver Anexo № 4) permite visualizar la semejanza que, tanto en materia de concentración como de distribución de casos, presenta esta competencia cívica en ambos colectivos poblacionales. En los dos grupos, los casos que estadísticamente se reconocen como outliers son los que presentan el valor más bajo en la variable (no realizan nunca ninguna de las actividades consideradas para la medición de la atención política).

\footnotetext{
212 En ninguno de los indicadores estipulados para la medición de esta variable, la diferencia entre ambos colectivos es digna de destacar. En otras palabras, ninguna de estas "dimensiones" de la atención política presenta un comportamiento que amerite describir información desagregada.
} 
Realizando un anuncio que es casi verdad de Perogrullo, la aplicación de la prueba Kolmogorov-Smirnov de comparación de distribuciones para muestras independientes concluye que no existen diferencias estadísticamente significativas entre las mismas ( $p$ valor igual a 1.000) ${ }^{213}$. Estos resultados vienen a contrariar las hipótesis iniciales. Para explicar esta coincidencia de registros, pueden barajarse dos explicaciones de tipo complementario.

La primera de ellas es que la distribución de las frecuencias es semejante entre ambos colectivos porque aquello sobre lo que se pregunta (seguir, de alguna manera, la realidad política de la sociedad de acogida) no exige (como sí se cree que pasaría con la incorporación de conocimiento político) ni que el encuestado haya residido un tiempo prudencial en el país anfitrión ni grandes cuotas de esfuerzo por su parte. En las sociedades contemporáneas (aún más en entornos urbanos), resulta difícil mantenerse completamente al margen de dispositivos o situaciones que proveen de información política. La distribución uniforme de esta competencia, entre nativos e inmigrantes, está de hecho prevista en la literatura para población adulta (White et al. 2008).

La segunda refiere, entonces, a que la semejanza en ciertas variables independientes podría estar explicando la similitud del registro en esta competencia cívica. Al aplicarse la Correlación de Pearson a esta competencia cívica, se encuentra que esa variable podría ser "Actitudes Pro-Sociales". La misma se presenta como estadísticamente significativa en las tres muestras (global, nativos e inmigrantes) y su distribución no difiere entre ambos colectivos (Prueba K-S con un p valor igual a .894) Esta influencia está prevista en la literatura (Metz y Youniss, 2005).

En concreto, esta competencia política no estaría atentando contra los niveles de integración política de los adolescentes inmigrantes en la sociedad de acogida. A su vez, la existencia de idénticas pautas de comportamiento en la materia podría favorecer, según delata la evidencia empírica histórica, tanto los procesos individuales de toma de

\footnotetext{
${ }^{213}$ Se aplicó este test estadístico porque la distribución de la variable es no normal. La aplicación de la prueba T, para muestras normales, arrojó idéntico sentido en el resultado ( $p$ valor igual a 0.769 ).

${ }^{214}$ Otra explicación podría vincularse al hecho de que se haya respondido en función de lo que se considera adecuado socialmente (es decir, estar informado sobre lo que sucede). En tal caso, el factor "deseabilidad social" podría estar distorsionando los registros.
} 
decisiones (Niemi y Chapman, 1998; Mclntosh et al. 2007) como la postrera igualación en otras competencias cívicas ${ }^{215}$.

\section{3) Una nueva brecha: diferencias en participación política}

La media de participación política es de 1.62 sobre un total posible de 3 puntos $^{216}$. La mediana es ligeramente inferior (1.50). Esta mediana coincide con el valor que presentan aquellos sujetos que actuarían ante uno de los dos escenarios propuestos. La desviación típica es más elevada que en las dos competencias cívicas previamente analizadas (1.18 puntos). Esto último delata que los datos se han encontrado mejor distribuidos entre todos los valores posibles de la variable.

Concretando aún más los registros, se encuentra que el $27,5 \%$ de los adolescentes no realizaría ninguna de las actividades sugeridas. El 36,8\% realizaría, al menos, una de las actividades propuestas y el 35,66\% realizaría ambas acciones propuestas. En términos globales, la muestra general exhibe patrones más cercanos a la participación política que al inmovilismo.

Desagregando por colectivo poblacional, emergen tendencias interesantes. Aunque las medianas son coincidentes en ambos grupos (1.5 puntos), la media de la muestra nativa es superior (1.72 versus 1.38). Esto último estaría reflejando dos rasgos complementarios. La primera es que, proporcionalmente, el colectivo autóctono posee mayor proporción de individuos que presentan los valores más altos en la variable (38.67\% versus $28.28 \%$ ). La segunda es que el grupo nacional presenta menor proporción de individuos que tienen el registro más bajo en la variable (24.03\% versus $36.18 \%)^{217}$. En tanto, las desviaciones típicas casi no difieren entre ambos colectivos

\footnotetext{
${ }^{215}$ A efectos de comprender cómo la atención política favorece la posesión de otras competencias cívicas, por favor, revisar el apartado "¿Cómo se obtiene la información sobre la realidad política? La atención política como competencia cívica" dentro del Capítulo I del presente documento.

${ }^{216} \mathrm{~A}$ las personas encuestadas se les preguntaba, para esta competencia cívica, si realizarían dos acciones concretas. Para la medición de la participación política, existen tres niveles posibles (combinación de dos respuestas negativas, combinación de una respuesta negativa y otra positiva y combinación de dos respuestas positivas). El máximo valor de esta competencia para una persona es de 3 . El mínimo valor, en tanto, es de 0 punto.

217 Al analizarse de manera desagregada a los dos componentes utilizados para la medición de esta competencia cívica, se observa que los nativos aventajan a los extranjeros en ambos casos. Un $50.73 \%$ de los adolescentes autóctonos afirman que escribirían a una oficina pública haciendo llegar su punto vista. Ese registro desciende al $43.26 \%$ entre los adolescentes inmigrantes. Esta ventaja se acrecienta cuando se analiza si los encuestados se animan a exponer su punto de vista en una reunión pública y/o
} 
poblacionales. Si bien es ligeramente superior entre los inmigrantes (1.20 puntos versus 1.16), esta cuasi-coincidencia estaría reflejando la existencia de varianzas semejantes.

\section{Cuadro 3.3}

Medidas de concentración y dispersión para participación política de los adolescentes según condición migratoria

\begin{tabular}{|l|r|r|r|r|c|}
\hline \multicolumn{1}{|c|}{$\begin{array}{c}\text { Condición } \\
\text { migratoria }\end{array}$} & Media & Desv. típ. & Mediana & $\begin{array}{c}\text { Porcentaje } \\
\text { de sujetos } \\
\text { con el valor } \\
\text { máximo } \\
(3)\end{array}$ & $\begin{array}{c}\text { Porcentaje } \\
\text { de sujetos } \\
\text { con el valor } \\
\text { mínimo } \\
(0)\end{array}$ \\
\hline Nacional (N=362) & 1,72 & 1,16 & 1,50 & $38,67 \%$ & $24,03 \%$ \\
Inmigrante (N=154) & 1,38 & 1,20 & 1,50 & $28,28 \%$ & $36,18 \%$ \\
Total (N=516) & 1,62 & 1,18 & 1,50 & $35,66 \%$ & $27,52 \%$ \\
\hline
\end{tabular}

Fuente: Elaboración propia.

El diagrama de caja en el gráfico 3.3 (ver Anexo № 4) ayuda a visualizar la distribución de ambos colectivos en esta competencia cívica. Es fácilmente detectable que, para los nativos, la concentración de casos se da en valores medio-altos. Los sujetos con el valor más bajo son menos frecuentes en este grupo. Por el contrario, entre los adolescentes inmigrantes, la distribución de los casos es más regular entre todos los tipos de valores.

Al realizarse la prueba $W$ de Wilcoxon para muestras independientes, se encuentra que existe diferencia significativa de distribución de datos ( $p$ valor igual a 0.003 ) entre ambos colectivos ${ }^{218}$. Por tanto, desde el punto de vista estadístico, se ha hallado que existe una brecha en esta competencia cívica en concreto. Los adolescentes autóctonos afirman que actuarían ante situaciones hipotéticas más que lo acusado por los adolescentes inmigrantes. Al aplicarse la Correlación de Pearson a esta competencia cívica en relación a las variables independientes trabajadas, parecería que las diferencias en materia de "Grupo de Pares" 219 podrían estar motivando las divergencias existentes

comunitaria. En el caso de los nativos, el $67.89 \%$ lo haría. En tanto, en el grupo de los inmigrantes, desciende a un 52.67 el porcentaje de quienes responden en tal sentido.

${ }^{218}$ Se aplicó este test estadístico porque la distribución de la variable es no normal. La aplicación de la prueba T, para muestras normales, arrojó idéntico sentido en el resultado ( $p$ valor igual a 0.000).

${ }^{219}$ La correlación entre Grupo de Pares y Participación Política es de .235 en la muestra global, de .213 entre los nativos y de .201 entre los inmigrantes. En todos los casos, la significación estadística se dio al .000 . 
entre los grupos en este guarismo ${ }^{220}$. La literatura prevé la existencia de esta relación (Youniss et al., 2001; McFarland y Thomas, 2006).

La integración política de los adolescentes inmigrantes se ve disminuida entonces por el registro en este atributo cívico. Este resultado es especialmente relevante porque, gracias al modo en el que se ha construido la variable, se ha descubierto que los adolescentes inmigrantes estarían menos dispuestos a influir en los procesos de toma de decisiones de asuntos que directamente les incumben. Su no participación también puede perjudicar tanto sus niveles de autonomía como su sensación de bienestar personal (Weitz-Shapiro y Winters, 2008). Ampliando la perspectiva hacia lo sistémico, la permanencia en el tiempo de records de esta naturaleza (menor participación relativa de determinados grupos sociales) podría afectar negativamente la fortaleza de las instituciones democráticas de la sociedad de acogida (Pateman, 1970; Levine y Molina, 2007).

\section{4) La brecha disminuye. Los registros adolescentes en eficacia política}

En materia de eficacia política, se hallan tendencias destacables. La media es de 1.02 sobre un total posible de 3 puntos $^{221}$. La mediana es bastante superior (1.50) a la media. La mediana coincide, como en el caso de la participación política, con el valor que presentan los sujetos que responden positivamente a una de las dos preguntas efectuadas. La desviación típica supera ligeramente el punto (1.09). Este último registro

\footnotetext{
${ }^{220}$ Como se dijo en su momento para "Conocimiento Político", la media de los nacionales (8.05) en "Grupo de Pares" es superior a la de los inmigrantes (7.37) y las diferencias de distribuciones entre ambas muestras es estadísticamente significativa (K-S con un $\mathrm{p}$ valor de .000). Tanto en una como en otra competencia cívica, esta diferencia podría haber estado escondiendo otra vinculada al hecho de que, en términos globales (promedio), los inmigrantes suelen concurrir a escuelas en las que hay mayor presencia de extranjeros $(37,30 \%)$ que a las que asisten los nativos (16.97\%). Ello, sin embargo, no se corrobora cuando se ve que, entre los nativos, existe una correlación (positiva) de Pearson entre ambas variables (Porcentaje de Inmigrantes en la Escuela e Integración Política del Grupo de Pares) de .224 con un p valor menor o igual a .005. Para los inmigrantes, la correlación es negativa (como aquí se ha propuesto y sería intuitivo pensar) pero no es estadísticamente significativa.

${ }^{221} \mathrm{~A}$ las personas encuestadas se les preguntaba, para esta competencia cívica, dos cuestiones. La primera de ellas estaba referida a la dimensión interna de la eficacia (capacidad de comprensión de la realidad política). La segunda de ellas estaba referida a la dimensión externa de la eficacia (si el sistema político reacciona a las demandas recibidas). Para la medición de la eficacia política, existen tres niveles posibles (combinación de dos respuestas negativas, combinación de una respuesta negativa y otra positiva y combinación de dos respuestas positivas). El máximo valor de esta competencia para una persona es de 3. El mínimo valor, en tanto, es de 0 punto.
} 
delata que la distribución de los sujetos entre los diferentes valores de la variable es más uniforme que lo observado para dos de las competencias cívicas ya analizadas (conocimiento político y atención política).

Si se analizan en detalle los valores encontrados, se observa que casi la mitad de la muestra (el $47.67 \%$ de los adolescentes encuestados) presenta el valor menor en esta variable. Esto quiere decir que ni afirman comprender la política ni creen que el sistema político es reactivo a las exigencias externas. Quienes se ubican en una posición intermedia son el $36,6 \%$ de la muestra. Estos sujetos son los que poseen una de las dos dimensiones de la eficacia. Sólo el 15,7\% afirma que comprende la realidad política y que el sistema político tiende a responder a las exigencias que le son hechas llegar o, en otras palabras, presenta registros altos en ambas dimensiones de la eficacia.

Cuando los datos se desagregan entre colectivos poblacionales, emergen pautas que delatan una relativa diferencia a favor de los nativos. Los adolescentes de origen nacional presentan una media ligeramente superior a 1 (1.05 puntos). Los adolescentes inmigrantes se ubican justo por debajo de 1 (0.96 puntos). Esta diferencia es producto de que, en el caso de los nativos, el porcentaje de individuos que presentan la posición más alta es de $17.12 \%$. Este registro baja al $12.5 \%$ en el caso de los inmigrantes. Esta diferencia se revierte en el caso de analizar los porcentajes de las personas que presentan los valores más bajos en la variable. Ambos grupos presentan valores escasamente inferiores al $50 \%$ (47.23\% para los nativos y $48.68 \%$ para los extranjeros) $)^{222}$.

Las medianas de ambos grupos coinciden, como se ha visto para la participación política, en el valor intermedio de 1.5 (es decir que, para ambos grupos, el sujeto mediano es aquel que tienen desarrollada sólo una de las dimensiones de la eficacia política). La desviación típica, en tanto, es algo superior entre los nacionales (1.17 puntos) en relación a la presentada por los inmigrantes (1.04 puntos). Esta diferencia puede encontrarse relacionada al hecho de que el primer grupo es cuantitativamente

\footnotetext{
${ }^{222}$ En el caso de la dimensión interna de la eficacia política, los nativos aventajan a los adolescentes inmigrantes en cantidad de individuos que afirman comprender la política (44.30\% versus $39.16 \%)$. En el caso de la dimensión externa de la eficacia política, la ventaja favorece por un margen estrecho a los adolescentes inmigrantes. El $30.15 \%$ de los adolescentes extranjeros afirman que es posible influir en las decisiones del gobierno. En tanto, ese valor es de $29.03 \%$ entre los nativos.
} 
mayor que el segundo en la muestra (362 individuos versus 154 individuos) y, por tanto, se encuentra expuesto a mayor variabilidad.

\section{Cuadro 3.4}

Medidas de concentración y dispersión para eficacia política de los adolescentes según condición migratoria

\begin{tabular}{|l|r|r|r|r|c|}
\hline \multicolumn{1}{|c|}{$\begin{array}{c}\text { Condición } \\
\text { migratoria }\end{array}$} & Media & Mediana & Desv. típ. & $\begin{array}{c}\text { Porcentaje } \\
\text { de sujetos } \\
\text { con el valor } \\
\text { máximo } \\
(3)\end{array}$ & $\begin{array}{c}\text { Porcentaje } \\
\text { de sujetos } \\
\text { con el valor } \\
\text { mínimo } \\
(0)\end{array}$ \\
\hline Nacional (N=362) & 1,05 & 1,50 & 1,11 & $17,12 \%$ & $47,23 \%$ \\
Inmigrante (N=154) & 0,96 & 1,50 & 1,04 & $12,50 \%$ & $48,68 \%$ \\
Total (N=516) & 1,02 & 1,50 & 1,09 & $15,70 \%$ & $47,67 \%$ \\
\hline
\end{tabular}

Fuente: Elaboración propia.

El diagrama de caja en el gráfico 3.4 (ver Anexo № 4) muestra que la mayor concentración de sujetos se da entre los valores 0 y 1.5 para ambos grupos poblacionales. En consecuencia, en los dos casos, quienes presentan el valor más alto para la variable ( 3 puntos) poseen un comportamiento no preponderante en esta variable.

Al realizarse la prueba Kolmogorov-Smirnov para la comparación de muestras independientes, se encuentra que no existe diferencia estadísticamente significativa ( $p$ valor igual a 0.976) $)^{223}$. Esta competencia cívica no sería la causante de la existencia de diferencias en materia de integración política entre ambos colectivos de adolescentes. Morales y Giugni (2011) ya han encontrado resultados semejantes, al comparar entre nativos e inmigrantes, para población adulta.

La literatura revisada sostiene que atención política y eficacia política se encuentran generalmente correlacionadas (Chaffee, 1977; Rubin, 1978). El no hallazgo de diferencias significativas para la atención política podría estar entonces asociado al no hallazgo de diferencias significativas para eficacia política en nuestra muestra. La

\footnotetext{
${ }^{223}$ Se aplicó este test estadístico porque la distribución de la variable es no normal. La aplicación de la prueba T, para muestras normales, arrojó idéntico sentido en el resultado ( $p$ valor igual a 0.227).
} 
aplicación de "Correlación de Pearson" entre ambas competencias cívicas confirma la sospecha. El nivel de asociación, si bien bajo (.212), presenta alta significación estadística ( $p$ valor igual a .000) en la muestra global. Al ser chequeada esta pauta en nativos e inmigrantes, la asociación estadística sólo se repite para los primeros (con una magnitud de .275 y un $p$ valor de .000).

Esta semejanza de resultados podría derivar de otro rasgo que es medianamente compartido entre autóctonos e inmigrantes: el status socioeconómico. La igualdad entre ambos grupos de registros bajos en esta competencia podría vincularse a la pertenencia a los estratos sociales medio-bajos por parte de las familias de los estudiantes tal como es previsto por la literatura especializada (Caprara et al. 2009). La Correlación de Pearson destacó la asociación entre ambas variables (status socioeconómico y eficacia política). Las dos muestras (nativos e inmigrantes) no difieren, según la prueba K-S, en la distribución de los valores en Status Socioeconómico (.642). Existe otra "igualdad" entre los grupos que podría estar propiciando esta uniformidad de medias en materia de eficacia política. Es la evidenciada en la variable Actitudes Pro-Sociales tal como se vio para el caso de la Atención Política ${ }^{224}$. Esta influencia está prevista en la literatura (Metz y Youniss, 2005).

Estos resultados vienen a contrariar parcialmente las hipótesis iniciales. A su vez, el que existan idénticas pautas de comportamiento entre los dos grupos podría favorecer, según es recogido por la literatura, la igualación postrera de otras competencias cívicas ${ }^{225}$.

\section{5) ¿"Quién tolera qué" entre los adolescentes?}

La tolerancia política es la competencia cívica en la que se presentan los valores más altos en la muestra global. La media de este atributo es de 2.39 puntos. La mediana, en tanto, coincide con el valor más alto de la variable (3 puntos). Esto implica que la

\footnotetext{
224 Para una mejor comprensión de lo mencionado en relación a la variable "Actitudes Pro-Sociales", por favor visitar, dentro de este capítulo, el apartado "2.2) Cuando el origen nacional no importa. Registros en atención política".

${ }^{225}$ A efectos de comprender cómo la eficacia política favorece la posesión de otras competencias cívicas, por favor, revisar el apartado "¿Cuánto se afirmar comprender sobre la realidad política y cuán moldeable se la considera? La eficacia política como competencia cívica" dentro del Capítulo I del presente documento.
} 
mitad de la muestra expresa ser, ante todas las situaciones planteadas, tolerante ${ }^{226}$. La desviación típica, en esta competencia, ha sido reducida (0.78 puntos). Ello implica que los casos se encuentran relativamente concentrados en un número limitado de valores.

El 53,1\% de los encuestados presentan el puntaje más alto en la variable. En esta muestra, sólo el $3,1 \%$ se posiciona como nada tolerante. Se observa, entonces, que existe un claro predominio de quienes toleran todas las situaciones planteadas. Los sujetos autodefinidos como no tolerantes son una porción mínima de la muestra.

Cuando los datos se desagregan entre colectivos poblacionales, aparece una tendencia que marca una diferencia en favor de los nativos. Mientras los adolescentes nativos poseen una media de 2.53 puntos, los inmigrantes apenas sobrepasan los 2 puntos (2.07). La observación de la mediana es aún más contundente al describir la brecha existente. Para los nacionales, es de 3 puntos (coincide con el valor más alto de la variable). Para los extranjeros, es de sólo 2.25 puntos $^{227}$. El $62.98 \%$ de los autóctonos presenta el valor más alto en este atributo. Ese registro desciende al $29.61 \%$ en el caso de los inmigrantes. Sobre el valor más bajo en esta competencia, sólo un $1.93 \%$ de los locales la presenta. Entre los extranjeros, esa suma alcanza el $5.92 \%$ sobre su total. Las desviaciones típicas, aunque mayor entre los inmigrantes, no reflejan una amplia diferencia entre ambos grupos (0.71 puntos para los nativos versus 0.84 para los inmigrantes).

\footnotetext{
${ }^{226}$ A las personas encuestadas se les preguntaba, para esta competencia cívica, cuatro cuestiones. La primera y la segunda de ellas estaban referida a la aceptación por parte de los encuestados de dos dispositivos legales propios de las sociedades avanzadas (matrimonio homosexual y aborto). En este caso, se mide lo que se llama tolerancia política lato sensu. La tercera y la cuarta de ellas estaban referida a la aceptación de dos situaciones en las que el propio punto de vista se puede ver confrontado por otras posiciones (posesión de material que exprese opiniones distintas a las propias y discusión con individuos que no coincidan con el parecer de los respondientes). En este caso, se mide lo que se llama tolerancia política stricto sensu. Las respuestas a las cuatro preguntas fueron combinadas. El máximo valor de esta competencia para una persona es de 3 . El mínimo valor, en tanto, es de 0 punto.

$227 \mathrm{Al}$ analizarse de manera desagregada los componentes de esta competencia cívica, se hallan comportamientos dignos de ser mencionados. En materia de aceptación del aborto, el $81.95 \%$ de los nacionales responde en tal sentido. Ese registro desciende al $49.32 \%$ en el caso de los inmigrantes (32.63 puntos de diferencia). La brecha se acorta al preguntarse sobre aceptación del matrimonio homosexual. Mientras el $88.86 \%$ de los nativos lo aprueba, un $70.95 \%$ de los inmigrantes lo hace (17.91 puntos de diferencia). Se mantiene una brecha, aunque menor a las mencionadas, cuando se pregunta si se discutiría con quienes tienen posiciones diferentes a las propias. Un $87.56 \%$ de los autóctonos lo haría. Entre los inmigrantes, un $82.01 \%$ actuaría en tal sentido (5.55 puntos de diferencia). Al preguntarse sobre la posibilidad de poseer material que describa posiciones o ideas distintas a las propias, la brecha es casi inexistente. Un $89.83 \%$ de los nacionales admite que lo haría y un $88.24 \%$ de los inmigrantes coincide con tal criterio.
} 


\section{Cuadro 3.5}

Medidas de concentración y dispersión para tolerancia política de los adolescentes según condición migratoria

\begin{tabular}{|l|r|r|r|r|c|}
\hline & & & $\begin{array}{c}\text { Porcentaje } \\
\text { de sujetos } \\
\text { con el valor } \\
\text { máximo } \\
\text { migratoria }\end{array}$ & $\begin{array}{c}\text { Porcentaje } \\
\text { de sujetos } \\
\text { con el valor } \\
\text { mínimo } \\
(0)\end{array}$ \\
\hline Nacional (N=362) & Media & Desv. típ. & Mediana & $(3)$ & \multicolumn{1}{c|}{$(0)$} \\
Inmigrante (N=154) & 2,53 & 0,71 & 3,00 & $62,98 \%$ & $1,93 \%$ \\
Total (N=516) & 2,07 & 0,84 & 2,25 & $29,61 \%$ & $5,92 \%$ \\
\hline
\end{tabular}

Fuente: Elaboración propia.

El diagrama de caja de esta competencia cívica en el gráfico 3.5 (ver Anexo №4) muestra que la mayor concentración de sujetos se da, para los vernáculos, entre los valores más altos de la variable. Entre los inmigrantes, la distribución de los casos es más amplia. Eso explicaría que este grupo posea una desviación típica algo superior. Solamente en el caso de los locales, los sujetos con valores bajos en la variable son los que asumen un comportamiento estadístico de tipo outlier.

Al realizarse la prueba Kolmogorov-Smirnov, se encuentra que existe una diferencia en la distribución de valores ( $p$ valor igual a 0.000$)^{228}$. Ello implica que ambos grupos son, desde el punto de vista estocástico, diferentes. Estos resultados vienen a confirmar las hipótesis iniciales. Esta divergencia vendría dada fundamentalmente por los componentes de esta variable asociados a lo que se llama tolerancia política lato sensu o, en otras palabras, el nivel de aceptación de dispositivos legales propio de sociedades occidentales (aborto y matrimonio homosexual).

El rezago del colectivo inmigrante en estos registros concretos puede deberse a la existencia de un "Nivel de Religiosidad" más pronunciado (2.64 puntos sobre un total de 6) que el evidenciado entre los autóctonos (2.09 puntos). Cuando se ha aplicado la Correlación de Pearson para explorar los niveles de asociación de la Tolerancia Política con diferentes variables independientes, el nivel de religiosidad se relaciona negativamente con esta competencia cívica y posee significación estadística para las tres

\footnotetext{
${ }^{228}$ Se aplicó este test estadístico porque la distribución de la variable es no normal. La aplicación de la prueba T, para muestras normales, arrojó idéntico sentido en el resultado ( $p$ valor igual a 0.000).
} 
muestras ${ }^{229}$. Ello responde a lo previsto por la literatura en la materia (Niemi y Chapman, 1998; Eisenstein, 2006).Cuando se compara mediante la prueba K-S a los colectivos inmigrante y nativo para el hallazgo de la existencia de distribuciones diferentes de valores, ésta es comprobada con un nivel de significación de .000.

Otra variable que aparece estadísticamente asociada con la Tolerancia Política pero con signo positivo es "Cantidad de Años de Residencia". Ello sucede en las tres muestras $^{230}$. Como se vio en el caso del "Conocimiento Político", este factor sociodemográfico se distribuye de manera distinta y estadísticamente significativa entre ambos colectivos (Prueba K-S con un p valor igual a .000). La combinación de "Cantidad de Años de Residencia" con "Nivel de Religiosidad" parecería estar promoviendo, en principio, la desigualdad entre las muestras nativa e inmigrante en materia de Tolerancia Política. La permanencia en el tiempo de esta diferencia inter-colectivos, según sugiere la literatura, podría afectar (negativamente) a futuro el funcionamiento y la eficacia de las instituciones democráticas (Owen y Dennis, 1987).

\section{6) Comparando brechas entre adolescentes autóctonos e inmigrantes}

Al compararse los registros alcanzados por cada grupo en cada competencia cívica, se percibe con claridad la existencia de las brechas a las que apunta esta investigación en sus hipótesis iniciales. En todos los casos, el colectivo autóctono presenta valores más elevados que el grupo inmigrante. Se verifica entonces la hipótesis inicial que preveía tal situación. Ello podría influir negativamente en el colectivo desfavorecido a la hora de hacer frente a futuros desafíos y responsabilidades vinculadas al mundo de lo político (Ruiz-Silva y Chaux, 2005).

Las diferencias son mínimas en el caso de la atención política (0.02 puntos) y eficacia política (0.09), es decir, cuando no ha existido significación estadística al comparar la distribución de valores entre ambos conjuntos de individuos. Las brechas se acrecientan, lógicamente, en el caso de las competencias en las que ha habido diferencias estadísticamente significativas. Es lo que sucede con la participación política

\footnotetext{
${ }^{229}$ En el caso de la muestra global, la correlación ha sido de -.256. Para los nativos, fue de -.180. En tanto, para los inmigrantes, fue de -.264. En los tres casos, el nivel de significación fue de 0.000 . ${ }^{230}$ En el caso de la muestra global, la correlación ha sido de .331 Para los nativos, fue de .177. En tanto, para los inmigrantes, fue de .269. En los tres casos, el nivel de significación fue de 0.000 .
} 
(0.34 puntos) y la tolerancia política (0.46 puntos). Son aún mayores en el caso del conocimiento político (0.58 puntos). Este último dato corrobora otra de las hipótesis iniciales: aquélla que preveía que las diferencias serían mayores para el caso concreto de este atributo cívico.

El siguiente cuadro resume las medias presentadas por cada colectivo en cada competencia cívica. En color rojo, se colocan aquellas medias que, una vez comparadas las muestras mediante las pruebas K-S y W de Wilcoxon, han generado diferencias estadísticamente significativas. Al mismo tiempo, se incorpora información sobre la brecha existente entre ambos grupos por registro cívico. La brecha sobremarcada en color rojo (conocimiento político) es la que señala la mayor distancia entre adolescentes autóctonos e inmigrantes.

\section{Cuadro 3.6}

Comparación de medias en competencias cívicas por colectivo poblacional

\begin{tabular}{||c|c|c|c|c|c||}
\hline \hline \multirow{2}{*}{$\begin{array}{c}\text { Colectivo } \\
\text { poblacional }\end{array}$} & \multicolumn{5}{|c|}{ Medias de Competencias Cívicas } \\
\cline { 2 - 6 } & $\begin{array}{c}\text { Conocimiento } \\
\text { Político }\end{array}$ & $\begin{array}{c}\text { Atención } \\
\text { Política }\end{array}$ & $\begin{array}{c}\text { Participación } \\
\text { Política }\end{array}$ & $\begin{array}{c}\text { Eficacia } \\
\text { Política }\end{array}$ & $\begin{array}{c}\text { Tolerancia } \\
\text { Política }\end{array}$ \\
\hline Nacional & 1.23 & 1.75 & 1.72 & 1.05 & 2.53 \\
\hline Inmigrante & 0.65 & 1.73 & 1.38 & 0.96 & 2.07 \\
\hline $\begin{array}{c}\text { Diferencia } \\
\text { de } \\
\text { medias }\end{array}$ & 0.58 & 0.02 & 0.34 & 0.09 & 0.46 \\
\hline \hline
\end{tabular}

Fuente: Elaboración propia.

En próximos apartados, se evaluará, desde una perspectiva multivariante, cómo las diferentes variables independientes pueden estar propiciando las convergencias y divergencias evidenciadas entre ambos grupos en las diferentes competencias cívicas. El Análisis de Correlación Canónica es la herramienta multivariante que se usará a tales efectos y que facilitará ver qué combinación de factores socio-demográficos, psicosociales y agentes de socialización facilitan la posesión simultánea de los atributos cívicos que han sido usados como indicadores de la integración política. 


\section{3) Explorando la medida global. Patrones de integración política entre adolescentes inmigrantes y autóctonos}

En este subcapítulo, la hipótesis principal que se desea verificar es la vinculada a la presunción de que los adolescentes locales presentan valores más elevados que los adolescentes inmigrantes en la variable integración política. La presentación se ha estructurado de la siguiente manera. En primer lugar, se analizarán las principales medidas de concentración y dispersión de esta variable. En segundo lugar, se procede a comparar idénticos indicadores entre ambos colectivos poblacionales. En los dos momentos, se visualizará el comportamiento de la variable mediante la utilización estratégica de diagramas de caja. Finalmente, se cierra con una comparación de medias a través de la aplicación de la prueba T para muestras independientes para detectar si existen diferencias estadísticamente significativas.

Al analizarse la medida global de integración política, sobre un valor máximo posible de 15 puntos $^{231}$, la media es de 7.85 puntos y la mediana es de 7.87 puntos (ambas son ligeramente superiores a 7.5, la mitad posible del registro). En tanto, la desviación típica es de 2.70 puntos. Los sujetos que se posicionan en el $20 \%$ de los valores inferiores (0-3) de la variable son el $2.51 \%$ de la muestra. En tanto, los sujetos que se ubican en el $20 \%$ de los valores superiores (12-15) de la variable representan el 6\%. Un único sujeto presentó el menor valor posible (0). Ningún sujeto alcanzó el máximo puntaje posible. El máximo puntaje obtenido ha sido de 14.85 y fue conseguido por un único individuo. La aplicación de la prueba Kolmogorov-Smirnov permitió comprobar que la distribución de la variable es de tipo normal.

La visualización del diagrama de caja en el Gráfico 3.6 (ver Anexo №4) de la integración política confirma el carácter normal de la muestra global de adolescentes. El 50\% de los sujetos se ha ubicado entre los valores 6 y 10 de la variable. La construcción de este gráfico no ha detectado la existencia de sujetos que asuman el comportamiento de outliers.

\footnotetext{
${ }^{231} \mathrm{El}$ valor que asume cada sujeto en esta variable es el resultado de sumar sus registros en cada una de las competencias cívicas ya mencionadas.
} 
Al desagregarse la información según colectivos poblacionales, se observa que los adolescentes nacionales superan en 1.49 puntos a sus pares inmigrantes. Mientras los primeros presentan una media de 8.29 puntos de integración política, la media de los segundos se ubica en 6.80. La observación de la mediana delata también idéntico comportamiento. Para los nacionales, es de 8.25 puntos. Para los extranjeros, es de 6.60 . El $8.28 \%$ de los adolescentes nativos presenta registros dentro del $20 \%$ de valores más elevados de la variable. Ese registro desciende al $0.65 \%$ (una única persona) entre los adolescentes inmigrantes. El 1.65\% de los nativos presenta algún registro dentro del $20 \%$ de los valores más bajos de la variable. Ese valor asciende al $4.60 \%$ entre los extranjeros. Las desviación típica es mayor entre autóctonos (2.68 versus 2.48 puntos).

\section{Cuadro 3.7}

Medidas de concentración y dispersión para integración política de los adolescentes según condición migratoria

\begin{tabular}{|c|c|c|c|c|c|}
\hline $\begin{array}{l}\text { Condición migratoria } \\
\text { del hijo }\end{array}$ & Media & Mediana & Desv. típ. & $\begin{array}{c}\text { Porcentaje } \\
\text { de sujetos } \\
\text { en el } 20 \% \\
\text { de valores } \\
\text { máximos }\end{array}$ & $\begin{array}{c}\text { Porcentaje } \\
\text { de sujetos } \\
\text { en el } 20 \% \\
\text { de valores } \\
\text { mínimos }\end{array}$ \\
\hline Nacional $(\mathrm{N}=362)$ & 8,29 & 8,25 & 2,68 & $8,28 \%$ & $1,65 \%$ \\
\hline Inmigrante $(\mathrm{N}=154)$ & 6,80 & 6,60 & 2,48 & $0.65 \%$ & $4,60 \%$ \\
\hline Total $(\mathrm{N}=516)$ & 7,85 & 7,80 & 2,71 & $6,00 \%$ & $2,51 \%$ \\
\hline
\end{tabular}

Fuente: Elaboración propia.

La observación del diagrama de caja (Gráfico 3.7 en Anexo № 4) para esta variable considerando a los dos grupos por separado da cuenta de las diferencias señaladas. En el mismo, se percibe que el 50\% de los adolescentes nativos presenta valores de integración política entre 6 y 10 puntos. Para este grupo, los individuos considerados estadísticamente como outliers son aquéllos que se posicionan en el valor más bajo posible de esta variable ( 0 punto). Los sujetos pertenecientes a este grupo cubren, tal como vaticinaba la desviación típica, un espectro más amplio de valores de la variable que sus pares extranjeros. En tanto, para los adolescentes inmigrantes, el $50 \%$ de los casos se ubica entre los 5 y 9 puntos. Para este colectivo, quienes son considerados como outliers son los individuos que se posicionan en el terreno cercano al máximo valor posible (15 puntos). 
Al aplicarse la prueba T para comparación de muestras independientes, se observa que existe igualdad de las varianzas (0.441). Sin embargo, las medias difieren desde el punto de vista estadístico (0.000). Esto, en otras palabras, implica que existe una diferencia significativa entre ambos colectivos en materia de integración política. El colectivo local aventaja estadísticamente al colectivo inmigrante.

Este resultado confirma la hipótesis inicial que preveía que la integración política sería mayor entre los adolescentes nativos en comparación a sus pares inmigrantes ${ }^{232}$. Si se parte del supuesto que la performance cívica durante la adolescencia es un correcto predictor de la performance cívica en la adultez, el presente diagnóstico podría estar encubriendo potenciales escenarios de infraciudadanía (Jennings y Niemi, 1981; Verba et al., 1995). En próximos apartados, se evaluarán las diferentes alternativas que tienen por objeto explicar las razones que se hallan detrás de esta diferencia de valores en integración política entre ambos colectivos poblacionales. Ello será realizado mediante la aplicación de Regresión Múltiple.

\section{1) Comprobación parcial de hipótesis de trabajo}

En el siguiente cuadro, se realiza una primera comprobación parcial de las hipótesis de trabajo asumidas por esta investigación. El mismo incluye a las hipótesis que han podido ser confirmadas mediante la exploración estadística que ha sido realizada hasta el momento.

\footnotetext{
${ }^{232}$ Si bien no puede afirmarse que los nativos tienen una integración política plena (su media se encuentra a 6.71 puntos del máximo posible de 15), su performance resulta ampliamente superior a la de los inmigrantes.
} 
Cuadro 3.8

Comprobación parcial de hipótesis de trabajo

\begin{tabular}{|c|c|c|c|}
\hline & Hipótesis & Hallazgo & Nota aclaratoria \\
\hline \multirow{2}{*}{ 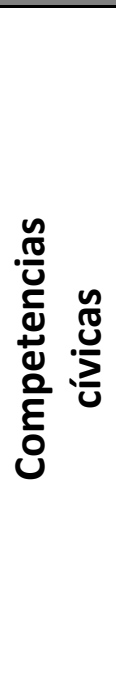 } & $\begin{array}{l}\text { Los niveles de posesión de las } \\
\text { competencias cívicas serán } \\
\text { mayores entre los adolescentes } \\
\text { nativos en comparación a sus pares } \\
\text { de origen inmigrante. }\end{array}$ & Confirmatorio & $\begin{array}{l}\text { Los valores han sido favorables para } \\
\text { los nativos en todas las } \\
\text { competencias cívicas. Las } \\
\text { diferencias estadísticamente } \\
\text { significativas de distribución se han } \\
\text { dado para Conocimiento Político, } \\
\text { Participación Política y Tolerancia } \\
\text { Política }\end{array}$ \\
\hline & $\begin{array}{l}\text { La competencia cívica en la que la } \\
\text { brecha será mayor entre nativos e } \\
\text { inmigrantes será el conocimiento } \\
\text { político debido a que la adquisición } \\
\text { de esta competencia requiere, en } \\
\text { comparación a otras, mayor } \\
\text { tiempo de asentamiento en la } \\
\text { sociedad de acogida }\end{array}$ & Confirmatorio & $\begin{array}{l}\text { Efectivamente, Conocimiento } \\
\text { Político es la competencia cívica } \\
\text { que más correlaciona con la } \\
\text { variable independiente Cantidad de } \\
\text { Años de Residencia en la sociedad } \\
\text { de acogida }\end{array}$ \\
\hline 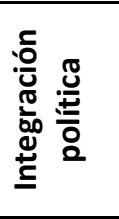 & $\begin{array}{l}\text { Los niveles de integración política } \\
\text { serán mayores entre los } \\
\text { adolescentes nativos en } \\
\text { comparación a sus pares de origen } \\
\text { inmigrante. }\end{array}$ & Confirmatorio & 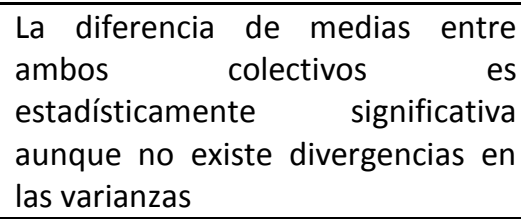 \\
\hline
\end{tabular}

Fuente: Elaboración propia.

4) Evaluación de la influencia de factores y agentes de socialización sobre las competencias cívicas. El Análisis de Correlación Canónica como estrategia multivariante

En este subcapítulo, las hipótesis que se desea verificar son las vinculadas a la influencia de los factores y agentes de socialización estudiados en las diferentes competencias cívicas. En primer lugar, se repasarán algunas de las características y ventajas del test estadístico multivariante que se ha usado a tales efectos. El que sea una prueba estocástica escasamente utilizada exige tal repaso para facilitar su comprensión por parte del lector. En segundo lugar, se procederá a presentar y discutir los resultados arrojados por la aplicación de esta técnica. En tal sentido, la detección de los factores y agentes "relevantes" para la producción de las competencias cívicas permitirá elaborar mejores modelos de Regresión Múltiple para la explicación de la integración política como medida global. 
En un tercer momento, mediante la aplicación de una innovadora herramienta para la visualización de resultados estadísticos (heliógrafo), se percibirá cómo se relacionan globalmente las diferentes variables independientes con cada uno de los atributos cívicos. Finalmente, en un cuarto momento, se hará una breve revisión de si se han o no corroborado las diferentes hipótesis de investigación.

\section{1) Complejidad social, análisis multivariante y correlación canónica}

Anteriormente, se expuso cuál es el comportamiento de las muestras de nativos e inmigrantes en cada una de las competencias cívicas. También, se especuló en relación a las variables que podrían estar propiciando divergencias o convergencias en cada uno de los diferentes atributos. Existe un test multivariante, poco aplicado pero de utilidad incrementalmente reconocida, para conocer cómo diferentes variables independientes (factores y agentes de socialización) pueden estar incidiendo simultáneamente en la producción de diferentes variables dependientes (competencias cívicas). Este test es el Análisis de Correlación Canónica (ACC).

Como se mencionaba en los últimos párrafos del Capítulo II, el Análisis de Correlación Canónica cuenta con una serie de ventajas. Una de ellas (y la que más relevante resulta de cara a la presente investigación) es que permite descifrar la relación simultánea que existe entre un grupo de variables predictoras y un grupo de variables criterio. En tal sentido, este test multivariante es una extensión de la correlación bivariante que permite el hallazgo de las mejores combinaciones lineales entre dos sets de variables. Por lo comentado, se afirma que esta prueba estocástica resulta altamente adecuada para dar cuenta de la complejidad existente en la realidad social.

Estos sets reciben también el nombre de pares de variables canónicas. Cada uno de los componentes de estos pares se encuentra identificado por un valor teórico canónico. Estos valores teóricos son los que se correlacionan canónicamente ${ }^{233}$. A la vez, las combinaciones lineales entre los sets pueden ser también denominadas funciones canónicas. En un Análisis de Correlación Canónica, existen tantas funciones canónicas

\footnotetext{
233 En inglés, estos valores son denominados "canonical variates" o "linear composites". Los mismos son como "variables resumen" de las variables incluidas en cada set.
} 
como número de variables tenga el set con menor cantidad de variables. Una función canónica es relevante cuando posee tanto significación estadística como significación práctica. En el caso concreto de esta investigación, puede haber hasta 5 (cinco) funciones canónicas ${ }^{234}$.

Cuando se analizan los resultados de una correlación canónica, son cuatro los registros que deben tomarse en cuenta (Hair et al. 2007). En primer lugar, como en toda prueba estadística, debe considerarse el nivel de significación de la función canónica. En segundo lugar, el investigador debe detenerse en la magnitud de las relaciones canónicas (o tamaño de las correlaciones canónicas) entre los valores teóricos canónicos. Esta última recibe también el nombre de $R$ canónico $\left(R_{c}\right)$.

En tercer lugar, es importante observar la medida o índice de redundancia. Esta proporciona una estimación de la varianza compartida entre los dos sets de variables. En otras palabras, este guarismo permite conocer cuánto de la varianza del set de variables dependientes es explicado o compartido por el set de variables independientes (y viceversa) ${ }^{235}$. Por sus características, puede ser usado como una medida de predicción. En cuarto lugar, deben mirarse las cargas canónicas. Las mismas miden la correlación lineal entre una variable de cualquiera de los sets (dependiente o independiente) y el valor teórico canónico del set al que pertenece. Puede ser entendida, así mismo, como una carga factorial para ponderar el aporte de la variable en cuestión a la función canónica.

Existen otras dos medidas que, siendo producto de la utilización de este test, también son recomendadas para su observación. Una es el $R^{2}$ canónico $\left(R^{2}{ }_{c}\right)$. Otro es el llamado coeficiente de adecuación ${ }^{236}$. La primera no es otra cosa sino la elevación al cuadrado del R canónico. El último permite conocer cuánta es la varianza compartida entre las variables que forman parte de un set (predictor y criterio) y el valor teórico

\footnotetext{
${ }^{234}$ Este número resulta de comparar los dos sets de variables. El que corresponde a las variables independientes cuenta con un máximo de 10 variables ( 5 variables socio-demográficas, 1 variable psicosocial, 3 agentes de socialización y 1 variable de control que también tiene naturaleza socio-demográfica: el género). El que se vincula a las variables dependientes cuenta con un número constante de 5 variables (las competencias cívicas). Este último número es igual a la cantidad de funciones canónicas que el análisis puede generar.

235 En ocasiones, la medida de redundancia es considerada semejante al $\mathrm{R}^{2}$ de la Regresión. Generalmente, sus valores son bajos porque el Análisis de Correlación Canónica no intenta optimizar su valor.

${ }^{236}$ La multiplicación de ambos da lugar a la obtención de la medida o índice de redundancia.
} 
atribuible al set en cuestión. En otras palabras, cuánto de la varianza de las variables es adjudicable al valor teórico. Se obtiene mediante la consecución de las medias de las cargas canónicas al cuadrado.

\section{2) Aplicando la correlación canónica. ¿En qué difieren nativos de inmigrantes?}

El Análisis de Correlación Canónica exige para su aplicación el que se respeten los supuestos de linealidad, homocedasticidad y multicolinealidad. Una vez comprobada su observación, se procedió a aplicar esta técnica multivariante a tres grupos: muestra global, muestra conformada sólo por adolescentes nativos y muestra conformada sólo por adolescentes inmigrantes.

El Análisis de Correlación Canónica exige trabajar con dos sets de variables: uno de ellos conformado por las variables dependientes y otro de ellos constituido por las variables independientes. El primero de estos conjuntos está formado por las cinco competencias cívicas ya referidas. El segundo de estos conjuntos está compuesto por las variables independientes referidas en el Cuadro 2.2 del Capítulo II (factores sociodemográficos, factores psico-sociales y agentes de socialización política). La variable "Género" ha sido adicionada al grupo de factores sociodemográficos. Como en otras investigaciones sobre estos temas, la incorporación de esta última variable tiene por objeto controlar si se detectan pautas cívicas atribuibles a ella.

La utilización de este test multivariante implicó el aprendizaje por parte del autor de esta investigación de lenguaje de sintaxis para IBM SPSS Statistics 21. En concreto, debió trabajarse con tres funciones. "INCLUDE" para la lectura del archivo de directorio señalado por el paquete estadístico a efectos de aplicar este test, "CANCORR" para proceder a la ejecución del Análisis de Correlación Canónica y "SELECT IF" para determinar el colectivo poblacional al que el mismo sería aplicado.

\subsection{1) Buceando en la muestra global}

Una vez aprendido el lenguaje de sintaxis, se procedió a la realización de este test multivariante en primer lugar sobre la muestra global, es decir, la conformada por sujetos tanto inmigrantes como nativos. Si bien en este caso tres funciones canónicas presentaron significación estadística ( $p$ valor igual a .000) y $R_{c}$ por encima de $30 \%$, sólo 
una de ellas presentó tanto un $\mathrm{R}_{\mathrm{c}}{ }^{2}$ elevado $(36,7 \%)$ como significación práctica. Esta función canónica tuvo un índice de redundancia de $11,4 \%{ }^{237}$. Este último guarismo refleja un valor más que aceptable para este tipo de técnicas (Clark, 2006; Glatfelter, 2009). El Cuadro 3.9 resume los resultados de este test multivariante sobre este conjunto muestral.

Para la selección de las variables que, dentro de cada set, poseían significación estadística, se utilizó la guía proporcionada por Hair et al. $2007^{238}$. En concreto, para un tamaño muestral mayor a 350 individuos (516 en el caso de la muestra global), las cargas superiores a 0.30 son consideradas relevantes para un nivel de significación de .05 . Usando este criterio, 7 variables independientes (70\% del total) y 4 competencias cívicas (80\% del total) tuvieron significación estadística. Ambos resultados confirman lo apropiado de haber integrado los sets de variables del modo en el que fueron constituidos.

En relación a las variables independientes significativas, todas, con excepción de "Nivel de Religiosidad", presentaron un comportamiento en relación a las competencias cívicas acorde a lo descrito por la literatura ${ }^{239}$. En tanto, todas las competencias cívicas se mueven en un idéntico sentido. Su coeficiente de adecuación es de 30.9\%. Estos resultados avalan la creación de un índice que, como en el caso de la Integración Política, se encuentra conformado por cada una de ellas ${ }^{240}$.

¿Qué delata la aplicación del Análisis de Correlación Canónica sobre las variables implicadas en la función canónica que reúne las condiciones de significación estadística y práctica? En primer lugar, en el caso de la "Condición Migratoria", la carga canónica (.556) refleja que el ser nativo (categoría de referencia) es un predictor de la posesión de las competencias cívicas. Esta pauta podría anticipar la distribución, durante la adultez, de estos atributos cívicos (Verba et al. 1995). Al mismo tiempo, la "Cantidad de Años de

\footnotetext{
${ }^{237}$ Este índice de redundancia sólo refleja la relación relevante desde el punto de vista teórico, es decir, aquélla que hace depender a las competencias cívicas de los factores y agentes de socialización sometidos a estudio.

${ }^{238}$ Ver por favor, en el texto mencionado, la Tabla 3.2.

${ }^{239}$ Debe recordarse que la evidencia empírica previa sostiene que el nivel de religiosidad de los individuos se encuentra positivamente asociado a diferentes competencias cívicas (excepto para Tolerancia Política). Para un mayor detalle sobre la cuestión, por favor dirigirse al Capítulo I de este documento.

${ }^{240}$ Sin embargo, una de las competencias (Eficacia Política) no obtiene nivel de significación estadística. En principio, esto debe ser comprendido como que las variables independientes con significación estadística en esta función canónica parecerían ser menos relevantes para su producción que para el resto de las variables dependientes.
} 
Residencia en la Sociedad de Acogida" se encuentra asociada positivamente (.687) con las competencias cívicas (es decir, a más años de residencia, mayores niveles en la posesión de las mismas).

En tanto, el "Nivel de Religiosidad" se encuentra negativamente asociado (-.469) a la posesión de competencias cívicas. En otras palabras, los sujetos más religiosos son los que menos atributos cívicos presentan. Política y religión parecen encontrarse en terrenos opuestos. Las experiencias comunitarias, bajo el marco cultual, no parecen estimular un interés por la realidad política ${ }^{241}$. Ello se encuentra en las antípodas de lo sugerido por la literatura sobre la cuestión (Djupe y Grant, 2001; Echazarra, 2011).

En esta muestra global, el "Género" (.052) es la variable que menos se encuentra vinculado a la posesión de competencias cívicas. Patrón semejante asumen el "Status Socioeconómico" (.176) y "Lengua Hablada en el Hogar" (.232). Estos son los tres factores socio-demográficos que no alcanzan significación estadística.

En relación al único factor psico-social incluido en el set de variables independientes ("Actitudes Pro-Sociales"), se halla que los individuos más empáticos y más dispuestos a ayudar son los que presentan mayor bagaje de competencias cívicas. Su carga canónica es de .399. De esta manera, se confirma, como sugiere la literatura, que lo político se haya antecedido por la posesión de predisposiciones que vinculan a los individuos con su entorno social más próximo (Metz y Youniss, 2005).

El Análisis de Correlación Canónica arroja entre sus resultados que los tres agentes de socialización política incluidos son relevantes a la hora de producir competencias cívicas. El más importante es "Grupo de Pares" con una carga canónica de .672. Luego, se ubica "Padres" con .380. A mayores niveles de "Integración Política" de compañeros de escuela y de padres y/o tutores, mayores niveles de competencias cívicas registrarán los adolescentes. En tanto, la asistencia a "Escuelas" más abiertas tiende a propiciar adolescentes más competentes cívicamente. Con estos hallazgos, la evidencia empírica de los estudios norteamericanos clásicos en socialización política es reconfirmada en esta muestra de adolescentes nativos e inmigrantes recogida en España (Easton y Dennis, 1967; Campbell, 1980).

\footnotetext{
241 De hecho, aplicando "Correlaciones de Pearson" a la vinculación de esta variable con todas las competencias cívicas, la relación es siempre de signo negativo.
} 
Según los resultados de haber aplicado este test estadístico, el perfil de la persona poseedora de las competencias cívicas en esta muestra global es el de nativo, más asentado en la sociedad de acogida ${ }^{242}$, menos religioso, con marcadas actitudes pro-sociales e influido positivamente por los tres agentes de socialización política estudiados (padres, grupo de pares y escuela). Si bien este resultado es poco alentador en relación a los niveles de atributos cívicos poseídos por los adolescentes extranjeros, se percibe que existen dos resortes/instancias sobre los que eventualmente puede incidirse para la propiciación de mejores registros sobre el particular: actitudes prosociales y agentes de socialización política. El diseño y ejecución consciente de políticas ad hoc tanto educativas como de gestión de la migración es un mecanismo que debe ser considerado estratégicamente a tales efectos ${ }^{243}$.

242 En el caso de los nativos, este más prolongado asentamiento en la sociedad de acogida puede ser entendido como más edad cronológica.

${ }^{243}$ La creación de atmósferas escolares más abiertas e inclusivas es un ejemplo en el terreno de las políticas educativas. La estimulación de las actitudes pro-sociales, mediante la formación en valores, es otro. El fomento de la participación de los inmigrantes (padres e hijos) en cursos de inmersión en la vida política de la sociedad de acogida es un ejemplo de políticas en el plano de la gestión de la inmigración. En próximos apartados, se ampliará información sobre este particular. 


\section{Cuadro 3.9}

Medidas de ajuste global del modelo para el Análisis de Correlación Canónica (Muestra Global)

\begin{tabular}{|c|c|c|}
\hline $\begin{array}{c}\text { Factores, } \\
\text { Agentes y } \\
\text { Competencias }\end{array}$ & Variables & $\begin{array}{l}\text { Cargas } \\
\text { Canónicas }\end{array}$ \\
\hline \multirow[t]{6}{*}{$\begin{array}{l}\text { Factores Socio- } \\
\text { Demográficos } \\
\text { (SET 1) }\end{array}$} & $\begin{array}{l}\text { Género } \\
\text { (0=Varón } \\
\text { 1=Mujer) }\end{array}$ & ,052 \\
\hline & $\begin{array}{c}\text { Condición } \\
\text { Migratoria } \\
\text { (0= Nativo } \\
1=\text { Inmigrante) }\end{array}$ &,- 556 \\
\hline & $\begin{array}{l}\text { Cantidad de años } \\
\text { de residencia en } \\
\text { sociedad de } \\
\text { acogida }\end{array}$ & ,687 \\
\hline & $\begin{array}{c}\text { Status } \\
\text { socioeconómico }\end{array}$ & ,176 \\
\hline & $\begin{array}{l}\text { Lengua Hablada } \\
\text { en el Hogar } \\
(0=\text { No Nativa } \\
1=\text { Nativa })\end{array}$ & ,232 \\
\hline & $\begin{array}{c}\text { Nivel de } \\
\text { Religiosidad }\end{array}$ &,- 469 \\
\hline $\begin{array}{l}\text { Factores Psico- } \\
\text { Sociales } \\
\text { (SET 1) }\end{array}$ & $\begin{array}{l}\text { Actitudes Pro- } \\
\text { Sociales }\end{array}$ & ,399 \\
\hline \multirow{5}{*}{$\begin{array}{l}\text { Agentes de } \\
\text { Socialización } \\
\text { (SET 1) }\end{array}$} & Padres & ,380 \\
\hline & Grupo de Pares & ,672 \\
\hline & Escuela & 331 \\
\hline & $\mathbf{R}_{\mathrm{c}}$ & $60.6 \%$ \\
\hline & $\mathbf{R}_{c}{ }^{2}$ & $36,7 \%$ \\
\hline \multicolumn{2}{|c|}{ Nivel de significación } & 0.000 \\
\hline \multicolumn{2}{|c|}{ Wilk's Lambda } & .469 \\
\hline \multicolumn{2}{|c|}{$\mathrm{Chi}^{2}$} & 328.169 \\
\hline \multicolumn{2}{|c|}{ Df } & 50 \\
\hline \multicolumn{2}{|c|}{ Índices de redundancia } & $11,4 \%$ \\
\hline \multicolumn{2}{|c|}{ Coeficientes de adecuación } & $19.5 \% \quad 30,9 \%$ \\
\hline \multirow{5}{*}{$\begin{array}{l}\text { Competencias } \\
\text { cívicas } \\
\text { (SET 2) }\end{array}$} & $\begin{array}{c}\text { Conocimiento } \\
\text { Político }\end{array}$ & ,733 \\
\hline & Atención Política & ,330 \\
\hline & $\begin{array}{c}\text { Participación } \\
\text { Política }\end{array}$ & ,554 \\
\hline & Eficacia Política & ,196 \\
\hline & Tolerancia Política & ,743 \\
\hline
\end{tabular}

Nota I: en algunos casos, los signos fueron revertidos para favorecer la comprensión de los datos.

Nota II: los signos señalan el carácter directo o inverso de la relación entre las diferentes variables independientes y dependientes. Nota III: las variables señaladas en rojo son aquéllas estadísticamente significativas (con una carga factorial por encima de 0.30).

Fuente: Elaboración propia. 


\subsection{2) ¿Qué es propio de los adolescentes nativos?}

Una vez analizada la muestra global, se procedió a la realización de este test multivariante sobre la muestra de nativos. Para este caso, como en el anterior, tres funciones canónicas presentaron significación estadística ( $p$ valor igual a .000) y $R_{c}$ por encima de $30 \%$. Otro rasgo semejante es que sólo una de ellas presentó un $\mathrm{R}_{\mathrm{c}}{ }^{2}$ elevado (31,36\%) y significación práctica. Esta función canónica tuvo un índice de redundancia de $9,8 \%{ }^{244}$ (1.6 puntos porcentuales por debajo de la muestra global). Este guarismo refleja también aquí un valor más que aceptable para este tipo de técnicas (Clark, 2006; Glatfelter, 2009). El Cuadro 3.10 resume los resultados de este test multivariante sobre este conjunto muestral.

Según la guía proporcionada por Hair et al. 2007, para un tamaño muestral mayor a 350 individuos (362 en el caso de la muestra de nativos), las cargas superiores a 0.30 son consideradas relevantes para un nivel de significación de .05 . Usando este criterio, 6 variables independientes (66,6\% del total) y 5 competencias cívicas ( $100 \%$ del total) tuvieron significación estadística. Ambos resultados reconfirman, para este subconjunto muestral, lo correcto de haber integrado los sets de variables del modo en el que fueron compuestos.

Las competencias cívicas se mueven, todas ellas, en un idéntico sentido. Su coeficiente de adecuación es de 31.3\%. Estos últimos hallazgos contribuyen a avalar la creación de un índice que, como en el caso de la Integración Política, se encuentra conformado por los mencionados atributos cívicos.

¿Cuáles son los hallazgos del Análisis de Correlación Canónica sobre las variables incorporadas en la función canónica que combina tanto significación estadística como práctica? En primer lugar, "Cantidad de Años de Residencia en la Sociedad de Acogida" se encuentra asociada positivamente con las competencias cívicas. Para el caso de los nativos, esta variable puede ser considerada una especie de proxy de "Edad"245. Por tanto, a mayor edad de los adolescentes nativos, mayor nivel de competencias cívicas.

\footnotetext{
${ }^{244}$ Este índice de redundancia sólo refleja la relación relevante desde el punto de vista teórico, es decir, aquélla que hace depender a las competencias cívicas de los factores y agentes de socialización sometidos a estudio.

${ }^{245}$ El lector debe recordar que las encuestas fueron suministradas, dependiendo del instituto secundario, a adolescentes del último año del bachillerato o a estudiantes del último año de la Educación Secundaria Obligatoria. Ello implica, naturalmente, diferencias de edad.
} 
Siguiendo con las variables independientes significativas, nuevamente "Nivel de Religiosidad" es la única que presenta un comportamiento en relación a las competencias cívicas distinto a lo descrito por la literatura. Esta variable se encuentra negativamente vinculada (-.431) a la posesión de competencias cívicas. En otras palabras, los sujetos más religiosos son los que menos desarrollan competencias cívicas. En tanto, la diferencia entre la muestra global y la conformada sólo por autóctonos es ínfima para esta variable (3.8\%). Uno y otro conjunto coinciden, entonces, en la tendencia asumida por este factor de tipo socio-demográfico. Contrariamente a lo sugerido por la evidencia empírica previa, la práctica religiosa aleja a los nativos del mundo de lo político. Se descarta entonces la hipótesis de trabajo que relacionaba de manera directa a ambas variables.

En esta muestra nativa, el "Género" (.086) es otra vez la variable que menos se encuentra vinculada a la posesión de competencias cívicas. Como aconteció con la muestra global, tampoco presenta significación estadística el "Status Socioeconómico" $(.216)^{246}$.

En relación al único factor psico-social incluido en el set de variables independientes ("Actitudes Pro-Sociales"), se encuentra nuevamente que los individuos más empáticos y más dispuestos a ayudar son los que presentan mayores niveles de competencias cívicas. La carga canónica es, para esta variable, de .517. La muestra nativa supera, en $11.8 \%$, a la muestra global para esta variable. Con este hallazgo, es posible afirmar que la dimensión política se haya antecedida por la posesión de tendencias o actitudes que hacen de los individuos sujetos más interesados por su entorno más

\footnotetext{
${ }^{246} \mathrm{Si}$ el Status Socioeconómico es desagregado (nivel educativo, nivel de ingreso y tipos de ocupación de padres y/o tutores), el patrón no dista de lo hallado cuando es considerado globalmente. Al aplicarse Correlaciones de Pearson entre las dimensiones del Status Socioeconómico y las diferentes competencias cívicas para la muestra de adolescentes inmigrantes, se encuentra que existen relaciones estadísticamente significativas entre un número limitado de "pares": Formación Académica de la Madre y Conocimiento Político; Ingreso Familiar Mensual y Conocimiento Político, Atención Política y Eficacia Política y, finalmente, Ocupación de la Madre y Eficacia Política. De lo hallado, emergen dos tendencias dignas de destacar: la relevancia del componente "Ingreso Familiar Mensual" al interior de la variable Status Socioeconómico y la mayor importancia relativa de los rasgos maternos en detrimento de los rasgos paternos a la hora de la producción de las competencias cívicas. Por tanto, se descartan parcialmente para este subconjunto poblacional las hipótesis de trabajo que hacían depender "positivamente" los niveles de competencias cívicas de los niveles de las dimensiones reseñadas. Por favor, para la obtención de un mayor detalle sobre los resultados de las correlaciones de Pearson mencionadas, revisar el Anexo № 3.
} 
próximo. Se confirma para este grupo la hipótesis de trabajo que hacía depender las competencias cívicas de este factor psico-social.

Así mismo, el Análisis de Correlación Canónica concluye una vez más que los tres agentes de socialización política incluidos son importantes en tanto generadores de competencias cívicas. El más importante es "Grupo de Pares" con una carga canónica de .578. Luego, se ubica "Padres" con .464. Igual que en el caso de la muestra global, estos registros deben ser comprendidos como que a mayores niveles de "Integración Política" de compañeros de escuela y de padres y/o tutores, mayores niveles de competencias cívicas registran los adolescentes nativos ${ }^{247}$. En tanto, la pertenencia a "Escuelas" más abiertas tiende a producir adolescentes autóctonos más competentes cívicamente. Estos descubrimientos confirman la evidencia empírica aportada por los estudios norteamericanos clásicos en materia de actuación de los agentes tradicionales de socialización política.

Según los resultados de haber aplicado este test estadístico, el perfil de la persona poseedora de las competencias cívicas en esta muestra de estudiantes autóctonos es el de adolescentes, con mayor edad, menos religioso, con marcadas actitudes pro-sociales e influido positivamente por los tres agentes de socialización política estudiados (padres, grupo de pares y escuela). La pauta hallada, entre los nativos, reconfirma la importancia de actuar sobre dos resortes concretos para el logro del incremento de las competencias cívicas entre los adolescentes: actitudes prosociales y agentes de socialización.

\footnotetext{
${ }^{247}$ La carga canónica positiva confirma la hipótesis de trabajo que vinculaba las competencias cívicas de los hijos con la integración política de sus padres.
} 
Cuadro 3.10

Medidas de ajuste global del modelo para el Análisis de Correlación Canónica (Muestra Nativos)

\begin{tabular}{|c|c|c|}
\hline $\begin{array}{c}\text { Factores, } \\
\text { Agentes y } \\
\text { Competencias }\end{array}$ & Variables & $\begin{array}{l}\text { Cargas } \\
\text { Canónicas }\end{array}$ \\
\hline \multirow[t]{4}{*}{$\begin{array}{l}\text { Factores Socio- } \\
\text { Demográficos } \\
\text { (SET 1) }\end{array}$} & $\begin{array}{l}\text { Género } \\
\text { (0=Varón } \\
\text { 1=Mujer) }\end{array}$ & .086 \\
\hline & $\begin{array}{l}\text { Cantidad de años } \\
\text { de residencia en } \\
\text { sociedad de } \\
\text { acogida }\end{array}$ & .460 \\
\hline & $\begin{array}{c}\text { Status } \\
\text { socioeconómico }\end{array}$ & .216 \\
\hline & $\begin{array}{l}\text { Nivel de } \\
\text { Religiosidad }\end{array}$ & -.431 \\
\hline $\begin{array}{c}\text { Factores Psico- } \\
\text { Sociales } \\
\text { (SET 1) }\end{array}$ & $\begin{array}{l}\text { Actitudes Pro- } \\
\text { Sociales }\end{array}$ & .517 \\
\hline Agentes de & Padres & .464 \\
\hline Socialización & Grupo de Pares & .578 \\
\hline (SET 1) & Escuela & .339 \\
\hline \multicolumn{2}{|c|}{$\mathbf{R}_{\mathbf{c}}$} & $56 \%$ \\
\hline \multicolumn{2}{|c|}{$\mathbf{R}_{\mathrm{c}}{ }^{2}$} & $31,3 \%$ \\
\hline \multicolumn{2}{|c|}{ Nivel de significación } & 0.000 \\
\hline \multicolumn{2}{|c|}{ Wilk's Lambda } & .517 \\
\hline \multicolumn{2}{|c|}{$\mathrm{Chi}^{2}$} & 193.438 \\
\hline \multicolumn{2}{|c|}{ df } & 45 \\
\hline \multicolumn{2}{|c|}{ Índices de redundancia } & $9.8 \%$ \\
\hline \multicolumn{2}{|c|}{ Coeficientes de adecuación } & $15.9 \% \quad 31,3 \%$ \\
\hline \multirow{5}{*}{$\begin{array}{l}\text { Competencias } \\
\text { cívicas } \\
\text { (SET 2) }\end{array}$} & $\begin{array}{c}\text { Conocimiento } \\
\text { Político }\end{array}$ & .583 \\
\hline & Atención Política & .374 \\
\hline & $\begin{array}{l}\text { Participación } \\
\text { Política }\end{array}$ & .606 \\
\hline & Eficacia Política & .426 \\
\hline & Tolerancia Política & .732 \\
\hline
\end{tabular}

Nota I: en algunos casos, los signos fueron revertidos para favorecer la comprensión de los datos. Nota II: los signos señalan el carácter directo o inverso de la relación entre las diferentes variables independientes y dependientes. Nota III: las variables señaladas en rojo son aquéllas estadísticamente significativas (con una carga factorial por encima de 0.30). Nota IV: Lengua Hablada en el Hogar fue eliminada del análisis por ser una constante. 


\subsection{3) ¿Qué es propio de los adolescentes inmigrantes?}

Una vez analizadas la muestra global y el subconjunto nativo, se procedió a la realización de este test multivariante en tercer lugar sobre la muestra de adolescentes inmigrantes. Para este caso, como en los dos ya expuestos, tres funciones canónicas presentaron significación estadística ( $p$ valor igual a .000) y $R_{c}$ por encima de $30 \%$. Otro patrón similar es que sólo una de ellas presentó un $\mathrm{R}_{c}{ }^{2}$ elevado $(36,36 \%)$ y significación práctica. Esta función canónica tuvo un índice de redundancia de $11,7 \%^{248}$ (el más alto entre los tres muestras consideradas). Este guarismo refleja nuevamente aquí un valor más que aceptable al aplicar esta técnica (Clark, 2006; Glatfelter, 2009). El Cuadro 3.11 resume los resultados de este test multivariante sobre este grupo en particular.

Según la guía proporcionada por Hair et al. 2007, para un tamaño muestral mayor a 150 individuos (154 en el caso de la muestra de nativos), las cargas superiores a 0.45 suelen ser consideradas relevantes para un nivel de significación de .05. Usando este criterio, 2 variables independientes ( $22,2 \%$ del total) y 4 competencias cívicas ( $80 \%$ del total) tuvieron significación estadística. $\mathrm{Si}$, en cambio, se usa como guía las cargas superiores a 0.30 (como ha pasado en las dos muestras previas), el número de variables independientes relevantes asciende a 5 (55,5\% sobre el total) y el de variables dependientes se mantiene constante. Este último criterio, menos conservador, es el que se ha utilizado para la lectura de los resultados para proceder a la obtención de mejores condiciones de comparabilidad entre las tres muestras ${ }^{249}$.

Todas las competencias cívicas, excepto la "Eficacia Política" 250 se movilizan en un idéntico sentido. Su coeficiente de adecuación es de 32.2\%. Estos últimos hallazgos refuerzan la necesidad de creación de un índice que, como en el caso de la Integración Política, se encuentra conformado por los mencionados atributos cívicos.

¿Cuáles son los hallazgos del Análisis de Correlación Canónica sobre las variables incorporadas en la función canónica que posee los dos tipos importantes de significación

\footnotetext{
248 Este índice de redundancia sólo refleja la relación relevante desde el punto de vista teórico, es decir, aquélla que hace depender a las competencias cívicas de los factores y agentes de socialización sometidos a estudio.

249 Mike Clark, Consultor Estadístico del Departamento de Investigación y Apoyo Estadístico de la Universidad del Norte de Texas, recomienda siempre considerar como valores importantes desde el punto de vista estadístico aquellos que sean iguales a o superen el .30 en el Análisis de Correlación Canónica.

${ }^{250}$ Esta competencia cívica no sólo presenta un signo distinto sino que su carga canónica (-.038) no llega a los niveles requeridos para ser considerada como dotada de significación estadística.
} 
(estadística y práctica)? En primer lugar, tal como sugería la literatura, "Cantidad de Años de Residencia en la Sociedad de Acogida" (.498) se encuentra asociada positivamente con la posesión de las competencias cívicas (Tam Cho, 1999; Wong, 2006). Ello implica que la teoría de la exposición, para explicar la socialización política de los inmigrantes adolescentes, encuentra evidencia empírica en esta muestra (White et al. 2008). Se comprueba entonces una de las hipótesis de trabajo enunciadas en el Capítulo II.

En relación a las variables independientes significativas, una vez más "Nivel de Religiosidad" es la única que presenta una tendencia en relación a las competencias cívicas distinta a la enunciada por la literatura. Se encuentra negativamente asociada (.341) a la posesión de competencias cívicas. En otras palabras, los sujetos más religiosos son los que menos desarrollan competencias cívicas. La diferencia entre la muestra global y la conformada sólo por inmigrantes es para esta variable de 12.8 puntos porcentuales. Ambos conjuntos coinciden en el patrón asumido por este factor. La práctica religiosa aleja también a los inmigrantes del mundo político en la sociedad receptora. De esta manera, se rechaza la hipótesis de trabajo que vinculaba de manera directa al Nivel de Religiosidad con las competencias cívicas.

En la muestra de adolescentes extranjeros, el "Género" (.039) es otra vez la variable que menos se encuentra vinculada a la posesión de competencias cívicas. La utilización de lenguas vernáculas tampoco arroja significación estadística (-.011). Este último resultado desestima la hipótesis de trabajo, elaborada en base a la literatura, que presumía que la suficiencia en lenguas vernáculas por parte de los inmigrantes acarreaba mejoras en los niveles de competencias cívicas (Brady et al., 1995).

No presenta ni significación estadística ni práctica el "Status Socioeconómico" ($.055)^{251}$. Por tanto, se descartan las hipótesis de trabajo, construidas en base a la literatura, que hacían depender "positivamente" los niveles de competencias cívicas de los niveles de las dimensiones reseñadas de Status Socioeconómico (Bevelander y Pendakur, 2009. Este hallazgo también implica que la teoría de la transferibilidad para

\footnotetext{
${ }^{251} \mathrm{Si}$ este factor sociodemográfico es desagregado (nivel educativo, nivel de ingreso y tipos de ocupación de padres y/o tutores), la pauta no dista de lo hallado cuando es considerado globalmente. Al aplicarse Correlaciones de Pearson entre las dimensiones del Status Socioeconómico y las diferentes competencias cívicas para la muestra de adolescentes inmigrantes, se encuentra que no existen relaciones estadísticamente significativas). Ver más detalle por favor en el Anexo № 3.
} 
la explicación de la socialización política de los inmigrantes adolescentes no encuentra asidero empírico (White et al. 2008).

En relación al único factor psico-social incluido en el set de variables independientes ("Actitudes Pro-Sociales"), se encuentra nuevamente que los individuos más empáticos y más dispuestos a ayudar son los que presentan mayores niveles de competencias cívicas. La carga canónica es, para esta variable, de .517. La muestra inmigrante supera, en $11.8 \%$, a la muestra global para esta variable. Con este hallazgo, es posible afirmar que la dimensión política se haya antecedida por la posesión de tendencias o actitudes que hacen de los individuos sujetos más interesados por su entorno más próximo. Se confirma entonces la hipótesis de trabajo que hacía depender a las competencias cívicas de la posesión de este factor psico-social.

Así mismo, el Análisis de Correlación Canónica halla que sólo los agentes de socialización política vinculados a la sociedad de acogida son importantes como dadores de competencias cívicas. El más relevante es "Grupo de Pares" con una carga canónica de $.661^{252}$. Luego, se ubica "Escuela" con .415. Ello implica que mayores niveles de "Integración Política" de compañeros de escuela y la asistencia a centros educativos más abiertos tienden a generar adolescentes inmigrantes más competentes cívicamente. Estos descubrimientos confirman la evidencia empírica que sostiene que la teoría de socialización política que mejor explica este proceso es la que pivotea en torno a la necesidad de que los inmigrantes se expongan a las reglas políticas de la sociedad de acogida. En el caso de los "Padres" como agentes de socialización, su escasa carga canónica (.266), aunque positiva, no alcanza significación estadística ${ }^{253}$.

El agente de socialización "Escuela" ha sido medido a través de una variable que es una especie de índice compuesto por diferentes dimensiones que, se supone, están relacionadas con la posesión de competencias cívicas entre los estudiantes. Para ver si estas dimensiones interactúan con las competencias cívicas como lo hace la variable genérica, se procedió a realizar "Comparaciones de Medias" o "Correlaciones de

\footnotetext{
${ }^{252}$ Con este hallazgo se confirma lo sugerido por literatura en relación a que el Grupo de Pares ejerce influencia como agente de socialización con independencia del origen étnico o nacional de los individuos influidos (Ryan, 2001).

${ }^{253}$ La carga canónica positiva confirma la hipótesis de trabajo que vinculaba las competencias cívicas de los hijos con la integración política de sus padres.
} 
Pearson" según correspondiese en función de la naturaleza de los datos ${ }^{254}$. Entre los hallazgos, se encontró, por un lado, que los estudiantes de origen inmigrante que cursan itinerarios formativos de Ciencias Sociales poseen en mayor medida todas las competencias cívicas y que, en dos de ellas (Atención Política y Participación Política), las diferencias son estadísticamente significativas. De esta manera, se comprueba la hipótesis de trabajo que sentenciaba en tal sentido.

Por otro lado, se ha hallado que aquellas escuelas en las que se, según la percepción de los adolescentes, se discute más sobre política en clase son las que tienen estudiantes inmigrantes con registros más altos en Atención Política, Participación Política y Eficacia Política. Con este resultado, se comprueba parcialmente otra hipótesis de trabajo enunciada en el Capítulo II y prevista por la literatura (Grossman, 1974; Ehman, 1980; Harwood, 1992; Niemi y Junn, 1998; Torney-Purta, Lehmann, Oswald y Schulz, 2001; Campbell, 2008). Las otras dos dimensiones trabajadas al interior de la variable "Escuela" no alcanzan significación estadística. El porcentaje de alumnado inmigrante en cada centro educativo y la frecuencia en el uso de innovaciones pedagógicas en asignaturas de naturaleza "cívica" no se encuentran vinculados a ninguna competencia cívica. En consecuencia, las hipótesis de trabajo que implicaban a estas dimensiones deben ser rechazadas.

Según los resultados de haber aplicado la correlación canónica, el perfil de la persona poseedora de las competencias cívicas en esta muestra de estudiantes inmigrantes es la de adolescentes que, habiendo vivido más tiempo en la sociedad de acogida, cuentan con marcadas actitudes pro-sociales, son menos religiosos y están influidos positivamente por los dos agentes de socialización política que representan o encarnan a la sociedad receptora (grupo de pares y escuela). El patrón encontrado, entre los inmigrantes, reconfirma la relevancia de una eventual actuación sobre dos resortes concretos para el logro del incremento de las competencias cívicas en este colectivo poblacional: actitudes pro-sociales y agentes de socialización. Ambas variables, tal como se recordaba en el capítulo teórico de esta investigación, pueden ser eficazmente moldeadas mediante la puesta en marcha en el marco escolar de políticas ad hoc (Huebner, 2003).

\footnotetext{
254 Por favor, para la obtención de un mayor detalle sobre los resultados de las correlaciones y comparaciones de medias mencionadas, revisar el Anexo № 3, Cuadros 2 y 3.
} 
Cuadro 3.11

Medidas de ajuste global del modelo para el Análisis de Correlación Canónica (Muestra Inmigrantes)

\begin{tabular}{|c|c|c|}
\hline $\begin{array}{c}\text { Factores, } \\
\text { Agentes y } \\
\text { Competencias }\end{array}$ & Variables & $\begin{array}{l}\text { Cargas } \\
\text { Canónicas }\end{array}$ \\
\hline \multirow[t]{5}{*}{$\begin{array}{l}\text { Factores Socio- } \\
\text { Demográficos } \\
\text { (SET 1) }\end{array}$} & $\begin{array}{l}\text { Género } \\
\text { (0=Varón } \\
\text { 1=Mujer) }\end{array}$ & .039 \\
\hline & $\begin{array}{l}\text { Cantidad de años } \\
\text { de residencia en } \\
\text { sociedad de } \\
\text { acogida }\end{array}$ & .498 \\
\hline & $\begin{array}{c}\text { Status } \\
\text { socioeconómico }\end{array}$ & -.055 \\
\hline & $\begin{array}{l}\text { Lengua Hablada } \\
\text { en el Hogar } \\
(0=\text { No Nativa } \\
1=\text { Nativa })\end{array}$ & -.011 \\
\hline & $\begin{array}{c}\text { Nivel de } \\
\text { Religiosidad }\end{array}$ & -.341 \\
\hline $\begin{array}{c}\text { Factores Psico- } \\
\text { Sociales } \\
\text { (SET 1) }\end{array}$ & $\begin{array}{l}\text { Actitudes Pro- } \\
\text { Sociales }\end{array}$ & .417 \\
\hline \multirow{5}{*}{$\begin{array}{l}\text { Agentes de } \\
\text { Socialización } \\
\text { (SET 1) }\end{array}$} & Padres & .266 \\
\hline & Grupo de Pares & .661 \\
\hline & \multirow[t]{2}{*}{ Escuela } & .415 \\
\hline & & $60,3 \%$ \\
\hline & $\mathbf{R}_{c}^{2}$ & $36,3 \%$ \\
\hline \multicolumn{2}{|c|}{ Nivel de significación } & .000 \\
\hline \multicolumn{2}{|c|}{ Wilk's Lambda } & .385 \\
\hline \multicolumn{2}{|c|}{$\mathrm{Chi}^{2}$} & 126.462 \\
\hline \multicolumn{2}{|c|}{ df } & 45 \\
\hline \multicolumn{2}{|c|}{ Índices de redundancia } & $11,7 \%$ \\
\hline \multicolumn{2}{|c|}{ Coeficientes de adecuación } & $13,6 \% \quad 32,2 \%$ \\
\hline \multirow{5}{*}{$\begin{array}{l}\text { Competencias } \\
\text { cívicas } \\
\text { (SET 2) }\end{array}$} & $\begin{array}{c}\text { Conocimiento } \\
\text { Político }\end{array}$ & .758 \\
\hline & Atención Política & .518 \\
\hline & $\begin{array}{l}\text { Participación } \\
\text { Política }\end{array}$ & .620 \\
\hline & Eficacia Política & -.038 \\
\hline & Tolerancia Política & .617 \\
\hline
\end{tabular}

Nota I: en algunos casos, los signos fueron revertidos para favorecer la comprensión de los datos.

Nota II: los signos señalan el carácter directo o inverso de la relación entre las diferentes variables independientes y dependientes. Nota III: las variables señaladas en rojo son aquéllas estadísticamente significativas (con una carga factorial por encima de 0.30).

Fuente: Elaboración propia. 


\section{3) Visualizando los resultados. Construcción de un heliógrafo para el Análisis de Correlación Canónica}

El Análisis de Correlación Canónica, a pesar de su evidente utilidad para analizar las relaciones existentes entre un set de variables independientes y otro set de variables dependientes, ha sido escasamente utilizado. Entre otros motivos, esa limitada utilización se ha debido a que la presentación de los resultados de este test multivariante en los diferentes procesadores estadísticos ha tenido lugar bajo el formato de tablas con un cúmulo importante de información que entrega pocas pistas a los eventuales intérpretes. A los fines de ordenar los datos originados en la aplicación de esta técnica, Degani et al. (2006) diseñaron el heliógrafo en base a las pautas señaladas para la visualización de datos que fueron recomendadas por Christopher Alexander (2002). Alexander, como se anticipó en el Capítulo II, elaboró consignas para la creación de gráficos en los que se observara la totalidad de la información de los procesos o fenómenos sometidos a estudio.

La aplicación del heliógrafo es novedosa y perfectamente asumible en Ciencias Sociales a la hora de analizar las relaciones existentes entre múltiples variables independientes y dependientes. Hasta el momento en el que se escriben estas páginas, ha sido aplicado con éxito solamente en el campo de la Ingeniería Aeronáutica ${ }^{255}$ (Degani et al. 2006) y de las Ciencias de la Salud (Talarico et al., 2013) ${ }^{256}$.

El heliógrafo, como su nombre lo indica, es una especie de sol conformado por círculos concéntricos que representan diferentes funciones canónicas. Las que presentan mayor magnitud (nivel de correlación) se encuentran en los círculos externos. A medida que se avanza hacia el centro de gráfico, se pierde en magnitud. Las funciones canónicas pueden referir a una única muestra o a diferentes muestras. Este último es el caso del gráfico utilizado en estas páginas.

Los elementos que particularizan a un heliógrafo, aparte de las circunferencias descritas, son los siguientes. En primer lugar, los círculos reposan sobre una superficie en la que se demarca o perimetra el espacio reservado para las variables independientes

\footnotetext{
255 En el campo de la Ingeniería Aeronáutica, ha sido utilizado para graficar la relación que existe entre elementos contextuales y las estrategias de acción elegidas por los pilotos comerciales.

${ }^{256}$ En el campo de las Ciencias de la Salud, se ha sido utilizado para graficar la relación que existe entre la inteligencia emocional y la performance de los médicos residentes.
} 
(X) y dependientes (Y). En el caso de esta investigación, las primeras son los factores socio-demográficos, los factores psico-sociales y los agentes de socialización que se ubican a la izquierda de la figura. En tanto, las variables dependientes son las competencias cívicas que se emplazan a la derecha del gráfico.

En segundo lugar, cada función canónica encarnada en cada círculo está compuesta por variables que asumen un comportamiento dado. El mismo se encuentra descrito por tres elementos: dirección, intensidad y significación estadística. La dirección se observa tanto en el color de las barras que salen de cada circunferencia y en el sentido que las mismas presentan. En esta investigación, las barras blancas y construidas hacia afuera representan relaciones positivas entre variables dependientes e independientes. Por el contrario, las barras negras y construidas hacia dentro representan relaciones negativas entre ambos sets de variables.

La intensidad, representada por el tamaño de las barras y el número (carga canónica) que se encuentra dentro de las mismas, recuerda el nivel de correlación entre cada variable y el set al que pertenece. En otras palabras, la misma implica cuánto cada variable contribuye relativamente a la función canónica en cuestión. A modo de ejemplo, en esta investigación, en el círculo externo que representa a la muestra global, la variable "Cantidad de Años de Residencia en la Sociedad de Acogida" es expresada a través de la barra de mayor tamaño y el número en ella inscrito es también el más grande.

La significación estadística está representada por la coloración que las cargas canónicas presentan. Si la misma es roja, eso implica que ha habido efectivamente significación estadística. Si la misma es negra (o blanca), implica lo contrario. El criterio para la determinación de la significación estadística está dado por el tamaño de la muestra de la que se ha obtenido la función canónica. A tamaños muestrales más pequeños, suelen corresponder umbrales más altos (de carga canónica) para considerar que debe asumirse significación estadística.

Finalmente, en tercer lugar, cada heliógrafo cuenta con información que resume la magnitud que corresponde a cada función canónica. En el caso de esta investigación, esta información se ubica en el extremo inferior del gráfico. Esta síntesis de la función canónica es expresada mediante los $R_{c}$ que corresponden a cada una de la muestras visualizadas. Estos son, viendo desde fuera hacia dentro, los registros correspondientes 
a las muestras global, de inmigrantes y de nativos. En la Figura 3.1, se encuentra el heliógrafo que resume visualmente los resultados del Análisis de Correlación Canónica aplicado a los descritos sets de variables. 
Figura 3.1

Heliógrafo en base a los resultados del Análisis de Correlación para factores y agentes de socialización $(\mathrm{X})$ y competencias cívicas (Y)

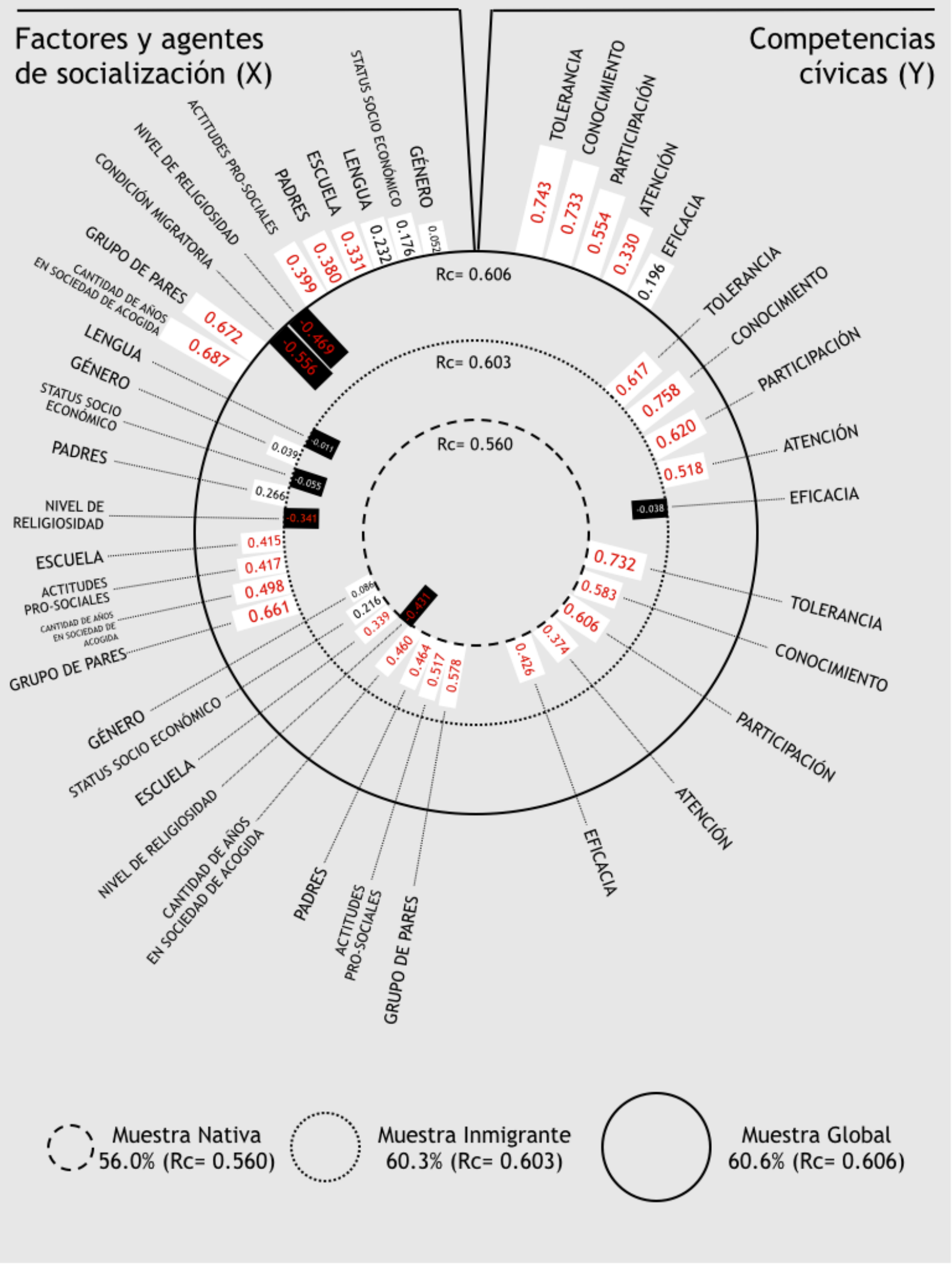

Fuente: Elaboración propia. 


\section{4) Comprobación parcial de hipótesis de trabajo}

En el siguiente cuadro, se realiza una segunda comprobación parcial de las hipótesis de trabajo asumidas por esta investigación. El mismo incluye a las hipótesis que han podido ser confirmadas mediante la aplicación del Análisis de Correlación Canónica y pruebas complementarias.

Cuadro 3.12

Comprobación parcial de hipótesis de trabajo

\begin{tabular}{|c|c|c|c|}
\hline & Hipótesis & Hallazgo & Nota aclaratoria \\
\hline \multirow{6}{*}{ 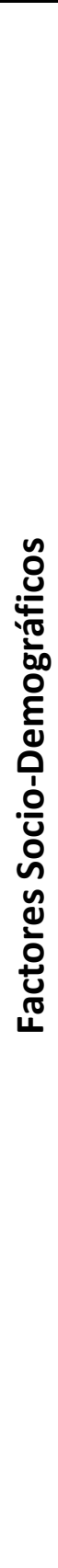 } & $\begin{array}{l}\text { La cantidad de tiempo } \\
\text { transcurrido en la sociedad de } \\
\text { acogida será directamente } \\
\text { proporcional al nivel de } \\
\text { competencias cívicas poseído } \\
\text { por los adolescentes de origen } \\
\text { inmigrante }\end{array}$ & Confirmatorio & $\begin{array}{l}\text { Según el Análisis de Correlación } \\
\text { Canónica, sólo la Eficacia Política } \\
\text { asume un comportamiento } \\
\text { divergente }\end{array}$ \\
\hline & $\begin{array}{l}\text { A mayor nivel educativo de los } \\
\text { padres y/o tutores, mayor nivel } \\
\text { de competencias cívicas entre } \\
\text { los adolescentes (con } \\
\text { independencia de su origen } \\
\text { nacional) }\end{array}$ & $\begin{array}{l}\text { Confirmatorio sólo } \\
\text { para la relación } \\
\text { entre Formación } \\
\text { Académica Materna } \\
\text { y Conocimiento } \\
\text { Político del Hijo } \\
\text { (sólo nativos) }\end{array}$ & $\begin{array}{l}\text { El Análisis de Correlación } \\
\text { Canónica no encontró al Status } \\
\text { Socioeconómico como dotado de } \\
\text { suficiente significación estadística }\end{array}$ \\
\hline & $\begin{array}{l}\text { A mayor nivel de ingreso de los } \\
\text { padres y/o tutores, mayor nivel } \\
\text { de competencias cívicas entre } \\
\text { los adolescentes (con } \\
\text { independencia de su origen } \\
\text { nacional) }\end{array}$ & $\begin{array}{c}\text { Confirmatorio para } \\
\text { la relación entre } \\
\text { Ingreso Familiar } \\
\text { Mensual y } \\
\text { Conocimiento } \\
\text { Político, Atención } \\
\text { Política y Eficacia } \\
\text { Política (sólo } \\
\text { nativos) } \\
\end{array}$ & Idem al anterior \\
\hline & $\begin{array}{l}\text { Los padres y/o tutores cuyas } \\
\text { ocupaciones sean no manuales } \\
\text { tendrán hijos con mayores } \\
\text { niveles de competencias cívicas } \\
\text { (con independencia de su origen } \\
\text { nacional) }\end{array}$ & $\begin{array}{l}\text { Confirmatorio sólo } \\
\text { para la relación } \\
\text { entre Ocupación } \\
\text { Materna y Eficacia } \\
\text { Política (sólo } \\
\text { nativos) } \\
\end{array}$ & Idem al anterior \\
\hline & $\begin{array}{l}\text { Los adolescentes de origen } \\
\text { inmigrante que hablen en el } \\
\text { hogar una lengua distinta a la de } \\
\text { la sociedad de acogida tendrán } \\
\text { menores niveles de } \\
\text { competencias cívicas que } \\
\text { aquellos que hablen en las } \\
\text { lenguas oficiales }\end{array}$ & No confirmatorio & $\begin{array}{l}\text { El Análisis de Correlación } \\
\text { Canónica no encontró a la Lengua } \\
\text { Hablada en el Hogar como dotada } \\
\text { de suficiente significación } \\
\text { estadística }\end{array}$ \\
\hline & $\begin{array}{l}\text { A mayor nivel de religiosidad del } \\
\text { alumno, mayores registros en }\end{array}$ & No confirmatorio & $\begin{array}{l}\text { El Análisis de Correlación } \\
\text { Canónica ha descubierto que la }\end{array}$ \\
\hline
\end{tabular}




\begin{tabular}{|c|c|c|c|}
\hline & $\begin{array}{l}\text { competencias cívicas } \\
\text { independencia de su origen } \\
\text { nacional) }\end{array}$ & & $\begin{array}{l}\text { relación entre el Nivel de } \\
\text { Religiosidad y las competencias } \\
\text { cívicas es inversa y no directa } \\
\text { como preveía la hipótesis de } \\
\text { trabajo }\end{array}$ \\
\hline 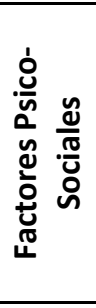 & $\begin{array}{l}\text { Los adolescentes que posean } \\
\text { mayores niveles en la posesión } \\
\text { de actitudes pro-sociales serán } \\
\text { los que presenten mayores } \\
\text { niveles de competencias cívicas } \\
\text { (con independencia de su origen } \\
\text { nacional) }\end{array}$ & Confirmatorio & $\begin{array}{l}\text { El Análisis de Correlación } \\
\text { Canónica ha encontrado a esta } \\
\text { variable como relevante tanto en } \\
\text { la muestra de los nativos como en } \\
\text { la muestra de los inmigrantes }\end{array}$ \\
\hline \multirow{5}{*}{ 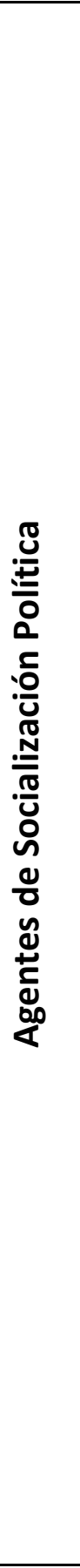 } & $\begin{array}{l}\text { Los niveles de integración } \\
\text { política poseídos por los padres } \\
\text { y/o tutores correlacionarán } \\
\text { positivamente con los niveles } \\
\text { de competencias cívicas } \\
\text { presentados por sus } \\
\text { hijos/tutorados (con } \\
\text { independencia de su origen } \\
\text { nacional) }\end{array}$ & $\begin{array}{l}\text { Parcialmente } \\
\text { Confirmatorio }\end{array}$ & $\begin{array}{l}\text { El Análisis de Correlación } \\
\text { Canónica sólo encontró } \\
\text { significación estadística para la } \\
\text { muestra conformada por nativos }\end{array}$ \\
\hline & $\begin{array}{l}\text { Escuelas con un ratio } \\
\text { inmigrantes/nativos menor, } \\
\text { como consecuencia de la } \\
\text { menor posibilidad de } \\
\text { interacción con población } \\
\text { autóctona, tendrán individuos } \\
\text { de origen inmigrante que } \\
\text { presentarán menores niveles } \\
\text { de competencias cívicas }\end{array}$ & No confirmatorio & $\begin{array}{l}\text { No se ha hallado significación } \\
\text { estadística para la relación de } \\
\text { esta variable con ninguna de las } \\
\text { competencias cívicas }\end{array}$ \\
\hline & $\begin{array}{l}\text { Los alumnos de origen } \\
\text { inmigrante que se encuentren } \\
\text { cursando los itinerarios } \\
\text { formativos de Ciencias Sociales } \\
\text { y/o Humanas presentarán } \\
\text { valores más elevados en } \\
\text { competencias cívicas que sus } \\
\text { pares pertenecientes a otros } \\
\text { itinerarios formativos. }\end{array}$ & $\begin{array}{l}\text { Parcialmente } \\
\text { confirmatorio }\end{array}$ & $\begin{array}{l}\text { Se ha encontrado significación } \\
\text { estadística para la relación entre } \\
\text { esta variable con Atención } \\
\text { Política y Participación Política }\end{array}$ \\
\hline & $\begin{array}{l}\text { Las escuelas en las que, según } \\
\text { lo declarado por los estudiantes } \\
\text { inmigrantes, son más } \\
\text { frecuentes las discusiones } \\
\text { políticas aquéllos tendrán } \\
\text { mayores niveles de } \\
\text { competencias cívicas }\end{array}$ & $\begin{array}{l}\text { Parcialmente } \\
\text { confirmatorio }\end{array}$ & $\begin{array}{l}\text { Se ha encontrado significación } \\
\text { estadística para la relación entre } \\
\text { esta variable con Atención } \\
\text { Política, Participación Política y } \\
\text { Eficacia Política }\end{array}$ \\
\hline & $\begin{array}{l}\text { Las escuelas en las que más } \\
\text { innovaciones pedagógicas se } \\
\text { utilizan para la enseñanza de } \\
\text { asignaturas vinculadas a la } \\
\text { formación cívica serán las que } \\
\text { presentarán individuos de } \\
\text { origen inmigrante con mayores } \\
\text { niveles de competencias cívicas }\end{array}$ & No confirmatorio & $\begin{array}{l}\text { No se ha hallado significación } \\
\text { estadística para la relación de } \\
\text { esta variable con ninguna de las } \\
\text { competencias cívicas }\end{array}$ \\
\hline
\end{tabular}




\begin{tabular}{|c|c|c|c|}
\hline & $\begin{array}{l}\text { Los niveles de integración } \\
\text { política de los compañeros de } \\
\text { clase, considerados éstos como } \\
\text { grupo de pares, correlacionarán } \\
\text { positivamente con los registros } \\
\text { presentados por cada } \\
\text { adolescente en sus } \\
\text { competencias cívicas }\end{array}$ & Confirmatorio & $\begin{array}{l}\text { El Análisis de Correlación } \\
\text { Canónica ha hallado que esta es la } \\
\text { variable que más contribuye a la } \\
\text { función canónica tanto entre } \\
\text { inmigrantes como entre nativos }\end{array}$ \\
\hline 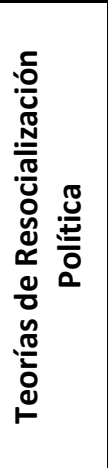 & $\begin{array}{l}\text { Ambas teorías de } \\
\text { resocialización política } \\
\text { (exposición y transferencia o } \\
\text { transferibilidad) contribuyen a } \\
\text { describir los niveles de } \\
\text { competencias cívicas entre los } \\
\text { adolescentes de origen } \\
\text { inmigrante en la sociedad de } \\
\text { acogida }\end{array}$ & $\begin{array}{l}\text { Parcialmente } \\
\text { Confirmatorio }\end{array}$ & $\begin{array}{l}\text { Se ha encontrado evidencia } \\
\text { empírica para la teoría de la } \\
\text { exposición. Las variables } \\
\text { asociadas a ella (vinculadas a la } \\
\text { sociedad de acogida) han } \\
\text { explicado mejor los niveles de las } \\
\text { competencias cívicas entre los } \\
\text { adolescentes inmigrantes que las } \\
\text { variables asociadas a la teoría de } \\
\text { la transferibilidad (vinculadas a la } \\
\text { sociedad de origen). }\end{array}$ \\
\hline
\end{tabular}

Fuente: Elaboración propia.

5) Explicando la integración política. Aplicación de la Regresión Múltiple para la identificación de factores y agentes de socialización relevantes

En este subcapítulo, las hipótesis que se desea verificar son las vinculadas a la influencia de los factores y agentes de socialización estudiados sobre los niveles de integración política en los adolescentes nativos e inmigrantes. En primer lugar, se repasarán algunas de las características y ventajas de la Regresión Múltiple (RM) y de la Regresión Jerárquica (RJ).

En segundo lugar, se procederá a presentar y discutir los resultados arrojados por la aplicación de estas técnicas. Esto se hará en tres momentos: para la muestra global, para el subconjunto de nativos y para el subconjunto de inmigrantes. El análisis en cada una de estas tres instancias estará conformado por los siguientes pasos:

a) Creación de un modelo de regresión en el que se incluyan sólo las variables independientes consideradas relevantes para cada grupo o conjunto muestral según el Análisis de Correlación Canónica.

b) Creación de un modelo de regresión en el que se incluyan como variables independientes todas las planteadas en el Capítulo II a efectos de añadir, al modelo del punto a), nuevas variables relevantes (estadísticamente significativas). 
c) Creación de un modelo de regresión en el que se incluyan las variables independientes que han presentado significación estadística en el Análisis de Correlación Canónica y en el punto b).

d) Comparación de los modelos obtenidos en los puntos a) y c) a efectos de ver si existen diferencias estadísticamente significativas entre ambos. Este paso requiere el trabajar con la técnica de Regresión Jerárquica. Con este paso, se evalúa cuán atinado resulta considerar como variables independientes, en el caso de la integración política (medida global), a las que han sido detectadas como tales para la explicación de las competencias cívicas (indicadores de la medida global) en el Análisis de Correlación Canónica. En otras palabras, se genera información sobre el porcentaje de varianza de la variable dependiente que se "gana" al sumar variables independientes a las estrictamente sugeridas por la técnica de dependencia antes utilizada.

Finalmente, como se hizo en relación al Análisis de Correlación Canónica se hará una breve revisión de si se han o no corroborado las diferentes hipótesis de investigación. De ese modo, se habrán chequeado la totalidad de las hipótesis presentadas en el Capítulo II.

\section{1) Características de la Regresión Múltiple y de la Regresión Jerárquica}

Anteriormente, se expuso, gracias a la aplicación del Análisis de Correlación Canónica, cómo diferentes variables independientes inciden en las distintas competencias cívicas. Estas últimas, como se ha dicho, conforman el índice de integración política. A efectos de averiguar cómo el último es producido por los diversos factores y agentes de socialización ${ }^{257}$, la Regresión Múltiple es el test multivariante más apropiado. Esta prueba estadística tiene por objeto explicar y predecir, a partir de variables independientes métricas y no métricas, la ocurrencia de una variable dependiente continua (Hair et al. 2007).

\footnotetext{
257 Las variables independientes son las referidas en el Cuadro 2.2 del Capítulo II (factores sociodemográficos, factores psico-sociales y agentes de socialización política). La variable "Género" ha sido adicionada al grupo de factores sociodemográficos. Como en otras investigaciones sobre estos temas, la incorporación de esta última variable tiene por objeto controlar si se detectan cambios en la integración política atribuibles a ella.
} 
En la jerga de la Regresión Múltiple, se habla de ajuste del modelo. Este último no es otra cosa sino la cuantía o nivel de varianza explicada, por parte de las variables independientes, de la variable dependiente. La aplicación de este test permite también detectar cómo cada variable predictora contribuye de manera individual a la varianza de la variable criterio.

En la Regresión Múltiple, tres son las medidas que describen cuán bien el modelo de regresión se ajusta a los datos (Guillén, 1992). En primer lugar, se debe observar el coeficiente de correlación múltiple (R). Este representa la correlación entre los valores predichos, por las variables independientes, de la variable dependiente y los valores que efectivamente la misma asume. En segundo lugar, se debe mirar el coeficiente de determinación $\left(\mathrm{R}^{2}\right)$. Este recuerda la proporción de la varianza de la variable dependiente que puede ser explicada por las variables independientes. En tercer lugar, se tiene que ver el $R^{2}$ ajustado. El mismo se obtiene del $R^{2}$ y es una especie de valor deflactado del anterior a partir de la eliminación de sesgos a efectos de obtener un registro más cercano al que existiría en la población.

Así mismo, una vez aplicada la Regresión Múltiple, es importante observar la significación estadística que se le atribuye al modelo globalmente. La misma evalúa en este caso si, efectivamente, al menos uno de los coeficientes de regresión es estadísticamente diferente a cero $\mathrm{y}$, por tanto, contribuye a explicar la variable dependiente.

Los coeficientes de regresión reportan cuánto cada variable independiente contribuye a explicar la varianza de la variable dependiente ${ }^{258}$. Pueden ser observados a través de los valores B (coeficientes no estandarizados) y Beta (coeficientes estandarizados). Los valores B presentan diferentes unidades de medida y los valores Beta, al unificarse la unidad de medida, favorecen la comparabilidad de las contribuciones relativas de cada variable independiente a la varianza explicada. Los coeficientes de regresión están acompañados de niveles de significación que permiten conocer si la contribución relativa de cada variable está dotada de significación estadística.

\footnotetext{
${ }^{258} \mathrm{El}$ valor del coeficiente de regresión de cada variable independiente debe ser leído como lo que crecería/decrecería la variable dependiente ante un incremento de la primera siempre y cuando se mantengan constantes los valores en el resto de las variables independientes.
} 
En esta investigación, como antes se anunció, también se hará uso de la llamada Regresión Jerárquica (o secuencial). La utilización de la misma tiene por objeto comparar dos modelos de Regresión Múltiple que intentan explicar una misma variable métrica dependiente. El primero de estos modelos tiene menos variables independientes que el segundo. Por tanto, lo que se desea conocer es cuán relevante, desde el punto de vista estadístico, es la capacidad explicativa/predictiva aportada por la inclusión de las nuevas variables independientes.

La Regresión Jerárquica calcula el cambio en $\mathrm{R}^{2}$ que existe entre los dos modelos. En otras palabras, calcula la modificación en varianza explicada entre ambos modelos. También determina si ese cambio es o no estadísticamente significativo. En tanto, los valores que produce la aplicación de esta variante de regresión son exactamente los mismos que los anteriormente mencionados para la Regresión Múltiple.

\section{2) Identificación de patrones en la muestra global}

En primer lugar, un análisis de Regresión Múltiple fue realizado para explicar "Integración Política" en base a las variables predictoras que el Análisis de Correlación Canónica consideró estadísticamente significativas. Por tanto, se incluyeron Condición Migratoria, Nivel de Religiosidad, Actitudes Pro-Sociales, Padres, Grupo de Pares y Escuela ${ }^{259}$. Estas variables combinadas predicen de manera significativa "Integración Política", $F(6,506)=32.150, p<.0005, R^{2}$ ajustado=.26. Si bien, la varianza es explicada es limitada $(26,7 \%$ del total), todas las variables suman significación estadística a la predicción, $p<.05$. Esto último refleja que el resultado del Análisis de Correlación Canónica ha sido un correcto "informante" de las variables a considerar como independientes a la hora de generar un modelo de Regresión Múltiple para saber cómo se explica la medida global de integración política.

\footnotetext{
259 "Cantidad de Años de Residencia" fue eliminada del análisis porque se encontraba multicolineada con "Condición Migratoria". Si bien se respetaban los valores de Tolerance y VIF (medidas estándar de multicolinealidad), "Condición Migratoria" en el modelo que incluyó a ambas presentaba un comportamiento contraintuitivo previsto en la literatura para situaciones de este tipo (Hair et al., 2007). El mismo consistía en presentar un valor no estadísticamente significativo y, a la vez, sugerente de que los inmigrantes presentan mayores dosis de integración política que los nativos. Ello condujo a que se corriera un nuevo análisis de Regresión Múltiple en el que "Cantidad de Años de Residencia" fuese extraída. "Condición Migratoria" asumió entonces un comportamiento predecible. Esta misma variable, por motivos semejantes, fue eliminada en el estudio de Echazarra (2011) sobre incorporación política de inmigrantes en Europa.
} 
"Condición Migratoria" está inversamente relacionada con "Integración Política". Por tanto, como se halló en el Análisis de Correlación Canónica, la condición de inmigrante atenta contra la integración en este plano en la sociedad de acogida. Otra relación negativa, repitiendo también la pauta hallada en la técnica de dependencia antes aplicada, se encuentra con "Nivel de Religiosidad". El resto de las variables independientes, como sucedió antes, presenta una relación positiva con la variable explicada. La variable más importante a la hora de explicar la varianza de la variable criterio es "Grupo de Pares". Detrás de ella, se ubican "Actitudes Pro-Sociales" y "Padres". Los coeficientes de regresión y los errores estándar correspondientes a este modelo pueden ser encontrados en el siguiente cuadro.

\section{Cuadro 3.13}

Resumen del Análisis de Regresión Múltiple (Muestra Global en base a Análisis de Correlación Canónica)

\begin{tabular}{||c|c|c|c||}
\hline Variable & $\boldsymbol{B}$ & SE & b \\
\hline Constante & -3.179 & 1.290 & \\
\hline Condición Migratoria & -.688 & .239 & $-.117^{*}$ \\
\hline Nivel de Religiosidad & -.380 & .088 & $.204^{*}$ \\
\hline Actitudes Pro- & 1.025 & .195 & $.201^{*}$ \\
\hline Sociales & .297 & .056 & $.223^{*}$ \\
\hline Padres & .604 & .116 & $.113^{*}$ \\
\hline Grupo de Pares & .877 & .314 & \\
\hline Escuela & & & \\
\hline
\end{tabular}

Nota: * $\mathrm{p}$ valor < .05; B=coeficientes de regresión no estandarizados; $\mathrm{SE}_{\mathrm{B}}=$ Error Estándar de los coeficientes no estandarizados; $\beta=$ coeficientes estandarizados; $N=513 ; R^{2}$ ajustado= .26; Condición Migratoria=0 Nativos, 1 Inmigrantes.

Fuente: Elaboración Propia

En segundo lugar, se aplicó un análisis de Regresión Múltiple a todas las variables que, en el Capítulo II, se consideraron como independientes. A éstas, se les adicionó como variable de control "Género". Con este nuevo modelo, lo que se pretende es hallar variables independientes que, no habiendo sido significativas a la hora de producir las competencias cívicas en el Análisis de Correlación Canónica, si lo sean para la medida global "Integración Política". Por tanto, se incluyeron Condición Migratoria, Status 
Socioeconómico, Género, Lengua Hablada en el Hogar, Nivel de Religiosidad, Actitudes Pro-Sociales, Padres, Grupo de Pares y Escuela ${ }^{260}$.

Estas variables combinadas predicen de manera significativa "Integración Política", $F(9,432)=20.031, p<.0005, R^{2}$ ajustado=.28. Naturalmente, por el incremento en el número de variables independientes, la varianza explicada ( $28 \%$ del total) es 1.3 puntos porcentuales superior a la del modelo anterior. Género y Lengua Hablada en el Hogar no suman significación estadística. El resto de las variables si lo hacen, $p<.05$. La variable, no incorporada en el modelo anterior, que si explica la "Integración Política" es "Status Socioeconómico". Según este resultado, quienes se encuentran mejor posicionados socialmente presentan mayor integración política. Los coeficientes de regresión y los errores estándar correspondientes a este modelo pueden ser encontrados en el siguiente cuadro.

260 "Cantidad de Años de Residencia" fue eliminada nuevamente del análisis por el motivo antes especificado. 
Cuadro 3.14

Resumen del Análisis de Regresión Múltiple

(Muestra Global en base a todas las variables independientes consideradas teóricamente relevantes)

\begin{tabular}{|c|c|c|c|}
\hline Variable & $\bar{B}$ & $\overline{S E_{B}}$ & $\bar{B}$ \\
\hline Constante & -4.900 & 1.648 & \\
\hline Género & -.304 & .220 & -.057 \\
\hline Condición Migratoria & -.635 & .275 & $-.110 *$ \\
\hline $\begin{array}{c}\text { Lengua Hablada en el } \\
\text { Hogar }\end{array}$ & .045 & .424 & .005 \\
\hline Nivel de Religiosidad & -.346 & .093 & $-.159 *$ \\
\hline $\begin{array}{c}\text { Status } \\
\text { Socioeconómico }\end{array}$ & .051 & .022 & $.103^{*}$ \\
\hline $\begin{array}{l}\text { Actitudes Pro- } \\
\text { Sociales }\end{array}$ & 1.217 & .213 & $.241^{*}$ \\
\hline Padres & .257 & .064 & $.176^{*}$ \\
\hline Grupo de Pares & .571 & .124 & $.204^{*}$ \\
\hline Escuela & .935 & .341 & $.116^{*}$ \\
\hline
\end{tabular}

Nota: * $\mathrm{p}$ valor <.05; $\mathrm{B}=$ coeficientes de regresión no estandarizados; $\mathrm{SE}_{\mathrm{B}}=$ Error Estándar de los coeficientes no estandarizados; $\beta=$ coeficientes estandarizados; $N=442 ; R^{2}$ ajustado= .28; Condición Migratoria=0 Nativos, 1 Inmigrantes; Género=0 Varón, 1 Mujer; Lengua Hablada en el Hogar= 0 No Nativa; 1 Nativa.

En tercer lugar, se aplicó un análisis de Regresión Múltiple a todas las variables consideradas relevantes por el Análisis de Correlación Canónica más la detectada en el punto anterior (Status Socioeconómico). Con este nuevo modelo, lo que se pretende es hallar los coeficientes de regresión definitivos para todas las variables independientes con significación estadística. Por tanto, se incluyeron Condición Migratoria, Status Socioeconómico, Nivel de Religiosidad, Actitudes Pro-Sociales, Padres, Grupo de Pares y Escuela ${ }^{261}$.

Estas variables combinadas predicen de manera significativa "Integración Política", $F(7,505)=28.738, p<.0005, R^{2}$ ajustado=.27. Lógicamente, por la adición de una nueva variable independiente (Status Socioeconómico), la varianza explicada (27,5\% del

261 "Cantidad de Años de Residencia" fue eliminada nuevamente del análisis por el motivo antes especificado. 
total) es 0.8 puntos porcentuales superior a la del modelo que sólo incluye las variables recomendadas por el Análisis de Correlación Canónica. En este caso, todas las variables suman significación estadística, $p<.05$.

Las variables más relevantes, en base a los coeficientes estandarizados, a la hora de explicar la integración política son "Grupo de Pares" y "Actitudes Pro-Sociales". La sugerida influencia, por parte de la literatura, de las Actitudes Pro-Sociales sobre algunas competencias cívicas encuentra también correlato en relación a su incidencia sobre la integración política (Metz y Youniss, 2005). El "Status Socioeconómico" es la variable menos relevante. Por ello, en la muestra global, se confirma parcialmente lo sugerido históricamente por la literatura sobre la importancia de este factor (Berelson et al. 1954; Verba et al. 1996; Bevelander y Pendakur, 2009).

En tanto, "Nivel de Religiosidad" conserva lógicamente su relación negativa con la variable criterio. Este hallazgo, como ya se ha dicho, es opuesto a lo sugerido por la literatura (Djupe y Grant, 2001; Jones-Correa y Leal, 2001). Los adolescentes extranjeros están menos integrados según revela la variable "Condición Migratoria". En tanto, el perfil de los integrados políticamente es el de los nativos, menos religiosos, con algo más de status socioeconómico, con una actitud de apertura hacia el entorno y positivamente influidos por los tres agentes de socialización estudiados. La importancia de los tres agentes de socialización confirma las conclusiones tradicionalmente obtenidas por la literatura anglosajona en la materia (Hess y Torney, 1967; Easton y Dennis, 1967; Grossman, 1974; Campbell, 1980).

Como se dijo en relación a los resultados del Análisis de Correlación Canónica, el panorama pintado por estos hallazgos es poco alentador en relación a los niveles de integración política poseídos por los adolescentes extranjeros. Sus menores niveles relativos actuales son, según afirma la literatura, adecuados predictores de su performance como adultos (Jennings y Niemi, 1981; Verba et al. 1995). Sin embargo, en base a los hallazgos descritos, existen dos resortes sobre los que sería posible actuar para la propiciación de mejores registros entre los foráneos: actitudes pro-sociales y agentes de socialización política. El trabajar conscientemente sobre estas variables puede balancear, entre los adolescentes extranjeros, la influencia negativa de revestir 
condición migratoria ${ }^{262}$. Los coeficientes de regresión y los errores estándar correspondientes a este modelo pueden ser encontrados en el siguiente cuadro.

Cuadro 3.15

Resumen del Análisis de Regresión Múltiple

(Muestra Global en base a todas las variables independientes que han presentado significación estadística)

\begin{tabular}{||c|c|c|c||}
\hline Variable & B & SE & B \\
\hline Constante & -4.596 & 1.403 & $-.113^{*}$ \\
\hline Condición Migratoria & -.664 & .237 & $-.160^{*}$ \\
\hline Nivel de Religiosidad & -.357 & .088 & $.102^{*}$ \\
\hline Status & .048 & .019 & $.207^{*}$ \\
\hline Actitudes Pro- & 1.040 & .194 & $.166^{*}$ \\
\hline Sociales & & & $.225^{*}$ \\
\hline Padres & .245 & .060 & $.116^{*}$ \\
\hline Grupo de Pares & .610 & .312 & \\
\hline Escuela & .897 & & \\
\hline
\end{tabular}

Nota: * p valor < .05; B=coeficientes de regresión no estandarizados; $\mathrm{SE}_{\mathrm{B}}=$ Error Estándar de los coeficientes no estandarizados; $\beta=$ coeficientes estandarizados; $\mathrm{N}=513 ; \mathrm{R}^{2}$ ajustado= .27; Condición Migratoria $=0$ Nativos, 1 Inmigrantes.

Fuente: Elaboración Propia

En cuarto lugar, se han comparado, mediante la Regresión Jerárquica, los modelos obtenidos en el primer y tercer paso. Esto se realiza para ver si, efectivamente, el añadido de la variable "Status Socieconómico" provoca cambios significativos en el $\mathrm{R}^{2}$. El haber agregado esta variable a la explicación de "Integración Política" condujo a un incremento estadísticamente significativo en el $\mathrm{R}^{2}$ de $.009, F(1,505)=6.263, p<.05$. A pesar de haberse conseguido la significación estadística, el aumento es desde el punto de vista porcentual mínimo (0.9\%). Se observa nuevamente que la relevancia de la variable adicionada es limitada a la hora de explicar la integración política. También se reconfirma que el reconocimiento de variables independientes estadísticamente

\footnotetext{
262 Políticas en el campo estrictamente migratorio y en el terreno educativo pueden ser útiles para el moldeado de ambas variables. En el primer caso, la puesta en marcha de programas de inmersión de los inmigrantes adultos en las características del sistema político de la sociedad receptora puede ser muy eficaz. En el segundo caso, el diseño e implementación de instrumentos pedagógicos especialmente diseñados pueden contribuir al empoderamiento psico-social y cívico-político de los niños y adolescentes escolarizados. Más adelante, se ahondará más sobre la cuestión.
} 
significativas que fue realizado por el Análisis de Correlación Canónica fue adecuado. El siguiente cuadro compara detalladamente ambos modelos:

Cuadro 3.16

Regresión Jerárquica Comparativa

(Modelos 1 y 3 para Muestra Global)

\begin{tabular}{||c|c|c|c|c||}
\hline Variable & $\boldsymbol{B}$ & $\boldsymbol{B}$ & $\mathbf{B}$ & $\mathbf{B}$ \\
\hline Constante & -3.179 & & -4.596 & $-.113^{*}$ \\
\hline $\begin{array}{c}\text { Condición } \\
\text { Migratoria }\end{array}$ & -.688 & $-.117^{*}$ & -.664 & \\
\hline Nivel de \\
Religiosidad
\end{tabular}

Nota: * p valor <.05; B=coeficientes de regresión no estandarizados; $\beta=$ coeficientes estandarizados. Condición Migratoria=0 Nativos, 1 Inmigrantes.

Fuente: Elaboración Propia

5.3) Dividiendo en colectivos. ¿Qué particulariza a la integración política de los adolescentes nativos?

En primer lugar, un análisis de Regresión Múltiple fue realizado para explicar "Integración Política" en base a las variables independientes que el Análisis de Correlación Canónica consideró estadísticamente significativas para este subconjunto muestral. Por tanto, se incluyeron Cantidad de Años de Residencia ${ }^{263}$, Nivel de Religiosidad, Actitudes Pro-Sociales, Padres, Grupo de Pares y Escuela. Estas variables combinadas predicen de manera significativa "Integración Política", F (6,354)=17.740, $p<.0005, R^{2}$ ajustado=.21. A pesar de que la varianza explicada es limitada $(21,8 \%$ del

${ }^{263}$ En este caso, esta variable puede ser considerada un proxy de edad del adolescente nativo. 
total), la mayoría de las variables suman significación estadística a la predicción, $p<.05$. Dos de ellas no lo hacen ("Cantidad de Años de Residencia" y "Escuela"). Esto último refleja que el resultado del Análisis de Correlación Canónica ha sido, para este colectivo, un "informante" parcialmente adecuado de las variables a considerar como predictoras a la hora de generar un modelo de Regresión Múltiple para saber cómo se explica la integración política como medida global.

La única relación negativa, repitiendo también la pauta hallada en el Análisis de Correlación Canónica, se encuentra con "Nivel de Religiosidad". Se reitera esta tendencia opuesta a lo sugerido por la literatura. El resto de las variables independientes, como sucedió también con la otra técnica de dependencia, presenta una relación positiva con la variable explicada. La variable más importante a la hora de explicar la varianza de la variable dependiente en este subconjunto muestral es "Padres". Detrás de ella, se ubican "Actitudes Pro-Sociales" y "Nivel de Religiosidad". Los coeficientes de regresión y los errores estándar correspondientes a este modelo pueden ser encontrados en el siguiente cuadro.

Cuadro 3.17

Resumen del Análisis de Regresión Múltiple

(Muestra Nativos en base a Análisis de Correlación Canónica)

\begin{tabular}{||c|c|c|c||}
\hline Variable & B & SE & B \\
\hline Constante & -4.363 & 1.636 & .087 \\
\hline \begin{tabular}{||c|c||} 
Cantidad de Años de \\
Residencia en \\
España
\end{tabular} & .121 & .075 & \\
\hline Nivel de Religiosidad & -.445 & .112 &. $.191^{*}$ \\
\hline Actitudes Pro- & 1.055 & .244 & $.205^{*}$ \\
\hline Sociales & & .065 & $.219^{*}$ \\
\hline Padres & .301 & .406 & $.181^{*}$ \\
\hline Grupo de Pares & .493 & & .073 \\
\hline Escuela & .570 & & \\
\hline
\end{tabular}

Nota: * $\mathrm{p}$ valor < .05; $\mathrm{B}=$ coeficientes de regresión no estandarizados; $\mathrm{SE}_{\mathrm{B}}=$ Error Estándar de los coeficientes no estandarizados; $\beta=$ coeficientes estandarizados; $N=361 ; R^{2}$ ajustado $=.21$.

Fuente: Elaboración Propia 
En segundo lugar, se aplicó un análisis de Regresión Múltiple a todas las variables que, en el Capítulo II, se consideraron como independientes ${ }^{264}$. Como variable de control, se agregó "Género". Con este nuevo modelo, lo que se pretende es hallar variables independientes que, no habiendo sido significativas a la hora de producir las competencias cívicas en el Análisis de Correlación Canónica, si lo sean para la medida global "Integración Política”. Por tanto, se incluyeron Cantidad de Años de Residencia en la Sociedad de Acogida, Status Socioeconómico, Género, Nivel de Religiosidad, Actitudes Pro-Sociales, Padres, Grupo de Pares y Escuela.

Estas variables combinadas predicen de manera significativa "Integración Política", $F(8,351)=14.854, p<.0005, R^{2}$ ajustado=.23. Por el aumento en el número de variables independientes ( 2 más), la varianza explicada (23,6\% del total) es 1.9 puntos porcentuales superior a la del modelo informado por los resultados del Análisis de Correlación Canónica. Excepto "Cantidad de Años de Residencia" y "Escuela”, el resto de las variables suman significación estadística, $p<.05$. El hallazgo sobre la última variable sugiere que, entre los autóctonos, el carácter más o menos abierto de los centros educativos no influye, ni positiva ni negativamente, en la integración política de los adolescentes escolarizados. Ello se contrapone a lo previsto en la literatura tradicional sobre el rol de este agente formal de socialización (Grossman, 1974; Ehman, 1980; Harwood, 1992; Niemi y Junn, 1998; Torney-Purta, Lehmann, Campbell, 2008).

La variable que, según los coeficientes beta, más aporta a la explicación de la integración política es "Actitudes Pro-Sociales". Su relevancia empírica refleja lo mencionado por la literatura (Metz y Youniss, 2005). La misma se encuentra seguida de "Padres" y "Grupo de Pares". La importancia de ambos agentes de socialización coincide con los hallazgos de los estudios clásicos sobre socialización política (Hess y Torney, 1967; Easton y Dennis, 1967; Campbell, 1980).

"Nivel de Religiosidad" es la única variable que presenta, como se ha visto anteriormente, una relación negativa con la variable dependiente. Ello se opone a lo sugerido por la literatura (Djupe y Grant, 2001; Jones-Correa y Leal, 2001). Las variables, no incorporadas en el modelo realizado en el paso previo, que contribuyen a explicar la "Integración Política" son "Género" y "Status Socioeconómico". Los varones nativos se

\footnotetext{
${ }^{264}$ Lengua Hablada en el Hogar fue eliminada por ser una constante dentro del subconjunto muestral.
} 
encuentran, según estos hallazgos, más integrados políticamente. La literatura prevé este tipo de comportamientos (Golebiowska, 1999, Hart, Atkins, Markey y Youniss, 2004; Morales y Giugni, 2011). En tanto, quienes se encuentran en mejor posición socioeconómica son poseedores de mayores niveles de integración política entre los autóctonos $^{265}$. La evidencia empírica histórica reconoce la existencia de este patrón (Berelson et al. 1954; Verba et al. 1995).

En base a lo descrito, el perfil de los adolescentes nativos integrados políticamente es el de varones con una marcada apertura social, menos religiosos, influidos por los agentes de socialización informales y con una mejor situación socioeconómica. Los coeficientes de regresión y los errores estándar correspondientes a este modelo pueden ser encontrados en el siguiente cuadro.

\footnotetext{
${ }^{265}$ Si se hacen correlacionar las dimensiones del Status Socioeconómico con la integración política, sólo existen asociaciones estadísticamente significativas en los casos de "Formación Académica de la Madre", "Ocupación de la Madre" y "Ingreso Familiar Mensual". Se repiten las tres variables ya enunciadas en el caso de las competencias cívicas. Así mismo, se observa la relevancia "materna" en relación a la integración política de los adolescentes escolarizados. Por favor, para un mayor detalle, revisar el Anexo №3.
} 
Cuadro 3.18

Resumen del Análisis de Regresión Múltiple

(Muestra Nativos en base a todas

las variables independientes consideradas teóricamente relevantes)

\begin{tabular}{|c|c|c|c|}
\hline Variable & B & $S E_{B}$ & b \\
\hline Constante & -5.004 & 1.725 & \\
\hline $\begin{array}{c}\text { Cantidad de Años de } \\
\text { Residencia }\end{array}$ & .112 & .074 & .080 \\
\hline Nivel de Religiosidad & -.383 & .111 & $-.166^{*}$ \\
\hline $\begin{array}{l}\text { Actitudes Pro- } \\
\text { Sociales }\end{array}$ & 1.141 & .243 & $.224^{*}$ \\
\hline Padres & .238 & .069 & $.174^{*}$ \\
\hline Grupo de Pares & .471 & .150 & $.174^{*}$ \\
\hline Escuela & .611 & .400 & .078 \\
\hline Género & -.592 & .249 & $-.112^{*}$ \\
\hline $\begin{array}{c}\text { Status } \\
\text { Socioeconómico }\end{array}$ & .054 & .022 & $.126^{*}$ \\
\hline
\end{tabular}

Nota: * p valor <.05; B=coeficientes de regresión no estandarizados; $\mathrm{SE}_{\mathrm{B}}=$ Error Estándar de los coeficientes no estandarizados; $\beta=$ coeficientes estandarizados; $N=360 ; R^{2}$ ajustado $=.23$; Género=0 Varón, 1 Mujer.

Fuente: Elaboración Propia

En tercer lugar ${ }^{266}$, se han comparado, mediante la Regresión Jerárquica, los modelos obtenidos en el primer y segundo paso. Esto se realiza para ver si, efectivamente, el agregar nuevas variables estadísticamente significativas provoca cambios significativos en el $\mathrm{R}^{2}$ en comparación al modelo original que incluía sólo a las variables recomendadas por el Análisis de Correlación Canónica. El haber incluido a la explicación de "Integración Política” a las variables "Status Socioeconómico" y “Género" condujo a un incremento estadísticamente significativo en el $R^{2}$ de $.023, F(2,351)=$ $5.362, p<.05$. El aumento, en términos porcentuales, entre ambos modelos resulta más bien limitado (2.3\%). Las variables agregadas parecen ser poco relevantes de cara a

\footnotetext{
${ }^{266}$ Para este subconjunto muestral, a diferencia de lo que sucede con la muestra global y la muestra de inmigrantes, no es necesario calcular un tercer modelo de Regresión Múltiple. Consecuentemente, es posible comparar, mediante una Regresión Jerárquica, los modelos obtenidos en los dos primeros pasos. Un tercer hipotético modelo incluiría exactamente las mismas variables independientes que las agregadas en el paso dos (que son, casualmente, las estadísticamente significativas tanto en la instancia del Análisis de Correlación Múltiple como para la Regresión Múltiple).
} 
explicar la integración política de los adolescentes nativos. En el caso concreto de este subconjunto muestral, las variables independientes con significación estadística detectadas por el Análisis de Correlación Canónica se aproximan con bastante verosimilitud al panorama hallado por la Regresión Múltiple para la integración política como medida global. El siguiente cuadro compara detalladamente ambos modelos:

\section{Cuadro 3.19}

Regresión Jerárquica Comparativa

(Modelos 1 y 2 para Muestra Nativos)

\begin{tabular}{|c|c|c|c|c|}
\hline Variable & $\bar{B}$ & b & $\bar{B}$ & B \\
\hline Constante & -4.363 & & -5.004 & \\
\hline $\begin{array}{c}\text { Cantidad de Años } \\
\text { de Residencia }\end{array}$ & .121 & .087 & .112 & .080 \\
\hline $\begin{array}{c}\text { Nivel de } \\
\text { Religiosidad }\end{array}$ & -.445 & $-.191 *$ & -.383 & $-.166^{*}$ \\
\hline $\begin{array}{l}\text { Actitudes Pro- } \\
\text { Sociales }\end{array}$ & 1.055 & $.205^{*}$ & 1.141 & $.224 *$ \\
\hline Padres & .301 & $.219 *$ & .238 & $.174^{*}$ \\
\hline Grupo de Pares & .493 & $.181^{*}$ & .471 & $.174^{*}$ \\
\hline Escuela & .570 & .073 & .611 & .078 \\
\hline Género & - & - & -.592 & $-.112^{*}$ \\
\hline $\begin{array}{c}\text { Status } \\
\text { Socioeconómico }\end{array}$ & . & 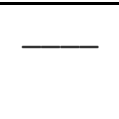 & .054 & $.126 *$ \\
\hline
\end{tabular}

Nota I: * p valor < .05; B=coeficientes de regresión no estandarizados; $\beta=$ coeficientes estandarizados.

Nota II: Lengua Hablada en el Hogar fue eliminada del análisis por ser una constante.

Nota III: Género=0 Varón, 1 Mujer.

Fuente: Elaboración Propia

\section{4) Dividiendo en colectivos. ¿Qué particulariza a la integración política de los adolescentes inmigrantes?}

En primer lugar, un análisis de Regresión Múltiple fue realizado para explicar "Integración Política" en base a las variables independientes que el Análisis de Correlación Canónica consideró estadísticamente significativas para el subconjunto muestral de los adolescentes inmigrantes. Por tanto, se incluyeron Cantidad de Años de 
Residencia, Nivel de Religiosidad, Actitudes Pro-Sociales, Grupo de Pares y Escuela. Estas variables combinadas predicen de manera significativa "Integración Política", F $(5,146)=7.929, p<.0005, R^{2}$ ajustado=.18. En este caso, la varianza explicada es limitada (18,7\% del total). La mayoría de las variables suman significación estadística a la predicción, $p<.05$. Sin embargo, dos de ellas no lo hacen ("Cantidad de Años de Residencia" y "Nivel de Religiosidad"). Esto último refleja que el resultado del Análisis de Correlación Canónica ha sido, para este colectivo en concreto, un "informante" parcialmente adecuado de las variables a considerar como predictoras a la hora de generar un modelo de Regresión Múltiple explicativo de la integración política.

Todas las variables estadísticamente significativas presentan una relación positiva con integración política. La variable más importante a la hora de explicar la varianza de la variable dependiente en el subconjunto muestral de los inmigrantes adolescentes es "Actitudes Pro-Sociales". Detrás de ella, se ubican "Grupo de Pares" y "Escuela". Los coeficientes de regresión y los errores estándar correspondientes a este modelo pueden ser encontrados en el siguiente cuadro.

\section{Cuadro 3.20}

Resumen del Análisis de Regresión Múltiple (Muestra Inmigrantes en base a Análisis de Correlación Canónica)

\begin{tabular}{|c|c|c|c|}
\hline Variable & $\bar{B}$ & $\overline{S E_{B}}$ & $\overline{6}$ \\
\hline Constante & -4.198 & 2.031 & \\
\hline $\begin{array}{c}\text { Cantidad de Años de } \\
\text { Residencia en } \\
\text { España }\end{array}$ & .091 & .059 & .116 \\
\hline Nivel de Religiosidad & -.179 & .148 & -.093 \\
\hline $\begin{array}{c}\text { Actitudes Pro- } \\
\text { Sociales }\end{array}$ & .977 & .328 & $.229 *$ \\
\hline Grupo de Pares & .635 & .220 & $.220 *$ \\
\hline Escuela & 1.155 & .514 & $.170 *$ \\
\hline
\end{tabular}

Nota: * p valor < .05; B=coeficientes de regresión no estandarizados; $\mathrm{SE}_{\mathrm{B}}=$ Error Estándar de los coeficientes no estandarizados; $\beta=$ coeficientes estandarizados; $N=152 ; R^{2}$ ajustado $=.18$.

En segundo lugar, se aplicó un análisis de Regresión Múltiple a todas las variables que, en el Capítulo II, se consideraron como independientes. Como variable de control, 
se adicionó otra vez "Género". Con este modelo, lo que se pretende es hallar variables independientes que, no habiendo sido significativas a la hora de producir las competencias cívicas en el Análisis de Correlación Canónica, si lo sean para la medida global "Integración Política". Por tanto, se incluyeron Cantidad de Años de Residencia en la Sociedad de Acogida, Status Socioeconómico, Género, Nivel de Religiosidad, Actitudes Pro-Sociales, Lengua Hablada en el Hogar, Padres, Grupo de Pares y Escuela.

Estas variables combinadas predicen de manera significativa "Integración Política", $F(9,131)=5.654, p<.0005, R^{2}$ ajustado=.23. El incremento en el número de variables independientes ( 4 más) provoca que la varianza explicada ( $23,0 \%$ del total) sea 4.3 puntos porcentuales superior a la del modelo informado por los resultados del Análisis de Correlación Canónica. A pesar de que la mayoría de las variables suman significación estadística, $p<.05$, cuatro no lo hacen: Nivel de Religiosidad (como sucedió en el modelo anterior), Género, Lengua Hablada en el Hogar y Status Socioeconómico ${ }^{267}$. Cantidad de Años de Residencia, en este nuevo modelo, sí presenta significación estadística. Con este último dato, encuentra soporte empírico la teoría de la exposición de la re-socialización política entre los inmigrantes (Tam Cho, 1999; White et al. 2008).

La variable que, según los coeficientes beta, más contribuye a explicar la integración política es "Grupo de Pares", seguida de "Actitudes Pro-Sociales" y "Padres". Esta última es la única variable, de las no incorporadas en el modelo previo, que contribuyen a explicar la "Integración Política". Los coeficientes de regresión y los errores estándar correspondientes a este modelo pueden ser encontrados en el siguiente cuadro.

267 En el caso del subconjunto muestral de inmigrantes, ninguna de las dimensiones de Status Socioeconómico se encuentra correlacionada con Integración Política. Esta falta de significación estadística puede ser consecuencia de que la muestra de los adolescentes extranjeros es relativamente pequeña ( $n=154)$. Para mayor información sobre el particular, por favor, revisar el Anexo № 3. 
Cuadro 3.21

Resumen del Análisis de Regresión Múltiple

(Muestra Inmigrantes en base a todas

las variables independientes consideradas teóricamente relevantes)

\begin{tabular}{|c|c|c|c|}
\hline Variable & $\bar{B}$ & $\overline{S E_{B}}$ & $\bar{b}$ \\
\hline Constante & -8.973 & 3.007 & \\
\hline $\begin{array}{c}\text { Cantidad de Años de } \\
\text { Residencia }\end{array}$ & .126 & .064 & $.155^{*}$ \\
\hline Nivel de Religiosidad & -.120 & .149 & -.062 \\
\hline $\begin{array}{c}\text { Lengua Hablada en el } \\
\text { Hogar }\end{array}$ & -.195 & .412 & -.036 \\
\hline $\begin{array}{l}\text { Actitudes Pro- } \\
\text { Sociales }\end{array}$ & .935 & .339 & $.220 *$ \\
\hline Padres & .333 & .124 & $.207^{*}$ \\
\hline Grupo de Pares & .758 & .228 & $.257^{*}$ \\
\hline Escuela & 1.349 & .513 & $.204^{*}$ \\
\hline Género & -.075 & .376 & -.015 \\
\hline $\begin{array}{c}\text { Status } \\
\text { Socioeconómico }\end{array}$ & .044 & .046 & .077 \\
\hline
\end{tabular}

Nota: * p valor < .05; B=coeficientes de regresión no estandarizados; $\mathrm{SE}_{\mathrm{B}}=$ Error Estándar de los coeficientes no estandarizados; $\beta=$ coeficientes estandarizados; $N=141 ; R^{2}$ ajustado= .23; Género=0 Varón, 1 Mujer; Lengua Hablada en el Hogar= 0 No Nativa; 1 Nativa.

Fuente: Elaboración Propia

En tercer lugar, se aplicó un análisis de Regresión Múltiple que lo que pretende es hallar los coeficientes de regresión definitivos para todas las variables independientes que han presentado significación estadística. Por tanto, se incluyeron Cantidad de Años de Residencia, Nivel de Religiosidad, Actitudes Pro-Sociales, Padres, Grupo de Pares y Escuela. Estas variables combinadas predicen de manera significativa "Integración Política”, $F(6,145)=8.304, p<.0005, R^{2}$ ajustado=.22. No presentan significación estadística ni Nivel de Religiosidad (como era previsible) ni, sorpresivamente, Cantidad de Años de Residencia ${ }^{268}$. El resto de las variables suman significación estadística, $p<$ .05 .

\footnotetext{
268 La variable "Cantidad de Años de Residencia" no ha sido estadísticamente significativa si se considera un $\mathrm{p}$ valor $<.05$. En tanto, si lo ha sido si se considera como umbral un $\mathrm{p}$ valor $<.1$
} 
Las variables más relevantes, en base a la información provista por los coeficientes estandarizados, a la hora de explicar la integración política entre los extranjeros escolarizados son (en orden decreciente) "Grupo de Pares", "Actitudes ProSociales", "Padres" y "Escuela"269. Los adolescentes inmigrantes se ven influidos, según los resultados de este modelo, por todos los agentes de socialización. Este hallazgo coincide con lo sugerido con los estudios clásicos sobre socialización política (Hess y Torney, 1967; Easton y Dennis, 1967; Grossman, 1974; Campbell, 1980). Este resultado también comparte la esencia de estudios más recientes que destacan la importancia de la "Escuela" como promotor de ciudadanos activos políticamente (Harwood, 1992; Finkel y Ernst, 2005). Al mismo tiempo, con este hallazgo, la importancia sugerida por la literatura de las Actitudes Pro-Sociales a la hora de producir la integración política se ha manifestado en las tres muestras analizadas (Metz y Youniss, 2005).

En tanto, el perfil concreto de los adolescentes inmigrantes integrados políticamente es el de individuos con más años de residencia en la sociedad de acogida, con una actitud de apertura hacia el entorno y positivamente influidos por los tres agentes de socialización estudiados. Estos resultados permiten concluir lo ya anticipado en apartados previos. A pesar del desequilibrio en materia de integración política entre nativos e inmigrantes, existen dos factores sobre los que es posible incidir mediante programas o acciones concretas para generar escenarios menos cívicamente divididos y, por tanto, inmigrantes más empoderados. La actuación sobre agentes de socialización y Actitudes Pro-Sociales parece estratégica en tal sentido. Los coeficientes de regresión y los errores estándar correspondientes a este modelo pueden ser encontrados en el siguiente cuadro.

\footnotetext{
${ }^{269}$ En el caso concreto de la muestra de inmigrantes, las únicas dos dimensiones de la variable "Escuela" relacionadas con la integración política son Itinerario Formativo y Discusión sobre Política en Clase. Quienes asisten a escuelas con una orientación clara en Ciencias Sociales están más integrados y quienes más discuten sobre política también.
} 
Cuadro 3.22

Resumen del Análisis de Regresión Múltiple

(Muestra Inmigrantes en base a todas las

variables independientes que han presentado significación estadística)

\begin{tabular}{||c|l|l|l||}
\hline Variable & \multicolumn{1}{|c|}{$B$} & \multicolumn{1}{|c|}{$S E_{B}$} & \multicolumn{1}{|c||}{} \\
\hline Constante & $-6,984$ & 2,208 & \\
\hline \begin{tabular}{||c|l|l||} 
Cantidad de Años de \\
Residencia
\end{tabular} &, 098 &, 058 &, $125^{\text {Nota II }}$ \\
\hline $\begin{array}{c}\text { Nivel de Religiosidad } \\
\text { Actitudes Pro- } \\
\text { Sociales }\end{array}$ &,- 173 &, 144 &,- 089 \\
\hline Padres &, 338 &, 321 &, $211^{*}$ \\
\hline Grupo de Pares &, 715 &, 118 &, $208^{*}$ \\
\hline Escuela & 1,242 &, 217 &, $248^{*}$ \\
\hline
\end{tabular}

Nota I: * p valor < .05; B=coeficientes de regresión no estandarizados; $\mathrm{SE}_{\mathrm{B}}=$ Error Estándar de los coeficientes no estandarizados; $\beta=$ coeficientes estandarizados; $N=152 ; R^{2}$ ajustado= 22 .

Nota II: La variable "Cantidad de Años de Residencia" ha sido estadísticamente significativa si se considera como umbral un $\mathrm{p}$ valor $<.1$

Fuente: Elaboración Propia

En cuarto lugar, se han comparado, mediante la Regresión Jerárquica, los modelos obtenidos en el primer y tercer paso. Esto se realiza para ver si, efectivamente, el agregar nuevas variables estadísticamente significativas provoca cambios significativos en el $\mathrm{R}^{2}$ en comparación al modelo original que incluía sólo a las variables sugeridas por el Análisis de Correlación Canónica. El haber incluido a la explicación de "Integración Política" a la variable "Padres" condujo a un incremento estadísticamente significativo en el $\mathrm{R}^{2}$ de $.042, F(1,145)=8.216, p<.05$. El aumento, porcentualmente, es de 4.2 puntos. La variable adicionada parece relevante de cara a explicar la integración política de los adolescentes inmigrantes. En el caso concreto de este subconjunto muestral, el Análisis de Correlación Canónica no reconoció a una variable predictora de la variable criterio. El siguiente cuadro compara detalladamente ambos modelos. 
Cuadro 3.23

Regresión Jerárquica Comparativa

(Modelos 1 y 3 para Muestra Inmigrantes)

\begin{tabular}{|c|c|c|c|c|}
\hline Variable & B & 6 & B & 8 \\
\hline Constante & -4.198 & & $-6,984$ & \\
\hline $\begin{array}{c}\text { Cantidad de Años } \\
\text { de } \\
\text { Residencia }\end{array}$ & .091 & .116 & 098 & 125 \\
\hline $\begin{array}{c}\text { Nivel de } \\
\text { Religiosidad }\end{array}$ & -.179 & -.093 &,- 173 &,- 089 \\
\hline $\begin{array}{c}\text { Actitudes Pro- } \\
\text { Sociales }\end{array}$ & .977 & $.229 *$ & 904 &, $211^{*}$ \\
\hline Padres & 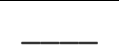 & $\underline{-}$ & ,338 & ,208* \\
\hline Grupo de Pares & .635 & $.220 *$ & ,715 & ,248* \\
\hline Escuela & 1.155 & $.170 *$ & 1,242 & ,183* \\
\hline
\end{tabular}

Nota I: * p valor <.05; B=coeficientes de regresión no estandarizados; $\beta=$ coeficientes estandarizados.

Fuente: Elaboración Propia

\section{5) Comprobación parcial de hipótesis de trabajo}

En el siguiente cuadro, se realiza una tercera y última comprobación parcial de las hipótesis de trabajo asumidas por esta investigación. El mismo incluye a las hipótesis que han podido ser confirmadas mediante la aplicación de la Regresión Múltiple y pruebas complementarias. 
Cuadro 3.24

Comprobación parcial de hipótesis de trabajo

\begin{tabular}{|c|c|c|c|}
\hline & Hipótesis & Hallazgo & Nota aclaratoria \\
\hline \multirow{6}{*}{ 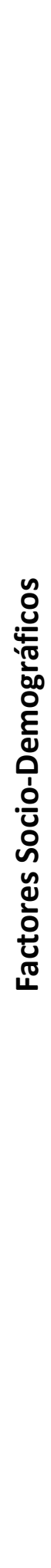 } & $\begin{array}{l}\text { La cantidad de tiempo } \\
\text { transcurrido en la sociedad de } \\
\text { acogida será directamente } \\
\text { proporcional al nivel de } \\
\text { integración política poseído } \\
\text { por los adolescentes de origen } \\
\text { inmigrante }\end{array}$ & $\begin{array}{l}\text { Parcialmente } \\
\text { confirmatorio }\end{array}$ & $\begin{array}{l}\text { Está variable sólo resulto } \\
\text { estadísticamente significativa } \\
(.049) \text { cuando fue incluida en un } \\
\text { modelo de Regresión Múltiple en el } \\
\text { que estaban presentes todas las } \\
\text { variables independientes } \\
\text { relevantes desde el punto de vista } \\
\text { teórico. }\end{array}$ \\
\hline & $\begin{array}{l}\text { A mayor nivel educativo de los } \\
\text { padres y/o tutores, mayor } \\
\text { nivel de integración política } \\
\text { entre los adolescentes (con } \\
\text { independencia de su origen } \\
\text { nacional) }\end{array}$ & $\begin{array}{l}\text { Confirmatorio } \\
\text { sólo para la } \\
\text { relación entre } \\
\text { Formación } \\
\text { Académica } \\
\text { Materna e } \\
\text { Integración } \\
\text { Política (sólo } \\
\text { nativos) }\end{array}$ & $\begin{array}{l}\text { Relevancia del rol materno como } \\
\text { fue sugerido también en el Análisis } \\
\text { de Correlación Canónica. El Status } \\
\text { Socioeconómico no explica la } \\
\text { Integración Política entre los } \\
\text { adolescentes inmigrantes. }\end{array}$ \\
\hline & $\begin{array}{l}\text { A mayor nivel de ingreso de los } \\
\text { padres y/o tutores, mayor } \\
\text { nivel de integración política } \\
\text { entre los adolescentes (con } \\
\text { independencia de su origen } \\
\text { nacional) }\end{array}$ & $\begin{array}{l}\text { Confirmatorio } \\
\text { para la relación } \\
\text { entre Ingreso } \\
\text { Familiar Mensual } \\
\text { e Integración } \\
\text { Política (sólo } \\
\text { nativos) } \\
\end{array}$ & $\begin{array}{l}\text { Similitud con los resultados } \\
\text { observados en el Análisis de } \\
\text { Correlación Canónica. El Status } \\
\text { Socioeconómico no explica la } \\
\text { Integración Política entre los } \\
\text { adolescentes inmigrantes. }\end{array}$ \\
\hline & $\begin{array}{l}\text { Los padres y/o tutores cuyas } \\
\text { ocupaciones sean no manuales } \\
\text { tendrán hijos con mayores } \\
\text { niveles de integración política } \\
\text { (con independencia de su } \\
\text { origen nacional) }\end{array}$ & $\begin{array}{l}\text { Confirmatorio } \\
\text { sólo para la } \\
\text { relación entre } \\
\text { Ocupación } \\
\text { Materna e } \\
\text { Integración } \\
\text { Política (sólo } \\
\text { nativos) }\end{array}$ & $\begin{array}{l}\text { Similitud con los resultados } \\
\text { observados en el Análisis de } \\
\text { Correlación Canónica. El Status } \\
\text { Socioeconómico no explica la } \\
\text { Integración Política entre los } \\
\text { adolescentes inmigrantes. }\end{array}$ \\
\hline & $\begin{array}{l}\text { Los adolescentes de origen } \\
\text { inmigrante que hablen en el } \\
\text { hogar una lengua distinta a la } \\
\text { de la sociedad de acogida } \\
\text { tendrán menores niveles de } \\
\text { integración política que } \\
\text { aquellos que hablen en las } \\
\text { lenguas oficiales }\end{array}$ & No confirmatorio & $\begin{array}{l}\text { La Regresión Múltiple no encontró } \\
\text { a la Lengua Hablada en el Hogar } \\
\text { como dotada de suficiente } \\
\text { significación estadística. }\end{array}$ \\
\hline & $\begin{array}{l}\text { A mayor nivel de religiosidad } \\
\text { del alumno, mayores registros } \\
\text { en integración política (con } \\
\text { independencia de su origen } \\
\text { nacional) }\end{array}$ & No confirmatorio & $\begin{array}{l}\text { La Regresión Múltiple ha } \\
\text { descubierto que la relación entre el } \\
\text { Nivel de Religiosidad y la } \\
\text { Integración Política es inversa y no } \\
\text { directa como preveía la hipótesis } \\
\text { de trabajo. La relación es } \\
\text { estadísticamente significativa sólo } \\
\text { para el caso de los nativos. }\end{array}$ \\
\hline
\end{tabular}




\begin{tabular}{|c|c|c|c|}
\hline 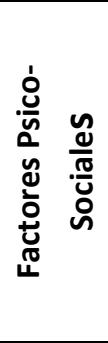 & $\begin{array}{l}\text { Los adolescentes que } \\
\text { presenten mayores niveles en } \\
\text { la posesión de actitudes pro- } \\
\text { sociales serán los que } \\
\text { presenten mayores niveles de } \\
\text { integración política (con } \\
\text { independencia de su origen } \\
\text { nacional) }\end{array}$ & Confirmatorio & $\begin{array}{l}\text { La Regresión Múltiple ha hallado } \\
\text { que esta es, junto a Grupo de Pares, } \\
\text { la variable que más contribuye a la } \\
\text { explicación de la Integración } \\
\text { Política tanto entre inmigrantes } \\
\text { como entre nativos }\end{array}$ \\
\hline \multirow{6}{*}{ 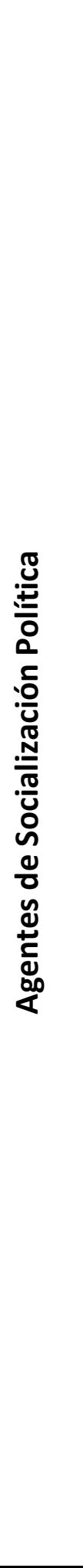 } & $\begin{array}{l}\text { Los niveles de integración } \\
\text { política poseídos por los } \\
\text { padres y/o tutores } \\
\text { correlacionarán positivamente } \\
\text { con los niveles de integración } \\
\text { política presentados por sus } \\
\text { hijos/tutorados (con } \\
\text { independencia de su origen } \\
\text { nacional) }\end{array}$ & Confirmatorio & $\begin{array}{l}\text { La Regresión Múltiple ha } \\
\text { encontrado a esta variable como } \\
\text { relevante tanto en la muestra de } \\
\text { los nativos como en la muestra de } \\
\text { los inmigrantes }\end{array}$ \\
\hline & $\begin{array}{l}\text { Escuelas con un ratio } \\
\text { inmigrantes/nativos menor, } \\
\text { como consecuencia de la } \\
\text { menor posibilidad de } \\
\text { interacción con población } \\
\text { autóctona, tendrán individuos } \\
\text { de origen inmigrante que } \\
\text { presentarán menores niveles } \\
\text { de competencias cívicas } \\
\end{array}$ & No confirmatorio & $\begin{array}{l}\text { No se ha hallado significación } \\
\text { estadística para la relación de esta } \\
\text { variable con la Integración Política. }\end{array}$ \\
\hline & $\begin{array}{l}\text { Los alumnos de origen } \\
\text { inmigrante que se encuentren } \\
\text { cursando los itinerarios } \\
\text { formativos de Ciencias } \\
\text { Sociales y/o Humanas } \\
\text { presentarán valores más } \\
\text { elevados en integración } \\
\text { política que sus pares } \\
\text { pertenecientes a otros } \\
\text { itinerarios formativos. }\end{array}$ & Confirmatorio & $\begin{array}{l}\text { Se ha encontrado significación } \\
\text { estadística para la relación positiva } \\
\text { entre esta variable e Integración } \\
\text { Política }\end{array}$ \\
\hline & $\begin{array}{l}\text { Las escuelas en las que, según } \\
\text { lo declarado por los } \\
\text { estudiantes inmigrantes, son } \\
\text { más frecuentes las discusiones } \\
\text { políticas aquéllos tendrán } \\
\text { mayores niveles de } \\
\text { integración política }\end{array}$ & Confirmatorio & $\begin{array}{l}\text { Se ha encontrado significación } \\
\text { estadística para la relación positiva } \\
\text { entre esta variable con Integración } \\
\text { Política }\end{array}$ \\
\hline & $\begin{array}{l}\text { Las escuelas en las que más } \\
\text { innovaciones pedagógicas se } \\
\text { utilizan para la enseñanza de } \\
\text { asignaturas vinculadas a la } \\
\text { formación cívica serán las que } \\
\text { presentarán individuos de } \\
\text { origen inmigrante con } \\
\text { mayores niveles de } \\
\text { integración política }\end{array}$ & No confirmatorio & $\begin{array}{l}\text { No se ha hallado significación } \\
\text { estadística para la relación de esta } \\
\text { variable con la Integración Política }\end{array}$ \\
\hline & $\begin{array}{l}\text { Los niveles de integración } \\
\text { política de los compañeros de } \\
\text { clase, considerados éstos } \\
\text { como grupo de pares, } \\
\end{array}$ & Confirmatorio & $\begin{array}{l}\text { La Regresión Múltiple ha hallado } \\
\text { que esta es, junto a Actitudes Pro- } \\
\text { Sociales, la variable que más } \\
\text { contribuye a la explicación de la }\end{array}$ \\
\hline
\end{tabular}




\begin{tabular}{|c|c|c|c|}
\hline & $\begin{array}{l}\text { correlacionarán positivamente } \\
\text { con los registros en la misma } \\
\text { variable presentados por cada } \\
\text { adolescente }\end{array}$ & & $\begin{array}{l}\text { Integración Política tanto entre } \\
\text { inmigrantes como entre nativos }\end{array}$ \\
\hline 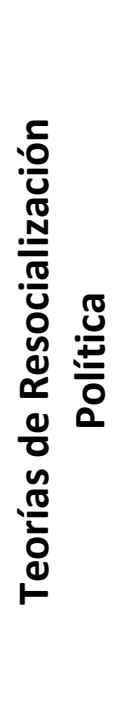 & $\begin{array}{l}\text { Ambas teorías de } \\
\text { resocialización política } \\
\text { (exposición y transferencia o } \\
\text { transferibilidad) contribuyen a } \\
\text { describir los niveles de } \\
\text { competencias cívicas entre los } \\
\text { adolescentes de origen } \\
\text { inmigrante en la sociedad de } \\
\text { acogida }\end{array}$ & $\begin{array}{l}\text { Parcialmente } \\
\text { Confirmatorio }\end{array}$ & $\begin{array}{l}\text { Se ha encontrado más evidencia } \\
\text { empírica para la teoría de la } \\
\text { exposición que para la teoría de la } \\
\text { transferibilidad. Las variables } \\
\text { asociadas a la primera (vinculadas a } \\
\text { la sociedad de acogida: Cantidad de } \\
\text { Años de Residencia y Agentes de } \\
\text { Socialización vinculados a la } \\
\text { comunidad de destino) han } \\
\text { explicado mejor los niveles de } \\
\text { Integración Política entre los } \\
\text { adolescentes inmigrantes que las } \\
\text { variables asociadas a la segunda } \\
\text { (vinculadas a la sociedad de origen: } \\
\text { Status Socioeconómico y Agentes } \\
\text { de Socialización vinculados a la } \\
\text { comunidad de la que se procede). }\end{array}$ \\
\hline
\end{tabular}

Fuente: Elaboración propia.

\section{6) Discusión de los hallazgos e identificación de tendencias}

\section{1) Desde las competencias cívicas hacia la integración política}

\subsection{1) Sobre la justificación de la utilización de las competencias cívicas como indicadores de la integración política}

La utilización de los registros en las competencias cívicas como indicadores de los niveles de la integración política de los adolescentes escolarizados ha demostrado ser suficientemente adecuada. Más allá de que su elección a tales fines se basó en la literatura sobre la cuestión, diferente evidencia empírica producto de esta investigación respalda tal afirmación. En primer lugar, todas las competencias cívicas han presentado una tendencia semejante considerando su distribución entre nativos e inmigrantes. Los primeros aventajan, en los valores promedio, a los últimos en cada uno de estos atributos cívicos.

En segundo lugar, en el Análisis de Correlación Canónica, el coeficiente de adecuación del set que incluía a las competencias cívicas ha presentado registros elevados en los tres conjuntos muestrales (por encima del 30\% en todos los casos). Debe recordarse que el mismo informa sobre la proporción de la varianza de las variables que 
conforman un set (en este caso, el set de variables independientes) que es explicada por el valor teórico atribuido al set en cuestión.

En tercer lugar, con excepción del comportamiento de la "Eficacia Política" en el caso de la muestra conformada por los adolescentes inmigrantes al aplicarse el Análisis de Correlación Canónica, todas las competencias cívicas han presentado un comportamiento positivamente correlacionado. Es decir, todas ellas se mueven en un idéntico sentido.

Un cuarto hallazgo que contribuye a sostener la utilización de las competencias cívicas como manifestación de la integración política se vislumbra en la comparación de las variables independientes consideradas como estadísticamente significativas por los dos métodos multivariantes aplicados en esta investigación. En otras palabras, las variables independientes significativas que ha detectado el Análisis de Correlación Canónica han sido correctas informantes de las variables independientes introducidas en los Modelos de Regresión Múltiple.

Este patrón ha estado relacionado con el tamaño de la muestra analizada y se percibe a través de dos datos concretos. Por un lado, se observa en el porcentaje de variables significativas encontradas por la RM en base a los factores significativos "informados" por el ACC (100\%, 66\% y 60\% para, respectivamente, las muestras global, de nativos y de inmigrantes). Por otro lado, se percibe que la capacidad explicativa de la varianza "agregada" por las nuevas variables independientes relevantes detectadas por la RM ha sido menor en la muestra más grande (global: 0,9\%) en comparación a las dos submuestras ( $2,3 \%$ para nativos y $4,2 \%$ para inmigrantes).

En otras palabras, la ACC tiene mayor poder "informante" de las variables a ingresar como explicativas de la RM cuando mayor es el tamaño de la muestra. Lo comentado avala la consideración de las variables independientes estadísticamente significativas detectadas por el ACC para cumplir una función semejante en la RM en escenarios metodológicos como el aquí descrito (una variable dependiente compuesta por diferentes indicadores/dimensiones que pueden fungir, a la vez, como varias variables dependientes). 


\subsection{2) Sobre las diferencias inter-colectivos en materia de competencias cívicas e integración política}

En este apartado, se hace mención de dos cuestiones vinculadas a las diferencias cívicas halladas entre autóctonos e inmigrantes. En primer lugar, se expone lo que desde el punto de vista teórico son las implicancias negativas y positivas de las distribuciones desiguales de competencias cívicas e integración política. En segundo lugar, se comentan ciertas limitaciones de la presente investigación que han impedido explorar la totalidad de la diversidad existente ad intra del colectivo de adolescentes extranjeros.

Sobre la primera cuestión, huelga decir que los adolescentes locales aventajan a los inmigrantes tanto en los niveles de todas las competencias cívicas como en la posesión de la integración política, medida resumen de las anteriores. Si bien los jóvenes vernáculos no tienen una "performance cívica promedio" ideal en los atributos analizados, el que exista esta brecha entraña, ciertamente, importantes riesgos por lo que implica en relación a la existencia de modos divergentes entre nativos y extranjeros de vinculación con el sistema político. La potencial exclusión política de parte importante de los "nuevos miembros" de la sociedad española es la consecuencia más clara de hallazgos como los descritos.

Carole Pateman (1980), en su crítica a los primeros estudios sobre cultura política, ya advertía sobre los potenciales efectos negativos de escenarios sociales en los que existen marcadas divergencias en el comportamiento y las actitudes políticas de distintos colectivos. La permanencia en el tiempo de un colectivo poblacional rezagado en su integración política afectará irremediablemente la fortaleza del entramado institucional democrático de la sociedad de acogida (Anduiza y San Martín, 2011). Consecuentemente, si un sector social importante (como en el caso de la población de origen inmigrante) se mantiene al margen de participar y controlar a las autoridades, la calidad del régimen democrático tenderá a verse seriamente menguada ${ }^{270}$. Ello

\footnotetext{
270 En la definición de Levine y Molina (2007), la calidad de la democracia es evaluada a partir de los niveles ciudadanos de participación y control sobre la actividad desarrollada por los gobiernos. El otorgamiento de relevancia teórica a la dimensión participativa en los regímenes democráticos no es privativo de estos autores. Corbetta y Pérez-Liñán (2001), Altman y Pérez-Liñán (2002), Diamond y Morlino (2004), Hagopian (2005), Alcántara (2008) y Barreda (2011) son, entre otros, algunos cientistas políticos que mencionan la importancia estratégica de la participación ciudadana, entre otros elementos, a la hora de evaluar la fortaleza de la democracia en un sistema político en concreto.
} 
acontece porque, en un contexto como el referido, las decisiones emanadas de los órganos gubernamentales no se encontrarán permeadas por los puntos de vistas del colectivo marginado ${ }^{271}$.

Obviamente, los resultados de un único estudio como el aquí descrito no aportan suficiente prueba empírica para hacer diagnosis o prognosis en relación a una afectación real de la calidad democrática en España. Para poder proceder a ello, dos estrategias de investigación podrían contribuir. En primer lugar, habría que llevar a cabo nuevas pesquisas como ésta para ver si el patrón se repite entre adolescentes escolarizados cada determinado periodo de tiempo. En segundo lugar, sería interesante relevar los niveles (potenciales y reales) de participación electoral de los inmigrantes adultos (naturalizados o no naturalizados) en elecciones locales y de inmigrantes adultos naturalizados en elecciones nacionales.

Sobre población inmigrante adulta, a día de hoy, lo que existe son análisis sobre encuestas realizadas en las dos principales ciudades españolas (Madrid y Barcelona) en las que ha quedado registro sobre intención de participación electoral futura y niveles de participación política real en el pasado. En tanto, algunos investigadores también han analizado el comportamiento de los inmigrantes en la muestra española de la Encuesta Social Europea (ESE). Los resultados de este conjunto de investigaciones reportan que el nivel de participación tanto real como potencial de los foráneos es menor que el de los locales (Echazarra, 2011, González-Ferrer, 2011; Morales y San Martín, 2011)272. Estas investigaciones también dejan constancia de que los inmigrantes adultos

\footnotetext{
${ }^{271}$ En su análisis sobre la integración política de los inmigrantes adultos en las sociedades europeas, Morales (2011) sostiene que las diferencias a favor de los autóctonos no deben ser siempre leídas como señales de exclusión política de los inmigrantes sino como manifestaciones de un modo de ser particular de una subcultura política. En su visión, lo importante es que los inmigrantes accedan, aunque no necesariamente por las mías vías que los locales, a procesos políticos en los que su punto de vista sea considerado. Teóricamente, en esta perspectiva, la integración política de los inmigrantes es el producto de un proceso en el que se compensa la "presencia" de actuaciones políticas de determinado tipo" con la "ausencia" de actuaciones políticas de otra naturaleza. Sin embargo, empíricamente, esta autora compara la performance de locales y extranjeros en base a un mismo estándar tanto a nivel de actitudes como de comportamientos políticos.

272 Concretamente, Morales y San Martín (2011) hallaron que, entre los inmigrantes naturalizados, la participación ha sido menor en comparación a los autóctonos en elecciones locales (2003), autonómicas (2003) y generales (2004). Esta pauta se reitera, entre todos los inmigrantes (naturalizados y no naturalizados), en relación a intención de voto. En la ciudad de Madrid, mientras el $85 \%$ de los nativos en la muestra afirma intención de votar, ese registro desciende a poco más del $75 \%$ en determinados colectivos inmigrantes. En base a datos provistos por la ESE, Echazarra (2011) detecta que la diferencia de participación electoral entre autóctonos e inmigrantes es, en el caso español, de un $28 \%$ a favor de los primeros.
} 
presentan guarismos rezagados, en comparación a los autóctonos, en Conocimiento Político y Atención Política ${ }^{273}$. Estos resultados, que atestiguan patrones de diferenciación cívica, engarzan con los descubrimientos reportados por esta investigación. Los hallazgos producto de la presente investigación y los descubrimientos generados por las investigaciones referidas estarían manifestando la presencia de un escenario en el que la población inmigrante se encuentra políticamente menos integrada.

Sin embargo, no todas las lecturas de los hallazgos provistos por esta investigación son tan pesimistas. A esta edulcoración de la mirada contribuye el hecho de que las diferencias inter-colectivos en competencias cívicas no han sido siempre estadísticamente significativas. En el caso de la Atención Política y la Eficacia Política ${ }^{274}$, la distribución es según la prueba estocástica equivalente entre ambos conjuntos poblacionales. Según la literatura, ello podría incidir en la activación futura de procesos cívicos virtuosos que provoquen una postrera equiparación de valores en aquellas competencias cívicas en las que el "saldo" a favor de los autóctonos sí ha sido estadísticamente significativo.

Según hallazgos previos, la Atención Política puede ser sindicada como causa del Conocimiento Político, la Participación Política y la Tolerancia Política (Jennings y Niemi, 1974; Chaffee, 1977; Rubin, 1978; Andolina et al. 2003; McIntosh et al. 2007). En tanto, la Eficacia Política ha sido identificada como origen tanto de la Participación Política como de la Tolerancia Política (Campbell et al., 1954; Easton y Dennis, 1967; Duch y Gibson, 1992; Morrell, 2005). Debe sumarse, a las mencionadas relaciones causales, la influencia que mutuamente se ejercen las dos competencias cívicas en las que no ha habido diferencias estadísticamente significativas entre nativos e inmigrantes. El tener presente estos antecedentes, a pesar de no ser los resultados inicialmente generosos en relación a la situación cívica de los adolescentes inmigrantes, arroja algo de luz sobre

\footnotetext{
${ }^{273}$ A nivel de Conocimiento Político, el $50 \%$ de los adultos nativos afirma encontrarse bastante informado sobre la realidad política. Ese registro desciende al $20 \%$ en el caso de los inmigrantes. Para la Atención Política, cerca del $46 \%$ de los adultos nativos afirma estar interesado en el seguimiento de la política. Ese porcentaje baja a cerca del $35 \%$ en el caso de los inmigrantes.

274 Registros similares en Eficacia Política entre autóctonos e inmigrantes de edad adulta fueron encontrados por Morales (2011) y Anduiza y San Martín (2011) en estudios de alcance europeo.
} 
los valores que su integración política en la sociedad receptora podría asumir a mediano y largo plazo.

Pasando a la segunda cuestión a discutir en este apartado, debe hacerse mención de que, como consecuencia del tamaño limitado del subconjunto muestral de los estudiantes extranjeros, no ha sido posible apreciar variabilidades internas. A modo de ejemplo, se hace mención de que no se realizaron análisis que compararan los guarismos entre adolescentes inmigrantes procedentes de diferentes backgrounds culturales porque algunos de ellos se encontraban insuficientemente presentes en la muestra recolectada ${ }^{275}$, circunstancia que invalidaba su consideración para la aplicación de diferentes análisis estadísticos. Posteriores estudios sobre la cuestión deben considerar la ampliación cuantitativa de los individuos de estos orígenes para la puesta en marcha de comparaciones robustas que permitan desentrañar la eventual influencia de cosmovisiones culturales en la relación que los adolescentes inmigrantes entablan con el sistema político de la sociedad de acogida.

Otra variabilidad interna a la muestra de adolescentes inmigrantes es la vinculada al background político de los sujetos. En otras palabras, se hace referencia a la naturaleza del régimen político de la sociedad de origen (democrátivo versus autoritario). A pesar de que en la muestra analizada la cuantía de los individuos procedentes de sociedades autoritarias es de 21 (versus 133 originarios de sociedades democráticas) y lo que ello implica a la hora de tomar con precaución cualquier exploración estadística, ha emergido cierto patrón que merece la pena mencionar. Los estudiantes inmigrantes originarios de países democráticos presentan valores más altos en la mayoría de las competencias cívicas (Atención Política, Participación Política y Tolerancia Política) y, por añadidura, en Integración Política.

Sería muy aventurado afirmar, dadas las restricciones mencionadas, que los alumnos inmigrantes procedentes de sociedades democráticas están mejor preparados para relacionarse con el sistema político receptor. Este hallazgo respondería a lo que intuitivamente puede presuponerse. Sólo a través de la conformación de muestras más amplias en posteriores estudios de este tenor se puede ayudar a comprobar hipótesis, para explicar la socialización política en destino, que han sido construidas a partir de la

\footnotetext{
${ }^{275}$ Lo dicho aplica, fundamentalmente, para el colectivo de alumnos procedentes de Extremo Oriente y de países islámicos.
} 
consideración estratégica de las características del sistema político de la sociedad expulsora (Landolt y Goldring, 2008).

Otra variabilidad, al interior del colectivo inmigrante, que no pudo ser suficientemente explorada por las mismas restricciones muestrales es la vinculada a lo que se da en llamar "contexto de recepción". Este es un concepto ampliamente considerado en los estudios migratorios (Herranz, 1997; Barry, 1997; Morales y San Martín, 2011). En tal sentido, ya existe prueba empírica acerca de que los niveles de integración política de los inmigrantes adultos pueden verse afectados por lo que se llama "capital político". Este no es otra cosa sino las oportunidades que el medio ambiente concreto de acogida genera en el plano político a los recién llegados. Morales y Giugni (2011), en su estudio paneuropeo, han descubierto que determinadas políticas públicas locales propician mejores niveles de integración política de los extranjeros.

En el caso concreto de la integración política de los inmigrantes adolescentes, la misma podría verse afectada tanto por políticas genéricas de gestión de la inmigración como por políticas específicas aplicadas a la gestión de la migración en el sistema educativo. Ambos tipos de políticas, en el pasado reciente español, han sido fundamentalmente desarrolladas en el nivel estatal autonómico. En futuras investigaciones sobre muestras de adolescentes, sería interesante rastrear si diferencias observadas entre Comunidades Autónomas en los niveles de integración política de los adolescentes inmigrantes en España son atribuibles a la existencia de variopintos escenarios generados por la existencia de estilos no coincidentes en los dos tipos descritos de políticas ${ }^{276}$.

\footnotetext{
${ }^{276}$ Sin mirar al número de sujetos inmigrantes incluidos en la muestra de cada ciudad (distribución no equilibrada), parecería que los adolescentes extranjeros con altos niveles de integración política son aquellos que asisten a institutos de educación secundaria ubicados en Comunidades Autónomas que no aplican políticas educativas de concentración de los inmigrantes en centros educativos específicos. A modo de ejemplo, Valencia presenta una media de integración política de 8.30 y Madrid tiene un promedio en este registro de 7.40. Ambos aventajan a Barcelona (que sí aplica estas políticas) y que cuenta con un valor medio de 6.76 .
} 


\section{2) Influencia de los factores socio-demográficos}

Un factor sociodemográfico, ligado estrechamente a la condición migratoria, que influye decisivamente en materia de integración política es la "Cantidad de Años de Residencia" en la sociedad de acogida. La relevancia de esta variable ha sido detectada en tres niveles: cuando se ha considerado las competencias cívicas de manera individualizada, cuando se las ha evaluado de manera simultánea en el Análisis de Correlación Canónica y cuando se ha corrido la Regresión Múltiple para la medida global.

El conocimiento político y la tolerancia política son las dos competencias cívicas que parecen estar más fuertemente provocadas por el tiempo que se ha vivido en la sociedad de acogida. Tanto la posesión de información sobre el sistema político local como la aceptación de ciertos dispositivos legislativos propios de sociedades occidentales se encontrarían causadas por los registros en esta variable.

En el ACC, cuando las competencias cívicas son consideradas como un set de variables dependientes, esta variable ("Cantidad de Años de Residencia") ha presentado en las tres muestras significación estadística. En el caso del subconjunto muestral de los inmigrantes, su carga canónica (.498) la ubica como uno de los dos factores que más contribuyen a la producción de los atributos cívicos. Idéntico patrón se observó en oportunidad de realizarse la RM. Si bien su coeficiente estandarizado en el caso de la muestra conformada sólo por inmigrantes la posiciona como la quinta variable en relevancia $(\beta=.125)$, su contribución a la explicación de la integración política es estadísticamente significativa (tomando como referencia un $p$ valor $<.1$ ) .

La importancia de esta variable sostiene los argumentos previstos por la teoría de la exposición de la resocialización política (White et al. 2008). La diferencia cívica entre adolescentes nativos e inmigrantes en los tres niveles analíticos referidos está causada, entre otros motivos, por el paso del tiempo. Mayor asentamiento en la sociedad receptora apareja, para los extranjeros, una mayor integración política en la misma. Este hallazgo invalida a aquellos argumentos que consideran el desempeño cívico de los inmigrantes en las sociedades de acogida como de tipo cristalizado o inalterable.

A pesar de la "luz al final del túnel" que implica este hallazgo en relación a la integración política de los inmigrantes, no debe olvidarse que por su especial naturaleza 
(es decir, el paso del tiempo) no es posible alterarla o intervenirla externamente. En otras palabras, para favorecer el empoderamiento cívico de los extranjeros, no puede contarse con el "adelantar" artificialmente años de residencia ${ }^{277}$. Otras variables, como la promoción de Actitudes Pro-Sociales entre los jóvenes o la influencia sobre los Agentes de Socialización, deben ser consideradas a efectos de promover tales estrategias.

El "Status Socioeconómico" es una clásica variable incluida en este tipo de estudios (Berelson et al. 1954; Verba et al. 1996; Bevelander y Pendakur, 2009). Sin embargo, la evidencia empírica, derivada de la realización de este estudio, respalda sólo parcialmente su relevancia. Esto puede deberse al hecho de que la muestra se ha conformado sólo por adolescentes que asisten a instituciones educativas secundarias en las que hay, según el registro estadístico de cada Comunidad Autónoma, mayor presencia de individuos de origen inmigrante. Estos, en el caso de España (como en el de otros países receptores de inmigración), se insertan en institutos públicos a los que asiste población perteneciente a estratos socioeconómicos medio-bajos (Alegre y Subirats, 2007; Cebolla, 2009). Ello implica que existe cierta "constancia socioeconómica" entre los sujetos incluidos en la investigación. En otras palabras, la variabilidad en este aspecto entre los miembros de la muestra es más bien mínima.

Es precisamente esa mínima variabilidad la que se escondería detrás de la coincidencia en los registros de Eficacia Política entre nativos e inmigrantes. La pertenencia de ambos grupos a los estratos medio-bajos de la población sería un potencial factor explicativo de los limitados registros en esta competencia cívica tal y como prevé la literatura sobre la cuestión (Caprara et. al. 2009).

Cuando las competencias cívicas son consideradas colectivamente en el Análisis de Correlación Canónica, el Status Socioeconómico no arroja significación estadística en ninguna de las tres muestras. Ello cambia en el caso de la Regresión Múltiple. En esta última, esta variable parece ser relevante a la hora de producir la integración política tanto en la muestra global $(B=.102)$ como en el subconjunto nativo $(B=.126)$. A pesar de ello, su contribución explicativa, en comparación a la de otras variables independientes,

\footnotetext{
277 Alfonso Echazarra (2011, p. 64), en un razonamiento semejante al aquí propuesto en su estudio sobre la integración política de los inmigrantes en Europa, afirma que "...el tiempo es, a fin de cuentas, un continente de sucesos sobre el que, además, las políticas públicas no podrán ejercer ningún impacto...”.
} 
es mínima. En tanto, la integración política de los inmigrantes no encuentra explicación en la consideración de este factor sociodemográfico.

Al desagregarse las dimensiones del Status Socioeconómico y ver cómo las mismas se vinculan con las competencias cívicas y la integración política, se detectan dos tendencias sólo en el subconjunto muestral de nativos. La primera de ellas es que las características "maternales" importan más que las características "paternales". Madres mejor formadas y con ocupaciones no manuales estimulan el empoderamiento cívico de sus vástagos. La segunda de ellas es que a mayor ingreso familiar los adolescentes tenderán a estar más integrados políticamente, pauta recurrentemente sugerida por los estudios (Verba et al. 1995). Sin embargo, ninguna tendencia ha sido hallada entre los inmigrantes en relación a los componentes de este factor sociodemográfico.

Lo descubierto por esta investigación en relación al Status Socioeconómico no ha permitido aportar evidencia empírica para la teoría de la transferibilidad de la resocialización política de los inmigrantes (White et al. 2008). A ello, pueden haber contribuido tanto el ya mencionado criterio para la selección de los centros educativos en los que se suministró el cuestionario como el hecho de que el subconjunto muestral de los inmigrantes es cuantitativamente limitado (154 individuos). Ambos elementos restringen el rango de valores que los sujetos pueden asumir en esta variable y, por tanto, menguan la capacidad de las técnicas estadísticas utilizadas para hallar significación estadística.

La "Lengua Hablada en el Hogar" ha demostrado no ser relevante a la hora de explicar las competencias cívicas y la integración política. En ninguno de los dos análisis multivariantes aplicados, ha conseguido significación estadística. Tanto en el Análisis de Correlación Canónica como en la Regresión Múltiple cuando son aplicados al subconjunto muestral de los inmigrantes, esta variable presenta, incluso, un signo contrario a lo teóricamente presumido. En principio, no se ha encontrado evidencia empírica para afirmar que la suficiencia en una lengua propia de la sociedad de acogida contribuye a la facilitación de la integración política de los inmigrantes. La conformación, en el futuro, de muestras más amplias de adolescentes de origen inmigrante seguramente facilite la detección de pautas como las sugeridas por la literatura para 
esta variable (el empoderamiento cívico potenciado a partir de un manejo solvente de la lengua local) (Brady et al, 1995; Leighley y Vedlitz, 1999).

La conducta asumida por "Nivel de Religiosidad" es la que más dista de lo hipotetizado en esta investigación y de lo sugerido por la academia anglosajona. Su posesión dificulta la adquisición de todas las competencias cívicas y, por tanto, de la integración política. Como se ha visto, la Tolerancia Política es el único atributo cívico con el que esta variable se relaciona de manera acorde a lo descrito por la literatura (Niemi y Chapman, 1998; Eisenstein, 2006). Quienes se manifiestan como más religiosos son aquéllos adolescentes que menos toleran en las tres muestras analizadas.

La relación negativa estadísticamente significativa entre Nivel de Religiosidad y el conjunto de competencias cívicas se presenta en las tres muestras para el ACC. En todos los casos, presenta una carga canónica superior a -.340 (-.341 para la submuestra inmigrante). La relación negativa con significación estadística se repite en el caso de la Regresión Múltiple para las muestras global ( $6=-.160)$ y nativa ( $6=-.166)$. En el caso de los inmigrantes, si bien el carácter no positivo del vínculo se mantiene ( $6=-.089)$, no se supera el umbral de la significación estadística.

La distancia entre los hallazgos de esta investigación y lo sugerido por la literatura puede deberse al hecho de que, en el caso de España a diferencia de lo que sucede en las sociedades anglosajonas, las diferentes iglesias no son un actor promotor del empoderamiento cívico de sus feligreses. Según recuerdan Jones-Correa y Leal (2001), en los Estados Unidos, las iglesias fungen a efectos de favorecer la actuación política de sus fieles como una asociación u organización de la sociedad civil. Ello es aún más patente si se considera que, en el escenario norteamericano, las iglesias existentes suelen estar asociadas a colectivos étnicos o raciales específicos ${ }^{\mathbf{2 7 8}}$ a los que se estimula desde los púlpitos a inmiscuirse en el terreno de lo político. Por la existencia de estos mecanismos, las iglesias son para los inmigrantes una catapulta para la integración política en la sociedad de acogida. Según estos autores, la invitación al protagonismo

\footnotetext{
${ }^{278} \mathrm{~A}$ tales efectos, el lector debe recordar la existencia de una miríada de iglesias protestantes afiliadas a la población afroamericana. Como ejemplo, sirve también recordar la vinculación histórica de determinados sectores de la Iglesia Católica estadounidense a específicos colectivos inmigrantes (irlandeses, alemanes o polacos). Este último patrón se repite en la actualidad con la existencia de ramas de la Iglesia Católica profundamente relacionadas con la inmigración de cuño latinoamericano (fundamentalmente de origen mexicano).
} 
político realizada desde las comunidades religiosas equilibra las carencias que, en otras materias (status socioeconómico, cantidad de años de residencia en destino, solvencia en el uso de lenguas locales, etc.) presentan los colectivos inmigrantes.

La evidencia empírica aportada por esta investigación permite afirmar que los adolescentes inmigrantes que profesan una religión en España no encuentran en su culto el estímulo necesario para proyectarse en el campo político. Por el contrario, su pertenencia a una comunidad religiosa parece condenarlos a la membresía a una esfera para-política ${ }^{279}$. Ello evidentemente dificulta (cuando no obstruye) la escucha, por parte de los poderes públicos, de sus puntos de vista. Los peligros que ello encierra en relación a la creación de espacios de infraciudadanía resultan harto evidentes.

\section{3) Influencia de los factores psico-sociales}

En la presente investigación, se ha encontrado suficiente evidencia empírica para sostener que las "Actitudes Pro-Sociales" son, como sugiere la literatura (Metz y Youniss, 2005), un adecuado predictor de las competencias cívicas y de la integración política. Las mismas pueden ser entendidas como predisposiciones del carácter de los individuos que ofician de caldo de cultivo para una posterior implicación cívica de los mismos.

En este estudio en concreto, su influencia pareció ser particularmente relevante en las dos competencias cívicas que se encuentran uniformemente distribuidas entre nativos e inmigrantes: Atención Política y Eficacia Política. En tanto, en los dos tests multivariantes aplicados, las Actitudes Pro-Sociales han presentado significación estadística. En el ACC, sus cargas canónicas han sido superiores a .390 en las tres muestras. En la RM, sus coeficientes estandarizados la posicionan como una de las dos variables que más contribuyen a la explicación de la integración política $(\beta>.200$ en las tres conjuntos muestrales).

Concretamente, en el caso del subconjunto muestral de los inmigrantes, la posesión de las Actitudes Pro-Sociales ha demostrado ser un pre-requisito fundamental para la posesión de competencias cívicas (.417 de carga canónica en el ACC) y,

\footnotetext{
${ }^{279}$ Estos resultados contrastan con el hallazgo de Echazarra (2011) en su estudio sobre integración política de inmigrantes adultos en Europa. La religiosidad es, junto a la edad, la variable que compensa los efectos negativos de otros factores sobre los niveles de participación política de los inmigrantes adultos.
} 
consecuentemente, para el favorecimiento de la integración política en la sociedad de acogida $(\beta=.211$ en la $\mathrm{RM})$. En otras palabras, los inmigrantes dispuestos a ayudar a otros y empáticos con sus congéneres serán más proclives a encontrarse empoderados cívicamente. El hecho de que estos recursos psico-sociales se encuentren semejantemente distribuidos entre nativos e inmigrantes los erige en contrapeso positivo de otros factores cívicamente empoderadores de los que los extranjeros carecen (por ejemplo, mayor cantidad de años de residencia en la sociedad receptora).

Las Actitudes Pro-Sociales, según lo descrito por la literatura, pueden ser estimuladas tanto por elementos biológicos como ambientales ${ }^{280}$ (Rushton, 2004). Entre las influencias contextuales, Jiménez y López-Zafra (2011) señalan la importancia de los programas de capacitación diseñados a efectos de incrementar los niveles de posesión de estas actitudes entre los destinatarios. Aplicando la lógica explicativa hallada en la presente investigación, el estímulo de estos recursos psico-sociales proporcionaría también competencias cívicas a los beneficiarios de estas acciones. Este razonamiento es refrendando por Stephan Meier (2006). Este autor recuerda, en su repaso a los estudios sobre este tipo de predisposiciones psico-sociales, como diferentes instancias en las que se invita a actuar pro-socialmente terminan provocando determinados comportamientos políticos (donación de dinero a causas puntuales, decisión de trabajar voluntariamente, participación en manifestaciones, etc.).

En sociedades con trasfondo migratorio, la puesta en marcha de programas tendientes a elevar las actitudes pro-sociales entre los miembros de colectivos en situación de desventaja relativa puede contribuir a la evitación de escenarios de marginación política. Jones-Correa y Leal (2001) han descubierto que, para determinados grupos poblacionales, la asunción de determinadas actitudes y comportamientos políticos requiere de promoción o incentivo externo. Los programas para el desarrollo de Actitudes Pro-Sociales, por los efectos de su adquisición en el incremento de las competencias cívicas, pueden ser un ejemplo específico de esa influencia exterior. Esa invitación procedente del entorno es la que podría facilitar la

\footnotetext{
${ }^{280}$ Según los hallazgos de Philippe Rushton de la Universidad de Western Ontario, el $42 \%$ de la causa de las Actitudes Pro-Sociales puede rastrearse en los genes de quienes las manifiestan mientras que el 58\% restante es atribuible a influencias medio ambientales. En el artículo "A survey of economic theories and field evidence on pro-social behavior", Stephan Meier (2006) realiza un interesante repaso de cómo elementos contextuales influyen en la producción de Actitudes Pro-Sociales.
} 
incursión en el campo político de sujetos que, consideradas otras especificidades, no se adentrarían en el mismo.

Lo comentado acuerda con dos de las tradicionales hipótesis que la Ciencia Política ha encontrado para la explicación de las competencias cívicas. Por un lado, se encuentra aquella que ve su origen en la presión o impulso ejercido sobre los sujetos por actores y/o resortes externos (Nie et al. 1969, Franklin, 2004; Giugni y Morales, 2011). Este incentivo externo dota a los individuos de recursos que terminan propiciando su implicación política. Por otro lado, se tiene a aquella que rastrea su génesis en proyectos educativos diseñados ad hoc (Torney-Purta et al., 2001; Finkel y Ernst, 2005; Pasek et al., 2008). La exposición a determinados contenidos y métodos educativos puede actuar de catalizador para el protagonismo político de los sujetos.

\section{4) Agentes y teorías de (re)socialización política}

\subsection{1) La marca cívica indeleble del Grupo de Pares}

Los tres agentes de socialización política estudiados influyen, en mayor o menor medida, en los niveles de competencias cívicas e integración política de los adolescentes. Si bien existen particularidades dentro de cada colectivo poblacional, la evidencia empírica encontrada en esta investigación respalda a la tradicional literatura anglosajona que enfatiza su relevancia en relación a la producción de resultados cívicos.

El agente de socialización política más relevante, en función de los tests estadísticos aplicados, ha sido el Grupo de Pares. Ello puede ser comprendido como que la pertenencia de un individuo a un entorno conformado por sujetos con elevadas competencias cívicas e integración política potencia los propios registros. La importancia de este agente se detectado, en primer lugar, a la hora de la generación de los valores de los individuos en Conocimiento Político y Participación Política. En el ACC, esta variable ha presentado en las tres muestras una carga canónica alta (entre .578 y .672). Idéntico patrón se halló en la aplicación de la RM: su contribución a la producción de integración política ha sido estadísticamente significativa en las tres muestras ( $\beta \geq .174)$. Esta es la variable que, junto a las Actitudes Pro-Sociales, en mayor medida provoca la integración política de los individuos. 
Estos hallazgos parecen confirmar lo sugerido por la literatura en relación a la relevancia del Grupo de Pares. Los compañeros de clase ejercerían, sobre la relación de los individuos con el mundo político, una influencia que podría emparentarse con el concepto de "campo de poder" expuesto por Campbell en 1980. Los pares actuarían como limitantes o potenciadores de las competencias cívicas de los sujetos. Entornos políticamente integrados tenderían a provocar adolescentes políticamente integrados no sólo en el momento histórico en el que tiene lugar la relación sujeto-grupo de pares sino (especialmente destacable en una investigación como la aquí descrita) también en circunstancias postreras (Youniss et al. 2001, McFarland y Thomas, 2006). En tal sentido, el Grupo de Pares pareciera dejar una especie de marca indeleble que provocaría cierta cristalización en los niveles de competencias cívicas de los individuos.

Lo dicho engarza perfectamente con lo que Jones-Correa y Leal (2001) hallaron en sus investigaciones sobre inmigrantes en los Estados Unidos: la incursión en el mundo de lo político depende de invitaciones cursadas por agentes externos. En el marco de la adolescencia, el grupo de pares desempeña un rol moldeador de la identidad (política y de otros tipos) difícilmente superable por otros actores. El que el influjo del Grupo de Pares se presente de manera semejante en los dos colectivos poblacionales analizados también cuaja con lo previsto por los expertos. Según Ryan (2001), el sello dejado por el Grupo de Pares en los individuos se da con independencia del sexo o etnia de los sujetos.

\subsection{2) ¿Distintos colectivos, distintas pautas de socialización?}

Si se comparan cuáles son los agentes de socialización política que influyen en uno y otro colectivo poblacional, se hallan patrones interesantes. Al interior del subconjunto muestral de los nativos, el ACC y la RM destacan que la mayor influencia es ejercida por agentes de socialización informales (Padres y Grupo de Pares). La Escuela, de hecho en la RM, no presenta significación estadística a la hora de producir la medida resumen de integración política $(\beta=.078)$ entre los adolescentes autóctonos. Las características del centro educativo no parecen ser decisivas a la hora de generar jóvenes cívicamente competentes. Los atributos cívicos, por el contrario, vendrían promovidos por la pertenencia a familias y grupos de pares poseedores de tales cualidades. 
La lectura es distinta en el caso de los adolescentes inmigrantes. Quienes son más competentes cívicamente $y$, por ende, se encuentran mejor integrados políticamente se encuentran positivamente influidos por agentes de socialización vinculados a la sociedad de acogida (Escuela y Grupo de Pares). Los niveles de integración política de los padres y/o tutores poco parecen importar a la hora de producir las competencias cívicas de los vástagos (la variable presenta una carga canónica de .266, es decir, por debajo del umbral de significación estadística) ${ }^{281}$. El descubrimiento de este patrón aporta evidencia empírica para el sostenimiento de la teoría de la exposición de la resocialización política en detrimento de explicaciones basadas en la transferencia de competencias entre sociedades (White et al. 2008). En otras palabras, el contacto con los parámetros vernáculos (conocidos a través del sistema educativo y los compañeros de clases) sería la catapulta, entre los adolescentes inmigrantes, para la adquisición de sus competencias cívicas. Por el contrario, la integración política de los Padres, influida por dinámicas propias de la sociedad de origen, tiene limitado poder explicativo sobre la performance cívica de la descendencia en la sociedad de destino.

El patrón encontrado entre los adolescentes inmigrantes recupera la relevancia de la Escuela como agente de socialización política. Según lo descubierto por las dos pruebas multivariantes aplicadas, las características de los centros educativos pueden ser un efectivo acicate para la propiciación de la integración política de los extranjeros en el sistema político receptor (carga canónica de .415 en la ACC y $\beta=.183$ en la RM). En la muestra recolectada, dos cualidades concretas de los institutos parecen ser particularmente importantes: el itinerario formativo que se ofrece a los alumnos en la institución y la frecuencia de discusión sobre política en clase. Los inmigrantes formados con mayor énfasis en Ciencias Sociales afirman atender más la política y participarían más que sus pares que siguen otras currículas. A su vez, quienes más discuten sobre política en el aula son más competentes en Atención Política, Participación Política y Eficacia Política. Estos hallazgos deben ser estratégicamente considerados a la hora del

\footnotetext{
${ }^{281}$ La influencia de los Padres es algo mayor en el caso de la explicación de la integración política ( $\left.\beta=.208\right)$. Sin embargo, su coeficiente estandarizado la ubica por detrás de variables explicativas más relevantes.
} 
procederse al diseño e implementación de políticas de gestión de la inmigración en el terreno educativo.

\subsection{3) Influir sobre los agentes de socialización. Una vía para la integración política de los adolescentes de origen inmigrante}

Lo hallado sobre la influencia de los agentes de socialización en los niveles de integración política de los inmigrantes invita a reflexionar sobre lo adecuado de utilizar ciertos mecanismos para la promoción de la igualación en esta materia entre nativos e inmigrantes. En consecuencia, el diseño de políticas públicas en el campo de la inmigración podría partir de verificaciones empíricas como la descrita en estas páginas.

Un terreno especialmente propicio a los efectos reseñados es el de la política educativa. A través de este instrumento, se puede moldear el carácter cívico de los adolescentes inmigrantes no sólo directamente a través de contenidos curriculares o métodos pedagógicos (las dos dimensiones de la variable llamada "Escuela" en esta investigación que resultaron ser estadísticamente significativas) sino también, indirectamente, mediante la conformación de entornos humanos cívicamente empoderados (la variable llamada "Grupo de Pares" en esta pesquisa).

Difícilmente todas las escuelas/institutos puedan incorporar igual cantidad de espacios formativos dedicados a la Ciencias Sociales. La existencia, prevista por la legislación, de diferentes itinerarios académicos lo impide. Habría que avanzar entonces en la identificación en el contexto español de aquellos "contenidos concretos" cuya transmisión al estudiantado resultan claves para empoderar políticamente a los alumnos. Ello requiere claramente la creación de experimentos que sometan a diferentes grupos a distintos estímulos procedentes del campo de las Ciencias Sociales. Una vez "fotografiados" estos saberes resulta más fácil recomendar su incorporación en las asignaturas pertenecientes a esta esfera del conocimiento tanto en escuelas especializadas en la misma como en otras que ofrecen orientaciones formativas diferentes. Próximas investigaciones, a los fines de afinar la aplicabilidad de lo descubierto en este trabajo, deben desandar el camino sugerido en estas líneas ${ }^{282}$.

\footnotetext{
282 Galston (2001, 2004), recuerda que para el caso norteamericano, se ha descubierto que el estudio de sistemas políticos distintos al vernáculo, la enseñanza de la lectura de tablas y cuadros con información política y la profundización en elementos propios de la teoría democrática provocan en los adolescentes
} 
Por el contrario, la necesidad de la inclusión de la discusión sobre política como herramienta pedagógica resulta más clara. Su uso puede tener lugar en cualquier tipo de centro educativo siendo irrelevante el itinerario académico ofrecido en el mismo. En lo que sí podría avanzarse al respecto es en la visualización de las formas que esta discusión como método debe asumir. Nuevamente, la experimentación se erige como el método más relevante para determinar qué tipo de discusión (libre, dirigida por el docente, en el marco de simulaciones con formato parlamentario, en relación a temáticas actuales, sobre situaciones hipotéticas, etc.) es la que potencia en mayor medida la integración política de los estudiantes inmigrantes ${ }^{283}$.

El influir, desde la política educativa, sobre los grupos de pares para que éstos favorezcan la integración política del alumnado inmigrante no reviste en principio mayor dificultad. A tales efectos, una solución radicaría en el armado de equipos de trabajo por parte de los docentes de asignaturas con contenidos políticos en los que haya presencia equilibradamente distribuida entre extranjeros y locales y entre individuos con elevados niveles de competencias cívicas y otros con niveles cívicos más modestos. Ello requiere que, antes de la puesta en marcha de esta estrategia y para proceder a un reparto que tenga efectos significativos, se midan estos valores entre los estudiantes.

En la misma sintonía, también se pueden crear sistemas de apadrinamiento cívico dentro de las escuelas. Los mismos pueden consistir en duetos entre adolescentes políticamente competentes y otros menos calificados en la materia (con independencia del origen nacional). Una alternativa se encontraría en la conformación de parejas en las que un compañero local competente cívicamente intercambie perspectivas sobre el mundo político vernáculo con un compañero extranjero menos integrado

mayores niveles de competencias cívicas. Yendo aún más lejos se ha hallado que un programa concreto de educación cívica llamado "The We the People: The Citizen and the Constitution Program" genera adolescentes más cívicamente competentes que otras alternativas pedagógicas. Este es un programa de educación cívica promovido por actores públicos y privados que se dicta en escuelas secundarias estadounidenses desde el año 1987.

283 Niemi y Junn (1998) hallaron que, para el caso norteamericano, la discusión en clase sobre eventos políticos actuales provoca adolescentes con mayores niveles de competencias cívicas. Torney-Purta et al. (2001) y Torney-Purta (2002) han llegado a idéntico resultado en una muestra recabada en estudiantes de secundaria de 28 países. La importancia de la discusión sobre situaciones presentes, junto a otros métodos de educación cívica, han sido destacados por el reporte preparado por la Carnegie Corporation of New York and The Center for Information and Research on Civic Learning and Engagement de la University of Maryland para las autoridades del gobierno norteamericano (2003). Según los autores de este informe, la misma se erige en verdadera "catapulta cívica" particularmente en individuos de origen inmigrante. 
políticamente. Estos intercambios deben acontecer en espacios pedagógicos creados a tales efectos (tareas escolares compartidas, exámenes resueltos conjuntamente, visitas a instituciones políticas encargadas a la pareja, seguimiento "guiado" por los docentes a tertulias políticas y/o televisivas, etc.). Siguiendo los hallazgos de esta investigación, la instauración de entornos de la naturaleza descrita podrían beneficiar los registros cívicos entre los alumnos de origen inmigrante.

El lograr influir sobre el Grupo de Pares que rodea a los adolescentes de origen inmigrante para que éstos mejoren su integración política puede ser realizado también en campos ajenos al de la política educativa. En tal sentido, las políticas públicas que tienen por objeto propiciar la integración de los inmigrantes son evidentemente un ámbito adecuado a tales efectos. Con acciones como las aquí sugeridas, se estaría respondiendo a la invitación cursada por el White Paper on Intercultural Dialogue elaborado por el Consejo de Europa (2008). Este texto invita al diseño creativo de mecanismos que favorezcan la integración de los extranjeros residentes en territorio europeo.

Cuando se actúa sobre el "Grupo de Pares" a través de la política educativa (o, para ser más precisos, mediante estrategias pedagógicas específicas) para estimular las competencias cívicas de individuos en situación de desventaja, se está trabajando sobre el "elenco estable de pares" que rodea permanentemente al alumnado. Por el contrario, cuando tal influencia es ejercida a través de otros resortes o políticas, es posible tanto el actuar estratégicamente sobre ese elenco permanente de pares como la búsqueda de la facilitación a los sujetos menos empoderados de la pertenencia a espacios en los que podrán interactuar con un "nuevo elenco de pares".

La puesta en marcha de sistemas de "social mentoring" sobre colectivos de los que interese la promoción de su protagonismo político es un ejemplo de actuación sobre el "elenco estable de pares" de los adolescentes ${ }^{284}$. Para ello, en el marco de partenariados entre actores públicos, privados y del tercer sector, se puede invitar a los miembros de "bandas" o "grupos de amigos" de adolescentes con limitados niveles de competencias cívicas a participar en proyectos sociales bajo la tutoría de trabajadores

\footnotetext{
${ }^{284}$ Una definición interesante de "social mentoring" es la provista por el Social Mentoring Research Group de la Universidad de Brighton (2007, p. 4): "(social mentoring) seeks to bring about a change in social status, from social exclusion to inclusion in mainstream society".
} 
sociales especializados en educación cívica. El objetivo de estos proyectos, a partir de alternar entre actividades formativas y lúdico-recreativas, es empoderar políticamente a su público beneficiario. La coordinación general de estas iniciativas, por la necesidad de cercanía con el grupo receptor, debería encontrarse en manos de autoridades o funcionarios locales 285 .

La creación ad hoc de espacios compartidos entre sujetos estratégicamente seleccionados y poseedores de diferentes niveles en sus competencias cívicas es un ejemplo de actuación sobre el "nuevo grupo de pares". Clubes de recreación o deportivos, centros vecinales, comandos escolares (o distritos escolares) y consejos asesores de políticas sobre juventud conformados por jóvenes de diferente extracción social y económica pueden erigirse en instancias que potencien la integración política de aquéllos que parten en situación de desventaja cívica ${ }^{286}$.

Mientras que la actuación sobre el Grupo de Pares desde la política educativa deja escasos márgenes para su rechazo por parte de los adolescentes y sus familias, la actuación sobre el Grupo de Pares en otros espacios de políticas públicas requiere del diseño (y posterior publicidad) de incentivos apropiados para asegurar su interés. Los mismos pueden ser de naturaleza diversa: económicos (retribución monetaria), recreativos (posibilidad de participación en conciertos, juegos deportivos, etc.) o estrictamente cívicos (acceso a información valiosa de cara a una mejor interacción con la administración pública vernácula o a la adquisición de la nacionalidad o residencia permanente en la sociedad de acogida).

\subsection{4) ¿Exposición o transferencia? La evidencia empírica sobre las teorías de re- socialización política}

En la presente investigación, la teoría de la exposición de la resocialización política de los inmigrantes ha encontrado mayor evidencia empírica que su contraparte,

\footnotetext{
285 Programas exitosos de "social mentoring" con inmigrantes como beneficiarios son, entre otros, los paneuropeos "Nightingale mentoring" y TANDEM ("Mentoring and Vocational Assistance for Migrant Youth"), el austríaco "Mentoring für MigrantInnen" o el alemán "Mentoren für Migranten".

${ }^{286}$ La Comisión Europea, a través de su Education, Audiovisual and Culture Executive Agency, financia la implementación diferentes programas que favorecen la adquisición de distintos tipos de competencias (incluidas las cívicas) por parte de jóvenes en riesgo de exclusión. Estos programas son gestionados por instituciones públicas, privadas y pertenecientes al tercer sector de todos los países de la Unión Europea.
} 
la teoría de la transferibilidad. Prueba de ello es que, tanto en el Análisis de Correlación Canónica como en la Regresión Múltiple, las variables vinculadas a la sociedad de acogida (Cantidad de Años de Residencia, Escuela y Grupo de Pares) han presentado mayor respaldo que aquéllas relacionadas a la sociedad de origen (Status Socioeconómico y Padres). Esto no debe leerse en clave de que los adolescentes inmigrantes arriban a España, desde sus países, como analfabetos cívicos o políticos y todo su aprendizaje sobre la cuestión es realizado en destino. Contrariamente, debe entenderse como que, a la hora de intentarse explicar la relación de estos sujetos con el entramado político de la sociedad receptora, parecen importar más los factores de destino que los de oriundez 287 .

Estos hallazgos implican, como ya se ha anticipado, que la integración política de los adolescentes inmigrantes en la sociedad de destino depende en mayor medida de los puntos de contacto con el sistema político receptor y no de pautas aprehendidas (o heredadas) en la relación con el sistema político del que se procede. Lo descubierto conlleva lecturas interesantes. En primer lugar, refleja la existencia de cierta disposición positiva entre los miembros de este colectivo por relacionarse con la realidad política del país en el que sus familias se han establecido ${ }^{288}$. Como sugerían Jones-Correa y Leal (2001), la presencia de entornos cívicamente estimulantes/competentes beneficia, al aprovecharse de ese ímpetu cívico, la integración política de los adolescentes inmigrantes. En el caso concreto de esta investigación, se ha detectado que dos agentes de socialización propios de la sociedad de acogida (Escuela y Grupo de Pares) son los que promueven este tipo de integración entre los jóvenes extranjeros.

287 La mayor relevancia de la teoría de la exposición también se observa cuando se correlacionan individualmente cada competencia cívica con los indicadores de las dos hipótesis de resocialización política. En tal sentido, no se presentan correlaciones con significación estadística entre indicadores de la teoría de la transferencia (en este caso, las variables Padres y Status Socioeconómico) y cada una de las competencias cívicas. Por el contrario, los indicadores de la teoría de la exposición (Escuela, Grupo de Pares y Cantidad de Años de Residencia en la Sociedad de Acogida) correlacionan con significación estadística con (dependiendo del indicador) entre dos y cuatro de las competencias cívicas consideradas de manera separada. La escasa relevancia empírica de los indicadores de la teoría de la transferibilidad puede deberse, como se ha sugerido, al carácter cuantitativamente reducido de la muestra (que ha impedido la obtención de variabilidad en guarismos tales como los registrados bajo el paraguas de Status Socioeconómico).

${ }^{288}$ Gibson y Levine en su informe "The Civic Mission of Schools" (2003) dejaron constancia de la existencia de tales inquietudes "cívicamente demandantes" para el caso de los colectivos inmigrantes radicados en los Estados Unidos de América. 
En segundo lugar, este resultado debe ser especialmente considerado de cara al diseño estratégico de políticas públicas en la materia. Los Estados receptores de población inmigrante deben canalizar adecuadamente esta predisposición cívica positiva. A través de mecanismos diversos, se puede propiciar la activación de procesos de incorporación política de los newcomers. En otras palabras, las instituciones vernáculas cuentan con la posibilidad de establecer instancias en las que la población foránea esté "expuesta" a la realidad política local. Ello puede materializarse, por ejemplo, tanto en la organización de cursos de capacitación cívica regulares y obligatorios durante los primeros años de estadía de los inmigrantes hasta la puesta en marcha de campañas de publicidad con contenido cívico en diferentes medios de comunicación de circulación al interior de las comunidades de inmigrantes.

En tercer lugar, si la integración política viene dada fundamentalmente por factores vinculados a la sociedad de acogida, otras dimensiones de la integración de los inmigrantes podrían verse consecuente y virtuosamente también impulsadas. Una mayor integración política describe la existencia de lazos profundos y basados en la confianza entre la administración pública y los inmigrantes. Ello puede traducirse en la obtención, por parte de los forasteros, de información calificada que le proporcione a medio y largo plazo mejores registros de integración en la sociedad receptora en otros planos (como el educativo o el laboral). En otros términos, inmigrantes más competentes cívicamente saben leer con más rapidez y sentido de la oportunidad las ventajas que les proporciona el sistema político del país de destino.

En cuarto lugar, el que el paso del tiempo correlacione positivamente con mayores niveles de integración política de los inmigrantes en la sociedad de acogida es un dato alentador. Según esta asociación estadística, los descubiertos gaps cívicos entre extranjeros e inmigrantes tenderán a desaparecer conforme los primeros ganen años de asentamiento en el país receptor. Las diferencias actuales inter-colectivos no serían estáticas ni delatoras de una "divergente naturaleza cívica". Por el contrario, serían tan sólo efecto del carácter novedoso de la inmigración masiva como proceso social en territorio español. La ejecución, si fuese posible, de la misma investigación en un par de años, incluyendo los mismos sujetos incorporados en esta muestra, debería arrojar según lo dicho resultados descriptores de una menor brecha cívica entre autóctonos y foráneos. 
En quinto lugar, en próximos estudios a desarrollar sobre este tema, a efectos de generar nuevas variabilidades, habría que lograr un número lo suficientemente amplio de individuos al interior de diferentes colectivos o divisiones de la población inmigrante. White et al. (2008) marcan una línea en tal sentido en su estudio sobre extranjeros adultos $^{289}$. El actuar de esta manera posibilitaría delimitar con mayor precisión si la teoría de la exposición explica mejor las diferencias de integración política en todos los colectivos/divisiones inmigrantes o si existen pautas diferenciadas de resocialización entre grupos procedentes de entornos socio-culturales (sociedades occidentales versus sociedades no occidentales) o socio-económicos (sociedades desarrolladas versus sociedades en desarrollo) distintos.

Finalmente, otra variabilidad interesante que debería ser estratégicamente buscada en futuras investigaciones consiste en comparar las pautas de resocialización política entre cohortes generacionales. Ello requiere la redefinición de los indicadores utilizados para medir las diferentes teorías en la materia. La variable "Cantidad de Años de Residencia en la Sociedad de Acogida" engarza, al respecto, bastante bien tanto para adultos como para adolescentes ${ }^{290}$. En este campo, el desafío consistiría en el logro de la medición de los niveles de integración política de factores/actores que formen parte del entorno, en la sociedad de acogida, de los inmigrantes de edad adulta (como, por ejemplo, compañeros de trabajo). Esta tarea, más asequible en el caso de las muestras de los adolescentes, puede resultar desde el punto de vista metodológico más complicada en la generación de padres y/o tutores 291 .

\footnotetext{
289 Estos autores construyen su investigación a partir de la utilización de datos externos originados en diferentes oleadas de los Canadian Election Studies (CES). Su muestra está conformada por 2548 individuos. La amplitud de su muestra permitió hallar pautas diferenciadas entre inmigrantes procedentes de sociedades industrializadas y otros originarios en sociedades en vías de desarrollo.

${ }^{290}$ En ambas muestras de inmigrantes (adolescentes y padres y/o tutores) en la presente investigación, la correlación entre cantidad de años de residencia e integración política es positiva.

291 La medición de las competencias cívicas en los miembros que conforman el grupo de pares de los adolescentes no resulta compleja. Los mismos pueden ser fácilmente ubicados en el recinto escolar. Sin embargo, en el caso de los adultos, el mensurar estos mismos rasgos entre los pares puede implicar mayores esfuerzos en el proceso de recolección de datos. Si bien parte importante de los miembros de ese entorno se encuentran en los ámbitos laborales, los espacios en los que los adultos interactúan con "pares" exceden al estrictamente vinculado al trabajo. Iglesias, sindicatos, partidos políticos, centros vecinales pueden ser ejemplos de escenarios en los que adultos de origen inmigrante entablan relación con distintos grupos de pares.
} 


\section{CONCLUSIONES}

"A mí la política no me interesa, porque a los políticos tampoco les importa lo que la gente piense, no respetan la opinión del pueblo...la política no vale para nada".

Adolescente inmigrante encuestado para este trabajo

Este trabajo ha pretendido, modestamente, realizar aportes en el estudio sobre la integración política de los inmigrantes en España. A tales fines, se ha generado evidencia empírica sobre un colectivo que, siendo investigado por otras ciencias sociales, no ha recibido suficiente atención por parte de la Ciencia Política: la población adolescente extranjera. En tal sentido, esta tesis doctoral ha sido un primer paso para la generación, análisis y discusión de datos tanto sobre los niveles de integración política de inmigrantes (comparados con los nativos) en este tramo etario como acerca de los factores sociodemográficos y psicológicos y de los agentes de socialización que propician tales registros.

El objeto de estudio descrito fue abordado gracias a la cobertura teórica brindada por dos miradas diferenciadas, con fecundo diálogo con otras disciplinas, en el marco de la Ciencia Política. Por un lado, el recurrir a la literatura sobre socialización política, muy ligada a los años en los que esta ciencia adquiría su carácter de tal, contribuyó a enmarcar las distintas manifestaciones que puede adquirir la relación de los inmigrantes con el sistema político de la sociedad de acogida. En otras palabras, su uso hizo posible el reconocer los mecanismos concretos (transferibilidad o exposición) que asume la resocialización política de los adolescentes de origen inmigrante en España. Su utilización permitió también la incorporación estratégica en el relevamiento realizado de preguntas tendientes a identificar qué agentes y factores pueden encontrarse detrás de los niveles de integración política de los inmigrantes radicados en territorio hispano.

Por otro lado, el recurrir a la literatura sobre competencias cívicas aparejó dos claros beneficios. En primer lugar, permitió encontrar, en las diferentes competencias estudiadas, a claros indicadores de la integración política para el periodo etario correspondiente a la adolescencia. En segundo lugar, favoreció la inclusión en el proceso de recolección de datos de preguntas conducentes a generar información sobre 
específicos factores sociodemográficos y psicológicos que pueden influir decisivamente en los niveles de competencias cívicas detentados por los individuos.

El diseño metodológico escogido para el relevamiento de la población objeto de estudio ha contado con, al menos, dos claras ventajas. En primer lugar, el haber usado a las competencias cívicas como indicadores de la integración política ha facultado la medición tanto de actitudes políticas (conocimiento político o atención política) como de potenciales comportamientos políticos (participación política o tolerancia política). El uso de las competencias cívicas también ha favorecido la posesión de indicadores de integración política que remiten a distintos niveles de esfuerzo por parte del individuo y a distintos niveles de desafío a sus esquemas socio-culturales. La aplicación de esta estrategia ha permitido detectar en la muestra analizada que las brechas entre nativos e inmigrantes no presentan para todas las competencias el mismo tenor. Por el contrario, si se hubieran utilizado menos competencias como indicadores de la integración política la variabilidad existente en la realidad no hubiese sido correctamente diagnosticada.

La combinación entre haber procedido a la medición de distintas variables independientes y el haber realizado el análisis estadístico de manera secuencial en las tres muestras posibles (global, nativos e inmigrantes) conduce a la existencia de un segundo beneficio asociado al diseño metodológico seleccionado. Es el que radica en haber podido identificar patrones diferenciados de integración política (y de su generación) entre los dos colectivos sometidos a estudio.

Los patrones encontrados sobre integración política de los inmigrantes, en base a la literatura escogida como referencia y al diseño metodológico utilizado, reflejan divergencias entre los grupos. En primer lugar, se observa una mejor posición de los adolescentes nativos en comparación a sus pares foráneos en esta materia. Aunque no detenten los valores teóricos máximos, los autóctonos aventajan a los extranjeros en todas las competencias cívicas. Esta brecha disminuye, hasta perder significación estadística pero no relevancia desde el punto de vista sustantivo, en dos competencias. Ello se encuentra en consonancia con resultados previos (White et al. 2008; Morales y Giugni, 2011) en investigaciones sobre población adulta. Estas competencias (atención política y eficacia política) son las que, en principio, exigirían menor esfuerzo y tiempo de permanencia por parte de los individuos en la sociedad de acogida. Por el contrario, 
aquéllas en las que los locales superan con mayor margen a los no vernáculos (conocimiento político, participación política y tolerancia política) implicarían mayor esfuerzo y tiempo de residencia en la sociedad receptora.

Traducido este primer patrón, en clave de teorías de resocialización política de los inmigrantes en las sociedades de destino, la posesión de aquellas competencias cívicas en las que el gap es menor (dos sobre cinco) pareciera estar poco explicada por factores vinculados al espacio receptor. Sin embargo, la teoría de la exposición (variables vinculadas a la influencia de la sociedad de acogida) es la que explica la posesión del mayor número de competencias cívicas (tres sobre cinco), atributos en los que casualmente las diferencias entre ambos grupos son más acusadas. El escaso hallazgo de resultados que respalden la teoría de la transferibilidad (variables vinculadas a la influencia de la sociedad de procedencia) puede deberse a la creación de una muestra con fines de comprobación de hipótesis. Sólo mediante la conformación de una muestra con propósito generalizador (lo que implicará mayor variabilidad entre los datos) se confirmará o refutará la limitada relevancia de los factores referidos a la sociedad de origen.

Este primer patrón tiene una lectura adicional: aquélla que intenta valorar la existencia o no de escenarios de exclusión cívica. Si las diferencias detectadas en materia de integración política entre autóctonos e inmigrantes persistieran en el tiempo, no cabría duda de la presencia de un "panorama excluyente". Ello implica una indudable afectación a la fortaleza del régimen democrático porque un sector importante de la población se hallaría al margen (total o parcialmente) de las tareas de participar y controlar a las autoridades. Como vaticinaba Pateman (1980) en sus críticas a los estudios genésicos sobre cultura política, el mayor riesgo en este tipo de situaciones radica en que los "apartados" de los procesos de toma de decisiones políticas tienen nula o escasa influencia en los resultados de tales procesos.

Sin embargo, esta visión pesimista se compensa por la comentada presencia de las dos competencias cívicas en las que las divergencias son mínimas entre ambos colectivos. Las dos tradiciones teóricas sobre las que se ha construido este análisis contribuyen a una "reversión optimista" de la lectura de los datos. La literatura sobre competencias cívicas y actitudes políticas recuerda que existe evidencia empírica que sostiene que la posesión de atención política y eficacia política puede derivar en la, a su 
vez, incorporación ulterior de otros atributos de este tipo. La literatura sobre resocialización política, como se ha dicho antes, interpreta que la adquisición de ciertas competencias cívicas no requiere de un contacto prolongado con la sociedad de acogida, requisito si exigido para otras. Ambas, como es posible observar, sugieren que existe una especie de timing o ciclo cívico. Siguiendo ambos razonamientos, una paulatina e incremental equiparación de registros entre ambos colectivos sería perfectamente factible.

Un segundo patrón de hallazgos se relaciona con la configuración causal que provocaría mayor integración política entre los adolescentes inmigrantes. La misma estaría conformada por dos factores sociodemográficos (cantidad de años de residencia en la sociedad de acogida y nivel de religiosidad), las actitudes pro-sociales (factor psicológico) y la influencia de los agentes de socialización vinculados a la sociedad de acogida (escuela y grupo de pares). Este cuadro detectado de variables independientes estadísticamente relevantes otorga nuevamente fuerte evidencia empírica a los supuestos de la teoría de la exposición de la resocialización política. En otras palabras, a mayor influencia recibida del entorno de destino, mayor tendería a ser el incremento de las competencias cívicas detentadas por los extranjeros.

Este segundo patrón detectado se operativiza en dos lecturas complementarias. Por un lado, se encuentra lo vinculado al signo de la relación entre estas variables identificadas y la integración política de los adolescentes. Excepto el nivel de religiosidad, todos los factores señalados se relacionan de manera positiva con la variable dependiente. El perfil del joven de origen extranjero mejor integrado políticamente es el de empático, dispuesto a ayudar, poco religioso, con más tiempo de permanencia en España, alumno de institutos secundarios con itinerarios formativos concentrados en las Ciencias Sociales, que asiste a escuelas en las que se discute sobre temas políticos como estrategia pedagógica y que, a la vez, se encuentra rodeado de un grupo de pares cívicamente empoderado.

La influencia negativa ejercida por el nivel de religiosidad sobre la integración política resulta sorpresiva. El que los jóvenes inmigrantes con mayores prácticas religiosas presenten limitadas competencias cívicas remite a que, a diferencia de lo que acontece en los Estados Unidos donde las iglesias fungen como catalizador del protagonismo político de sus feligreses (Jones-Correa y Leal, 2001), los espacios 
cultuales propiciarían en España (al menos, en la franja etaria estudiada) cierto repliegue actitudinal y conductual de los individuos sobre su esfera privada. Los hallazgos de esta investigación en esta materia son también antagónicos a las relaciones positivas encontradas por Eggert y Giugni (2011) y Echazarra (2011) sobre población adulta en Europa.

Por otro lado, se encuentra la lectura relacionada a discutir cuáles de estas variables permite el diseño de planes concretos de acción para estimular externamente los niveles de integración política de los adolescentes inmigrantes en aquellos escenarios en los que hubiese brechas pronunciadas entre nativos y extranjeros. Entre los factores detectados, la capacidad que los mismos presentan de ser influidos es variopinta. La cantidad de años de residencia de los inmigrantes en la sociedad de acogida, como ya señalara Echazarra (2011) en su estudio sobre población inmigrante adulta en Europa, no es una variable que pueda ser exógenamente alterada.

El nivel de religiosidad de los individuos es, naturalmente, un registro sobre el que el margen de actuación externa es cercano a la imposibilidad (aparte de no deseable). Sin embargo, en aquellos escenarios en los que los miembros de los colectivos inmigrantes se encuentren en peligro grave de sufrir marginación política, podría pensarse en la puesta en marcha de programas de intervención que (contando con el concurso de instituciones y autoridades civiles, religiosas y educativas) incentiven el protagonismo político de los inmigrantes desde los espacios cultuales ${ }^{292}$. La asunción de conductas como la descrita intentaría asemejar, mediante la reversión del signo de la relación entre nivel de religiosidad e integración política, la realidad de las iglesias españolas a lo que acontece en escenarios anglosajones.

El nivel de las actitudes pro-sociales poseídas por las personas, los contenidos y métodos pedagógicos utilizados en los centros escolares a los que las mismas asisten y los rasgos cívicos predominantes en los grupos de pares que les circundan son los resortes sobre los que sería posible actuar estratégicamente con menos limitaciones según sugiere la evidencia empírica (Ryan, 2001; Rushton, 2004; McFarland y Thomas, 2006; Meier, 2006; Torney-Purta et al. 2007). Las herramientas que más nítidamente

\footnotetext{
${ }^{292}$ La experiencia norteamericana de las Communities Organised for Public Service (COPS) es un ejemplo concreto que responde a lo aquí sugerido. COPS es una coalición de actores e instituciones que tiene por objeto, entre otros, favorecer la conversión de los inmigrantes radicados en la ciudad de San Antonio en ciudadanos plenos de su comunidad.
} 
emergen a tales efectos son las vinculadas a las políticas y las prácticas educativas formales y no formales.

Los caminos a recorrer, en tal sentido, son múltiples ${ }^{293}$. Las actitudes pro-sociales pueden ser estimuladas a partir de la puesta en marcha de programas de aprendizajeservicio estratégicamente diseñados, implementados y evaluados. Los contenidos políticos concretos que deben ser trasmitidos a los adolescentes inmigrantes requieren de la construcción consensuada, entre docentes e investigadores, de vías de acción en la que se prevea la medición longitudinal/evolutiva de los niveles de integración política. Idéntica conducta debe adoptarse para reconocer las formas apropiadas que debe asumir la discusión (libre, dirigida por el docente, en el marco de simulaciones con formato parlamentario, en relación a temáticas extraídas de la actualidad, acerca de situaciones hipotéticas, mediante el planteo de dilemas éticos, etc.) sobre temas políticos en las escuelas para ejercer un real efecto sobre las competencias cívicas de los adolescentes. En tanto, la creación de un grupo de pares cívicamente estimulante puede tener lugar mediante la puesta en marcha de rutinas pedagógicas (trabajos grupales dirigidos, sistemas de apadrinamiento, etc.) en la que se asegure cierta interacción continua entre individuos políticamente competentes con otros menos dotados en esta esfera.

No sólo las políticas educativas pueden ser usadas como instrumento para incidir sobre las variables que provocan la posesión de competencias cívicas. Las políticas de gestión de la inmigración son indudablemente otro terreno fértil en aras de lo descrito. Los programas de "social mentoring" en los que los adolescentes inmigrantes interactúan con trabajadores sociales, nativos y foráneos, son un mecanismo que ha sido ejecutado exitosamente en países del entorno europeo. Estas iniciativas tienen por objeto dotar de herramientas que multipliquen y profundicen los vínculos entre las personas de origen extranjero y el sistema político de acogida. Otras acciones que pueden encararse en el campo de las políticas migratorias son la creación de clubes de recreación o deportivos, centros vecinales, comandos escolares y consejos asesores de políticas sobre juventud conformados por individuos de diferente extracción social-

\footnotetext{
293 El informe "The Civic Mission of Schools" coordinado por Gibson y Levine (2003) ofrece, en base a los aportes de decenas de los más reconocidos expertos en materia de educación para la ciudadanía, interesantes líneas de acción que pueden ser aplicadas al desafío planteado en estas líneas.
} 
económica y origen nacional. Estos espacios pueden erigirse en instancias que potencien la integración política de aquellos jóvenes que parten en situación de desventaja cívica.

Tres cuestiones merecen ser aclaradas sobre acciones como las planteadas en los párrafos precedentes. Es lo vinculado a la estimación de su efectividad, el espacio de concreción de las mismas y las potenciales fuentes para su financiamiento. El cálculo de los verdaderos niveles de "transformación cívica" de emprendimientos como los sugeridos sólo podrá tener lugar mediante la aplicación de técnicas de policy experimentation. La utilización de estas herramientas permite "probar" determinadas políticas y "mensurar" sus logros en distritos específicos (Berk, Boruch, Chambers, Rossi y Witte, 1985; Pierson, 1995; Berlin, 2007). El recurrir a estos instrumentos permite identificar qué acciones específicas son conducentes a la adquisición de qué competencias cívicas puntuales. Los ámbitos local y autonómico, por su proximidad a la realidad de los ciudadanos, son los propicios para el impulso de políticas como las descritas $^{294}$. Algunas de las líneas de trabajo sugeridas podrían ser inteligentemente articuladas con mecanismos ya establecidos como el reconocimiento del derecho al voto para individuos de origen extranjero (comunitario y no comunitario) en elecciones municipales ${ }^{295}$. En contextos de contracción económica, la disposición de fondos para iniciativas como las mencionadas es limitada. Sin embargo, la Unión Europea cuenta con líneas de financiación diversas e institucionalizadas para apoyar la implementación de actividades de este tipo tanto a nivel municipal como regional ${ }^{296}$.

A modo de recapitulación de este trabajo, es importante hacer mención breve y sistematizada de sus contribuciones, sus limitaciones y la agenda de investigación que

\footnotetext{
294 Las acciones enmarcadas dentro de la política educativa formal requieren del concurso de las autoridades autonómicas. Ello es debido a que, en este nivel político-institucional, se concentran tales competencias en el sistema político español. Actividades de educación no formal y aquellas iniciativas que puedan contextualizarse dentro de políticas de gestión de la integración de inmigrantes pueden desarrollarse tanto a nivel local como a nivel regional.

295 Los adolescentes inmigrantes, en el periodo previo a su primera votación formal a nivel local (al cumplir los 18 años de edad), podrían recibir por parte de funcionarios del Ayuntamiento en el que residan entrenamiento especializado para potenciar su interés en la participación en estos comicios.

${ }^{296}$ Como dadora de fondos para proyectos tendientes al empoderamiento cívico de los adolescentes en riesgo de exclusión, destaca especialmente la Education, Audiovisual and Culture Executive Agency. Otra agencia europea activa a los efectos comentados es el Directorate General for Employment, Social Affairs and Inclusion. Otra agencia europea de referencia en la materia es el Asylum, Migration and Integration Fund. Muchos de los proyectos avalados por estos organismos son gestionados en el marco de partenariados públicos-privados en los que las instituciones públicas, las empresas privadas y las organizaciones no gubernamentales aportan diagnósticos, instrumentos y criterios de evaluación complementarios.
} 
el mismo invita a abordar en el futuro cercano. Las contribuciones han tenido lugar, fundamentalmente, en tres planos: debate teórico, recolección y análisis de datos y potenciales insumos para el diseño de políticas públicas. Desde el punto de vista teórico, su mayor mérito radica en el haber estudiado la integración política de un colectivo inmigrante no explorado hasta el momento mediante los marcos proporcionados por dos tradiciones investigativas (socialización política y competencias cívicas) que, aunque pocas veces consideradas simultáneamente, son perfectamente complementarias. Ambas hacen uso inteligente de conceptos y formulaciones procedentes de otras ciencias sociales también enfocadas en el mismo objeto de estudio. En tal sentido, empresas de investigación como la expuesta en estas páginas fungen como correa de transmisión transdisciplinar.

Desde el punto de vista de la recolección de datos, una contribución sustantiva de esta investigación radica en que la obtención de información sobre el objeto de estudio se realizó no sólo mediante cuestionarios dirigidos a los adolescentes sino también a través de instrumentos distribuidos a padres y/o tutores y directivos de centros educativos. Ello permitió expandir cuantitativamente y calibrar cualitativamente la medición de los factores y agentes estudiados como probables promotores de los niveles de competencias cívicas. En tanto, considerando el análisis de datos, la aplicación de una estrategia multivariante dual (Análisis de Correlación Canónica y Regresión Múltiple) facilitó la detección de los mecanismos explicativos existentes ante un panorama metodológico como el escogido: múltiples variables independientes y múltiples variables dependientes que, en el caso de las últimas, son luego articuladas para la construcción de un índice-resumen.

Considerando la aplicabilidad de los conocimientos, esta investigación contribuye en la recomendación de acciones puntuales para favorecer la integración política de los adolescentes inmigrantes menos aventajados tanto en el ámbito de las políticas educativas como en el campo de las políticas de gestión de la inmigración. De esa manera, se intenta aportar propuestas concretas a la discusión promovida, a nivel europeo, a partir de los documentos Common Basic Principles on Integration y de la European Agenda for Integration 2011 y, a nivel español, desde el texto del Plan Estratégico de Ciudadanía e Integración 2011-2014. 
Este trabajo cuenta, como se mencionaba previamente, con limitaciones en tres áreas en concreto. En primer lugar, la visualización de pautas divergentes entre nativos e inmigrantes en materia de integración política, por haberse realizado la medición de los datos en un único momento en el tiempo, obliga (tal como se sugería con anterioridad) a su consideración con precaución. Si bien patrones similares también han sido registrados entre adultos en España (Echazarra, 2011, González Ferrer, 2011; Morales y San Martin, 2011), el poder afirmar sin margen a dudas la existencia de escenarios de exclusión política de inmigrantes en este país sólo sería posible en el caso de estudios longitudinales. Estas investigaciones, sobre las mismas personas ya encuestadas o sobre otros sujetos con características semejantes, deberían reportar resultados de la misma naturaleza. Conocidos los rasgos sincrónicos de este estudio, sus resultados deben ser considerados entonces como una "notificación pesimista corroborable".

En segundo lugar, existe una razón de peso que ha restringido la inclusión de preguntas en el cuestionario para los adolescentes sobre otras variables individuales que la literatura también explora como probables causantes de la integración política (sensación/experiencia de discriminación, posesión de la condición de irregularidad, posesión de la condición de refugiado/asilado, etc.) (Flanagan et al. 2009; Myrberg y Rogstad, 2011; Morales y Morariu, 2011). Este motivo está vinculado, precisamente, a la franja etaria a la que se dirigía el interrogatorio. Sus peculiares características obligan a, entre otras cuestiones, la evitación de redacción de cuestionarios largos, omisión de la realización de preguntas que puedan ser consideradas inapropiadas por el tenor del tema abordado y cuidado extremo de la claridad y precisión conceptual de los interrogantes finalmente incorporados.

En tercer lugar, al haber construido la muestra con el objetivo de prueba de hipótesis sustantivas y no de generalización de los resultados, resulta dificultoso extraer información sobre interesantes pautas de variabilidad existentes en la población. La más importante de todas es la que podría encubrirse tras los diferentes orígenes (nacionales, de procedencia socio-cultural o de background democrático-autoritario) de los inmigrantes. Otra variabilidad, también relevante y no cubierta en este estudio, es la que se escondería en una muestra en la que hubiese una mayor diversidad de orígenes socio-económicos en autóctonos y extranjeros. 
Finalmente, debe hacerse mención de la agenda pendiente que, sobre el estudio de la integración política de los adolescentes inmigrantes, podría abordar la Ciencia Política en los próximos años en el contexto español. Al igual que ha acontecido recientemente en el estudio de la población inmigrante en edad adulta, una línea de investigación a explorar es la centrada en la búsqueda y detección de relaciones entre pertenencia de los jóvenes a organizaciones o grupos y los niveles que los mismos exhiben de competencias cívicas. En relación a este vínculo resultaría interesante ahondar no sólo en la influencia ejercida por el tipo de asociación (religiosa, deportiva, étnica, económica, política, etc.) a la que los individuos se afilian sino también en la capacidad moldeadora de otros rasgos de estas agrupaciones (distribución del poder al interior: rasgos democráticos versus autoritarios; nivel de acción: local, regional, nacional o transnacional; composición demográfica, etc.).

Otra línea de investigación que podría desandarse en los siguientes años también seguiría la estela de lo acaecido en el estudio de los inmigrantes adultos. Es importante relevar la influencia que ejerce el sistema político receptor en la integración política de los adolescentes inmigrantes. Distintas variables pueden fungir como indicadores de la influencia del sistema político de acogida ${ }^{297}$. Los diferentes regímenes de ciudadanía imperantes o los diversos discursos políticos existentes sobre la migración pueden ser sindicados como factores a sondear. Más concretamente, las características de las políticas públicas en los ámbitos de la educación, la gestión de la inmigración o la sanidad pueden ser estudiadas a tales efectos. La presencia relativa de inmigrantes en cargos de representación política o la tasa de naturalización pueden ser también foco de atención como variables independientes. Todos estos abordajes pueden darse, privilegiando estrategias comparadas, según un criterio multinivel (local, autonómico o estatal).

Como es posible observar, en este terreno los desafíos teóricos y metodológicos son muchos y complejos. El avanzar sobre esta agenda pendiente permitirá delinear con mayor exactitud cuáles son los factores y condiciones detrás de la integración política de los adolescentes inmigrantes. Coadyuvará también en la identificación de la existencia (o no) de pautas de emergencia de nuevas subculturas políticas. En cualquier caso, el profundizar en estos estudios favorecerá conocer si, tal como se advertía en las

\footnotetext{
${ }^{297}$ Los indicadores estudiados en la dimensión “Participación Política” del Migrant Integration Policy Index elaborado por el Migration Policy Group pueden ser usados también para los efectos aquí reseñados.
} 
críticas a las investigaciones primigenias sobre cultura política, determinados colectivos sociales se encuentran potencialmente fuera de los resortes de toma de decisiones políticas y de control sobre las autoridades. La continuidad en el tiempo de este tipo de relevamientos es fundamental para proceder a la diagnosis de potenciales situaciones de infraciudadanía y marginación política. Escenarios de esta naturaleza implican una amenaza real a la vitalidad de la democracia y la Ciencia Política cuenta hoy con las herramientas para preverlos y sugerir los antídotos adecuados. 


\section{ANEXO I \\ Cuestionarios}

\section{Cuestionario para adolescentes escolarizados}

Nota: buenos días/buenas tardes. El Instituto de Estudio de Iberoamérica de la Universidad de Salamanca está llevando a cabo una investigación sobre las competencias cívicas de los jóvenes españoles. Los datos a recoger serán tratados confidencialmente. Su ayuda servirá para reconocer cuáles son los factores que influyen en los niveles de integración política de los adolescentes que asisten a la escuela secundaria española. Por favor, responda a las preguntas según las indicaciones ofrecidas.

- Número de encuesta: (a rellenar por los investigadores)

- Ciudad de residencia:

- Tipo de Bachillerato:

Ciencias y Tecnología (01) Humanidades y Ciencias Sociales (02)

Otro (¿Cuál?) (03)

- Edad:

- Género: Masculino Femenino

- Lugar de nacimiento (pueblo o ciudad y país):

- Nacionalidad del padre y nacionalidad de la madre (en ese orden):

- Lengua que se habla en el hogar:

- Cantidad de años que tú has residido en España:

- ¿Cuántas personas viven en tu vivienda?:

- ¿Quiénes viven en la vivienda en la que habitas?: 
- Formación académica de los padres y/o tutores (marcar la respuesta adecuada):

Padre:

$\begin{array}{ll}\text { Sin formación } & 1 \\ \text { Primaria incompleta } & 2 \\ \text { Primaria completa } & 3 \\ \text { Secundaria incompleta } & 4 \\ \text { Secundaria completa } & 5 \\ \text { Universitaria incompleta } & 6 \\ \text { Universitaria completa } & 7 \\ \text { Posgrado } & 8\end{array}$

\section{Madre:}

Sin formación

1

Primaria incompleta 2

Primaria completa 3

Secundaria incompleta 4

Secundaria completa 5

Universitaria incompleta 6

Universitaria completa 7

Posgrado 8

- Tu promedio académico es (marcar la respuesta adecuada):

$\begin{array}{llllllllll}1 & 2 & 3 & 4 & 5 & 6 & 7 & 8 & 9 & 10\end{array}$

- ¿Eres religioso? (marcar la respuesta adecuada):

Soy ateo y/o agnóstico 1

$>$ Creo en un ser superior pero no practico ninguna religión 2

> Sólo asisto al templo en oportunidad de la celebración de los Sacramentos y/o fiestas de mi religión 3

Asisto semanalmente a los oficios y/o celebraciones de mi religión 4

> Asisto semanalmente a los oficios y/o celebraciones de mi religión y soy un miembro activo en mi comunidad religiosa

$>$ Asisto semanalmente a los oficios, soy un miembro activo de mi comunidad religiosa y procuro que mi vida sea un ejemplo de coherencia entre lo que creo y lo que hago 
- “Con qué frecuencia ayudas a compañeros que necesitan tu apoyo en sus tareas?"

$>$ Nunca

$>$ Casi nunca

$>$ A veces

$>$ Casi siempre

$>$ Siempre 5

- ¿Con qué frecuencia ayudas a tus padres y/o tutores en la realización de las tareas del hogar?"

$>$ Nunca 1

$>$ Casi nunca 2

$>$ A veces 3

$>$ Casi siempre 4

$>$ Siempre 5

- "Me preocupa el bienestar de quienes me rodean"

$>$ Totalmente en desacuerdo 1

$>$ Parcialmente en desacuerdo 2

$>$ Me da lo mismo 3

$>$ Parcialmente de acuerdo 4

$>$ Totalmente de acuerdo 5

- "Los problemas de los otros provocan mi atención"

$>$ Totalmente en desacuerdo 1

$>$ Parcialmente en desacuerdo 2

$>$ Me da lo mismo 3

> Parcialmente de acuerdo 4

$>$ Totalmente de acuerdo 5

- ¿Cuán abierto crees que es el clima de clase en tu escuela (para discutir, opinar, disentir, Etc.)?

$>$ Muy cerrado 1

$>$ Cerrado

$>$ Regular 3

$>$ Abierto

$>$ Muy abierto 
- ¿Con qué frecuencia discutes en tus asignaturas sobre temas políticos?

$>$ Nunca 1

$>$ Casi nunca 2

$>$ A veces 3

$>$ Casi siempre 4

$>$ Siempre 5

- ¿Cuál es el nombre del Vicepresidente Económico?

- ¿En qué año retorna la democracia a España?

- Nombre a tres ministros nacionales de la legislatura 2004-2008

- ¿Quién es el Jefe del Estado en España?

- ¿Cuántos años duró el último gobierno del Partido Popular a nivel nacional?

- ¿Con qué frecuencia lees en periódicos noticias nacionales?

$>$ Nunca 1

$>$ Casi nunca 2

$>$ A veces 3

$>$ Casi siempre 4

$>$ Siempre 5

- ¿Con qué frecuencia ves en televisión o escuchas por radio noticias nacionales?

(33)

$>$ Nunca 1

$>$ Casi nunca 2

$>$ A veces 3

D Casi siempre 4

$>$ Siempre 5

- ¿Con qué frecuencia ves en televisión o escuchas por radio, con tus padres y/ o tutores, noticias nacionales?

$>$ Nunca

1

$>$ Casi nunca

2

$>$ A veces

3

$>$ Casi siempre

4

$>$ Siempre 5

- ¿Con qué frecuencia discutes sobre politica con tus padres?

$\begin{array}{ll}>\text { Nunca } & 1 \\ >\text { Casi nunca } & 2 \\ >\text { A veces } & 3 \\ >\text { Casi siempre } & 4 \\ >\text { Siempre } & 5\end{array}$


- ¿Escribirías una carta con tus demandas a una oficina de gobierno? SI

(36)

- ¿Expondrías en una reunión pública tu punto de vista sobre un problema social y / o comunitario? SI NO

- ¿Comprendes el mundo de la política? SI

$\mathrm{NO}$

- ¿Tu familia influye directa o indirectamente en las decisiones que toma el gobierno? SI NO

- ¿Aceptas la práctica del aborto? SI

$\mathrm{NO}$

- ¿Aceptas el matrimonio homosexual? SI

$\mathrm{NO}$

- ¿Estarías dispuesto a discutir y / o negociar con quien tenga ideas opuestas a las tuyas?

SI NO

- ¿Permitirías que en tu hogar haya revistas y libros en los que se reflejen ideas distintas a las tuyas? SI

$\mathrm{NO}$

\section{COMENTARIOS}




\section{Cuestionario para padres y/o tutores}

Nota: buenos días/buenas tardes. El Instituto de Estudio de Iberoamérica de la Universidad de Salamanca está llevando a cabo una investigación sobre las competencias civicas de los jóvenes españoles. Los datos a recoger serán tratados confidencialmente. Su ayuda servirá para reconocer cuáles son los factores que influyen en los niveles de integración politica de los adolescentes que asisten a la escuela secundaria española. Por favor, responda a las preguntas según las indicaciones ofrecidas.

- Número de encuesta: (a rellenar por los investigadores)

- Ciudad de residencia:

- Tipo de Bachillerato al que asiste su hijo:

Ciencias y Tecnología (01) Humanidades y Ciencias Sociales (02)

Otro (¿Cuál?) (03)

- Edad:

Madre (46-47) Padre

(48-49)

- Lugar de nacimiento (pueblo o ciudad y país) de padres y/o tutores:

Madre

Padre

- Cantidad de años residiendo en España:
Madre
(54-55)
Padre

$(56-57)$

- Formación académica de los padres (marcar la respuesta adecuada):

Padre:

Sin formación

Primaria incompleta

2

Primaria completa

Secundaria incompleta

4

Secundaria completa

5

Universitaria incompleta

Universitaria completa

Posgrado 
Madre:

Sin formación 1

Primaria incompleta 2

Primaria completa 3

Secundaria incompleta 4

Secundaria completa 5

Universitaria incompleta 6

Universitaria completa 7

Posgrado 8

- Ingreso familiar mensual aproximado:

$(60)$

$\begin{array}{ll}\text { Menos o igual a } 300 & 1 \\ \text { De } 301 \text { a } 600 & 2 \\ \text { De } 600 \text { a } 900 & 3 \\ \text { De } 901 \text { a } 1200 & 4 \\ \text { De } 1201 \text { a } 1800 & 5 \\ \text { De } 1801 \text { a } 2400 & 6 \\ \text { De } 2401 \text { a } 3000 & 7 \\ \text { De } 3001 \text { a } 4500 & 8 \\ \text { De } 4501 \text { a } 6000 & 9 \\ \text { Más de } 6000 & 10\end{array}$

- ¿Son propietarios de su vivienda?:

- ¿Cuántas personas viven en su vivienda?:

- ¿Quiénes viven en la vivienda en la que habita?:

- Ocupación:
Madre
(65) Padre

(66)

- Prácticas religiosas de padres y/o tutores:

Madre:

$>$ Soy ateo y/o agnóstico

1

$>$ Creo en un ser superior pero no practico ninguna religión

2

$>$ Sólo asisto al templo en oportunidad de la celebración de los Sacramentos y/o fiestas de mi religión

$>$ Asisto semanalmente a los oficios y/o celebraciones de mi religión 3

$>$ Asisto semanalmente a los oficios y/o celebraciones de mi religión y soy un miembro activo en mi comunidad religiosa

4

$>$ Asisto semanalmente a los oficios, soy un miembro activo de mi comunidad religiosa y procuro que mi vida sea un ejemplo de coherencia entre lo que creo y lo que hago

5 
$>$ Soy ateo y/o agnóstico 1

$>$ Creo en un ser superior pero no practico ninguna religión

$>$ Sólo asisto al templo en oportunidad de la celebración de los Sacramentos y/o fiestas de mi religión

$>$ Asisto semanalmente a los oficios y/o celebraciones de mi religión 3

$>$ Asisto semanalmente a los oficios y/o celebraciones de mi religión y soy un miembro activo en mi comunidad religiosa

> Asisto semanalmente a los oficios, soy un miembro activo de mi comunidad religiosa y procuro que mi vida sea un ejemplo de coherencia entre lo que creo y lo que hago

- ¿Cuál es el nombre del Ministro del Interior?

- ¿Cuál es la capital política de Cataluña/Catalunya?

- Nombre dos partidos políticos españoles identificados con la derecha

- ¿Cuál fue el tercer partido más votado a nivel nacional en las elecciones generales de marzo de 2008 ?

¿Quién es el actual presidente del Congreso de los Diputados?

- ¿Con qué frecuencia lee en periódicos noticias nacionales?

$>$ Nunca

$>$ Casi nunca

1

A veces

2

Casi siempre

$>$ Siempre

4

5

- ¿Con qué frecuencia ve en televisión o escuch a por radio noticias nacionales?

$>$ Nunca

1

$>$ Casi nunca

2

$>$ A veces

$>$ Casi siempre

4

$>$ Siempre 5

- ¿Con qué frecuencia ve en televisión o escucha por radio, con sus hijos, noticias nacionales?

$>$ Nunca

$>$ Casi nunca

2

$>$ A veces

$>$ Casi siempre

4

$>$ Siempre 
- ¿Con qué frecuencia discute sobre politica con sus hijos?

$>$ Nunca

$>$ Casi nunca

$>$ A veces

$>$ Casi siempre

$>$ Siempre

- ¿Usted escribiría una carta con sus demandas a una oficina de gobierno?

SI NO

- ¿Expondría en una reunión pública su punto de vista sobre un problema social y/ o comunitario?

SI $\mathrm{NO}$

- ¿Usted comprende el mundo de la política? SI

- ¿Su familia influye directa o indirectamente en las decisiones que toma el gobierno? SI NO

- ¿Usted acepta la práctica del aborto? SI

$\mathrm{NO}$

- ¿Usted acepta el matrimonio homosexual? SI

$\mathrm{NO}$

- ¿Estarías dispuesto a discutir y / o negociar con quien tenga ideas opuestas a las tuyas?

SI $\quad \mathrm{NO}$

- ¿Permitirías que en tu hogar haya revistas y libros en los que se reflejen ideas distintas a las tuyas?

SI

$\mathrm{NO}$

\section{COMENTARIOS}




\section{Cuestionario para directivos de centros escolares}

Nota: buenos dias/buenas tardes. El Instituto de Estudio de Iberoamérica de la Universidad de Salamanca está llevando a cabo una investigación sobre las competencias cívicas de los jóvenes españoles. Los datos a recoger serán tratados confidencialmente. Su ayuda servirá para reconocer cuáles son los factores que influyen en los niveles de integración política de los adolescentes que asisten a la escuela secundaria española. Por favor, responda a las preguntas según las indicaciones ofrecidas.

Número de encuesta: (a rellenar por los investigadores)

Ciudad en la que se encuentra el establecimiento educativo:

- Tipo de Bachillerato en el que trabaja:

Ciencias y Tecnología $01 \quad$ Humanidades y Ciencias Sociales 02

Otro (¿Cuál?) 03

- ¿Con qué frecuencia los docentes a cargo de asignaturas vinculadas a la formación cívica (ética, historia, filosofía, ciencias sociales) bacen uso de recursos interactivos (role play, tecnología aplicada a la educación, Etc.)?

$\begin{array}{ll}>\text { Nunca } & 1 \\ >\text { Casi nunca } & 2 \\ >\text { A veces } & 3 \\ >\text { Casi siempre } & 4 \\ >\text { Siempre } & 5\end{array}$

- ¿Con qué frecuencia los docentes a cargo de asignaturas vinculadas a la formación cívica (ética, historia, filosofía, ciencias sociales) hacen uso de materiales oficiales en la planificación de sus clases?

$>$ Nunca

1

$>$ Casi nunca 2

$>$ A veces 3

$>$ Casi siempre

4

$>$ Siempre

- ¿Cuál es el porcentaje de alumnado de origen inmigrante en su centro educativo?: $(90-91)$

\section{COMENTARIOS}




\section{ANEXO II \\ Listado definitivo de Institutos de Educación Secundaria en los que se recogió la muestra298}

\section{Valencia:}

- José Ballester Gonzalvo

- San Vicente Ferrer

Sevilla:

- Instituto Macarena

- Instituto Azahar

- Miguel de Cervantes

Málaga:

- Instituto Huelin

- Miraflores de los Ángeles

Barcelona:

- Joan Coromines

- Pau de Claris

Madrid:

- Moratalaz

- Luis Buñuel

Salamanca:

- Francisco Salinas

Burgos:

- Enrique Florez

${ }^{298}$ La ciudad de Ávila fue visitada pero no fueron recibidos los cuestionarios allí suministrados. 
- Diego de Siloé

Zamora:

- Alfonso IX

Segovia:

- La Albuera

Valladolid:

- Centro Vega del Prado

- Santa Teresa de Jesús 


\section{ANEXO III \\ Análisis Estadístico Complementario}

\section{Cuadro 4.1}

Niveles de significación estadística

de las Correlaciones de Pearson

entre las competencias cívicas y las dimensiones de la variable Status

Socioeconómico

\begin{tabular}{ccccccc}
\hline $\begin{array}{c}\text { Competencia } \\
\text { s Cívicas }\end{array}$ & Colectivo & $\begin{array}{c}\text { Formación } \\
\text { Académica } \\
\text { Padre }\end{array}$ & $\begin{array}{c}\text { Formación } \\
\text { Académica } \\
\text { Madre }\end{array}$ & $\begin{array}{c}\text { Ocupación } \\
\text { Padre }\end{array}$ & $\begin{array}{c}\text { Ocupación } \\
\text { Madre }\end{array}$ & $\begin{array}{c}\text { Ingreso } \\
\text { Familiar } \\
\text { Mensual }\end{array}$ \\
\hline Conocimiento & Nativo & .297 & .002 & .084 & .242 & .048 \\
Político & Inmigrante & .861 & .229 & .236 & .316 & .175 \\
Atención & Nativo & .084 & .055 & .131 & .063 & .045 \\
Política & Inmigrante & .938 & .685 & .189 & .595 & .794 \\
Participación & Nativo & .307 & .232 & .719 & .214 & .088 \\
Política & Inmigrante & .588 & .707 & .447 & .391 & .505 \\
Eficacia & Nativo & .052 & .114 & .497 & .000 & .016 \\
Política & Inmigrante & .275 & .055 & .957 & .967 & .138 \\
Tolerancia & Nativo & .412 & .133 & .925 & .908 & .958 \\
Política & Inmigrante & .235 & .100 & .305 & .783 & .504 \\
\hline
\end{tabular}

\section{Cuadro 4.2}

Medias, por tipo de itinerario formativo, de los adolescentes inmigrantes en cada competencia cívica

\begin{tabular}{|c|c|c|}
\hline $\begin{array}{l}\text { Competencias } \\
\text { Cívicas }\end{array}$ & $\begin{array}{c}\text { Tipo de } \\
\text { Itinerario } \\
\text { Formativo }\end{array}$ & Medias \\
\hline Conocimiento & $\begin{array}{l}\text { Ciencias } \\
\text { Sociales }\end{array}$ & .7615 \\
\hline Político & Otros & .5901 \\
\hline Atención & $\begin{array}{l}\text { Ciencias } \\
\text { Sociales }\end{array}$ & 1.97 \\
\hline Política & Otros & 1.69 \\
\hline Participación & $\begin{array}{l}\text { Ciencias } \\
\text { Sociales }\end{array}$ & 1.85 \\
\hline Política & Otros & 1.29 \\
\hline Eficacia & $\begin{array}{l}\text { Ciencias } \\
\text { Sociales }\end{array}$ & 1.15 \\
\hline Política & Otros & .92 \\
\hline Tolerancia & $\begin{array}{l}\text { Ciencias } \\
\text { Sociales }\end{array}$ & 2.07 \\
\hline Política & Otros & 2.05 \\
\hline
\end{tabular}




\section{Cuadro 4.3}

Niveles de significación estadística

de las Correlaciones de Pearson y Comparaciones de Medias.

Relación entre competencias cívicas y dimensiones de la variable "Escuela" para el colectivo inmigrante

\begin{tabular}{ccccc}
\hline $\begin{array}{c}\text { Competencias } \\
\text { Cívicas }\end{array}$ & $\begin{array}{c}\text { Itinerarios } \\
\text { Formativos }^{\mathbf{a}}\end{array}$ & $\begin{array}{c}\text { Discusión } \\
\text { sobre } \\
\text { política } \\
\text { en clase }^{\mathbf{b}}\end{array}$ & $\begin{array}{c}\text { Porcentaje } \\
\text { de } \\
\text { alumnado } \\
\text { inmigrante }^{\mathbf{b}}\end{array}$ & $\begin{array}{c}\text { Uso de } \\
\text { innovaciones } \\
\text { pedagógicas }^{\mathbf{b}}\end{array}$ \\
\hline $\begin{array}{c}\text { Conocimiento } \\
\text { Político }\end{array}$ & .280 & .113 & .621 & .152 \\
$\begin{array}{c}\text { Atención } \\
\text { Política }\end{array}$ & .012 & .000 & .075 & .269 \\
$\begin{array}{c}\text { Participación } \\
\text { Política }\end{array}$ & .037 & .000 & .280 & .312 \\
$\begin{array}{c}\text { Eficacia } \\
\text { Política }\end{array}$ & .335 & .001 & .217 & .069 \\
$\begin{array}{c}\text { Tolerancia } \\
\text { Política }\end{array}$ & .723 & .642 & .829 & .603 \\
\hline
\end{tabular}

a) Se aplicó la prueba $U$ de Mann-Whitney para muestras no paramétricas b) Se aplicaron Correlaciones de Pearson Fuente: Elaboración propia.

\section{Cuadro 4.4}

Niveles de significación estadística de las Correlaciones de Pearson

entre integración política y las dimensiones de la variable Status Socioeconómico

\begin{tabular}{cccccc}
\hline Colectivo & $\begin{array}{c}\text { Formación } \\
\text { Académica } \\
\text { Padre }\end{array}$ & $\begin{array}{c}\text { Formación } \\
\text { Académica } \\
\text { Madre }\end{array}$ & $\begin{array}{c}\text { Ocupación } \\
\text { Padre }\end{array}$ & $\begin{array}{c}\text { Ocupación } \\
\text { Madre }\end{array}$ & $\begin{array}{c}\text { Ingreso } \\
\text { Familiar } \\
\text { Mensual }\end{array}$ \\
\hline Nativo & .078 & .002 & .172 & .005 & .002 \\
Inmigrante & .250 & .139 & .389 & .928 & .539 \\
\hline
\end{tabular}




\section{Cuadro 4.5}

Medias de integración política, por tipo de itinerario formativo, de los adolescentes inmigrantes

\begin{tabular}{cc}
\hline $\begin{array}{c}\text { Tipo de } \\
\text { Itinerario } \\
\text { Formativo }\end{array}$ & Medias \\
\hline $\begin{array}{c}\text { Ciencias } \\
\text { Sociales } \\
\text { Otros }\end{array}$ & 7.80 \\
\hline
\end{tabular}

Fuente: Elaboración propia.

\section{Cuadro 4.6}

Niveles de significación estadística

de las Correlaciones de Pearson y Comparaciones de Medias.

Relación entre integración política y dimensiones de la variable "Escuela"

para el colectivo inmigrante

\begin{tabular}{cccc}
\hline $\begin{array}{c}\text { Itinerarios } \\
\text { Formativos }^{\mathbf{a}}\end{array}$ & $\begin{array}{c}\text { Discusión } \\
\text { sobre } \\
\text { política } \\
\text { en clase }^{\mathbf{b}}\end{array}$ & $\begin{array}{c}\text { Porcentaje } \\
\text { de } \\
\text { alumnado } \\
\text { inmigrante }^{\mathbf{b}}\end{array}$ & $\begin{array}{c}\text { Uso de } \\
\text { innovaciones } \\
\text { pedagógicas }^{\mathbf{b}}\end{array}$ \\
\hline .028 & .000 & .922 & .085 \\
\hline
\end{tabular}

a) Se aplicó la prueba $U$ de Mann-Whitney para muestras no paramétricas b) Se aplicaron Correlaciones de Pearson Fuente: Elaboración propia. 


\section{ANEXO IV \\ Visualización de Datos - Análisis Descriptivo}

Gráfico 3.1

Diagrama de caja de conocimiento político según colectivo (nacional e inmigrante)

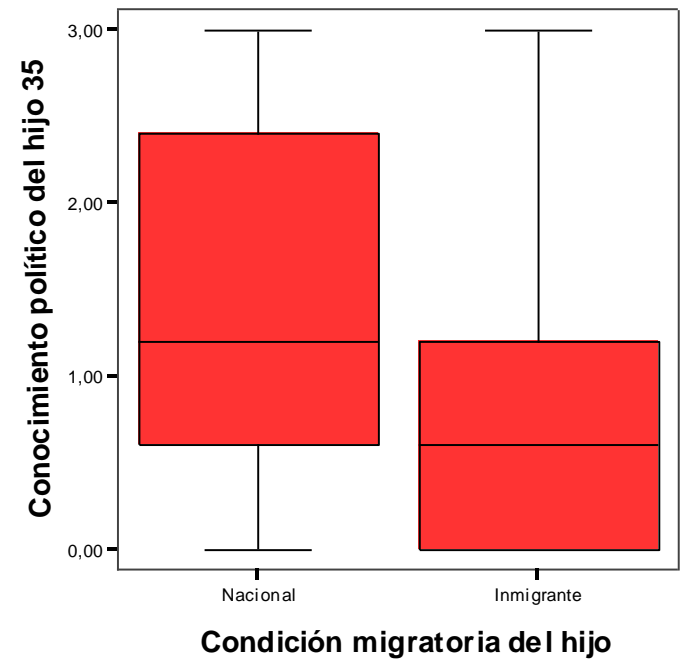

Fuente: Elaboración propia.

\section{Gráfico 3.2}

Diagrama de caja de atención política según colectivo (nacional e inmigrante)

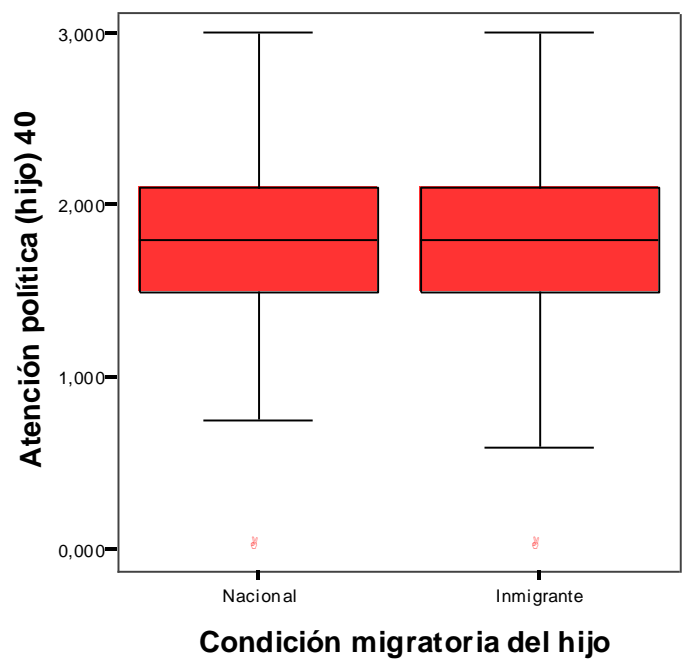

Fuente: Elaboración propia. 


\section{Gráfico 3.3}

Diagrama de caja de participación política según colectivo (nacional e inmigrante)

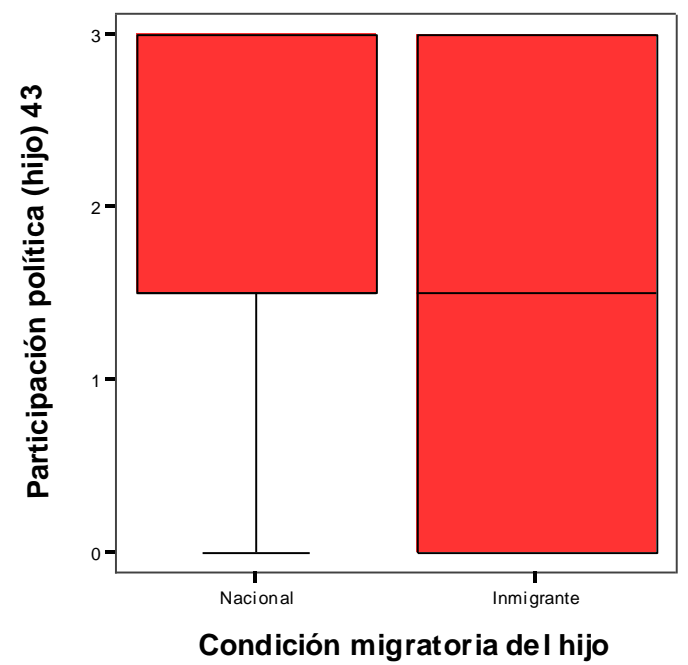

Fuente: Elaboración propia.

\section{Gráfico 3.4}

Diagrama de caja de eficacia política según colectivo (nacional e inmigrante)

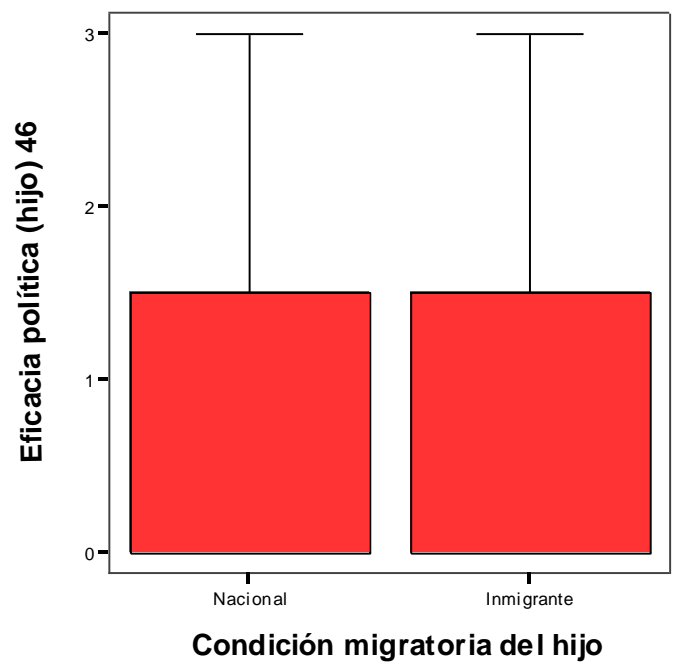

Fuente: Elaboración propia. 


\section{Gráfico 3.5}

Diagrama de caja de tolerancia política según colectivo (nacional e inmigrante)

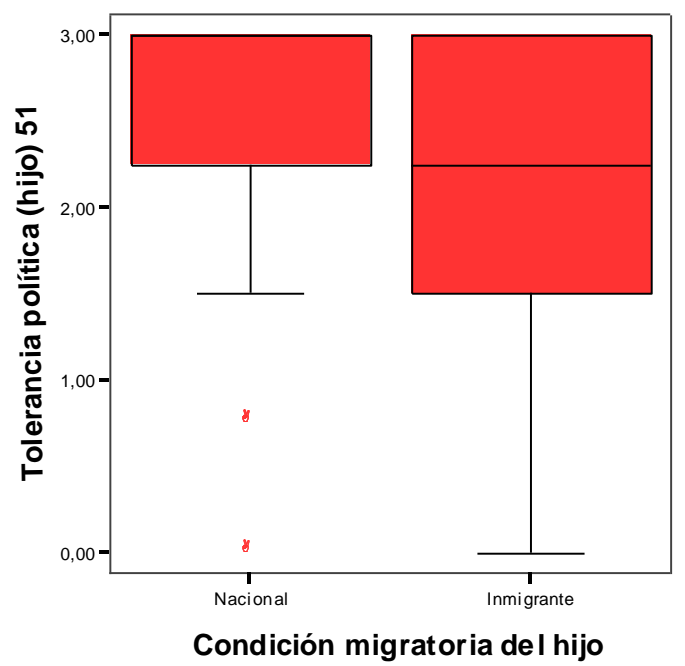

Fuente: Elaboración propia.

\section{Gráfico 3.6}

Diagrama de caja de integración política para la muestra global

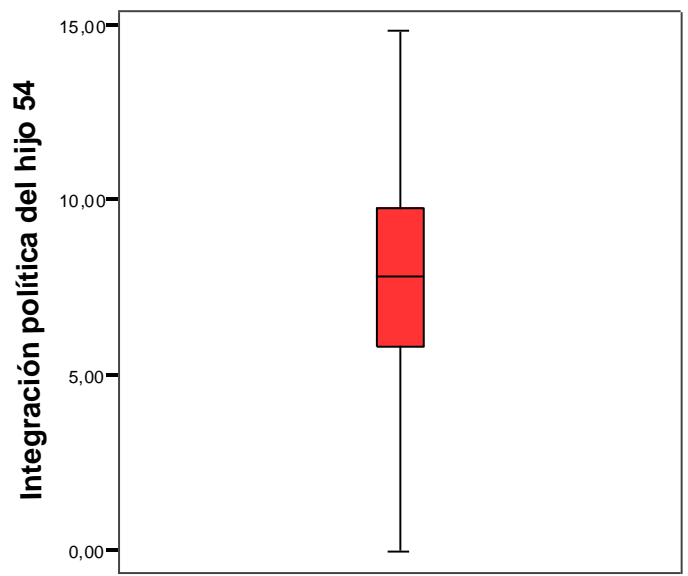

Fuente: Elaboración propia. 


\section{Gráfico 3.7}

Diagrama de caja de integración política según colectivo (nacional e inmigrante)

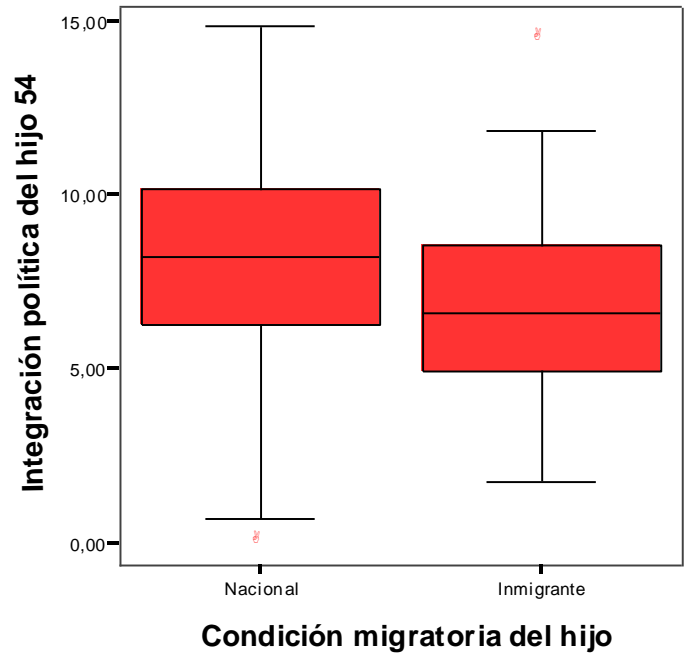

Fuente: Elaboración propia. 


\section{BIBLIOGRAFÍA}

Abramson, P. R. (1977). The Political Socialization of Black Americans: A Critical Evaluation of Research on Efficacy and Trust. Nueva York: Free Press.

Abramson, P. R. y Aldrich, J. H. (1982). The decline of electoral participation in America. The American Political Science Review, 76(3), 502-521.

Acock, A. C. (2005). Working with missing values. Journal of Marriage and Family, 67(4), 1012-1028.

Adamson, F. B. (2006). Crossing borders: international migration and national security. International Security, 31(1), 165-199.

Agrela, B. (2002). La política de inmigración en España: reflexiones sobre la emergencia del discurso de la diferencia cultural. Migraciones internacionales, 1(2).

Alba, R. y Nee, V. (2003). Remaking the American mainstream. Assimilation and Contemporary Immigration. Cambridge, MA: Harvard University Press.

Alcántara, M. (2008). Luces y sombras de la calidad de la democracia en América Latina. Revista de Derecho Electoral (6), 1-15.

Alcántara, M. y García Díez, F. (2009). De la reforma política en nuevas democracias: aspectos sistémicos e institucionales y calidad de la democracia (Documento de Trabajo No 8). Madrid: CEU Ediciones.

Alegre, M. A. y Subirats, J. (Eds.). (2007). Educación e inmigración: nuevos retos para España en una perspectiva comparada. Madrid: Centro de Investigaciones Sociológicas.

Alexander, C. (2002). The phenomenon of life. Berkeley: The Center of Environmental Structure.

Almond, G. A. y Verba, S. (1963). The Civic Culture. Nueva York: Sage Publications.

Almond, G. A. y Verba, S. (1980). The Civic Culture Revisited. Londres: Little, Brown Book Group.

Altman, D. y Pérez-Liñán, A. (2002). Assessing the Quality of Democracy: Freedom, Competitiveness and Participation in Eighteen Latin American Countries. Democratization, 9(2), 85-100.

Álvarez-Miranda, B. (2012). Confianza generalizada e inmigración: evidencia cualitativa del caso español. Revista Española de Sociología (RES) (17), 119-131.

Amadeo, J., Torney-Purta, J., Lehmann, R. Husfeldt, V. y Nikolova, R. (2002). Civic Knowledge and Engagement. An IEA Study of Upper Secondary Students in Sixteen Countries. Amsterdam: IEA. 
Ancin, D. (2004). El asociacionismo de los inmigrantes marroquíes y senegaleses en la ciudad de Granada. En Pascual, A. (Ed.). (2004). IV Congreso sobre la inmigración en España: Ciudadanía y Participación (pp. 14-41). Girona: Ediciones Universidad de Girona.

Anderson, M. R. (2010). Community Psychology, Political Efficacy, and Trust. Political Psychology, 31(1), 59-84.

Andolina, M. W., Jenkins, K., Zukin, C. y Keeter, S. (2003). Habits from Home, Lessons from School: Influences on Youth Civic Engagement. Political Science and Politics, 36(2), 275-280.

Anduiza, E. y San Martín, J. (2011). Political efficacy and confidence among migrants. En Morales, L. y Giugni, M. G. (Eds.). (2011). Social Capital, Political Participation and Migration in Europe: Making Multicultural Democracy Work? (pp. 198-218). Basingstoke: Palgrave.

Aparicio, R. (2011). Participación ciudadana y asociaciones de inmigrantes. Oñati SocioLegal Series, 1(3).

Aparicio, R. y Tornos, A. (2002). El Estado de bienestar y la inmigración en España. Madrid: IMSERSO (OPI).

Arango, J. (2005a). Dificultades y dilemas de la política de inmigración. Arbor, 181(713), $17-25$.

Arango, J. (2005b). La inmigración en España: demografía, sociología y economía. En Del Águila, R. (Ed.). (2005). Inmigración: un desafío para España (pp. 247-273). Madrid: Editorial Pablo Iglesias.

Arthur, J., Davies, I. y Hahn, C. (Eds.) (2008). SAGE Handbook of Education for Citizenship and Democracy. Londres: Sage.

Arzheimer, K. y Carter, E. (2006). Political Opportunity Structures and Right-Wing Extremist Party Success. European Journal of Political Research, 45(3), 419-443.

Atkin, C. K. y Gantz, W. (1978). Television News and Political Socialization. Public Opinion Quarterly, 42(2), 183-194.

Ayers, J. W. (2007). Changing Sides: $9 / 11$ and the American Muslim Voter. Review of Religious Research, 49(2), 187-198.

Ayuso, A. y Pinyol, G. (2010). Inmigración latinoamericana en España: el estado de la investigación. Barcelona: Fundación CIDOB.

Bahry, D., Boaz, C. y Gordon, S. B. (1997). Tolerance, Transition, and Support for Civil Liberties in Russia. Comparative Political Studies, 30(4), 484-510.

Banaji, S. (2008). The trouble with civic: a snapshot of young people's civic and political engagements in twenty-first-century democracies. Journal of Youth Studies, 11(5), 543560 . 
Bandura, A. (Ed.). (1995). Self-Efficacy in Changing Societies. Cambridge: Cambridge University Press.

Barber, B. R. (1984). Strong Democracy. Berkeley: University of California Press.

Barber, B. R. (2003). Strong Democracy: Participatory Politics for a New Age. Berkeley: University of California Press.

Barber, B. R. y Battistoni, R. (1993). A season of service: Introducing service learning into the liberal arts curriculum. PS: Political Science \& Politics, 26(2), 235-240.

Barber, C., Fennelly, K. y Torney-Purta, J. (2013). Nationalism and Support for Immigrants' Rights Among Adolescents in 25 Countries. Applied Developmental Science, 17(2), 60-75.

Barreda, M. (2011). La calidad de la democracia: Un análisis comparado de América Latina. Política y Gobierno, 18(2), 265-295.

Barreto, M. A. y Muñoz, J. A. (2003). Reexamining the "politics of in-between": Political participation among Mexican immigrants in the United States. Hispanic Journal of Behavioral Sciences, 25(4), 427-447.

Basabe, N., Zlobina, A. y Páez, D. (2004). Integración socio-cultural y adaptación psicológica de los inmigrantes extranjeros en el País Vasco. Informe no 15 de la Colección Cuadernos Sociológicos Vascos. Vitoria: Gobierno Vasco.

Bauböck, R., Heller, A. y Zolberg, A.R. (Eds.). (1998). The challenge of diversity: Integration and pluralism in societies of immigration. Aldershot: Avebury.

Beck, P. A. y Jennings, M. K. (1991). Family traditions, political periods, and the development of partisan orientations. The Journal of Politics, 53(3), 742-763.

Becker, R., Amundson, N., Anderson, D., Wenzel, K., Yakubova, M., Sajaia, N. y Frannea, R. (2009). Political Participation, Efficacy and the 2008 Minnesota Presidential Caucuses. Qualitative Research Reports in Communication, 10(1), 38-45.

Beiser, M., Barwick, C., Berry, J. W., da Costa, G., Fantino, A., Ganesan, S.,...y Vela, E. (1988). After the Door has been Opened. Mental Health Issues Affecting Immigrants and Refugees in Canada. Report of the Canadian Task Force on Mental Health Issues Affecting Immigrants and Refugees. Ottawa: Minister of Supply and Services y Health and Welfare Canada.

Bengtsson, B. (2010). Political Opportunity Structure and Ethnic Organization: How Political, What Opportunities, Which Structures? En Bengtsson, B., Strömblad, P. y Bay, A. (Eds.). Diversity, Inclusion and Citizenship in Scandinavia (pp. 241-268). Newcastle: Cambridge Scholars.

Bennett, S. E. (1995). Comparing Americans' political information in 1988 and 1992. The Journal of Politics, 57(2), 521-532. 
Bennett, S. E. y Bennett, L. L. (1993). Out of sight, out of mind: Americans' knowledge of party control of the House of Representatives, 1960-1984. Political Research Quarterly, 46(1), 67-80.

Bennett, W. L. (Ed.) (2008). Civic life online: Learning how digital media can engage youth. Cambridge, MA: MIT Press.

Berelson, B. R., Lazarsfeld, P. y McPhee, W. N. (1954). Voting: A study of opinion formation in a presidential campaign. Chicago: University of Chicago Press.

Berger, M., Galonska, C. y Koopmans, R. (2004). Political integration by a detour? Ethnic communities and social capital of migrants in Berlin. Journal of Ethnic and Migration Studies, 30(3), 491-507.

Berk, R. A., Boruch, R. F., Chambers, D. L., Rossi, P. H. y Witte, A. D. (1985). Social Policy Experimentation: A Position Paper. Evaluation Review, 9(4), 387-429.

Berlin, G. (2007). Experimentation and Social Welfare Policy Making in the United States. Nueva York: MDRC.

Bermúdez, A. (2011). La integración política de los migrantes latinoamericanos en Andalucía, Madrid y Cataluña. En García, F. J. y Kressova, N. (Eds.). (2011). Actas del I Congreso Internacional sobre Migraciones en Andalucía (pp. 1149-1158). Granada: Universidad de Granada e Instituto de Migraciones.

Berry, J. W. (1997). Immigration, acculturation, and adaptation. Applied psychology, 46(1), 5-34.

Berry, J. W. y Kalin, R. (1995). Multicultural and ethnic attitudes in Canada: An overview of the 1991 National Survey. Canadian Journal of Behavioural Science, 27(3), 301-320.

Bevelander, P. y Pendakur, R. (2009). Social capital and voting participation of immigrants and minorities in Canada. Ethnic and Racial Studies, 32(8), 1406-1430.

Bevelander, P. y Spång, M. (2014). From Aliens to Citizens: The Political Incorporation of Immigrants. IZA Discussion Paper No. 7920. Bonn: Institute for the Study of Labor.

Biderbost, P. (2007a). El voto ciudadano en tiempos de ajuste estructural y exclusión social. Perú y Venezuela en perspectiva comparada. Papel político, 12(1), 13-38.

Biderbost, P. (2007b). Percepciones políticas en contraste. La imagen de las instituciones políticas latinoamericanas y españolas en los inmigrantes latinoamericanos radicados en España. Ponencia en VIII Congreso de la Asociación Española de la Ciencia Política y de la Administración. Valencia: Universidad de Valencia.

Biderbost, P. (2008). Adolescencia y cultura política. El desarrollo cívico de los inmigrantes latinoamericanos en la escuela secundaria española. Documento de trabajo del Instituto de Estudios de Iberoamérica. Salamanca: Universidad de Salamanca.

Biderbost, P. (2009). Inmigración latinoamericana e integración cívico-política en España. Diálogo Político, 26(2), 39-84. 
Biderbost, P. (2010). La cultura política de los jóvenes inmigrantes latinoamericanos en España. El desarrollo cívico como indicador de su integración política. En Ayuso, A. y Pinyol, G. (Eds.). (2010). Inmigración latinoamericana en España. El estado de la investigación (pp. 167-215). Barcelona: Fundació CIDOB, Edicions Bellatera y Fundación Carolina.

Biderbost, P. (2011). Los procesos migratorios en Argentina: el péndulo entre la expulsión y la recepción de la población. En Prieto, C. (Ed.). (2011). Bicentenarios de Independencia en América Latina: construir el presente y el futuro (pp. 255-262). Madrid: Universidad Pontificia Comillas y Fundación Superación de la Pobreza.

Biderbost, P. (2012). Políticas de gestión de la inmigración en las sociedades latinoamericanas receptoras: los casos de Argentina, Chile y Costa Rica. En Reyes, M., Figueroa, A. y Ramírez, K. M. (Eds.). (2012). Gestión pública, migración y desarrollo (pp. 73-100). Mexicali: Universidad Autónoma de Baja California.

Biderbost, P. y Boscán, G. (2011). Comunicación política, emigración y voto en América Latina. Revista El Molinillo (33).

Bilchick, S. y Howell, J. C. (1995). Guide for Implementing the Comprehensive Strategy for Serious, Violent, and Chronic Juvenile Offenders. Washington, D. C.: U.S. Department of Justice, Office of Justice Programs y Office of Juvenile Justice and Delinquency Prevention.

Bilodeau, A. (2009). Residential Segregation and the electoral participation of immigrants in Australia. International Migration Review, 43(1), 134-159.

Black, J. H., Niemi, R. G. y Powell, G. B., Jr. (1987). Age, Resistance, and Political Learning in a New Environment: The Case of Canadian Immigrants. Comparative Politics, 20(1), 73-84.

Bleich, E. (2008). Immigration and integration studies in Western Europe and the United States: The road less traveled and a path ahead. World Politics, 60(3), 509-538.

Bloemraad, I. (2006). Becoming a citizen: Incorporating immigrants and refugees in the United States and Canada. Berkeley: University of California Press.

Bolce, L. y DeMaio, G. (2008). A Prejudice for the Thinking Classes. Media Exposure, Political Sophistication, and the Anti-Christian Fundamentalist. American Politics Research, 36(2), 155-185.

Bolzman, C. (2009). Chilenos en Suiza. De una comunidad política a una comunidad de residentes. En Escrivá, A., Bermúdez, A. y Moraes, N. (Eds.). (2009). Migración y participación política (pp. 183-202). Madrid: Consejo Superior de Investigaciones Científicas.

Bolzman, C. (2011). The transnational political practices of Chilean migrants in Switzerland. International Migration, 49(3), 144-167.

Bouton, M. M. y Page, B. I. (Eds.). (2002). Worldviews 2002: American Public Opinion \& Foreign Policy. Chicago: Chicago Council on Foreign Relations. 
Bover, O. y Velilla, P. (2005). Migrations in Spain: Historical Background and Current Trends. En Zimmermann, K. F. (Ed.). (2005). European Migration: What Do We Know? Oxford: Oxford University Press.

Boyd, C. P. (1999). "Madre España": Libros de texto patrióticos y socialización política. Historia y política: Ideas, procesos y movimientos sociales (1), 49-70.

Brady, H. E., Verba, S. y Schlozman, K. L. (1995). Beyond SES: A resource model of political participation. American Political Science Review, 89(2), 271-294.

Breakwell, G. M., Fife-Schaw, C. y Devereux, J. (1989). Political activity and political attitudes in teenagers: is there any correspondence? A research note. Political psychology, 10(4), 745-755.

Brettell, B. y Hollifield, J. (Eds.). (2008). Migration Theory. Talking across disciplines, Nueva York: Routledge.

Brochmann, G. y Hammar, T. (Eds.) (1999). Mechanisms of Immigration Control: A Comparative Analysis of European Regulation Policies. Oxford: Berg.

Bueker, C. S. (2005). Political incorporation among immigrants from ten areas of origin: The persistence of source country effects. International Migration Review, 39(1), 103 140.

Burns, N., Schlozman, K. L. y Verba, S. (1997). The public consequences of private inequality: Family life and citizen participation. American Political Science Review, 91(2), 373-389.

Burns, N., Schlozman, K. L. y Verba, S. (2001). The Private Roots of Public Action: Gender, Equality, and Political Participation. Cambridge, MA: Harvard University Press.

Butler, D. y Stokes, D. (1969). Political change in Britain. Nueva York: St. Martin's Press.

Cachón, L. (1998). Los sindicatos españoles y la inmigración. Migraciones (4), 71-109.

Cachón, L. (2000). Sindicatos e inmigración: caras nuevas para un viejo desafío. Sociedad y Utopia: Revista de Ciencias Sociales (16), 103-117.

Cámara, G. (1984). Nacional-catolicismo y escuela: socialización política del franquismo, 1936-1951. Jaén: Hesperia.

Campbell, A., Converse, P., Miller, W. y Stokes, D. (1960). The American Voter. Ann Arbor: University of Michigan Press.

Campbell, D. E. (2008). Voice in the classroom: How an open classroom climate fosters political engagement among adolescents. Political Behavior, 30(4), 437-454.

Campbell, A., Gurin, G. y Miller, W. E. (1954). The Voter Decides. Evanston: Row and Peterson.

Capel, S. A., Leask, M. y Turner, T. (2009). Learning to Teach in the Secondary School: A Companion to School Experience. Londres: Routledge. 
Caprara, G. V. y Zimbardo, P. G. (2004). Personalizing Politics: A Congruency Model of Political Preference. American Psychologist, 59(7), 581-594.

Caprara, G. V., Vecchione, M., Capanna, C. y Mebane, M. (2009). Perceived political selfefficacy: Theory, assessment, and applications. European Journal of Social Psychology, 39(6), 1002-1020.

Carabaña, J. (2006). Los alumnos inmigrantes en la escuela española. En Aja, E. y Arango, J. (Eds.). (2006). Veinte años de inmigración en España: Perspectiva jurídica y sociológica (1985-2004). Barcelona: Fundación CIDOB.

Casals, X. (2009). La Plataforma per Catalunya: la eclosión de un nacional-populismo catalán (2003-2009) (Working Paper No. 274). Barcelona: Institut de Ciències Polítiques i Socials.

Castles, S. y Kosack, G. (1972). The Function of Labour Migration in Western European Capitalism. New Left Review, 73, 3-21.

Castles, S. y Miller, M. J. (2009). The Age of Migration: international population movements in the modern world. Basingstoke: Macmillan.

Cazorla, J. (1995). La inmigración marroquí en España. Datos, opiniones y previsiones. Revista Internacional de Sociología (12), 117-144.

Cea D’Ancona, M. A. y Valles, M. S. (2000). Los medios de comunicación y la formación de la opinión pública ante la inmigración y el racismo. Sociedad y Utopía: Revista de Ciencias Sociales (16), 133-148.

Cebolla, H. (2009). La concentración de inmigrantes en las escuelas españolas. Análisis del Real Instituto Elcano (ARI) (7)

Chaffee, S. H. (1977). Mass media effects: New research perspectives. En Lerner, D. Nelson, L. M. y Schramm, W. L. (Eds.). (1977). Communication research: A half-century appraisal (pp. 210-241). Honolulu: University Press of Hawaii.

Chaffee, S. H., Ward, L. S. y Tipton, L. P. (1970). Mass Communication and Political Socialization. Journalism Quarterly, 47, 647-659.

Chang, T. y Lee, J. (1992). Factors affecting gatekeepers' selection of foreign news: A national survey of newspaper editors. Journalism \& Mass Communication Quarterly, 69(3), 554-561.

Cho, W. K. T. (1999). Naturalization, Socialization, Participation: Immigrants and (Non) Voting. Journal of Politics, 61(4), 1140-1155.

Claes, E., Hooghe, M. y Stolle, D. (2009). The political socialization of adolescents in Canada: Differential effects of civic education on visible minorities. Canadian Journal of Political Science, 42(3), 613-636.

Clark, M. (2006). Canonical Correlation with SPSS. Recuperado de: http://www.unt.edu/benchmarks/archives/2006/january06/rss.htm 
Cochrane, R. y Billig, M. (1983). Youth and politics. Youth Policy, 2(1), 31-34.

Ioé, C. (2001). Política migratoria española en el marco europeo. Studi emigrazione, 144, 855-868.

Colomer, J. M. (1991). Benefits and costs of voting. Electoral Studies, 10(4), 313-325.

Comber, B. (2006). Pedagogy as work: Educating the next generation of literacy teachers. Pedagogies, 1(1), 59-67.

Conge, P. J. (1988). The Concept of Political Participation: Toward a Definition. Comparative Politics, 20(2), 241-249.

Connell, B. (1987). Why the" Political Socialization" Paradigm Failed and What Should Replace It. International Political Science Review, 8(3), 215-223.

Converse, P.E. (1962). Information Flow and the Stability of Partisan Attitudes. The Public Opinion Quarterly, 26(4), 578-599.

Coraza, E. (2010). Realidades y visiones del exilio uruguayo en España. América Latina Hoy (34) 79-102.

Corbett, M. (1982). Political tolerance in America: Freedom and equality in public attitudes. Nueva York: Longman.

Corbetta, J. y Pérez-Liñán, A. (2001). Calidad de la democracia: Un análisis de la trayectoria argentina. Instituciones y Desarrollo, 10, 149-169.

Cornelius, W. y Rosemblum, M. (2005). Immigration and politics. Annual Review of Political Science, 8, 99-119.

Cornelius, W., Martin, P. y Hollifield, J. (1994). Introduction: the ambivalent quest for immigration control. En Cornelius, W., Martin, P. y Hollifield, J. (Eds.). (1994). Controlling Immigration: A Global Perspective. Stanford: Stanford University Press.

Corrochano, D. H. (2010). Guía bibliográfica sobre inmigración en España (1990-2009). Datos y reflexiones sobre la institucionalización de una comunidad académica. Documento de trabajo del Instituto de Políticas y Bienes Públicos (IPP). Madrid: Consejo Superior de Investigaciones Científicas.

Craig, S. C. y Maggiotto, M.A. (1982). Measuring political efficacy. Political Methodology, 8(3), 85-109.

Craig, S. C., Niemi, R. G. y Silver, G. E. (1990). Political Efficacy and Trust: A Report on the NES Pilot Study Items. Political Behavior, 12(3), 289-314.

Crick, B. (2004). Foreword. En Heater, D. (2004). Citizenship: the civic ideal in world history, politics and education. Manchester: Manchester University Press.

Dahl, R. J. (1961). Who Governs? Democracy and Power in an American City. New Haven: Yale University Press. 
Dalton, R. J. (2002). Citizen Politics: Public Opinion and Political Parties in Advanced Industrial Democracies. Londres: Chatham House.

Dalton, R. J., Cain, B. E. y Scarrow, S. E. (2003). Democracy Transformed? Expanding Political Opportunities in Advanced Industrial Democracies. Oxford: Oxford University Press.

Davies, I. (2010). Defining citizenship education. En Gearon, I. (2010). Learning to teach Citizenship in the Secondary School. Nueva York: Routledge.

De la Garza, R. O. y DeSipio, L. (1999). Awash in the mainstream: Latino politics in the 1996 elections. Boulder: Westview.

De la Garza, R. O., Falcon, A. y Garcia, F. C. (1996). Will the real Americans please stand up: Anglo and Mexican-American support of core American political values. American Journal of Political Science, 40(9) 335-351.

De Lucas, J. (2009). Inmigración, diversidad cultural, reconocimiento político. Papers Revista de Sociología (94), 11-27.

DeFrancesco, V. M. y Merolla, J. L. (2006). Vota por tu Futuro: Partisan Mobilization of Latino Voters in the 2000 Presidential Election. Political Behaviour, 28(4), 285-304.

Degani, A., Shafto, M. y Olson, L. (2006). Canonical correlation analysis: Use of composite heliographs for representing multiple patterns. En Barker-Plummer, D., Cox, R. y Swoboda, N. (Eds.). (2006). Diagrammatic Representation and Inference (pp. 93-97). Berlín: Springer.

Del Olmo, M. (2003). El exilio después del exilio. América Latina Hoy (34), 35-47.

Delgado, L. M. (2010). La acción exterior como innovación en la política española de inmigración. Revista CIDOB d'Afers Internacionals (91), 63-85.

Delli Carpini, M. X. y Keeter, S. (1993). Measuring Political Knowledge: Putting First Things First. American Journal of Political Science, 37(4), 1179-1206.

Delpino, M. A. (2008). El adolescente inmigrado latinoamericano en la escuela española: las miradas docentes. Revista española de educación comparada (14), 79-102.

Demireva, N. y Heath, A. (2014). Diversity and the Civic Spirit in British Neighbourhoods: An Investigation with MCDS and EMBES 2010 Data. Sociology. Artículo pre-publicado el 31 de enero de 2014. doi: 10.1177/0038038513516695

Dennis, J. (1973). Socialization to politics: A reader. Nueva York: J. Wiley \& Sons.

DeSipio, L. (1996). Making citizens or good citizens? Naturalization as a predictor of organizational and electoral behavior among Latino immigrants. Hispanic Journal of Behavioral Sciences, 18(2), 194-213.

DeSipio, L. (2002). Immigrant organizing, civic outcomes: Civic engagement, political activity, national attachment, and identity in Latino immigrant communities. 
Documento de trabajo del Center for the Study of Democracy. Irvine: University of California.

DeSipio, L., Pachon, H., De la Garza, R. y Lee, J. (2003). Immigrant Politics at Home and Abroad: How Latino Immigrants Engage the Politics of their Home Communities and the United States. Claremont: Tomas Rivera Policy Institute.

Diamond, L. y Morlino, L. (2004). The Quality of Democracy. An Overview. Journal of Democracy, 15(4), 20-31.

Díez Nicolás, J. (1999). Los españoles y la inmigración. Madrid: Ministerio de Trabajo y Asuntos Sociales, Secretaría General de Asuntos Sociales, Instituto de Migraciones y Servicios Sociales y Observatorio Permanente de la Inmigración.

Díez Nicolás, J. (2005). Las dos caras de la inmigración. Madrid: Ministerio de Trabajo y Asuntos Sociales.

Djupe, P. A. y Grant, J. T. (2001). Religious institutions and political participation in America. Journal for the Scientific Study of Religion, 40(2), 303-314.

Dolan, K. A. y Holbrook, T. M. (2001). Knowing Versus Caring: The Role of Affect and Cognition in Political Perceptions. Political Psychology, 22(1), 27-44.

Downs, A. (1957). An Economic Theory of Democracy. Nueva York: Harper and Row.

Dowse, R. E. y Hughes, J. A. (1971). The Family, the School, and the Political Socialization Process. Sociology, 5(1), 21-45.

Duch, R. M. y Gibson, J. L. (1992). "Putting Up With" Fascists in Western Europe: a Comparative, Cross-Level Analysis of Political Tolerance. The Western Political Quarterly, 45(1), 237-273.

Dudley, R. L. y Gitelson, A. R. (2002). Political literacy, civic education, and civic engagement: A return to political socialization? Applied Developmental Science, 6(4), 175-182.

Duncan, L. E. (2005). Personal Political Salience as a Self-Schema: Consequences for Political Information Processing. Political Psychology, 26(6), 965-976.

Duncan, L. E. y Stewart, A. J. (2007). Personal political salience: The role of personality in collective identity and action. Political Psychology, 28(2), 143-164.

Durand, V. M. (2000). Etnia y cultura política. Los mexicanos en Estados Unidos. México, D. F.: Miguel Ángel Porrúa y Centro Regional de Investigaciones Multidisciplinarias de la UNAM.

Easton, D. (1957). An approach to the analysis of political systems. World Politics, 9(3), 383-400.

Easton, D. y Dennis, J. (1967). The child's acquisition of regime norms: Political efficacy. The American Political Science Review, 61(1), 25-38. 
Echazarra, A. (2011). La incorporación política de los nuevos ciudadanos en Europa: participación electoral y origen inmigrante. Revista Española de Ciencia Política (25), 5777.

Echazarra, A. y Morales, L. (2012). El efecto de la diversidad en la cultura cívica en España a examen. Revista Española de Sociología (17), 133-149.

Edwards, S. (2005). National Issues Forums: An alternative to promote students' civic development and community service. DeKalb: Northern Illinois University.

Eggert, N. y Giugni, M. (2011). The impact of religion on the political participation of migrants. En Morales, L. y Giugni, M. G. (Eds.). (2011). Social Capital, Political Participation and Migration in Europe: Making Multicultural Democracy Work? (pp. 219237). Basingstoke: Palgrave.

Ehman, L. H. (1969). An Analysis of the Relationships of Selected Educational Variables with the Political Socialization of High School Students. American Educational Research Journal, 6(4), 559-580.

Ehman, L. H. (1980). The American school in the political socialization process. Review of Educational Research, 50(1), 99-119.

Eisenstein, M. A. (2006). Rethinking the relationship between religion and political tolerance in the US. Political Behavior, 28(4), 327-348.

Elkins, D. J. y Simeon, R. E. B. (1979). A Cause in Search of Its Effect, or What Does Political Culture Explain? Comparative Politics, 11(2), 127-145.

Escobar, C. (2004). Dual citizenship and political participation: migrants in the interplay of United States and Colombian politics. Latino Studies, 2(1), 45-69.

Escrivá, A., Bermúdez, A., y Moraes, N. (Eds.). (2009). Migración y participación política. Estados, organizaciones y migrantes latinoamericanos en perspectiva localtransnacional. Madrid: CSIC.

Fagen, R. R. (1969). The transformation of political culture in Cuba (Vol. 2). Stanford: Stanford University Press.

Fennema, M. y Tillie, J. (2001). Civic Community, Political Participation and Political Trust of Ethnic Groups. Connections, 24(1), 26-41.

Fernández, J. (2003). Los institutos obreros, un ensayo de innovación pedagógica y de socialización política. Cuadernos republicanos (52), 31-43.

Finifter, A. W. y Finifter, B. M. (1989). Party identification and political adaptation of American migrants in Australia. The Journal of Politics, 51(3), 599-630.

Finkel, S. E. (1985). Reciprocal effects of participation and political efficacy: A panel analysis. American Journal of Political Science, 9(4), 891-913.

Finkel, S. E. (1987). The effects of participation on political efficacy and political support: Evidence from a West German panel. The Journal of Politics, 49(2), 441-464. 
Finkel, S. E. y Ernst, H. R. (2005). Civic Education in Post-Apartheid South Africa: Alternative Paths to the Development of Political Knowledge and Democratic Values. Political Psychology, 26(3), 333-364.

Fiske, S. T., Lau, R. R. y Smith, R. A. (1990). On the Varieties and Utilities of Political Expertise. Social Cognition, 8, 31-48.

Flanagan, C. A. (2004). Volunteerism, leadership, political socialization, and civic engagement. En Lerner, R. M. y Steinberg, L. (Eds.). (2004). Handbook of Adolescent Psychology (pp. 721-746). Nueva York: John Wiley \& Sons.

Flanagan, C. A. y Van Horn, B. (2003). Youth civic development: A logical next step in community youth development. En Villarruel, F. A., Perkins, D. F., Borden, L. M. y Keith, J. G. (Eds.). (2003). Community youth development: Practice, policy, and research (pp. 273-296). Thousand Oaks: Sage.

Flanagan, C. A., Syvertsen, A. K., Gill, S., Gallay, L. S. y Cumsille, P. (2009). Ethnic awareness, prejudice, and civic commitments in four ethnic groups of American adolescents. Journal of Youth and Adolescence, 38(4), 500-518.

Flores, F., Biderbost, P. y Carrera, M. (2013). El inmigrante como nuevo stakeholder. Las políticas de responsabilidad social corporativa y la integración de los nuevos ciudadanos en España. En Delpino, M. A., Roll, D. y Biderbost, P. (Eds.). (2013). Claves para la comprensión de la inmigración latinoamericana en España (pp. 277-306). Córdoba: EDUCC.

Fraga, L. R., Garcia, J., Hero, R., Jones-Correa, M., Martinez-Ebers, V. y Segura, G. (2006). Su casa es nuestra casa: Latino politics research and the development of American political science. American Political Science Review, 100(4), 515-521.

Fraile, M. (2006). Cuánto saben los ciudadanos de política. Documento de trabajo no 97 de Laboratorio de Alternativas. Madrid: Fundación Alternativas.

Fraile, M., Ferrer, M. y Martín, I. (2007). Jóvenes, conocimiento político y participación. Madrid: Centro de Investigaciones Sociológicas.

Franklin, C. H. (1984). Issue preferences, socialization, and the evolution of party identification. American Journal of Political Science, 28(3), 459-478.

Franklin, M. N. (2001). The dynamics of electoral participation. En LeDuc, L., Niemi, R. y Norris, P. (Eds.). (2001). Comparing Democracies 2: Elections and Voting in Global Perspective (pp. 148-168). Thousand Oaks: Sage.

Franklin, M. N. (2004). Voter turnout and the dynamics of electoral competition in established democracies since 1945. Cambridge: Cambridge University Press.

Freeman, G. (1979). Immigrant Labor and Racial Conflict in Industrial Societies. Princeton: Princeton University Press.

Freeman, G. P. (2006). National models, policy types, and the politics of immigration in liberal democracies. West European Politics, 29(2), 227-247. 
Freie, J. F. (1997). The effects of campaign participation on political attitudes. Political Behavior, 19(2), 133-156.

Freire, P. (1975). Acción cultural para la libertad. Lima: Tierra nueva.

Fuchs, L. H. (1956). Some political aspects of immigration. Law and Contemporary Problems, 21(2), 270-283.

Funes, J. (2000). Migración y adolescencia. En Aja, E. (Ed.) (2000). La inmigración extranjera en España: los retos educativos (pp. 69-96). Barcelona: Fundación La Caixa.

Funes, M. J. (2003). Socialización política y participación ciudadana. Jóvenes en dictadura y jóvenes en democracia. Revista de estudios de Juventud (Extra 1), 57-76.

Fung, A. y Wright, E. O. (2001). Deepening democracy: Innovations in empowered participatory governance. Politics \& Society, 29(1), 5-41.

Galindo, F. (1997). Televisión y participación política en Euskadi. ZER (2), 71-86.

Gallego, M. T. (1982). Notas sobre el poder, la socialización política y la mujer (la Sección Femenina de Falange). En Folguera, P. (Ed.). (1982). Nuevas perspectivas sobre la mujer: actas de las Primeras Jornadas de Investigación Interdisciplinaria (pp. 42-49). Madrid: Universidad Autónoma de Madrid y Seminario de Estudios de la Mujer.

Galston, W. A. (2001). Political knowledge, political engagement, and civic education. Annual Review of Political Science, 4(1), 217-234.

Galston, W. A. (2004). Civic education and political participation. Phi Kappa Phi Forum, 84(1), 36-40.

Galván, M. y Medina, F. (2007). Imputación de datos: teoría y práctica. Documento no 54 de la Serie Estudios Estadísticos y Prospectivos. Santiago de Chile: Naciones Unidas.

Garcia, F.C. (1973). Political Socialization of Chicano Children. New York: Praeger Publishers.

Garcia, J. A. (1981). Political integration of Mexican immigrants: Explorations into the naturalization process. International Migration Review, 608-625.

Garcia, J. (1987). The political integration of Mexican immigrants: Examining some political orientations. International Migration Review, 21, 372-389.

García, T., Ordoñez, E., Preckler, M., Sainz, V., Pérez Manjarrez, E., Plascencia, M., Juanes García, A., Maldonado, A. \& Jacott, L. (2012) 'From traditional to cosmopolitan views on citizenship education: A new instrument for evaluation', in P. Cunningham \& N. Fretwell (eds.) Creating Communities: Local, National and Global. London: CiCe, pp. 528 - 537.

Gastil, J. y Dillard, J. P. (1999). The aims, methods, and effects of deliberative civic education through the National Issues Forums. Communication Education, 48(3), 179192. 
Gastil, J. y Xenos, M. (2010). Of attitudes and engagement: Clarifying the reciprocal relationship between civic attitudes and political participation. Journal of Communication, 60(2), 318-343.

Gearon, L. (Ed.). (2010). Learning to teach citizenship in the secondary school: $A$ companion to school experience. Nueva York: Routledge.

Geddes, A., Niessen, J., Balch, A., Bullen, C. y Peiro, M.J. (2005). Índice Europeo de Ciudadanía Cívica e Inclusión. Barcelona: CIDOB.

Geissel, B. (2008). Do critical citizens foster better governance? A comparative study. West European Politics, 31(5), 855-873.

Gibney, M. J. (2004). The Ethics and Politics of Asylum: Liberal Democracy and the Response to Refugees. Cambridge: Cambridge University Press.

Gibson, C. y Levine, P. (2003). The Civic Mission of Schools. Informe de la Carnegie Corporation of New York y de CIRCLE: Center for Information and Research on Civic Learning and Engagement. Nueva York: Carnegie Corporation of New York y CIRCLE.

Gibson, J. L. (1992). Alternative Measures of Political Tolerance: Must Tolerance be" Least-Liked"? American Journal of Political Science, 36(2) 560-577.

Gibson, J. L. (2005). On the Nature of Tolerance: Dichotomous or Continuous? Political Behavior, 27(4), 313-323.

Gibson, J. L. y Anderson, A. J. (1985). The political implications of elite and mass tolerance. Political Behavior, 7(2), 118-146.

Gibson, J. L., Duch, R. M. y Tedin, K. L. (1992). Democratic Values and the Transformation of the Soviet Union. The Journal of Politics, 54(2), 329-371.

Gil-García, J. R., Chengalur-Smith, I. y Duchessi, P. (2007). Collaborative e-Government: impediments and benefits of information-sharing projects in the public sector. European Journal of Information Systems, 16(2), 121-133.

Giugni, M. y Morales, L. (2011). Conclusion. Towards an integrated approach to the political inclusion of migrants. En Giugni, M. y Morales, L. (Eds.) (2011). Social capital, political participation and migration in Europe. Making multicultural democracy work (pp. 262-274). Basingstoke: Palgrave.

Givens, T. y Luedtke, A. (2005). European Immigration Policies in Comparative Perspective: Issue Salience, Partisanship and Immigrant rights. Comparative European Politics, 3, 1-22.

Glanville, J. L. (1999). Political socialization or selection? Adolescent extracurricular participation and political activity in early adulthood. Social Science Quarterly, 80(2), 279-290.

Glatfelter, A. (2009). Canonical correlation [Material de clase]. Recuperado de: http://academic.csuohio.edu/neuendorf_ka/COM53109/CC.pdf 
Glazer, N. (1956). The integration of American immigrants. Law and Contemporary Problems, 21(2), 256-269.

Glazer, N. (1998). We are all multiculturalists now. Cambridge, MA: Harvard University Press.

Goldenson, D. R. (1978). An alternative view about the role of the secondary school in political socialization: A field-experimental study of the development of civil liberties attitudes. Theory \& Research in Social Education, 6(1), 44-72.

Golebiowska, E. A. (1999). Gender gap in political tolerance. Political Behavior, 21(1), 4366.

González-Enríquez, C. (2005). Active civic participation of immigrants in Spain. Informe de país preparado para el proyecto europeo Politis. Oldenburg: Carl von Ossietzky Universität.

González-Enríquez, C. (2013). ¿Emigran los españoles? Análisis del Real Instituto Elcano (ARI) (39).

González-Ferrer, A. (2011). The electoral participation of naturalized immigrants in ten European cities. En Morales, L. y Giugni, M. G. (Eds.). (2011). Social Capital, Political Participation and Migration in Europe: Making Multicultural Democracy Work? (pp. 6384). Basingstoke: Palgrave.

González-Ferrer, A. (2013). La nueva emigración española. Lo que sabemos y lo que no. Informe no 18 de la Colección Zoom Político. Madrid: Fundación Alternativas.

González-Ferrer, A. y Eremenko, T. (2014). Explaining Children Migration Patterns to France and Spain. Methodological Challenges for Cross--National Research. Documento de trabajo del Instituto de Economía, Geografía y Demografía (IEGD). Madrid: Consejo Superior de Investigaciones Científicas.

González-Ferrer, A. y Morales, L. (2006). Las Asociaciones de Inmigrantes en Madrid: una nota de investigación sobre su grado de integración política. Revista Española del Tercer Sector (4).

González-Ferrer, A., Beauchemin, C. y Baizán, P. (2014). Incidence and duration of childparent separation due to international migration. Selection and integration effects. Documento de trabajo del Instituto de Economía, Geografía y Demografía (CCHS-IEGD). Madrid: Consejo Superior de Investigaciones Científicas.

González-Ferrer, A., Castro, T., Séiz, M. y Martín-García, T. (2014). Partnership formation and dissolution among native and immigrant population in Spain. An intergenerational analysis. Documento de trabajo del Instituto de Economía, Geografía y Demografía (IEGD). Madrid: Consejo Superior de Investigaciones Científicas.

Granberg, D. y Holmberg, S. (1990). The Intention-Behavior Relationship Among U.S. and Swedish Voters. Social Psychology Quarterly, 53(1), 44-54. 
Gray, M. y Caul, M. (2000). Declining Voter Turnout in Advanced Industrial Democracies 1950-1997: The Effects of Declining Group Mobilization. Comparative Political Studies, 33(9), 1091-1122.

Greenstein, F. I. (1965). Children and Politics. New Haven: Yale University Press.

Grossman, D. L. (1976). Educational climates and attitudes toward dissent: A study of political socialization of conflict norms in adolescents (Tesis doctoral). Stanford: Stanford University.

Guarnizo, L. E., Portes, A. y Haller, W. (2003). Assimilation and Transnationalism: Determinants of Transnational Political Action among Contemporary Migrants. American Journal of Sociology, 108(6), 1211-1248.

Guérin, D., Petry, F. y Crete, J. (2004). Tolerance, protest and democratic transition: Survey evidence from 13 post-communist countries. European Journal of Political Research, 43(3) 371-395.

Guichot-Reina, V. (2011). Necesidad y constitucionalidad de la asignatura Educación para la ciudadanía en el currículum del sistema educativo español. Cuestiones pedagógicas: Revista de ciencias de la educación (21), 121-146.

Guillén, M. F. (1992). Análisis de regresión múltiple. Madrid: Centro de Investigaciones Sociológicas-CIS.

Guiraudon, V. y Lahav, G. (2000). A Reappraisal of the State Sovereignty Debate: The Case of Migration Control. Comparative political studies, 33(2), 163-195.

Gurr, T. R. (Ed.). (1989). Violence in America: Protest, rebellion, reform (Vol. 2). Londres: Sage.

Gustafsson, G. (1987). Political Socialization Studies in Scandinavia .International Political Science Review, 8(3), 225-233.

Hackett, J. D. y Omoto, A. M. (2009). Efficacy and Estrangement: Effects of Voting. Analyses of Social Issues and Public Policy, 9(1), 297-314.

Hagopian, F. (2005). Derechos, representación y la creciente calidad de la democracia en Brasil y Chile. Política y Gobierno, 12(1), 41-90.

Hair, J. F., Anderson, R. E., Tatham, R. L. y Black, W. C. (2007). Multivariate data analysis. Madrid: Macmillan.

Hammar, T. (1989). Comparing European and North American International Migration. International Migration Review, 23(3), 631-637.

Harbers, I. (2007). Democratic deepening in third wave democracies: experiments with participation in Mexico City. Political Studies, 55(1), 38-58.

Hart, D., Atkins, R., Markey, P. y Youniss, J. (2004). Youth bulges in communities: the effects of age structure on adolescent civic knowledge and civic participation. Psychological Science, 15(9), 591-597. 
Harwood, A. M. (1992). Classroom climate and civic education in secondary social studies research: Antecedents and findings. Theory \& Research in Social Education, 20(1), 47-86.

Heath, A. F., Fisher, S. D., Rosenblatt, G., Sanders, D. y Sobolewska, M. (2013). The Political Integration of Ethnic Minorities in Britain. Oxford: Oxford University Press.

Hensher, D. A. y Golob, T. F. (1999). Searching for policy priorities in the formulation of a freight transport strategy: a canonical correlation analysis of freight industry attitudes. Transportation Research Part E: Logistics and Transportation Review, 35(4), 241-267.

Hernández, A. (2011). ¿La hora del populismo?: elementos para comprender el" éxito" electoral de Plataforma per Catalunya. Revista de Estudios Políticos (153), 47-74.

Herranz, Y. (1997). Formas de incorporación laboral de la inmigración latinoamericana en Madrid: la importancia del contexto de recepción. Madrid: Universidad Autónoma de Madrid.

Herreros, F. y Criado, H. (2009). Social trust, social capital and perceptions of immigration. Political Studies, 57(2), 337-355.

Herzog, B., Gómez, J., Gómez, E., Valderrama, J. C. y Aleixandre, R. (2009). Identificación y solución de problemas para la participación ciudadana de los inmigrantes. Papers Revista de Sociología (91) 45-64.

Hess, D. E. (2004). Controversies about controversial issues in democratic education. Political science and politics, 37(2), 257-261.

Hess, R. D. y Torney, J. (1967). The Development of Political Attitudes in Children. Chicago: Aldine Publishing Company.

Hinckley, R. A. (2010). Personality and political tolerance: The limits of democratic learning in postcommunist Europe. Comparative Political Studies, 43(2), 188-207.

Hirsch, H. (1971). Poverty and politicization: political socialization in an American subculture. Washington, D.C.: Free Press.

Hollifield, J. (2008). The Politics of International Migration. En Brettell, B. y Hollifield, J. (Eds.). (2008). Migration Theory. Talking across disciplines. Nueva York: Routledge.

Hooghe, M. (2004). Political socialization and the future of politics. Acta Politica, 39(4), 331-341.

Hooghe, M. y Dassonneville, R. (2013). Voters and Candidates of the Future: The Intention of Electoral Participation among Adolescents in 22 European Countries. Young, 21(1), 1-28.

Hooghe, M. y Wilkenfeld, B. (2008). The stability of political attitudes and behaviors across adolescence and early adulthood: A comparison of survey data on adolescents and young adults in eight countries. Journal of Youth and Adolescence, 37(2), 155-167. 
Huddy, L. y Khatib, N. (2007). American patriotism, national identity, and political involvement. American Journal of Political Science, 51(1), 63-77.

Huebner, A. J. (2003). Positive youth development: The role of competence. En Villarruel, F. A., Perkins, D. F., Borden, L. M. y Keith, J. G. (Eds.). (2003). Community youth development: Programs, policies, and practices (pp. 341-357). Thousand Oaks: Sage.

Huntington, S. (1968). The Bases of Accommodation. Foreign Affairs, 46(4), 642-656.

Huntington, S. P. (2004). The Hispanic Challenge. Foreign policy, 141(2), 30-45.

Hyman, H. H. (1959). Political Socialization. Glencoe: Free Press.

Ikeda, K., Kobayashi, T. y Hoshimoto, M. (2008). Does political participation make a difference? The relationship between political choice, civic engagement and political efficacy. Electoral Studies, 27(1), 77-88.

Inglehart, R. (1988). The renaissance of political culture. American political science review, 82(4), 1203-1230.

Inglehart, R. (1997). Modernization and Postmodernization: Cultural, Economic, and Political Change in 43 Societies. Cambridge: Cambridge University Press.

Inglehart, R. y Norris, P. (2009). Muslim integration into Western cultures: Between origins and destinations. Political Studies, 60(2), 228-251.

Inglehart, R. y Welzel, C. (2005). Modernization, cultural change and democracy. The human development sequence. Cambridge: Cambridge University Press.

Inkeles, A. y Levinson, D. J. (1954). National character: The study of modal personality and sociocultural systems. En Lindzey, G. y Aaronson, E. (Eds.). (1954). Handbook of Social Psychology IV (pp. 418- 506). Nueva York: McGraw-Hill.

Ireland, P. (1994). The Policy Challenge of Ethnic Diversity: Immigrant Politics in France and Switzerland. Cambridge, MA: Harvard University Press.

Itzigsohn, J. (2000). Immigration and the Boundaries of Citizenship: The Institutions of Immigrants' Political Transnationalism. International Migration Review, 34(4), 11261154.

Ivarsflaten, E. (2005). The Vulnerable Populist Right Parties. European Journal of Political Research, 44(3), 465-492.

Izquierdo, A. C. (Ed.) (2009). El modelo de inmigración y los riesgos de exclusión. Madrid: Cáritas Española.

Izquierdo, A. y Cornelius, W. A. (2012). Políticas de control migratorio. Estudio comparado de España y EE.UU. Barcelona: Edicions Bellaterra.

Jabbaz, M. y Simó, C. (2004). Los inmigrantes y el mundo asociativo en la Comunidad Valenciana: una reflexión en torno a las formas de participación y las funciones sociales. 
En Pascual, A. (Ed.) (2004). IV Congreso sobre la inmigración en España: Ciudadanía y Participación. Girona: Ediciones Universidad de Girona.

Jackman, M. R. (1978). General and applied tolerance: Does education increase commitment to racial integration? American Journal of Political Science, 22(2), 302-324.

Jackson, R. (2003). Differential influences on Latino Electoral Participation. Political Behaviour, 25(4), 339-366.

Jacobs, D. y Tillie, J. (2004). Introduction: social capital and political integration of migrants. Journal of Ethnic and Migration Studies, 30(3), 419-427.

Jaime, A. M. (2000). Familia y socialización política. La transmisión de orientaciones ideológicas en el seno de la familia española. Reis: Revista española de investigaciones sociológicas (92), 71-92.

Jennings, M. K. (1987). Residues of a movement: The aging of the American protest generation. American Political Science Review, 81(2), 367-382.

Jennings, M. K. (2002). Generation Units and the Student Protest Movement in the United States: An Intra-and Intergenerational Analysis. Political Psychology, 23(2), 303324.

Jennings, M. K. (2007). Political Socialization. En Dalton, R. J. y Klingemann, H. (Eds.). (2007). The Oxford Handbook of Political Behavior (pp. 29-44). Oxford: Oxford University Press.

Jennings, M. K. y Niemi, R. G. (1968). The Transmission of Political Values from Parent to Child. The American Political Science Review, 62(1), 169-184.

Jennings, M. K. y Niemi, R. G. (1974). The Political Character of Adolescence. Princeton: Princeton University Press.

Jennings, M. K. y Niemi, R. G. (1981). Generations and Politics. Princeton: Princeton University Press.

Jensen, S. y Yankelevich, P. (2007). Una aproximación cuantitativa para el estudio del exilio político argentino en México y Cataluña (1974-1983). Estudios Demográficos y Urbanos, 22(2), 399-442.

Jiménez, M. I. y López-Zafra, E. (2011). Actitudes sociales y adaptación social en adolescentes españoles: el papel de la inteligencia emocional percibida. Revista de Psicología Social, 26(1), 105-117.

Jones-Correa, M. (1998). Between two nations: the political predicament of Latinos in New York City. Ithaca: Cornell University Press.

Jones-Correa, M. A. y Leal, D. L. (2001). Political participation: Does religion matter? Political Research Quarterly, 54(4), 751-770.

Joppke, C. (1998). A Challenge to the Nation-State. Immigration in Western Europe and the United States. Oxford: Oxford University Press. 
Joppke, C. (2007). Transformation of citizenship: status, rights, identity. Citizenship studies, 11(1), 37-48.

Judd, C. M. y Milburn, M. A. (1980). The Structure of Attitude Systems in the General Public: Comparisons of a Structural Equation Model. American Sociological Review, 45(4), 627-643.

Junn, J. (1999). Participation in Liberal Democracy: The Political Assimilation of Immigrants and Ethnic Minorities in the United States. American Behavioral Scientist, 42(9), 1417-1438.

Justel, M. (1992). Edad y cultura política. Reis: Revista española de investigaciones sociológicas (58), 57-96.

Justice and Home Affairs Council of the European Union (2004). Common Basic Principles for immigrant integration policy in the European Union [Comunicado de prensa]. Recuperado de: http://www.eesc.europa.eu/resources/docs/2_councilconlusions_cbps_2004.pdf

Kahne, J. y Middaugh, E. (2006). Is Patriotism Good for Democracy? A Study of High School Seniors' Patriotic Commitments. Phi Delta Kappan, 87(8), 600-607.

Karasek, R. A. (2004). Job socialization: The carry-over effects of work on political and leisure activities. Bulletin of Science, Technology \& Society, 24(4), 284-304.

Karpov, V. (1999). Political tolerance in Poland and the United States. Social Forces, 77(4), 1525-1549.

Kavanaugh, A., Kim, B. J., Perez-Quinones, M. A., Schmitz, J. y Isenhour, P. (2008). Net gains in political participation: secondary effects of internet on community. Information, Communication \& Society, 11(7), 933-963.

Kelly, N. J. y Morgan, J. (2005). Religion and Latino partisanship in the United States. Political Research Quarterly, 58(1), 87-95.

Key, V. O., Jr. (1968). The responsible electorate: Rationality in presidential voting, 19361960. Nueva York: Vintage Books.

Kinder, D. R. (2006). Belief systems today. Critical Review, 18(1-3), 197-216.

Kinder, D. R. y Winter, N. (2001). Exploring the Racial Divide: Blacks, Whites, and Opinion on National Policy. American Journal of Political Science, 45(2), 439-456.

Koopmans, R., Statham, P., Giugni, M. y Passy, F. (2005). Contested Citizenship. Minneapolis: University of Minnesota Press.

Krackhardt, D. (1990). Assessing the political landscape: Structure, cognition, and power in organizations. Administrative Science Quarterly, 35(2), 342-369.

Krampen, G. (2002). Transition of Adolescent Political Action Orientations to Voting Behavior in Early Adulthood in View of a Social-Cognitive Action Theory Model of Personality. Political Psychology, 21(2), 277-299. 
Kuklinski, J. H. y Peyton, B. (2007). Belief Systems and Political Decision-Making. En Dalton, R. J. y Klingemann, H. (Eds.). (2007). The Oxford Handbook of Political Behavior. Oxford: Oxford University Press.

Kymlicka, W. (1995). Multicultural citizenship. Oxford: Oxford University Press.

Kymlicka, W. y Bashir, B. (2008). The Politics of Reconciliation in Multicultural Societies. Nueva York: Oxford University Press.

Lamare, J. W. (1982). The political integration of Mexican American children: A generational analysis. International Migration Review, 16(1), 169-188.

Landolt, P. y Goldring, L. (2008). Immigrant Political Socialization as bridging and Boundary Work: Mapping the Multi-Layered Incorporation of Latin American Immigrants in Toronto. Ethnic and Racial Studies, 32(7), 1226-1247.

Langton, K. P. (1969). Political socialization. Nueva York: Oxford University Press.

Langton, K. P. y Jennings, M. K. (1968). Political socialization and the high school civics curriculum in the United States. The American Political Science Review, 62(3), 852-867.

Langton, K. P. y Karns, D. A. (1969). The relative influence of the family, peer group, and school in the development of political efficacy. Political Research Quarterly, 22(4), 813826.

Layton-Henry, Z. (Ed.). (1990). The political rights of migrant workers in Western Europe (Vol. 25). Londres: Sage.

Leal, D. L. (2002). Political participation by Latino non-citizens in the United States. British Journal of Political Science, 32(2), 353-370.

Leighley, J. E. (1995). Attitudes, opportunities and incentives: A field essay on political participation. Political Research Quarterly, 48(1), 181-209.

Leighley, J. E. y Vedlitz, A. (1999). Race, ethnicity, and political participation: Competing models and contrasting explanations. Journal of Politics, 61(4), 1092-1114.

Levine, D. H. y Molina, J. E. (2007). La calidad de la democracia en América Latina: una visión comparada. América Latina Hoy (45), 17-46.

Levine, D.H. y Molina, J.E. (Eds.). (2011). The Quality of Democracy in Latin America. Londres: Lynne Rienner Publishers.

Liebes, T. y Ribak, R. (1991). A Mother's Battle Against TV News: A Case Study of Political Socialization. Discourse and Society, 2(2), 203-222.

Linares, S. (2008). La (i) legitimidad democrática del control judicial de las leyes. Madrid: Marcial Pons.

Lijphart, A. (1980). The structure of inference. En Almond, G. A. y Verba, S. (Eds.). (1980). The civic culture revisited (pp. 37-56). Londres: Little, Brown Book Group.

Lipset, S. M. (1987). El hombre político: las bases sociales de la política. Madrid: Tecnos. 
Liu, A. H. y Baird, V. (2012). Linguistic Recognition as a Source of Confidence in the Justice System. Comparative Political Studies, 45(10), 1203-1229.

López, A. M. (2005). Inmigrantes y Estados: la respuesta política ante la cuestión migratoria (Vol. 43). Barcelona: Anthropos Editorial.

López, M. D. y Scheu, D. (2003). Students' discourse on immigration attitudes and ideological values: a critical view. International Journal of English Studies, 31(1), 209235.

Lutz, O. y Walker, P. (1985). Exiliados Latinoamericanos en España. Estudios del CESERAD (3).

Marcus, G. E., Sullivan, J. L., Theiss-Morse, E. y Stevens, D. (2005). The Emotional Foundation of Political Cognition: The Impact of Extrinsic Anxiety on the Formation of Political Tolerance Judgments. Political Psychology, 26(6), 949-963.

Marcus, G. E., Sullivan, J. L., Theiss-Morse, E. y Wood, S. L. (1995). With Malice Toward Some: How People Make Civil Liberties Judgments. Nueva York : Cambridge University Press.

Marquart-Pyatt, S. y Paxton, P. (2007). In Principle and in Practice: Learning Political Tolerance in Eastern and Western Europe. Political Behavior, 29(1), 89- 113.

Marsh, C. y Tonoyan, A. (2009). The Civic, Economic, and Political Consequences of Pentecostalism in Russia and Ukraine. Society, 46(6), 510-516.

Martiniello, M. y Lafleur, J. M. (2008). Towards a transatlantic dialogue in the study of immigrant political transnationalism. Ethnic and Racial Studies, 31(4), 645-663.

Massey, D. (2006). Capital social, política social y migración desde comunidades tradicionales y nuevas comunidades de origen en México. Revista Española de Investigaciones Sociológicas (116), 97-121.

Mata, J. M., Lavia, C. y Alkorta, E. (2007). Socialización política y opinión pública en la Comunidad Autónoma Vasca: los centros de enseñanza y otras agencias de socialización. En Ávila R. M., López, J. R. y Fernández de Larrea, E. (Eds.). (2007). Las competencias profesionales para la enseñanza-aprendizaje de las ciencias sociales ante el reto europeo y la globalización (pp. 295-320). Bilbao: Asociación Universitaria del Profesorado de Didáctica de las Ciencias Sociales, Universidad del País Vasco.

Mateos, A. y Moral, F. (2000). Europeos e inmigrantes: La Unión Europea y la inmigración extranjera desde la perspectiva de los jóvenes. Madrid: Centro de Investigaciones Sociológicas.

Mattei, F. y Niemi, R. G. (2005). Political efficacy. En Best, S. J. y Radcliff, B. (Eds.). (2005). Polling America: An Encyclopedia of Public Opinion (pp. 525-534). Westport: Greenwood Press. 
Maxwell, R. y Bleich, E. (2014). Do Muslims Really Have Unique Integration Challenges? A Study of National Identification in France (Artículo por publicar). Chapel Hill: University of North Carolina.

Mayordomo, A. (2000). Regenerar la sociedad, construir el patriotismo o la ciudadanía: Educación y socialización política en la España del siglo XX. Encounters on Education (1), 49-80.

McAdam, D. (1982). Political process and the development of black insurgency. Chicago: University of Chicago Press.

McClosky, H. y Brill, A. (1983). Dimensions of Tolerance. Nueva York : Russell Sage Foundation.

McDevitt, M., \& Chaffee, S. (2000). Closing gaps in political communication and knowledge effects of a school intervention. Communication research, 27(3), 259-292.

McDevitt, M. y Chaffee, S. H. (2002). The Family in a Sequence of Political Activation: Why Civic Interventions Can Succeed. Journalism \& Communication Monographs, $4(1), 6-42$.

McFarland, D. A. y Thomas, R. J. (2006). Bowling young: How youth voluntary associations influence adult political participation. American sociological review, 71(3), 401-425.

McGlone, M., Aronson, J. y Kobrynowicz, D. (2006). Stereotype Threat and the Gender Gap in Political Knowledge. Psychology of Women Quarterly, 30(4), 392-398.

Mclntosh, H. (2006). The Development of Active Citizenship in Youth. Washington: The Catholic University of America.

Mclntosh, H., Hart, D. y Youniss, J. (2007). The influence of family political discussion on youth civic development: Which parent qualities matter? PS: Political Science \& Politics (3), 495-499.

McIntosh, M. E., Mac Iver, M. A., Abele, D. G. y Nolle, D. B. (1995). Minority Rights and Majority Rule: Ethnic Tolerance in Romania and Bulgaria. Social Forces, 73(3), 939-967.

McLeod, D. M. y Perse, E. M. (1994). Direct and Indirect Effects of Socioeconomic Status on Public Affairs Knowledge. Journalism \& Mass Communication Quarterly, 71(2), 433442.

McLeod, J. M., Kosicki, G. M. y Pan, Z. (1991). On understanding and misunderstanding media effects. En Curran, J. y Gurevitch, M. (Eds.). (1991). Mass Media and Society (pp. 235-266). Londres: Edward Arnold.

Meier, S. (2006). A survey of economic theories and field evidence on pro-social behavior. Documento de trabajo del Federal Reserve Bank of Boston. Boston: Federal Reserve Bank of Boston. 
Méndez, M., Cebolla, H. y Pinyol, G. (2013). ¿Han cambiado las percepciones sobre la inmigración en España? Informe no 17 de la Colección Zoom Político. Madrid: Fundación Alternativas.

Menezes, I., Mendes, M., Ferreira, C., Marques, G., Monteiro, C., Gião, J.,...y Amaro, G. (2003). The impact of school education, family, cultural background and political attitudes and experiences in civic knowledge. Journal of Social Science Education (1).

Merelman, R. M. (1973). Public Education and Social Structure: Three Modes of Adjustment. The Journal of Politics, 35(4), 797-829.

Merriam, C. E. (1931). The making of citizens: a comparative study of methods of civic training. Chicago: University of Chicago Press.

Metz, E. C. y Youniss, J. (2005). Longitudinal gains in civic development through schoolbased required service. Political Psychology, 26(3), 413-438.

Mezzadra, S. y Colectivo Situaciones. (2005). Derecho de fuga: migraciones, ciudadanía y globalización. Madrid: Traficantes de Sueños.

Michaud, K. E. H., Carlisle, J. E. y Smith, E. R. A. N. (2009). The Relationship between Cultural Values and Political Ideology, and the Role of Political Knowledge. Political Psychology, 30(1), 27-42.

Michelsen, E., Zaff, J. F. y Hair, E. (2002). Civic Engagement Programs and Youth Development: A Synthesis. Washington, D. C.: Child Trends.

Michelson, M. (2003). The Corrosive Effect of Acculturation: How Mexican Americans Lose Political Trust. Social Science Quarterly, 84(4), 918-933.

Milbrath, L. (1965). Political Participation. Chicago: Rand McNally.

Milbrath, L. y Goel, M. (1977). Political Participation: How and Why Do People Get Involved in Politics? Lanham: University Press of America.

Miller, D. (2008). Immigrants, Nations, and Citizenship. Journal of political philosophy, 16(4), 371-390.

Mira, G. (2003). ¿Sobrevivir o vivir en Madrid? Exiliados argentinos del 76. En Espina, A. B. (Ed.). (2003). Emigración e integración cultural (pp. 187-198). Salamanca: Ediciones Universidad de Salamanca.

Molero, F., Navas, M. S. y Morales, J. F. (2001). Inmigración, prejuicio y exclusión social: reflexiones en torno a algunos datos de la realidad española. International Journal of Psychology and Psychological Therapy, 1(1), 11-32.

Mondak, J. J. y Anderson, M. R. (2004). The Knowledge Gap: A Reexamination of GenderBased Differences in Political Knowledge. Journal of Politics, 66(2), 492-512.

Moraes, N., Bermúdez, A., Escrivá, A. y Padilla, B. (2009). Estrategias de vinculación de los Estados latinoamericanos con sus diásporas: Un análisis de las iniciativas desarrolladas por Colombia, Perú, Brasil y Uruguay. En Escrivá, A., Bermúdez, A., y 
Moraes, N. (Eds.). (2009). Migración y participación política. Estados, organizaciones y migrantes latinoamericanos en perspectiva local-transnacional (pp. 297-325). Madrid: CSIC.

Morales, L. (2011). Conceptualizing and Measuring Migrants' Political Inclusion. En Morales, L. y Giugni, M. G. (Eds.). (2011). Social Capital, Political Participation and Migration in Europe: Making Multicultural Democracy Work? (pp. 19-42). Basingstoke: Palgrave.

Morales, L. y Anduiza, E. (Eds.). (2009). Actituds, comportament polític i xarxes organizatives dels immigrants a la ciutat de Barcelona. Barcelona: Fundación Jaime Bofill.

Morales, L. y Giugni, M. G. (Eds.). (2011). Social Capital, Political Participation and Migration in Europe: Making Multicultural Democracy Work? Basingstoke: Palgrave.

Morales, L. y Morariu, M. (2011). Is Home a distraction? The role of migrants' transnational practices in their political integration into receiving-country politics. En Morales, L. y Giugni, M. G. (Eds.). (2011). Social Capital, Political Participation and Migration in Europe: Making Multicultural Democracy Work? (pp. 140-171). Basingstoke: Palgrave.

Morales, L. y Ros, V. (2012). La politización de la inmigración en España en perspectiva comparada. Documentos CIDOB. Migraciones (25), 1-33.

Morales, L. y San Martín, J. (2011). ¿Cómo votarían los inmigrantes? Informe no 2 de la Colección Zoom Político. Madrid: Fundación Alternativas.

Morales, L., Anduiza, E., Rodríguez, E. y San Martín, J. (2008). Capital social, pautas identitarias y actitudes hacia "los otros": la incorporación cívica de la población de origen inmigrante en Barcelona y Madrid. Panorama Social (8).

Morales, L., González-Ferrer, A. y Sánchez, G. (2005). La Integración política de los inmigrantes. Un estudio sobre las asociaciones de inmigrantes en Madrid y Murcia. Cuadernos electrónicos de filosofía del derecho (12).

Morán, M. L. (1999). Los estudios de cultura política en España. Revista Española de Investigaciones Sociológicas (85), 97-129.

Morán, M. L. (2003). Jóvenes, inmigración y aprendizajes de la ciudadanía. Revista de Estudios de Juventud (60), 33-47.

Morán, M. L. y Benedicto, J. (1995). La cultura política de los españoles. Un ensayo de reinterpretación. Madrid: Centros de Investigaciones Sociológicas.

Moreno, F. J. y Callejo, M. B. (2011). Inmigración y Estado de bienestar en España. Barcelona: Obra Social Fundación la Caixa.

Moreno, M. (2006). Imagen y discurso sobre la inmigración: la campaña electoral del 14 de marzo de 2004 en los medios escritos de comunicación. Revista de Dialectología y Tradiciones Populares, 61(1), 211-227. 
Morrell, M. E. (2005). Deliberation, Democratic Decision-Making and Internal Political Efficacy. Political Behavior, 27(1), 49-69.

Morris, L. (2002). Britain's asylum and immigration regime: the shifting contours of rights. Journal of Ethnic and Migration Studies, 28(3), 409-425.

Morrissey, G. E. (2011). Democracy's Future: The Relationship of Instructional Methods and Curriculum Structure to Immigrant Adolescents' Sociopolitical Integration in Europe (Tesis doctoral no publicada). Michigan: The University of Michigan.

Moya, M. C. y Puertas, S. (2008). Estereotipos, inmigración y trabajo. Papeles del psicólogo, 29(1), 6-15.

Myrberg, G. y Rogstad, J. (2011). Patterns of participation: engagement among ethnic minorities and the native population in Oslo and Stockholm. En Morales, L. y Giugni, M. G. (Eds.). (2011). Social Capital, Political Participation and Migration in Europe: Making Multicultural Democracy Work? (pp. 172-197). Basingstoke: Palgrave.

Naïr, S. (2007). Política de ciudadanía. En Guerra, A. y Tezanos, J. F. (Eds.). (2008). La inmigración y sus causas. VI Encuentro Salamanca. Madrid: Editorial Sistema.

Navarro, A. et al (2008) Spanish secondary students' attitudes towards Citizenship Education: indicators based on the IEA Civic Education Study, in Ross, A. \& Cunningham, P. (eds.) Reflecting on Identities: Research, Practice and Innovation. London: CiCe, pp. $473-482$.

Nettles, S. M. (1991). Community involvement and disadvantaged students: A review. Review of Educational Research, 61(3), 379-406.

Newcomb, T. M. (1943). Personality and Social Change: Attitude Formation in a Student Community. Nueva York: Dryden Press.

Nie, N. H., Powell, G. B., Jr., y Prewitt, K. (1969). Social structure and political participation: developmental relationships, II. The American Political Science Review, 63(3), 808-832.

Niemi, R. G. (1974). The politics of future citizens. San Francisco: Jossey-Bass.

Niemi, R. G. y Chapman, C. (1998). The Civic Development of $9^{\text {th }}$ Through $12^{\text {th }}$ Grade Students in the United States: 1996. Washington: National Center for Education Statistics.

Niemi, R. G. y Hepburn, M. A. (1995). The rebirth of political socialization. Perspectives on Political Science, 24(1), 7-16.

Niemi, R. G. y Junn, J. (1998). Civic Education: What Makes Students Learn. New Haven: Yale University Press.

Niemi, R. G. y Sobieszek, B. I. (1977). Political socialization. Annual Review of Sociology, 3(1), 209-233. 
Niemi, R. G., Craig, S. C. y Mattei, F. (1991). Measuring internal political efficacy in the 1988 National Election Study. The American Political Science Review, 85(4), 1407-1413.

Niessen, J., Huddleston, T. y Citron, L. (2007). Migrant Integration Policy Index. Bruselas: British Council y Migration Policy Group.

Niessen, J., Peiró, J. y Schibel, Y. (2005). Civic citizenship and immigrant inclusion. A guide for the implementation of civic citizenship policies. Bruselas: Migration Policy Group.

Norris, P. (1999). Institutional Explanations for Political Support. En Norris, P. (Ed.). (1999). Critical Citizens: Global Support for Democratic Governance. Oxford: Oxford University Press.

Norris, P. (2004). The 'new cleavage' thesis and the social basis of radical right support. Documento preparado para el APSA Panel 36-15 The Right in Elections en la reunión anual de la American Political Science Association. Cambridge: Harvard University.

Norris, P. e Inglehart, R. (2004). Sacred and Secular: Religion and Politics Worldwide. Cambridge: Cambridge University Press.

O'Toole, T., Lister, M., Marsh, D., Jones, S. y McDonagh, A. (2003). Tuning Out or Left Out? Participation and Non-participation among Young People. Contemporary Politics, 9, 45-61.

Obiols, E. S. y Blanch, J. P. (2013). La influencia de los medios de comunicación en la socialización política de los jóvenes de 12-16 años en un contexto de crisis económica. En Díaz, J. J., Santisteban, A. y Cascajero, A. (Eds.). (2013). Medios de comunicación y pensamiento crítico: nuevas formas de interacción social (pp. 207-217). Alcalá de Henares: Universidad de Alcalá y Servicio de Publicaciones.

O'Neill, B., Gidengil, E. y Young, L. (2012). The Political Integration of Immigrant and Visible Minority Women. Canadian Political Science Review, 6(2-3), 185-196.

Ortega, M. P. y Morales, L. (2006). Las asociaciones de la población inmigrante en el municipio de Madrid: un informe sobre sus perfiles organizativos, relación con la política $y$ redes interorganizativas. Documento de trabajo $\mathrm{n} 01$ del proyecto CAPSOCINMIG. Murcia: Universidad de Murcia.

Owen, D. y Dennis, J. (1987). Preadult development of political tolerance. Political Psychology, 8(4), 547-561.

Pajares, M. (2002). Inmigración y políticas de integración social. Documento de trabajo no 45 de Laboratorio de Alternativas. Madrid: Fundación Alternativas.

Pardos, S. (2012). Inmigración y comportamiento electoral: Cataluña desde una perspectiva comparada. Documentos CIDOB. Migraciones (23), 1-13.

Park, K., Lee, S., Kim, E., Park, M., Park, J. y Cha, M. (2013). Mood and Weather: Feeling the Heat? Informe presentado en la Seventh International AAAI Conference on Weblogs and Social Media. Cambridge, MA: Massachusetts Institute of Technology. 
Parra, J. (2006). Discursos y modelos sobre la ampliación de los electorados: el voto en el extranjero a ciudadanos emigrantes en perspectiva comparada. Studia Politicae (6), 105-132.

Pasek, J., Feldman, L., Romer, D. y Hall, K. (2008). Schools as incubators of democratic participation: Building long-term political efficacy with civic education. Applied Development Science, 12(1), 26-37.

Pateman, C. (1970). Participation and democratic theory. Cambridge: Cambridge University Press.

Pateman, C. (1980). The civic culture: a philosophic critique. En Almond y Verba (Eds.). (1980). The civic culture revisited, 57-102.

Patti, J. y Cepeda, A. (2007). Citizenship competencies in Colombia: Learning from policy and practice. Conflict Resolution Quarterly, 25(1), 109-125.

Peffley, M., y Rohrschneider, R. (2003). Democratization and political tolerance in seventeen countries: A multi-level model of democratic learning. Political Research Quarterly, 56(3), 243-257.

Penninx, R., Martiniello, M. y Vertovec, S. (2004). Citizenship in European Cities. London: Ashgate.

Pérez, C. (2006). Enfoques teórico-metodológicos en el estudio de la participación electoral. Cuestiones Políticas, 22(37), 74-93.

Pérez, M. y Desrues, T. (2007). Los españoles ante la inmigración [versión provisional]. En Guerra, A. y Tezanos, J. F. (Eds.). (2008). La inmigración y sus causas. VI Encuentro Salamanca. Madrid: Editorial Sistema.

Peterson, A. (2008). The civic republican tradition and citizenship education (Tesis doctoral). Canterbury: University of Kent.

Peterson, B. E., Duncan, L. E. y Pang, J. S. (2002). Authoritarianism and Political Impoverishment: Deficits in Knowledge and Civic Disinterest. Political Psychology, 23(1), 97-112.

Peterson, B. E., Smirles, K. A. y Wentworth, P. A. (1997). Generativity and authoritarianism: Implications for personality, political involvement, and parenting. Journal of Personality and Social Psychology, 72(5), 1202-1216.

Pichler, F. y Wallace, C. (2007). Patterns of formal and informal social capital in Europe. European Sociological Review, 23(4), 423-435.

Pierson, P. (1995). Fragmented welfare states: federal institutions and the development of social policy. Governance, 8(4), 449-478.

Pittman, K. J. (1991). Promoting youth development: Strengthening the role of youth serving and community organizations. Washington, D. C.: Center for Youth Development and Policy Research, Academy for Educational Development. 
Pollock III, P. H. (1983). The Participatory Consequences of Internal and External Political Efficacy: A Research Note. The Western Political Quarterly, 36(3), 400-409.

Portes, A. (1996). Transnational communities: Their emergence and significance in the contemporary world-system. En Korzeniewicz, R. y Smith, W. C. (Eds.). (1996). Latin America in the World-Economy (Contributions in Economics \& Economic History) (pp. 151-168). Westport: Praeger.

Portes, A. (2000). The two meanings of social capital. Sociological Forum, 15(1), 1-12.

Portes, A. y Mozo, R. (1985). The Political Adaptation Process of Cubans and Other Ethnic Minorities in the United States: A Preliminary Analysis. International Migration Review, 19(1), 35-63.

Portes, A. y Rumbaut, R. G. (1990). Immigrant America: A Portrait. Oakland: University of California Press.

Portes, A., Aparicio, R., Haller, W. y Vickstrom, E. (2010). Moving ahead in Madrid: Aspirations and expectations in the Spanish second generation. International Migration Review, 44(4), 767-801.

Portes, A., Escobar, C. y Arana, R. (2008). Bridging the gap: transnational and ethnic organizations in the political incorporation of immigrants in the United States. Ethnic and Racial Studies, 31(6), 1056-1090.

Portes, A., Escobar, C. y Radford, A. W. (2007). Immigrant Transnational Organizations and Development: A Comparative Study. International Migration Review, 41(1), 242281.

Portes, A., Guarnizo, L. E. y Landolt, P. (1999). The study of transnationalism: pitfalls and promise of an emergent research field. Ethnic and Racial Studies, 22(2), 217-237.

Portes, A., Vickstrom, E., Haller, W. y Aparicio, R. (2013). Dreaming in Spain: parental determinants of immigrant children's ambition. Ethnic and Racial Studies, 36(4), 557589.

Portes, A., Vickstrom, E., y Aparicio, R. (2011). Coming of age in Spain: the selfidentification, beliefs and self-esteem of the second generation. The British Journal of Sociology, 62(3), 387-417.

Preston, V., Kobayashi, A. y Man, G. (2006). Transnationalism, gender, and civic participation: Canadian case studies of Hong Kong immigrants. Environment and Planning A, 38(9) 1633-1651.

Price, R. H., Cioci, M., Penner, W. y Trautlein, B. (1993). Webs of Influence: School and Community Programs That Enhance Adolescent Health and Education. Teachers College Record, 94, 487-521.

Prior, M. y Lupia, A. (2008). Money, Time, and Political Knowledge: Distinguishing Quick Recall and Political Learning Skills. American Journal of Political Science, 52(1), 168-182. 
Putnam, R. D. (2000). Bowling Alone: The Collapse and Revival of American Community. Nueva York: Simon and Schuster.

Putnam, R., Leonardi, R. y Nanetti, R. (1993). Making democracy work: Civic traditions in modern Italy. Princeton: Princeton University Press.

Ramakrishnan, S. K. y Espenshade, T. J. (2001). Immigrant Incorporation and Political Participation in the United States. International Migration Review, 35(3), 870-909.

Ramírez, M. (1980). La socialización política en España: una empresa para la democracia. Sistema: Revista de ciencias sociales (34), 91-116.

Ramírez, M. C. y Rodríguez, A. (2006). Variables predictoras de la actitud hacia los inmigrantes en la Región de Murcia (España). Anales de Psicología, 22(1), 76-80.

Ramos, R. (1990). La familia como agente de socialización política. Revista Interuniversitaria (9), 85-99.

Rex, J. y Singh, G. (2003). Pluralism and Multiculturalism in Colonial and Post-Colonial Society - Thematic Introduction. International Journal of Multicultural Societies, 5(2), 106-118.

Rice, K. L., y Brown, J. R. (1998). Transforming Educational Curriculum and Service Learning. Journal of Experiential Education, 21(3), 140-46.

Rinken, S., Silva, M., Velasco, S. y Escobar, M. S. (2009). Opiniones y actitudes de la población andaluza ante la inmigración (II): entre la estabilidad y el cambio. Sevilla: Consejería de Empleo de la Junta de Andalucía.

Rivera-Salgado, G., Bada, X. y Escala, L. (2005). Participación cívica y política de los migrantes mexicanos en los Estados Unidos: las asociaciones de paisanos en Los Angeles y Chicago. En la conferencia Mexican Migrant Social and Civic Participation in the United States. Washington DC: Woodrow Wilson International Center for Scholars.

Roggeband, C. y Verloo, M. (2007). Dutch women are liberated, migrant women are a problem: The evolution of policy frames on gender and migration in the Netherlands, 1995-2005. Social Policy \& Administration, 41(3), 271-288.

Rothstein, B. y Stolle, D. (2002). How political institutions create and destroy social capital: an institutional theory of generalized trust. En la Reunión Anual de la American Political Science Association. Boston: American Political Science Association.

Rubin, A. M. (1978). Child and Adolescent Television Use and Political Socialization. Journalism Quarterly, 55(1), 125-129.

Rudolph, C. (2005). National Security and Immigration: Explaining Policy Development in the United States and Western Europe since 1945. Stanford: Stanford University Press.

Rudolph, T. J., Gangl, A. y Stevens, D. (2000). The Effects of Efficacy and Emotions on Campaign Involvement. Journal of Politics, 62(4), 1189-1197. 
Ruiz, M. A. (1996). El Sindicato Español Universitario (SEU), 1939-1965: Ia socialización política de la juventud universitaria en el franquismo. Madrid: Siglo Veintiuno de España Editores.

Ruiz, N. y Usero, M. P. (2005). Opinión y actitudes de los inmigrantes hacia el mercado político español. Investigación y marketing (89), 5-11.

Ruiz-Silva, A. y Chaux, E. (2005). La formación de competencias ciudadanas. Bogotá: Asociación Colombiana de Facultades de Educación ASCOFADE.

Rushton, J. P. (2004). Genetic and environmental contributions to pro-social attitudes: a twin study of social responsibility. Proceedings of the Royal Society of London. Series B: Biological Sciences, 271(1557), 2583-2585.

Ryan, A. M. (2001). The peer group as a context for the development of young adolescent motivation and achievement. Child Development, 72(4), 1135-1150.

Salguero, M. S. (1997). Socialización política y lealtad a la Constitución. Revista de estudios políticos (97), 319-332.

Sánchez, B. (2011). La política migratoria en España: Un análisis de largo plazo. Revista Internacional de Sociología, 69(M1), 243-268.

Sánchez, F. (2008). El ciudadano ausente: un estudio de la participación electoral de los votantes en el extranjero. Ponencia en VI Encuentro Anual REDGOB: Migraciones, Cohesión social y Gobernabilidad. Lisboa: REDGOB.

Sánchez-Montijano, E. (2008). La politización de la inmigración en España. En ZapataBarrero, R., González, E. y Sánchez E. (2008). El discurso político en torno a la inmigración en España y en la Unión Europea (pp. 81-112). Documento no16 del Observatorio Permanente de la Inmigración. Madrid: Ministerio de Trabajo e Inmigración.

Sanders, L. M. (2001). The psychological benefits of political participation. En la Reunión Anual de la American Political Science Association. San Francisco: American Political Science Association.

Santiuste, S. (2013). Ignorancia y conocimiento político: nuevos datos y apuntes sobre España. Documento de trabajo. Salamanca: Universidad de Salamanca.

Sapiro, V. (2004). NOT YOUR PARENTS' POLITICAL SOCIALIZATION: Introduction for a New Generation. Annual Review of Political Science, 7, 1-23.

Sarrible, G. (2007). Los latinoamericanos y las instituciones públicas en España. Percepción social de colectivos extranjeros. Papers Revista de Sociología (86), 109-129.

Sassen, S. (1999). Guests and aliens. Nueva York: New York Press.

Scales, P. C. y Leffert, N. (1999). Developmental Assets: A Synthesis of the Scientific Research on Adolescent Development. Minneapolis: Search Institute. 
Schaie, K. W. y Willis, S. L. (1999). Theories of everyday competence and aging. En Bengtson, V. L. y Schaie, K. W. (Eds.). (1999). Handbook of Theories of Aging (pp. 174195). Nueva York: Springer.

Schildkraut, D. (2005). The rise and fall of political engagement among latinos: the role of identity and perceptions of discriminations. Political Behaviour, 27(3).

Schine, J. (1997). School-based service: Reconnecting schools, communities, and youth at the margin. Theory into Practice, 36(3), 170-175.

Schwarzer, R., Hahn, A. y Schöeder, H. (1994). Social integration and social support in a life crisis: Effects of macrosocial change in East Germany. American Journal of Community Psychology, 22(5), 685-706.

Schyns, P. y Koop, C. (2010). Political Distrust and Social Capital in Europe and the USA. Social Indicators Research, 96(1), 145-167.

Sears, D. (1975). Political Socialization. En Greenstein, F. y Polsby, N. (1975). Handbook of Political Science. Reading: Addison-Wesley.

Sears, D. O. y Levy, S. (2003). Childhood and Adult Political Development. En Sears, D. O., Huddy, L. y Jervis, R. (Eds.). (2003). Oxford Handbook of Political Psychology (pp. 60109). Nueva York: Oxford University Press.

Semetko, H. A., van der Brug, W. y Valkenburg, P. M. (2003). The Influence of Political Events on Attitudes Towards the European Union. British Journal of Political Science, 33(4), 621-634.

Shaw, D., De la Garza, R. y Lee, J. (2000). Examining Latino Turnout in 1996: A ThreeState, Validated Survey Approach. American Journal of Political Science, 44(2), 338-346.

Sherrod, L. R., Torney-Purta, J. y Flanagan, C. A. (Eds.). (2010). Handbook of Research on Civic Engagement in Youth. Hoboken: John Wiley \& Sons.

Siguán, M. (2003). Inmigración y Adolescencia. Barcelona: Paidós.

Smith, E. R. (1989). The unchanging American voter. Berkeley: University of California Press.

Smith, M. A. (2002). Ballot initiatives and the democratic citizen. Journal of Politics, 64(3), 892-903.

Sniderman, P. M., Brody, R. A. y Tetlock, P. E. (1991). Reasoning and Choice: Explorations in Political Psychology. Nueva York: Cambridge University Press.

Sniderman, P. M., Peri, P., de Figuereido, R. J. P. y Piazza, T. (2000). The Outsider: Prejudice and Politics in Italy. Contemporary Sociology, 31(2), 166-168.

Sniderman, P. M., Tetlock, P. E., Glaser, J. M., Green, D. P. y Hout, M. (1989). Principled Tolerance and the American Mass Public. British Journal of Political Science, 19(1), 2545. 
Social Mentoring Research Group (2007). Towards an understanding of Mentoring, Social Mentoring and Befriending (Practice Briefing Paper). Brighton: University of Brighton / Equal Brighton and Hove.

Solé, C. y Cachón, L. (2006). Globalización e inmigración. Los debates actuales. Revista Española de Investigaciones Sociológicas (116), 13-52.

Stenner-Day, K. y Fischle, M. (1992). The effects of political participation on political efficacy: A simultaneous equations model. Politics, 27(2), 282-305.

Stokes, S. C. (2001). Mandates and democracy: Neoliberalism by surprise in Latin America. Cambridge: Cambridge University Press.

Stoll, M. y Wong, J. (2007). Immigration and Civic Participation in a Multiracial and Multiethnic Context. International Migration Review, 41(4), 880-908.

Stouffer, S. C. (1955). Communism, Conformity, and Civil Liberties. Nueva York: Doubleday.

Suárez-Orozco, C. y Baolian, D. (2006). Gendered Perspectives in Psychology: Immigrant Origin Youth. International Migration Review, 40(1), 165-198.

Sullivan, J. L., Marcus, G. E., Feldman, S. y Piereson, J. E. (1981). The Sources of Political Tolerance: A Multivariate Analysis. The American Political Science Review, 75(1), 92-106.

Sullivan, J. L., Piereson, J. y Marcus, G. E. (1982). Political Tolerance and American Democracy. Chicago: University of Chicago Press.

Talarico, J. F., Varon, A. J., Banks, S. E., Berger, J. S., Pivalizza, E. G., Medina-Rivera, G., ...y Qin, L. (2013). Emotional intelligence and the relationship to resident performance: a multi-institutional study. Journal of Clinical Anesthesia, 25(3), 181-187.

Techio, E. M. y Calderón-Prada, A. (2005). Relaciones intergrupales, valores, identidad social y prejuicio en España después del atentado terrorista del 11 de marzo. Revista de Psicología Social, 20(3), 277-287.

Terrén, E. (2007). Adolescencia, inmigración e identidad. En López, A. M. y Cachón, L. (Eds.). (2007). Juventud e Inmigración. Desafíos para la Participación y la Integración (pp. 186-203). Santa Cruz de Tenerife: Dirección General de Juventud de la Consejería de Empleo y Asuntos Sociales del Gobierno de Canarias.

Theiss-Morse, E. y Hibbings, J. R. (2005). Citizenship and Civic Engagement. Annual Review of Political Science, 8, 227-49.

Timpone, R. J. (1998). Structure, Behavior, and Voter Turnout in the United States. The American Political Science Review, 92(1), 145-158.

Tocqueville, A. (1956). Democracy in America. Londres: Penguin Classics.

Togeby, L. (2004). It depends... how organisational participation affects political participation and social trust among second-generation immigrants in Denmark. Journal of Ethnic and Migration Studies, 30(3), 509-528. 
Torney-Purta, J. (2002). The school's role in developing civic engagement: A study of adolescents in twenty-eight countries. Applied Developmental Science, 6(4), 203-212.

Torney-Purta, J. (2004). Adolescents' political socialization in changing contexts: An international study in the spirit of Nevitt Sanford. Political Psychology, 25(3), 465-478.

Torney-Purta, J., Barber, C. y Wilkenfeld, B. (2006). Differences in the civic knowledge and attitudes of adolescents in the United States by immigrant status and Hispanic background. Prospects, 36(3), 343-354.

Torney-Purta, J., Barber, C. y Wilkenfeld, B. (2007). Latino Adolescents' civic development in the United States: research results from the IEA Civic Education Study. Journal of Youth and Adolescence, 36(2), 111-125.

Torney-Purta, J., Lehmann, R., Oswald, H. y Schulz, W. (2001). Citizenship and education in 28 countries: Civic knowledge and engagement at age 14. La Haya: International Association for the Evaluation of Educational Achievement.

Torney-Purta, J., Oppenheim, A. N. y Farnen, R. (1975). Civic Education in Ten Countries: An Empirical Study. Hoboken: John Wiley \& Sons.

Tucker, R. C. (1973). Culture, political culture, and communist society. Political Science Quarterly, 88(2), 173-190.

Uhlaner, C. J., Cain, B. E. y Kiewiet , D. R. (1989). Political Participation of Ethnic Minorities in the 1980s. Political Behavior, 11(3), 195-231.

Valenzuela, S. (2009). Variations in media priming: The moderating role of knowledge, interest, news attention, and discussion. Journalism \& Mass Communication Quarterly, 86(4), 756-774.

Vallespín, F. (2005). Inmigración y derechos: un enfoque liberal. En Del Águila, R. (Ed.). (2005). Inmigración: un desafío para España (pp. 103-118). Madrid: Fundación Pablo Iglesias.

Van der Brug, W., Semetko, H. A. y Valkenburg, P. (2007). Priming in a Multi-Party Context: The Impact of European Summit News on Evaluations of Political Leaders. Political Behavior, 29(1), 115-141.

Van Deth, J. W. (1997). Private Groups and Public Life: Social Participation and Political Involvement in Representative Democracies. Nueva York: Routledge.

Van Egmond, M., De Graaf, N. D. y Van Der Eijk, C. (1998). Electoral participation in the Netherlands: Individual and contextual influences. European Journal of Political Research, 34(2), 281-300.

Varsanyi, M. W. (2005). The paradox of contemporary immigrant political mobilization: organized labor, undocumented migrants, and electoral participation in Los Angeles. Antipode, 37(4), 775-795. 
Vasileva, K. (2012). Nearly two-thirds of the foreigners living in EU Member States are citizens of countries outside the EU-27. Informe no 31 de la Colección Statistics in Focus. Luxemburgo: Eurostat y Comisión Europea.

Velasco, J. C. (2012). Fronteras abiertas, derechos humanos y justicia global. Arbor, 188(755), 457-473.

Verba, S., Schlozman, K. L. y Brady, H. E. (1995). Voice and Equality: Civic Voluntarism in American Politics. Cambridge, MA: Harvard University Press.

Verba, S., Schlozman, K. L., Brady, H. E. y Shapiro, R. Y. (1996). Voice and Equality: Civic Voluntarism in American Politics. Political Science Quarterly, 111(4), 706-707.

Veredas, S. (1998). Visones cruzadas, percepción de España y de los españoles entre inmigrantes marroquíes y peruanos. Ofrim suplementos (2), 63-78.

Veredas, S. (2000). Condiciones de vida y necesidades de la población inmigrante beneficiaria del programa Rainbow Iniciativa Comunitaria empleo integradesfavorecidos en la Comunidad de Valencia. Ofrim Suplementos (7), 187-207.

Veredas, S. (2003). Las asociaciones de inmigrantes en España. Revista Internacional de Sociología (132), 207-225.

Veredas, S. (2004). Factores condicionantes de la movilización étnica entre la población inmigrante extracomunitaria. Revista de Sociología (72) 2004, 87-111.

Vertovec, S. (1999). Conceiving and researching transnationalism. Ethnic and Racial Studies, 22(2), 447-462.

Vujčić, V. (1998). Politička kultura i međunacionalni odnosi u demokraciji. Politička misao, 35(2), 25-49.

Waiss, O. (1983). La literatura hispanoamericana y el exilio. Anales de Literatura Hispanoamericana, 12, 228-234.

Waldstein, F. A. y Reiher, T. C. (2001). Service-learning and students' personal and civic development. Journal of Experiential Education, 24(1), 7-13.

Weber, L. (2003). Rugged individuals and social butterflies: the consequences of social and individual political participation for political tolerance. The Social Science Journal, 40(2), 335-342.

Wei, R. y Leung, L. (1998). A cross-societal study on the role of the mass media in political socialization in China and Taiwan. International Communication Gazette, 60(5), 377-393.

Weitz-Shapiro, R. y Winters, M. S. (2008). Political participation and quality of life (Working Paper No. 4583). Washington, D.C.: Inter-American Development Bank, Research Department.

Welch, S. (1993). The concept of political culture. Nueva York: St. Martin's Press. 
White, S., Nevitte, N., Blais, A., Gidengil, E. y Fournier, P. (2008). The Political Resocialization of Immigrants: Resistance or Lifelong Learning? Political Research Quarterly, 61(2), 268-281.

Whitley, B. E., Jr. (1999). Right-wing authoritarianism, social dominance orientation, and prejudice. Journal of Personality and Social Psychology, 77(1), 126.

Wiatr, J. J. (1980). The civic culture from a Marxist-Sociological Perspective. En Almond, G. A. y Verba, S. (Eds.). (1980). The civic culture revisited (pp. 103-123). Londres: Little, Brown Book Group.

Wilkenfeld, B. (2009). Does context matter? How the family, peer, school, and neighborhood contexts relate to adolescents' civic engagement (Tesis doctoral). College Park: University of Maryland.

Williams, J. A., Jr., Nunn, C. Z. y St. Peter, L. (1976). Origins of Tolerance Findings from a Replication of Stouffer's Communism, Conformity, and Civil Liberties. Social Forces, 55(2), 394-408.

Willis, P. E. (1977). Learning to labor: How working class kids get working class jobs. Nueva York: Columbia University Press.

Wong, J. S. (2000). The effects of age and political exposure on the development of party identification among Asian American and Latino immigrants in the United States. Political Behavior, 22(4), 341-371.

Wong, J. S. (2006). Democracy's promise. Ann Arbor: University of Michigan Press.

Wu, C. (2003). Psycho-Political Correlates of Political Efficacy. The Case of the 1994 New Orleans Mayoral Election. Journal of Black Studies, 33(6), 729-760.

Yates, M. y Youniss, J. (Eds.). (1999). Roots of Civic Identity: International Perspectives on Community Service and Activism in Youth. Nueva York: Cambridge University Press.

Youniss, J., McLellan, J. A. y Mazer, B. (2001). Voluntary service, peer group orientation, and civic engagement. Journal of Adolescent Research, 16(5), 456-468.

Youniss, J., McLellan, J. A. y Yates, M. (1997). What We Know About Engendering Civic Identity. American Behavioral Scientist, 40(5), 620-631.

Zabin, C. y Escala, L. (2002). From Civic Association to Political Participation: Mexican Hometown Associations and Mexican Immigrant Political Empowerment in Los Angeles. Revista Frontera Norte, 14(27).

Zaller, J. R. (1992). The Nature and Origins of Mass Opinion. Cambridge: Cambridge University Press.

Zapata-Barrero, R. (2000). Ciudadanía, democracia y pluralismo cultural: hacia un nuevo contrato social. Barcelona, Proyecto A Ediciones/ Biblioteca Episteme. 
Zapata-Barrero, R. (2005). Construyendo una filosofía pública de la inmigración en Catalunya: Ios términos del debate. Revista de Derecho Migratorio y Extranjería (10), 938.

Zapata-Barrero, R. (2008). Democracia y multiculturalidad: el "ciudadanismo" como argumentación política. Sistema: Revista de Ciencias Sociales (203-204), 171-195.

Zapata-Barrero, R. Z. y Van Dijk, T. A. (2007). Discursos sobre la inmigración en España: los medios de comunicación, los Parlamentos y las Administraciones. Barcelona: Fundación CIDOB.

Zapata-Barrero, R., Gabrielli, L., Sánchez-Montijano, E. y Jaulin, T. (2013). The political participation of immigrants in host countries: An interpretative framework from the perspective of origin countries and societies. INTERACT Research Report 2013/07. San Domenico di Fiesole: European University Institute, Robert Schuman Centre for Advanced Studies y Migration Policy Centre.

Ziblatt, D. (1965). High school extracurricular activities and political socialization. Annals of the American Academy of Political and Social Science, 361(1), 20-31.

Zinovyev, A. (2010). Data visualization in political and social sciences. Artículo prepublicado el 6 de agosto de 2010 en: http://arxiv.org/abs/1008.1188

Zolberg, A. R. (1999). Matters of state: Theorizing immigration policy. En Hirschman, C. Kasinitz, P. y Dewind, J. (Eds.). (1999). The Handbook of International Migration (pp. 7193). Nueva York: Russell Sage Foundation.

Zolberg, A. R. (2008). Immigrants as Citizens. Sociological Forum, 23(2), 403-407. 